Correlações da expressão de MHC-I e II, C5b-9 e fenotipagem de células inflamatórias em tecido muscular na dermatomiosite juvenil (DMJ)

Tese apresentada à Faculdade de Medicina da Universidade de São Paulo para obtenção do título de Doutor em Medicina

Área de concentração: Pediatria

Orientadora: Profa. Dra. Suely Kazue Nagahashi Marie

Co-orientadora: Profa. Dra. Maria Helena Bittencourt Kiss

SÃO PAULO 


\section{FICHA CATALOGRÁFICA}

Preparada pela Biblioteca da

Faculdade de Medicina da Universidade de São Paulo

Creprodução autorizada pelo autor

Sallum, Adriana Maluf Elias

Correlações da expressão de MHC-I e II, C5b-9 e fenotipagem de células inflamatórias em tecido muscular na dermatomiosite juvenil (DMJ) / Adriana Maluf Elias Sallum. -- São Paulo, 2005.

Tese(doutorado)--Faculdade de Medicina da Universidade de São Paulo.

Departamento de Pediatria.

Área de concentração: Pediatria.

Orientadora: Suely Kazue Nagahashi Marie.

Co-orientadora: Maria Helena Bittencourt Kiss.

Descritores: 1.DERMATOMIOSITE 2.MÚSCULOS 3.GENES CLASSE I DO COMPLEXO DE HISTOCOMPATIBILIDADE (MHC) 4. GENES CLASSE II DO COMPLEXO DE HISTOCOMPATIBILIDADE (MHC) 5.COMPLEXO DE ATAQUE À MEMBRANA DE COMPLEMENTO 6.ANTÍGENOS CD4 7.ANTÍGENOS CD8 8.ANTÍGENOS CD20 9.MACRÓFAGOS 
"Se eu não tivesse um sonho, não poderia se tornar realidade." Martin Luther King 


\section{DEDICATÓRIA}

Às crianças portadoras de Dermatomiosite Juvenil.

Que os resultados deste estudo possam auxiliar na compreensão da fisiopatologia desta doença e, em um futuro próximo, a possibilidade de uma terapêutica mais eficaz e com menores efeitos colaterais. 
Aos meus pais, alicerces para concretização de meus objetivos.

Ao Ricardo, cujo amor impulsionou a luta pelos meus sonhos e deu sentido ao meu caminhar.

Aos meus irmãos e cunhados, que a nossa união esteja sempre presente, fortalecendo os nossos ideais. 


\section{AGRADECIMENTOS}

Aos Prof. Dr. Yassuhiko Okay e Prof. Dr. Flávio A. Costa Vaz pelo apoio.

Às Profa. Dra. Suely Kazue Nagahashi Marie e Profa. Dra. Maria Helena Bittencourt Kiss, minhas orientadoras, não foram apenas ensinamentos na área médica, como também de vida e demonstração de verdadeira amizade.

Ao Dr. Clóvis Artur Almeida Silva, chefe da Unidade de Reumatologia Pediátrica do Instituto da Criança, pela compreensão e apoio durante a realização desta tese.

Às assistentes da Unidade de Reumatologia Pediátrica do Instituto da Criança: Dra. Bernadete Lourdes Liphaus, Dra. Lúcia Maria Arruda Campos e Dra. Ana Paola Navarete Lotito.

Aos pós graduandos da Unidade de Reumatologia Pediátrica do Instituto da Criança: Dra. Ana Julia Pantoja de Moraes, Dra. Elisabeth Gonzaga Canova Fernandes, Dra. Georgiana Leal, Dra. Marília Vieira Febrônio, Dra. Mércia Facó, Dr. Ricardo Suehiro e Dra. Rosabraulia Acioly Santiago.

Às residentes da Unidade de Reumatologia Pediátrica do Instituto da Criança: Dra. Adriana Almeida de Jesus, Dra. Aline Garcia Islabão, Dra. Daniela Rodrigues Lipai, Dra. Nadyesda Diehl Brandão.

À Alda Wakamatsu, pelo auxílio na realização das técnicas de imunohistoquímica.

À Sandra Malagutti, pelo auxílio na realização da análise estatística. 
Lista de Figuras

Lista de Tabelas

Lista de Gráficos

Lista de Abreviaturas

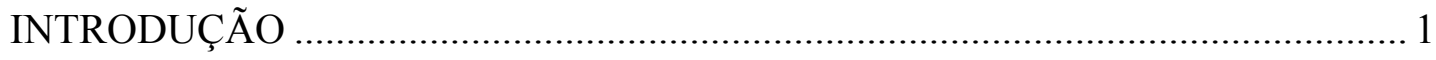

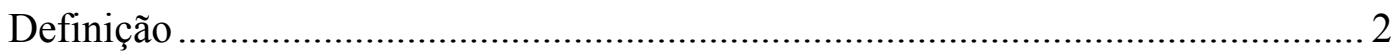

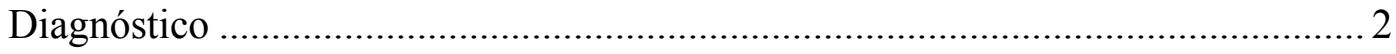

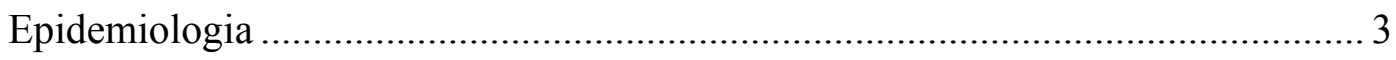

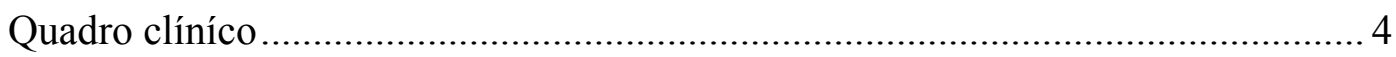

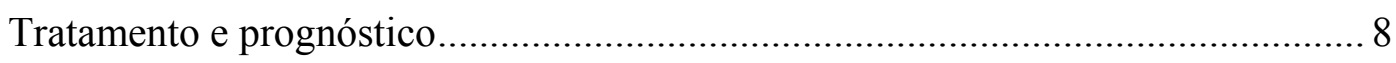

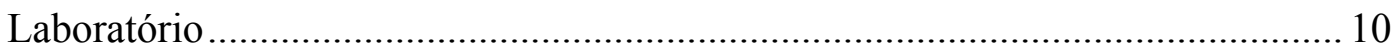

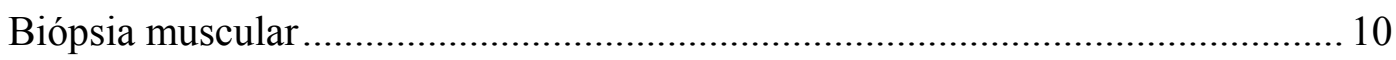

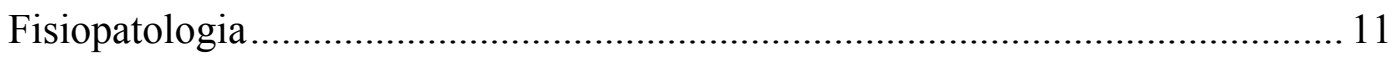

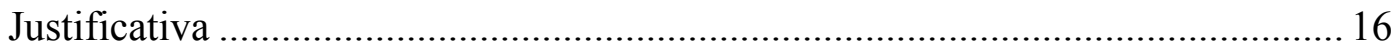

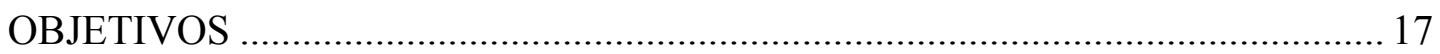

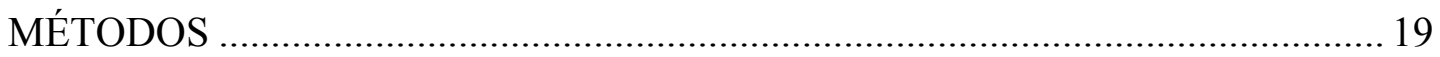

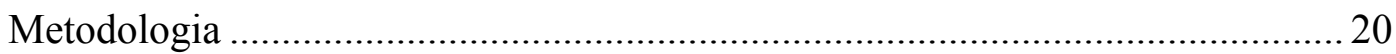

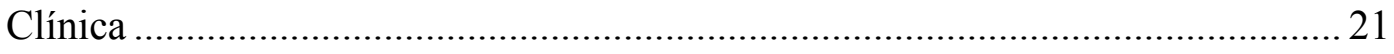

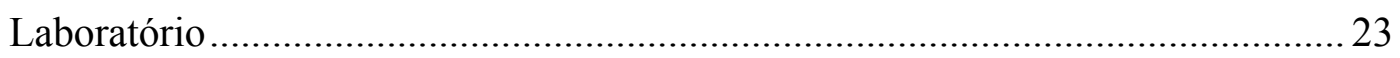

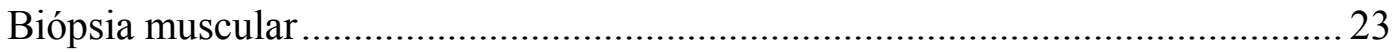

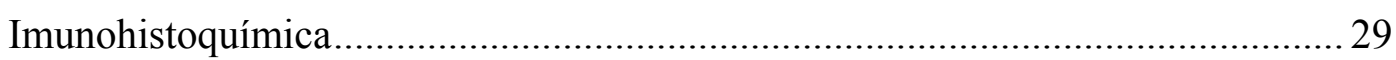

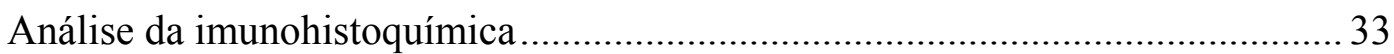

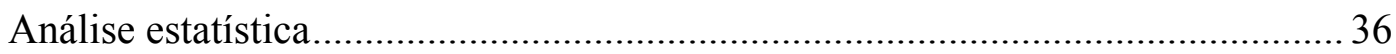

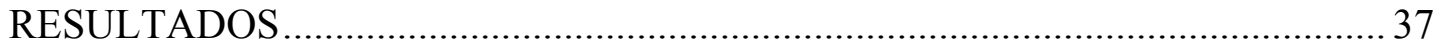

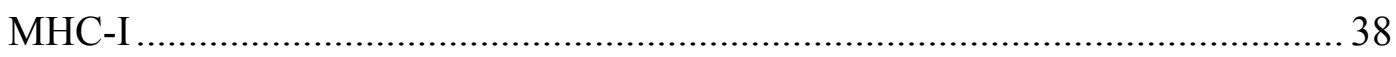

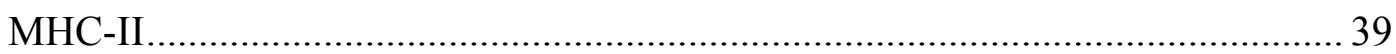

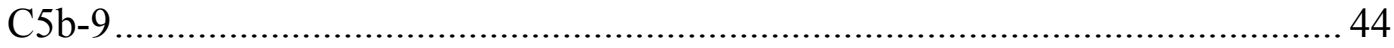

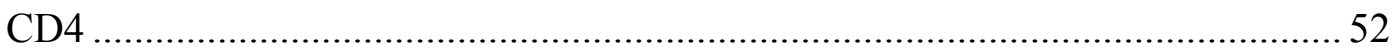

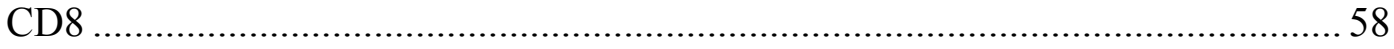

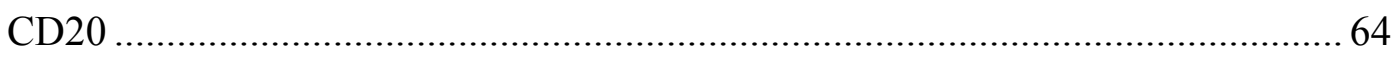

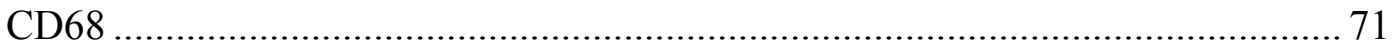

Correlações entre MHC I e II, C5b-9, CD4, CD8, CD4+CD8, CD20, CD68, ICAM-1 e VCAM-1 78 


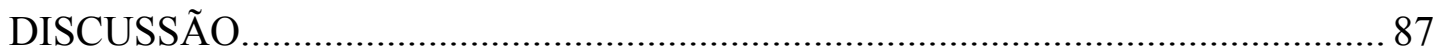

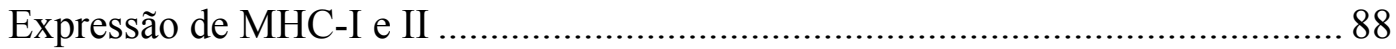

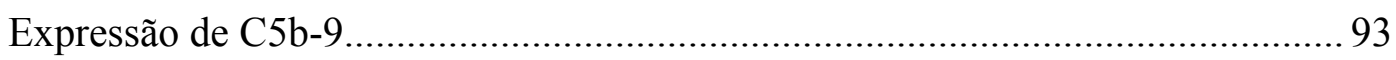

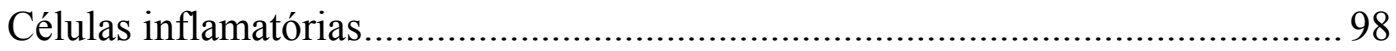

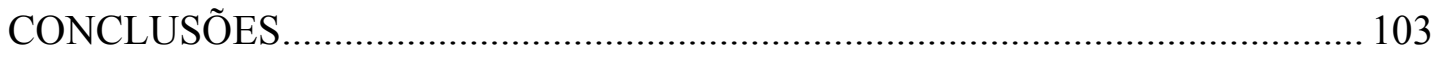

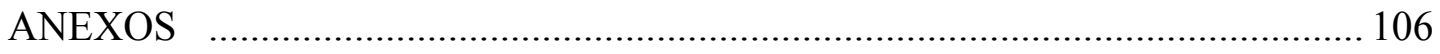

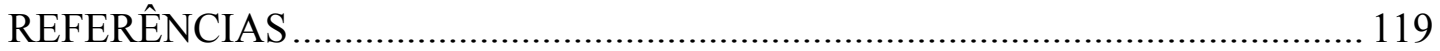

APÊNDICES 


\section{LISTA DE FIGURAS}

Figura 1: Reação imunohistoquímica StreptABCcomplex, para identificação de ICAM-1 e VCAM-1 na DMJ, DM, PM e MCI.

Figura 2: Reação hematoxilina e eosina (HE) de fragmento muscular da DMJ....... 35

Figura 3: Reação imunohistoquímica StreptABCcomplex, para identificação de MHC-I e II na DMJ, DM, PM e distrofia

Figura 4: Reação imunohistoquímica StreptABCcomplex, para identificação de C5b-9 na DMJ

Figura 5: Reação imunohistoquímica EnVision-AP para identificação de células CD4 na DMJ

Figura 6: Reação imunohistoquímica EnVision-AP para identificação de células CD8 na DMJ

Figura 7: Reação imunohistoquímica LSAB+ para identificação de células CD20 na DMJ

Figura 8: Reação imunohistoquímica LSAB+ para identificação de células CD68 na DMJ 


\section{LISTA DE TABELAS}

Tabela 1: Características clínicas, laboratoriais e histológicas dos pacientes com DMJ

Tabela 2: Características terapêuticas e evolutivas dos pacientes com DMJ 27

Tabela 3: Anticorpos monoclonais comerciais (Dakopatts) utilizados para imunofenotipagem das células mononucleares e dos antígenos de superfície expressos nos vasos e fibras musculares

Tabela 4: Correlação da análise semi-quantitativa da expressão de MHC-I nas fibras de fragmentos musculares de pacientes com DMJ, DM, PM e distrofia

Tabela 5: Correlação da análise semi-quantitativa da expressão de MHC-II nas fibras de fragmentos musculares de pacientes com DMJ, DM, PM e distrofia.

Tabela 6: Análise semi-quantitativa da expressão de C5b-9 na região endomisial, perimisial, capilares e fibras de fragmentos musculares de pacientes com DMJ...

Tabela 7: Correlações positivas da análise semi-quantitativa da expressão de C5b-9 nos vasos das regiões endomisial e perimisial, capilares e fibras de fragmentos musculares de pacientes com DMJ com características clínicas, laboratoriais, histológicas, terapêuticas e evolutivas

Tabela 8: Correlação da análise semi-quantitativa da expressão de C5b-9 nos vasos das regiões endomisial e perimisial, capilares e fibras de fragmentos musculares de pacientes com DMJ, DM, PM e distrofia ..... 50

Tabela 9: Análise quantitativa de células CD4 nas regiões endomisial, perimisial e perivascular (endomisial e perimisial) de fragmentos musculares de pacientes com DMJ

Tabela 10: Correlações positivas da análise quantitativa de células CD4 nas regiões endomisial, perimisial e perivascular (endomisial e perimisial) de fragmentos musculares de pacientes com DMJ com características clínicas, laboratoriais, histologicas, terapêuticas e evolutivas

Tabela 11: Correlação da análise quantitativa de células CD4 nas regiões endomisial, perimisial e perivascular (endomisial e perimisial) de fragmentos musculares de pacientes com DMJ, DM, PM e distrofia 
Tabela 12: Análise quantitativa de células CD8 nas regiões endomisial, perimisial e perivascular (endomisial e perimisial) de fragmentos musculares de pacientes com DMJ

Tabela 13: Correlações positivas da análise quantitativa de células CD8 nas regiões endomisial, perimisial e perivascular (endomisial e perimisial) de fragmentos musculares de pacientes com DMJ com características clínicas, laboratoriais, histologicas, terapêuticas e evolutivas

Tabela 14: Correlação da análise quantitativa de células CD8 nas regiões endomisial, perimisial e perivascular (endomisial e perimisial) de fragmentos musculares de pacientes com DMJ, DM, PM e distrofia..... 62

Tabela 15: Análise quantitativa de células CD20 nas regiões endomisial, perimisial e perivascular (endomisial e perimisial) de fragmentos musculares de pacientes com DMJ

Tabela 16: Correlações positivas da análise quantitativa de células CD20 nas regiões endomisial, perimisial e perivascular (endomisial e perimisial) de fragmentos musculares de pacientes com DMJ com características clínicas, laboratoriais, histológicas, terapêuticas e evolutivas

Tabela 17: Correlação da análise quantitativa de células CD20 nas regiões endomisial, perimisial e perivascular (endomisial e perimisial) de fragmentos musculares de pacientes com DMJ, DM, PM e distrofia....

Tabela 18: Análise semi-quantitativa da expressão de células CD68 nas regiões endomisial, perimisial e perivascular (endomisial e perimisial) de fragmentos musculares de pacientes com DMJ

Tabela 19: Correlações positivas da análise semi-quantitativa de células CD68 nas regiões endomisial, perimisial e perivascular (endomisial e perimisial) de fragmentos musculares de pacientes com DMJ com características clínicas, laboratoriais, histologicas, terapêuticas e evolutivas

Tabela 20: Correlação da análise semi-quantitativa de células CD68 nas regiões endomisial, perimisial e perivascular (endomisial e perimisial) de fragmentos musculares de pacientes com DMJ, DM, PM e distrofia ..... 77

Tabela 21: Resumo da expressão, localização e correlações positivas de MHC-I e II, C5b-9, CD4, CD8, CD20 e CD68 


\section{LISTA DE GRÁFICOS}

Gráfico 1: Análise semi-quantitativa da expressão de MHC-I nas fibras de fragmentos musculares de pacientes com DMJ

Gráfico 2: Análise semi-quantitativa da expressão de MHC-II nas fibras de fragmentos musculares de pacientes com DMJ

Gráfico 3: Análise semi-quantitativa da expressão de C5b-9 na região endomisial, perimisial, capilares e fibras de fragmentos musculares de pacientes com DMJ.

Gráfico 4: Análise quantitativa de células CD4 nas regiões endomisial, perimisial e perivascular (endomisial e perimisial) de fragmentos musculares de pacientes com DMJ

Gráfico 5: Análise quantitativa de células CD8 nas regiões endomisial, perimisial e perivascular (endomisial e perimisial) de fragmentos musculares de pacientes com DMJ.

Gráfico 6: Análise quantitativa de células CD20 nas regiões endomisial, perimisial e perivascular (endomisial e perimisial) de fragmentos musculares de pacientes com DMJ.

Gráfico 7: Análise semi-quantitativa da expressão de células CD68 nas regiões endomisial, perimisial e perivascular (endomisial e perimisial) de fragmentos musculares de pacientes com DMJ. 


\section{LISTA DE ABREVIATURAS}

ALT-TGP: aspartato alaninatransferase

AST-TGO: aspartato aminotransferase

ATPase: adenosina trifosfatase

CD4: linfócito T CD4+

CD8: linfócito T CD8+

CD20: linfócito B

CD68: macrófago

C5b-9: complexo de ataque à membrana

$\mathrm{CK}$ : creatinoquinase

COX: citocromo $\mathrm{C}$ oxidase

DHL: desidrogenase lática

DM: dermatomiosite

DMJ: dermatomiosite juvenil

HE: hematoxilina e eosina

ICAM-1: molécula 1 de adesão intercelular

MCI: miosite por corpo de inclusão

MHC-I: complexo maior de histocompatibilidade classe I

MHC-II: complexo maior de histocompatibilidade classe II

MII: miopatia inflamatória idiopática

NADH: NADH-tetrazolium redutase

ORO: oil-red O

PAS: ácido periódico de Schiff 
PM: polimiosite

PMJ: polimiosite juvenil

MRC: Medical Research Council

VCAM-1: molécula 1 de adesão vascular 


\section{RESUMO}

Sallum AME. Correlações da expressão de MHC-I e II, C5b-9 e fenotipagem de células inflamatórias em tecido muscular na dermatomiosite juvenil (DMJ) [tese]. São Paulo: Faculdade de Medicina, Universidade de São Paulo; 2005. 132p.

A presença de uma inflamação crônica no músculo, a associação com outras doenças e a presença de auto-anticorpos, sugere o envolvimento de um mecanismo autoimune na patogênese da DMJ. Trinta e sete fragmentos musculares de pacientes com o diagnóstico de DMJ foram estudados com o objetivo de avaliar a expressão de MHC classes I e II, C5b-9 e fenotipagem das células inflamatórias CD4, CD8, CD20 e CD68 em tecido muscular e correlacionar com os principais parâmetros clínicos, laboratoriais, histológicos e terapêuticos desta doença. Os achados foram comparados à expressão em oito fragmentos musculares de pacientes com polimiosite (PM), cinco de dermatomiosite (DM) e quatro de distrofia. As expressões de MHC-I, MHC-II e C5b-9 foram identificadas por imunohistoquímica, através da técnica de imunoperoxidase StreptABComplex/HRP; as células CD20 e CD68, pelo sistema LSAB+ e CD4 e CD8, pela técnica EnVision-AP. A expressão de MHC-I apresentou positividade em $97,2 \%$ dos casos, enquanto que a expressão de MHC-II foi observada em apenas 21,6\% dos casos. C5b-9 (83,8\% de positividade), correlacionou-se com a presença de calcinose e envolvimento cardíaco. A presença de linfócitos CD4 (81,1\% de positividade), CD8 (86,5\% de positividade) e CD20 (62,2 \% de positividade), e CD68 (97,2\% de positividade) correlacionaram-se com o grau de inflamação observada na histologia muscular. A presença de CD4 e CD68, e marcação de C5b-9 também se correlacionaram com a intensidade de fraqueza muscular, e laboratorialmente, CD4 correlacionou-se com níveis elevados de CK e CD20 com DHL. Na DMJ observou-se maior expressão de C5b-9, CD4 e CD8 e menor expressão de MHC-I e II em comparação à DM e PM. A expressão destes marcadores foi sempre menor na distrofia. A expressão de MHC-I, adjuvante ao envolvimento dos linfócitos CD4 e CD8, sugere um mecanismo inicial celular citotóxico relacionado a maior gravidade do envolvimento muscular. A concomitância da maior expressão de C5b-9 foi um fator preditivo de comprometimento sistêmico e demanda de terapêutica imunossupresssora. Os resultados deste estudo apontam para o papel do MHC-I e II, C5b-9, CD4, CD8, CD20 e CD68 na patogênese da DMJ. 


\section{SUMMARY}

Sallum AME. Correlations of the expression of MHC-I and II, C5b-9 and inflammatory cells phenotyping in juvenile dermatomyositis (JDM) [thesis]. São Paulo: "Faculdade de Medicina, Universidade de São Paulo". 2005. 132p.

The presence of chronic muscle inflammation, in association with other diseases and seric autoantibodies in JDM patients, suggest the involvement of an autoimmune mechanism in the pathogenesis of this inflammatory myopathy. Thirty seven muscle biopsy specimens from patients with JDM were analyzed in order to assess the expression of MHC-I and II, C5b-9, CD4, CD8, CD20 and CD68 and to correlate with the clinical, laboratorial, histological and therapeutical parameters. These findings were compared to the expression in five dermatomyositis (DM), eight polymyositis (PM) and four dystrophy cases. Immunohistochemical reactions for MHC-I and II and C5b-9 (StreptABCcomplex/HRP), CD4, CD8 (EnVision-AP) and CD20, CD68 (LSAB+) were evaluated. MHC-I expression was positive in $97.2 \%$ of the cases, whilst MHC-II was positive in only $21.6 \%$ of the cases. C5b-9 expression (positivity of $83.8 \%$ ) correlated with calcinosis and cardiac involvement. The presence of lymphocytes CD4 (positivity of $81.1 \%$ ), CD8 (positivity of $86.5 \%$ ), CD20 (positivity of $62.2 \%$ ), and CD68 (positivity of 97.2\%) correlated with inflammation in muscular histology. The presence of CD4 and CD8 and expression of C5b-9 also correlated with the severity of muscle weakness, and CD4 expression correlated with serum levels of CK and CD20 with LDH. In JDM, the expressions of C5b-9, CD4 and CD8 were statistically more significant when compared to PM and DM, while expressions of MHC-I and II were lower in JDM. All expressions were lower in dystrophy. MHC-I expression, adjuvant to the presence of CD4 and CD8 lymphocytes, corroborates the involvement of the cytotoxic cellular mechanism of muscular lesion in JDM, which correlates to severity. Concomitantly, C5b-9 expression was a predictive factor of systemic involvement and of the need for imunossupressive treatment. The results of this study indicate for the function of MHC-I and II, C5b-9, CD4, CD8, CD20 e CD68 at JDM pathogenesis. 


\section{DEFINIÇÃO}

A dermatomiosite juvenil (DMJ) é uma doença do tecido conectivo, de etiologia desconhecida, caracterizada por uma vasculite que compromete vários órgãos e sistemas, em especial a pele e os músculos (CASSIDY,1988; ANSELL,1991; ANSELL,1992). A dermatomiosite (DM), juntamente com a polimiosite $(\mathrm{PM})$ e a miosite por corpo de inclusão (MCI), faz parte de um grupo heterogêneo de doenças musculares adquiridas, as miopatias inflamatórias idiopáticas (MII), cujo denominador comum é a presença de fraqueza muscular e de infiltrado inflamatório no músculo. A caracterização deste grupo de doenças baseiase no padrão de envolvimento muscular, presença de manifestações clínicas associadas, alterações histopatológicas, resposta terapêutica e prognóstico (MASTAGLIA e OJEDA, 1985; MILLER,1991; RIDER e MILLER, 1997).

\section{DIAGNÓSTICO}

Para o diagnóstico da DMJ utilizam-se os critérios de BOHAN e PETER (1975) referendados pelo Colégio Americano de Reumatologia: 1) quadro dermatológico caracterizado pela presença de coloração violácea e edema periorbitário 
(heliotropo) e/ou eritema sobre as articulações metacarpofalangeanas e interfalangeanas proximais (sinal de Gottron), 2) fraqueza muscular simétrica, progressiva de cintura escapular, pélvica e flexores anteriores do pescoço, com ou sem disfagia e envolvimento da musculatura respiratória, 3) elevação das enzimas musculares particularmente a creatinoquinase (CK), frequentemente a aldolase, aspartato aminotransferase (AST-TGO), aspartato alaninatransferase (ALT-TGP) e desidrogenase lática (DHL), 4) eletromiografia mostrando unidades motoras curtas, polifásicas, fibrilações, ondas positivas, irritabilidade insercional, descargas de alta frequência e repetitivas, 5) biópsia muscular com evidências de miopatia inflamatória. A presença do eritema característico associado a três dos quatro critérios permite o diagnóstico de DM. Na ausência de lesões cutâneas define-se a PM.

DALAKAS, 1991 propos um novo critério diagnóstico para PM com a inclusão do complexo MHC/CD8 na biópsia muscular (DALAKAS e HOHFELD, 2003; BRONNER et al, 2004).

\section{EPIDEMIOLOGIA}

A DMJ é a forma mais comum de miopatia inflamatória na infância $(85 \%$ dos casos), a PM é rara e existem apenas poucos relatos de MCI na literatuta. Estudos iniciais relataram uma incidência de DMJ isolada ou associada a polimiosite juvenil (PMJ) variando de 2,5 a 5,1/milhão e recentemente foi demonstrada uma incidência de 3,2 casos/milhão nos Estados Unidos (HANSON, 1976; HANISSIAN et al, 1982; MENDEZ et al, 2003; WARGULA, 2003; 
WEDDERBURN e LI, 2004; COMPEYROT-LACASSAGNE e FELDMAN, 2005). Existe um predomínio do sexo feminino na proporção de 2:1 (CRONIN e PLOTZ, 1990; PACHMAN, 1990, WEDDERBURN e LI, 2004). Dos pacientes com DM, 12 a 20\% têm início da doença na infância (CASSIDY, 1988; SINGSEN, 1990). A idade média de início dos sintomas é em torno dos sete anos, podendo raramente ocorrer em lactentes a partir dos dois meses de idade (COOK et al, 1963; SULLIVAN et al, 1977; MALLESSON, 1982; CROWE et al, 1983).

\section{QUADRO CLÍNÍCO}

A doença pode ter início agudo, em um terço dos casos, com fraqueza muscular intensa, quadro cutâneo característico, sintomas constitucionais importantes (SULLIVAN, 1982; MILLER et al, 1987). Na maioria das vezes, contudo, o início é insidioso (MILLER et al, 1987; CASSIDY, 1988). Sintomas como febre, astenia, perda de peso, vertigem, sonolência, anorexia, náuseas e vômitos podem estar presentes (SULLIVAN, 1982; DUFFAU, 1984; CRESPI et al, 1990).

O comprometimento cutâneo da DMJ é bastante polimorfo. Porém, segundo CASSIDY (1988, 1990), em 75\% dos casos, as lesões são patognomônicas. As lesões cutâneas mais características são o heliotropo e as pápulas de Gottron. Com freqüência, as lesões eritematosas não se restrigem a região periorbitária, estendendo-se à região malar e nasal, nuca, áreas expostas do tórax, superfícies extensoras e em áreas palmo-plantares. A extensão e intensidade do eritema variam consideravelmente e podem progredir para atrofia, leucodermia ou hiperpigmentação 
(STRONGWATER, 1988; CRESPI et al, 1990; SOGABE et al, 1996; SALLUM et al, 2002). A análise histológica da pele na DMJ mostra atrofia da epiderme com liquefação, degeneração da membrana basal, dilatação vascular e infiltrado linfohistiocitário perivascular, proliferação endotelial de arteríolas e capilares (ARA, 1985; BOYER et al, 1986; KAGEN, 1989).

A fraqueza muscular proximal simétrica é referida em mais de $90 \%$ dos casos de literatura (SULLIVAN et al, 1977; PACHMAN e COOKE, 1980; MILLER et al, 1987; BURGOS-VARGAS et al, 1987; CASSIDY, 1988; SOGABE et al, 1996; SALLUM et al, 2002). O comprometimento dos músculos respiratórios, intercostais e diafragmático contribui para a morbidade pulmonar podendo levar à insuficiência respiratória. Envolvimento dos músculos faríngeos, laríngeos e linguais levam a disfonia e disfagia (CASSIDY, 1988; STRONGWATER, 1988; KAGEN, 1989; NORINS, 1989; CASSIDY e PETTY, 1990).

A calcinose ou calcificação distrófica é mais freqüente na DMJ do que na DM em adultos, ocorrendo em 26 a $50 \%$ dos casos. Está associada aos casos mais graves e não responsivos aos corticóides e ao uso de doses inadequadas destes medicamentos nas fases iniciais da doença (BITNUM et al, 1964; CROWE, 1983; BOWYER et al, 1983; GOEL e KING, 1986; MILLER et al, 1987; BURGOSVARGAS et al, 1987; SOGABE et al, 1996; SALLUM et al, 2002). Sua causa é desconhecida.

Em adultos, sinais de comprometimento do sistema respiratório na DM são encontrados em aproximadamente 45-50\% dos casos (DICKEY e MYERS, 1984; CHWALINSKA-SADOWSKA e MALDYKOWA, 1990). Diversas manifestações pulmonares podem ser atribuídas à DM: pneumonia aspirativa secundária a disfagia, 
insuficiência ventilatória secundária à fraqueza muscular, pneumonite intersticial, reação induzida por droga, neoplasias primárias ou metastáticas, pleurites, infecções oportunistas, hipertensão pulmonar, pneumotórax espontâneo e proteinose alveolar pulmonar. Existem poucos relatos em crianças (SOGABE et al, 1996; SALLUM et al, 2002). Acredita-se que o envolvimento pulmonar é freqüente, porém subclínico e seu diagnóstico dificultado por problemas técnicos como o fato de crianças pequenas não conseguirem realizar as provas de função pulmonar.

O comprometimento gastrointestinal em pacientes com DMJ pode se traduzir por dor abdominal, disfagia, náuseas, vômitos, diarréia, obstipação, hematemêse e melena chegando a acometer 50\% dos casos (KLECKNER, 1970; SOGABE et al, 1996; SALLUM et al, 2002). Ulceração e perfuração podem ocorrer em qualquer parte do trato gastrintestinal, sendo o comprometimento vasculítico a sua principal causa, podendo envolver a mucosa, submucosa e serosa. A camada íntima se hipertrofia levando à oclusão dos vasos com infarto de tecidos em todo o trato gastrintestinal. É causa importante de mortalidade (CROWE, 1983; THOMPSON, 1984; SCHULLINGER et al, 1985; DOWNEY et al, 1988).

Manifestações articulares (artrite ou artralgia) são freqüentemente encontradas no início da doença (STRONGWATER, 1988; CRESPI et al, 1990). Em geral, a artrite é simétrica, pouco dolorosa, não erosiva, afetando principalmente articulações interfalangeanas proximais, metacarpofalangeanas, punhos e joelhos (SULLIVAN, 1982; STRONGWATER, 1988; CRESPI et al, 1990; SOGABE et al, 1996).

Em adultos, o comprometimento cardíaco pode ocorrer em até $75 \%$ dos casos (GOTTDIENER et al, 1978; DENBOW et al, 1979; RAMANA et al, 1984; 
STRONGWATER et al, 1988). O comprometimento miocárdico é o mais freqüentemente descrito (ASKARI e HUETTNER, 1982). Existem poucos relatos sobre o comprometimento cardíaco na DMJ podendo ocorrer miocardite, pericardite e distúrbios de condução (BITNUM et al, 1964; PACHMAN e COOKE, 1980; PEREIRA et al, 1982; YOSHIOKA et al, 1985; GOEL e KING, 1986; SOGABE et al, 1996; SALLUM et al, 2002).

O comprometimento ocular é caracterizado por alterações na retina, sendo freqüente o aparecimento de exsudatos algodonosos, corpos citóides e edema de mácula. O mecanismo de lesão é provavelmente por vasculite com isquemia de retina, podendo ocorrer diminuição do campo visual e atrofia óptica (HARRISON et al, 1973; WINFIELD, 1977; CROWE, 1983).

A DMJ e a DM apresentam algumas diferenças: 1) a apresentação clínica na criança é freqüentemente insidiosa e predominam sintomas constitucionais como fadiga, mal estar, febre, anorexia e perda de peso; 2) esses pacientes mais freqüentemente apresentam vasculites multisistêmicas que podem envolver músculo, pele, mucosa gastrointestinal, coração e retina; 3) calcinoses também são mais freqüentes na faixa etária pediátrica, em especial naquelas com vasculites cutâneas generalizadas e/ou com cursos de doença mais graves e crônicos; 4) quando atingem a remissão, as crianças retornam força e função muscular mais freqüentemente que os adultos; e 5) associação com malignidade é descrita em 13,3\% dos adultos e é excepcionalmente descrita na faixa etária pediátrica (CALLEN, 1994; RIDER, 1995; SOGABE et al, 1996; CALOEW et al, 1997; SALLUM et al, 2002). 


\section{TRATAMENTO E PROGNÓSTICO}

Anteriormente ao uso dos corticóides, cerca de um terço das crianças com DMJ, evoluíam para óbito, um terço apresentava remissão e um terço permanecia com moderada a grave incapacitação funcional. A mortalidade reduziu para menos de $10 \%$ dos casos, após introdução da corticoterapia. Mas algumas complicações como calcinose, retardo de crescimento e lipodistrofia ainda são comuns (BOWYER et al, 1983; PACHMAN, 1990; CASSIDY e PETTY, 1995; REED, 2001; MARIE et al, 2001; RAMANAN e FELDMAN, 2002).

A maioria dos pacientes $(72,7 \%)$ evolui com curso monocíclico, mas alguns apresentam curso crônico-policíclico ou crônico contínuo (CASSIDY e PETTY, 1995; SOGABE et al, 1996; SALLUM et al, 2002).

Alguns fatores de pior prognóstico da doença são: atraso no diagnóstico e tratamento (início dos sintomas seis meses antes do diagnóstico e tratamento), atividade da doença não responsiva ao tratamento, ulcerações cutâneas, calcinoses, gravidade do envolvimento muscular com envolvimento distal, disfagia e disfonia, comprometimento sistêmico (pulmonar, cardíaco e gastrointestinal), capilaroscopia alterada, biópsia muscular com vasculopatia não inflamatória e a presença de anticorpos específicos (BOWYER et al, 1983; PACHMAN, 1990; CASSIDY e PETTY, 1995; SOGABE et al, 1996; REED, 2001; MARIE et al, 2001; RAMANAN e FELDMAN, 2002; SALLUM et al, 2002). A mortalidade está relacionada à insuficiência respiratória ou pneumonite intersticial, ulceração e hemorragia gastrointestinal (BOWYER et al, 1983; PACHMAN, 1990; CASSIDY e PETTY, 1995; SOGABE et al, 1996; REED, 2001 MARIE et al, 2001; RAMANAN e FELDMAN, 2002; SALLUM et al, 2002). 
A melhora no prognóstico parece estar diretamente relacionada com a introdução da corticoterapia, mas a incapacitação está diretamente relacionada aos eventos adversos com esta terapia medicamentosa (osteonecrose e fratura vertebral secundária a osteoporose) (BOWYER et al, 1983; YOSHIOKA et al, 1985; PACHMAN, 1990; CASSIDY e PETTY, 1995; SOGABE et al, 1996; REED, 2001; MARIE et al, 2001; RAMANAN e FELDMAN, 2002; SALLUM et al, 2002; CHOY e ISENBERG, 2002). Conseqüentemente, busca-se um tratamento mais eficaz e com menor toxicidade.

Vários esquemas terapêuticos foram sugeridos, mas preconizou-se uma dose inicial de $2 \mathrm{mg} / \mathrm{kg} /$ dia via oral fracionado, em um período de quatro a seis semanas. Após este período dose única por quatro a seis semanas e retirada progressiva até três anos (CASSIDY e PETTY, 1995; REED, 2001).

Metilprednisolona na forma de pulso, metotrexato, gamaglobulina, ciclosporina, azatioprina e ciclofosfamida são consideradas drogas de segunda linha. Estas são indicadas nas seguintes situações: pacientes refratários ao tratamento com corticóide, cortico-dependente ou com toxicidade importante; curso crônico ou policíclico. Buscando-se um tratamento mais eficaz e com menor toxicidade tem-se considerado a utilização das terapias de segunda linha em todos os pacientes na fase inicial da doença (BUNCH et al, 1980; LOVELL e LINSLEY, 1986; BASTA e DALAKAS, 1994; CASSIDY e PETTY, 1995; MILLER e KOEHLER, 1997; REED, 2001; CHOY e ISENBERG, 2002).

Para o estabelecimento de parâmetros determinantes de gravidade da doença, está sendo proposto um escore para a biópsia muscular com a inclusão da expressão de linfócitos, macrófagos e MHC-I (LI et al, 2004). 


\section{LABORATÓRIO}

\section{ENZIMAS MUSCULARES}

As enzimas musculares são liberadas pelo dano muscular e estão elevadas em 86,7 a $100 \%$ dos casos (SULLIVAN et al, 1977; HANISSIAN et al, 1982; MILLER et al, 1987; BURGOS-VARGAS et al, 1987; CASSIDY, 1988; SOGABE et al, 1996; SALLUM et al, 2002; RAMANAN e FELDMAN, 2005). Raramente podem estar normais na vigência de miosite ativa, especialmente nos estágios mais avançados da doença (CASSIDY, 1988; SHALLER e SZER, 1989; CHWALINSKASADOWSKA e MALDYKOWA, 1990).

\section{BIÓPSIA MUSCULAR}

A biópsia de músculo é um procedimento importante para estabelecer o diagnóstico da DMJ (ARA, 1985; CHAHADE et al, 1985; CASSIDY, 1988; ROELOFS, 1988; STRONGWATER, 1988; KAGEN, 1989; CASSIDY e PETTY, 1990; SOGABE et al, 1996; SALLUM et al, 2002). À microscopia óptica, as alterações histólogicas mais significativas são: 1) alterações musculares: necrose de fibras em vários estágios, regeneração, variação no diâmetro das fibras, aumento no tecido conjuntivo, infiltrado inflamatório constituido por linfócitos, plasmócitos e histiócitos perivasculares, atrofia perifascicular (achado importante na DMJ, onde a isquemia das fibras seria secundária a alterações vasculares) e infarto muscular. 2) alterações vasculares: na DMJ, observa-se hiperplasia endotelial nos vasos 
intramusculares com formação de trombos, oclusão e subsequente infarto muscular. A microscopia eletrônica pode mostrar na DMJ inclusões citoplasmáticas formadas por agregados tubulares, abundantes no endotélio dos capilares intramusculares, localizadas próximas ao núcleo ou na periferia da célula. Os achados são característicos e ocorrem em 75 a 95\% dos casos (SULLIVAN et al, 1977; PACHMAN e COOKE, 1980; HANISSIAN et al, 1982; MILLER et al, 1987; BURGOS-VARGAS et al, 1987; CASSIDY, 1988; SOGABE et al, 1996; SALLUM et al, 2002).

\section{FISIOPATOLOGIA}

A importância dos linfócitos na fisiopatologia das miopatias inflamatórias foi avaliada em vários estudos. Os resultados são conflitantes, mas, na sua maioria, sugerem uma citotoxicidade mediada por células T, com predomínio de células CD8, na PM e MCI, e infiltrado de células CD4 associado a células B, na DM. (ROWE et al, 1983; ENGEL e ARAHATA, 1984; OLSSON, 1985; LEMOINE et al, 1986; KIKUCHI et al, 2001; MIZUNO et al, 2004).

Poucos estudaram as células inflamatórias na biópsia muscular de pacientes com DMJ. ARAHATA e ENGEL (1984) observaram predomínio de células B e não encontraram diferença entre a expressão na DM e DMJ, enquanto que MCDOUALL et al (1990) observaram predomínio de macrófagos e células T, especialmente células CD4. 
A função das células $\mathrm{T}$ é determinada pelo complexo maior de histocompatibilidade (MHC). As células T reconhecem um antígeno ligado ao MHC. Comumente moléculas MHC-I apresentam antígenos derivados de uma proteína endógena ou peptídeos para células T expressando glicoproteínas CD8 (células T citotóxicas) e moléculas MHC classe II apresentando antígenos derivados de proteínas exógenas ou endógenas para células T expressando CD4. Moléculas MHC classe II são expressas principalmente nos macrófagos, monócitos e células B, enquanto que moléculas MHC classe I são expressas na maioria das células.

As fibras musculares normais não expressam MHC-I ou II (ROWE et al, 1983; DAAR et al, 1984; KARPATI et al, 1988; ZUK e FLETCHER, 1988; MCDOUALL et al, 1989; REED et al, 1991; INUKAI et al, 2000; ENGLUND et al, 2001). Expressão de MHC-I foi amplamente observada nas fibras musculares de pacientes adultos portadores de miopatias inflamatórias (DM, PM e MCI) (APPLEYARD et al, 1985; ISENBERG et al, 1986; KARPATI et al, 1988; MCDOUALL et al, 1989, EMSLIE-SMITH et al, 1989; KALOVIDOURUS e SMITH, 1991; BARTOCCIONI et al, 1994; LINDBERG et al, 1995; FLADBY et al, 1997; ENGLUND et al, 2001), enquanto que a expressão de MHC-II apresentou baixa positividade, localizada especialmente em fibras pequenas e em regeneração (OLSSON et al, 1985; CIFUENTES-DIAZ et al, 1992; INUKAI et al, 2000; ENGLUND et al, 2001).

Na DMJ, MCDOUALL et al, 1989, observaram intensa expressão de MHC-I e ausência de MHC-II. TOPALOGLU et al, 1997 e LI et al, 2004 sugeriram que a expressão de MHC-I possa ser um marcador diagnóstico, ocorrendo anteriormente à presença do infiltrado inflamatório e da lesão muscular. 
Embora o infiltrado inflamatório seja característico do grupo de doenças denominadas miopatias inflamatórias idiopáticas, diferenças clínicas, assim como histopatológicas sugerem etiologia e mecanismos patogênicos específicos para cada subgrupo (PM, DM e MCI). Acredita-se que na PM e MCI, células T CD8 citotóxicas, invadam e destruam as fibras musculares que expressam MHC-I. Enquanto que na DM, a ativação do complemento, leva ao depósito do complexo de ataque de membrana (C5b9) nos capilares endomisiais, resultando em inflamação perivascular, depleção capilar, isquemia muscular, necrose e atrofia da fibra muscular (KISSEL et al, 1986; 1991; EMSLIE-SMITH e ENGEL, 1990; DALAKAS, 1995; HOHFELD et al, 1997; BENVENISTE et al, 2001; LUNDBERG, 2001; GONÇALVES, 2002).

O complemento ativado nas células endoteliais irá regular a expressão das moléculas de adesão: ICAM-1 e VCAM-1. SALLUM et al (2002; 2004) estudando a expressão das moléculas de adesão ICAM-1 e VCAM-1 em tecido muscular de pacientes com DMJ acompanhados na Unidade de Reumatologia Pediátrica do ICrHC-FMUSP, observaram: 1. a expressão de ICAM-1 foi maior quando comparado à expressão de VCAM-1; 2. a expressão de ICAM-1, nos capilares e vasos perimisiais, foi semelhante e maior nos vasos endomisiais; 3. houve correlação entre a maior expressão de ICAM -1 e o sexo feminino, menor grau de força muscular, presença de comprometimento pulmonar, níveis séricos mais elevados de $\mathrm{CK}$ e presença de degeneração na histologia muscular. SALLUM et al (2005) comparando a expressão de ICAM-1 e VCAM-1 entre pacientes com DMJ, PM, DM e MCI, a expressão de ICAM-1 na DMJ foi maior nos vasos e menor em fibras musculares, quando comparado à PM e DM. Enquanto que a expressão de VCAM-1 na PM e DM foi maior nos vasos quando comparado com a DMJ. 
Figura 1: Reação imunohistoquímica Strept $A B C$ complex, para identificação de ICAM-1 e VCAM-1 na DMJ, DM, PM e MCI, onde se observa a positividade em marrom.

[DMJ]: Reação positiva para expressão de ICAM-1 (A) e negativa para expressão de VCAM-1 (B) nos vasos. Fibras musculares com reação positiva para expressão de ICAM-1 (C) e negativa de VCAM-1 (D) (400X).

[DM]: Reação positiva para expressão de ICAM-1 (E) e VCAM-1 (F) nas fibras musculares $(-)$ ) e vasos $(\rightarrow)$ (200X).

[PM]: Reação positiva para expressão de ICAM-1 (G) e VCAM-1 (H) nas fibras musculares $(\rightarrow)$ e vasos $(\rightarrow)$, especialmente ao redor do infiltrado inflamatório. Expressão de VCAM-1 observada no sarcolema $(-)$ (200X).

[MCI]: Reação negativa para expressão de ICAM-1 (I) e VCAM-1 (J) nas fibras musculares e vasos (200X). 
ICAM-1
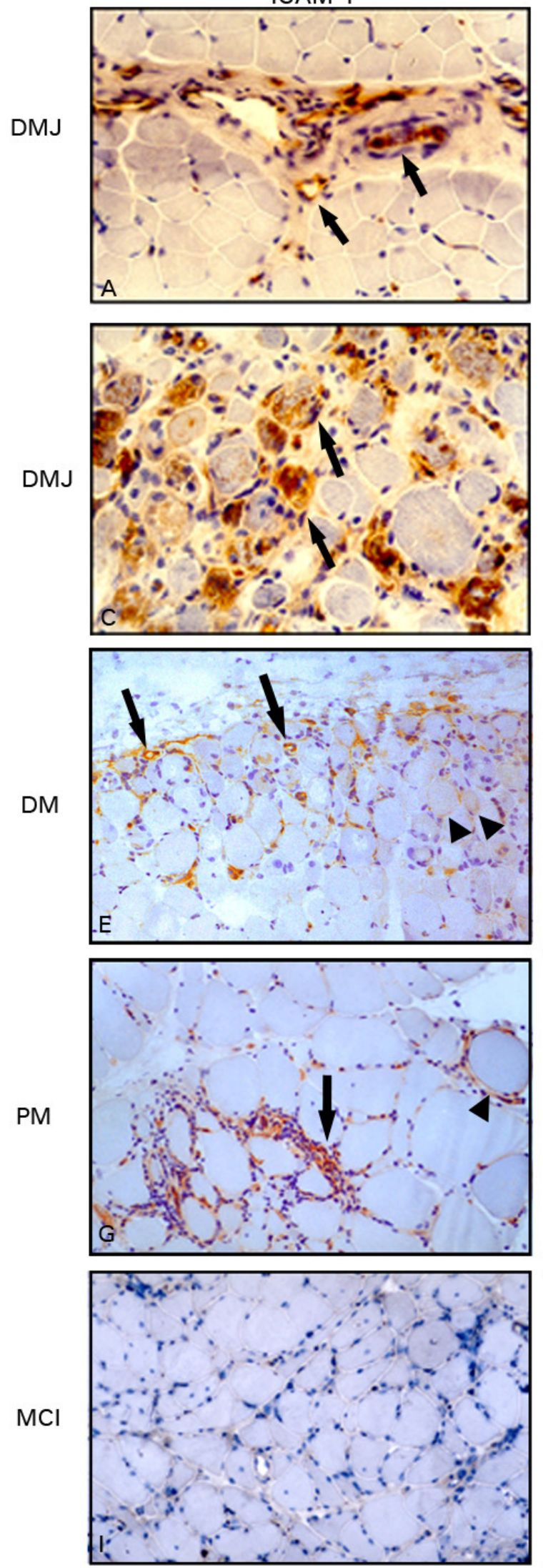

VCAM-1
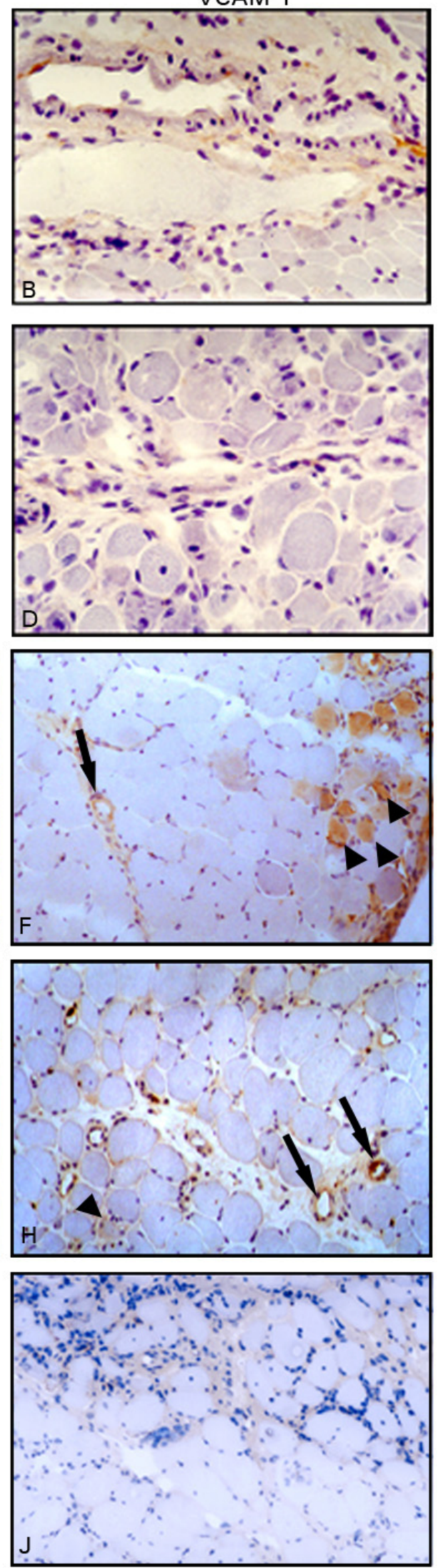


\section{JUSTIFICATIVA}

A dermatomiosite juvenil é uma doença rara cuja etiopatogenia ainda é desconhecida.

Vários estudos foram realizados quanto à fisiopatologia da doença em pacientes adultos.

Não existem estudos correlacionando concomitantemente características clínicas, laboratoriais, histológicas, terapêuticas e evolutivas, exceto correlacionando de modo não sistemático, algumas características da DMJ, em casuísticas pequenas, devido à raridade da doença.

A maioria dos estudos analisa a expressão sérica dos anticorpos e não sua expressão em tecido muscular.

A DMJ e DM são na maioria dos estudos consideradas uma entidade única, mas a diferente apresentação clínica, em especial associada ao comprometimento vascular, corroborada com a diferença encontrada na expressão das moléculas de adesão entre as duas doenças, e a correlação da expressão da molécula de adesão ICAM-1 com características clínicas, laboratoriais, histológicas e terapêuticas da doença evidenciada em estudos anteriores (SALLUM et al, 2001; 2002; 2004; 2005), motivou a investigação da fenotipagem das células inflamatórias, C5b9 e expressão de MHC classes I e II em fragmentos musculares da DMJ, para melhor compreensão dos mecanismos etiopatogênicos. 
1. Avaliar a fenotipagem do infiltrado inflamatório quanto à expressão de linfócitos T (CD4, CD8), linfócitos B (CD20) e macrófagos (CD68) em tecido muscular de pacientes com DMJ.

2. Avaliar a expressão da ativação do complemento (C5b-9) e dos antígenos de MHC classes I e II em tecido muscular de pacientes com DMJ.

3. Correlacionar os achados dos itens 1 e 2 com os achados em pacientes com DM, PM e distrofia.

4. Correlacionar os achados dos itens 1 e 2 com as características clínicas, laboratoriais, histológicas, terapêuticas e evolutivas da doença.

5. Correlacionar os achados dos itens 1 e 2 com os resultados prévios da expressão das moléculas de adesão ICAM-1 e VCAM-1 em tecido muscular de pacientes com DMJ. 


\section{CASUÍSTICA}

Foram estudados 37 fragmentos musculares de pacientes acompanhados no Ambulatório da Unidade de Reumatologia Pediátrica do Instituto da Criança do Hospital das Clínicas, da Faculdade de Medicina da Universidade de São Paulo (ICrHC-FMUSP) e Faculdade de Ciências Médicas da Santa Casa de Misericórdia de São Paulo, com diagnóstico de DMJ, de acordo com os critérios de BOHAN e PETER (1975), referendados pelo Colégio Americano de Reumatologia (Anexo 1).

Os 37 fragmentos musculares utilizados foram referentes aos mesmos pacientes incluídos no estudo da expressão das moléculas de adesão (mestrado) (SALLUM et al, $2002 ; 2004)$

Dezessete controles foram incluídos: oito pacientes adultos com PM, cinco com DM e quatro com distrofia.

\section{METODOLOGIA}

Foi realizada análise retrospectiva (março de 1991 a janeiro de 2004) de 10 prontuários de pacientes em seguimento na Unidade de Reumatologia Pediátrica do 
ICr-HC-FMUSP e prospectiva (fevereiro de 1999 a janeiro de 2004) de 25 pacientes admitidos durante o período de fevereiro de 1999 a janeiro de 2001 (período da realização do estudo da expressão das moléculas de adesão).

Todos os pacientes admitidos durante o período do estudo foram examinados pela autora na ocasião da realização da biópsia muscular.

Os pacientes foram avaliados por meio de um protocolo clínico, laboratorial e anatomo-patológico (Anexo 2).

\section{CLÍNICA}

A avaliação clínica foi realizada com atenção especial a:

1. alterações cutâneas: heliotropo, pápulas de Gottron, eritemas malar, palmoplantar, periungueal, e em tronco e pescoço, fotossensibilidade e úlceras;

2. alterações de partes moles, com ênfase para a presença de calcinoses caracterizadas por depósitos de cálcio intradérmicos ou subcutâneos localizados preferencialmente em dedos, joelhos, cotovelos, superfícies extensoras da tíbia e ulna passíveis de ulcerar e drenar um material cálcico;

3. avaliação quantitativa da força muscular determinada pelos parâmetros do MEDICAL RESEARCH COUNCIl, 1981 (MRC), que utiliza a seguinte escala: 0. nenhuma contração; 1. contração mínima; 2. movimento ativo na ausência de gravidade; 3 . movimento contra gravidade; 4. movimento contra gravidade e resistência; 5. força normal; 
4. presença de comprometimento do trato gastrointestinal caracterizada por quadro clínico de dor abdominal, disfagia, náuseas, vômitos, diarréia, obstipação, hematêmese e melena, com auxílio de exames complementares como radiografia contrastada de esôfago, estômago e duodeno e esofagogastroduodenoscopia;

5. presença de comprometimento pulmonar caracterizada por pneumonia aspirativa secundária a disfagia, insuficiência ventilatória secundária à fraqueza muscular, pneumonite intersticial, infecções oportunistas, pleurites e hipertensão pulmonar, com auxílio de exames complementares, como radiografia de tórax, ecocardiograma, prova de função pulmonar, cintilografia e tomografia computadorizada de tórax.

A resposta terapêutica foi baseada no resultado inicial ao tratamento com corticoterapia (prednisona ou pulso de metilprednisolona), sendo definida como boa resposta quando, após um período de quatro a seis semanas, o paciente apresentasse melhora clínica baseada especialmente na melhora da força muscular; parcial, quando não houvesse melhora significativa, necessitando da introdução de outras terapêuticas, e ruim, quando não se observasse qualquer sinal de melhora com o uso da corticoterapia.

Foram diferenciados dois grupos, tendo em vista a introdução da corticoterapia anterior ou posteriormente à realização da biópsia muscular.

Para análise da evolução dos pacientes, foi realizada uma divisão entre aqueles que mantiveram atividade clínica (fraqueza muscular) e/ou laboratorial (elevação dos níveis de CK e DHL) e/ou cutânea (rash cutâneo, heliotropo, Gottron, úlceras cutâneas); os que estiveram fora de atividade, com o uso de medicamentos; e os que estiveram em remissão, sem o uso de medicamentos; por ocasião do encerramento do estudo. 


\section{LABORATÓRIO}

Os níveis séricos das enzimas musculares foram determinados por ocasião da realização da biópsia muscular.

\section{BIÓPSIA MUSCULAR}

As biópsias musculares, indicadas com finalidades diagnósticas em todos os pacientes, foram realizadas na sala de procedimentos ambulatoriais ou no centro cirúrgico do ICr-HC-FMUSP.

A biópsia, realizada a céu aberto, consta de uma pequena incisão de cerca de $3 \mathrm{~cm}$ na região do músculo proximal acometido, preferencialmente o bíceps braquial, após assepsia e anestesia local com lidocaína a 2\%, sem vasoconstritor. Uma vez feita a divulsão do tecido subcutâneo e a hemostasia, procede-se a incisão da fáscia muscular, expondo, então, o tecido muscular a ser biopsiado. Colhe-se um fragmento muscular de aproximadamente $1 \mathrm{~cm}^{3}$, reparado antes de ser retirado. A seguir, a fáscia muscular é suturada, assim como os planos subcutâneos, com fio absorvível e, a pele, com fio de nylon.

Todas as crianças foram submetidas à biópsia do músculo bíceps braquial na ausência de traumas internos, inclusive o provocado pelas agulhas da eletroneuromiografia.

Após retirada, uma parte do fragmento muscular foi separada para rotina diagnóstica e o restante do material, armazenado em nitrogênio líquido a $-170^{\circ} \mathrm{C}$. A 
rotina diagnóstica inclui cortes seriados e transversais, de 5 micra de espessura, para realização das reações histológicas, histoquímicas e imunohistoquímicas. Cortes de congelação seriados corados pelos métodos de hematoxilina e eosina (HE), tricomo de Gomori modificado por ENGEL e CUNNINGHAN, em 1963, ácido periódico de Schiff (PAS), oil-red O (ORO), NADH-tetrazolium redutase (NADH), succinato dehidrogenase (SDH), citocromo $\mathrm{C}$ oxidase (COX), adenosina trifosfatase (ATPase) em pHs ácidos (4.3 e 4.6) e alcalino (9.4), fosfatases ácida e alcalina. Todas as colorações histológicas e histoquímicas são realizadas segundo a técnica padronizada por DUBOWITZ, 1985.

Os parâmetros analisados na histologia foram análise qualitativa da variação do calibre das fibras musculares, atrofia perifascicular (atrofia de uma a duas camadas de fibras na periferia do fascículo) e infiltrado inflamatório: presença de células mononucleares na região perimisial, endomisial e/ou perivascular.

Os parâmetros analisados na histoquímica foram: degeneração definida como dissociação miofibrilar, presença de vacúolos com ou sem macrofagia, presença de reação lisossomal a fosfatase ácida, presença de alterações do sarcolema, presença de células inflamatórias no interior da fibra muscular; e regeneração, definida pela presença de basofilia na fibra, presença de núcleo vesiculoso e nucléolo, e presença de reação a fosfatase alcalina.

Todo o processamento do material seguiu a rotina diagnóstica estabelecida pelo Grupo de Miopatias do Departamento de Neurologia, LIM-15, FMUSP.

As características clínicas, laboratoriais, histológicas, terapêuticas e evolutivas dos 37 pacientes com DMJ estão discriminadas nas tabelas 1 e 2 . 
Tabela 1: Características clínicas, laboratoriais e histológicas dos pacientes com DMJ

\begin{tabular}{|c|c|c|c|c|c|c|c|c|c|c|c|c|c|c|c|c|c|}
\hline \multirow[b]{2}{*}{ Caso } & \multirow[b]{2}{*}{ Sexo } & \multirow{2}{*}{$\begin{array}{c}\text { Idade } \\
\text { de } \\
\text { início } \\
\text { da } \\
\text { doença }\end{array}$} & \multirow{2}{*}{$\begin{array}{c}\text { Tempo de } \\
\text { doença até } \\
\text { realização } \\
\text { da biópsia } \\
\text { (m) }\end{array}$} & \multirow[b]{2}{*}{$\begin{array}{l}\text { Sinais e } \\
\text { sintomas }\end{array}$} & \multirow[b]{2}{*}{$\begin{array}{c}\text { Força } \\
\text { muscular }\end{array}$} & \multicolumn{5}{|c|}{ Enzimas } & \multicolumn{7}{|c|}{ Biópsia muscular } \\
\hline & & & & & & Aldolase & TGO & TGP & $\mathrm{CK}$ & DHL & $\begin{array}{l}\text { Atrofia } \\
\text { perifas- } \\
\text { cicular }\end{array}$ & $\begin{array}{c}\text { Dissociação } \\
\text { miofibrilar }\end{array}$ & $\begin{array}{l}\text { Fibras } \\
\text { necróticas }\end{array}$ & $\begin{array}{l}\text { Fibras em } \\
\text { regene- } \\
\text { ração }\end{array}$ & $\begin{array}{c}\text { Inflamação } \\
\text { perivascular }\end{array}$ & $\begin{array}{l}\text { Inflamação } \\
\text { endomisial }\end{array}$ & $\begin{array}{c}\text { Aumento } \\
\text { tecido } \\
\text { conectivo }\end{array}$ \\
\hline 1 & $\bar{F}$ & $6 \mathrm{a} 3 \mathrm{~m}$ & 1 & & II & & 59 & 32 & 711 & 530 & $\bar{P}$ & + & + & ++ & ++ & +++ & + \\
\hline 2 & M & $3 \mathrm{a} 1 \mathrm{~m}$ & 24 & Cca & $\mathrm{V}$ & & 83 & 54 & & 820 & $\mathrm{P}$ & ++ & + & + & ++ & + & + \\
\hline 3 & $\mathrm{~F}$ & $7 a$ & 2 & & IV & & & & 1785 & & $\mathrm{P}$ & ++++ & ++++ & ++++ & ++ & + & + \\
\hline 4 & $\mathrm{~F}$ & $9 \mathrm{a} 11 \mathrm{~m}$ & 4 & PG & I & & 47 & 21 & 1051 & 592 & $\mathrm{P}$ & +++ & ++ & ++ & ++++ & ++++ & +++ \\
\hline 5 & M & $3 \mathrm{a} 1 \mathrm{~m}$ & 64 & $\mathrm{C}$ & V & & & & & 604 & $\mathrm{P}$ & + & + & + & + & + & ++ \\
\hline 6 & $\mathrm{~F}$ & $3 \mathrm{a} 8 \mathrm{~m}$ & 4 & & II & & 54 & 34 & 141 & 668 & $P$ & +++ & ++ & ++ & +++ & ++ & ++ \\
\hline 7 & $\mathrm{~F}$ & $9 \mathrm{a} 6 \mathrm{~m}$ & 3 & PC & III & & 95 & 51 & 1281 & 672 & $P$ & ++ & + & + & + & + & + \\
\hline 8 & M & $8 \mathrm{a} 8 \mathrm{~m}$ & 24 & $\mathrm{C}$ & IV & & & & & 276 & $\mathrm{P}$ & + & + & - & + & + & - \\
\hline 9 & $\mathrm{~F}$ & $4 \mathrm{a} 8 \mathrm{~m}$ & 36 & & III & & 46 & 48 & 4365 & 2355 & - & - & - & - & + & - & + \\
\hline 10 & M & $1 \mathrm{a} 6 \mathrm{~m}$ & 4 & $\mathrm{UCCaG}$ & II & & 40 & 13 & 240 & 387 & $\mathrm{P}$ & + & + & - & + & + & + \\
\hline 11 & $\mathrm{~F}$ & $5 \mathrm{a} 6 \mathrm{~m}$ & 4 & UPGC & IV & 18 & 38 & 25 & 358 & 385 & $\mathrm{P}$ & + & + & + & + & + & + \\
\hline 12 & M & $9 \mathrm{a}$ & 18 & & III & 4 & 22 & 12 & 197 & 307 & $\mathrm{P}$ & + & + & + & ++ & ++ & + \\
\hline 13 & $\mathrm{~F}$ & $5 \mathrm{a} 8 \mathrm{~m}$ & 3 & & IV & 10 & 23 & 14 & 636 & 337 & $\mathrm{P}$ & + & + & + & + & + & + \\
\hline 14 & $\mathrm{~F}$ & $4 \mathrm{a} 8 \mathrm{~m}$ & 44 & & V & & 102 & 230 & 503 & & $\mathrm{P}$ & - & - & + & + & + & + \\
\hline 15 & $\mathrm{~F}$ & $4 a 6 m$ & 12 & & III & & 148 & 146 & 371 & 986 & $\mathrm{P}$ & ++ & + & + & ++ & + & + \\
\hline 16 & $\mathrm{~F}$ & $9 \mathrm{a} 9 \mathrm{~m}$ & 4 & & IV & 16 & & & & 1148 & $\mathrm{P}$ & - & - & - & + & - & - \\
\hline 17 & M & $7 \mathrm{a} 8 \mathrm{~m}$ & 1 & & III & & 79 & 30 & 2168 & 1667 & $\mathrm{P}$ & +++ & +++ & +++ & +++ & +++ & - \\
\hline 18 & $\mathrm{~F}$ & $1 \mathrm{a} 5 \mathrm{~m}$ & 12 & & III & & 1420 & 1010 & 2488 & & $\mathrm{P}$ & +++ & +++ & +++ & +++ & ++ & + \\
\hline 19 & $\mathrm{~F}$ & $9 \mathrm{a} 1 \mathrm{~m}$ & 2 & UPGC & III & & 1236 & 1739 & & 692 & $\mathrm{P}$ & ++ & + & + & + & + & - \\
\hline 20 & F & $8 \mathrm{a} 8 \mathrm{~m}$ & 3 & & IV & & 87 & 45 & 5022 & 2123 & $\mathrm{P}$ & + & + & + & ++ & + & - \\
\hline 21 & $\mathrm{~F}$ & $8 \mathrm{a} 1 \mathrm{~m}$ & 1 & & V & 14 & 33 & 22 & 138 & 738 & $\mathrm{P}$ & - & - & - & + & - & - \\
\hline 22 & $\mathrm{~F}$ & $9 \mathrm{a}$ & 4 & & III & 24 & 81 & 39 & 1874 & 1513 & $\mathrm{P}$ & ++ & + & + & ++ & + & + \\
\hline 23 & $\mathrm{~F}$ & $7 \mathrm{a} 11 \mathrm{~m}$ & 9 & UC & III & & 77 & 46 & 507 & 718 & $\mathrm{P}$ & +++ & ++ & +++ & +++ & +++ & + \\
\hline
\end{tabular}




\begin{tabular}{|c|c|c|c|c|c|c|c|c|c|c|c|c|c|c|c|c|c|}
\hline \multirow[b]{2}{*}{ Caso } & \multirow[b]{2}{*}{ Sexo } & \multirow{2}{*}{$\begin{array}{c}\text { Idade } \\
\text { de } \\
\text { início } \\
\text { da } \\
\text { doença } \\
\end{array}$} & \multirow{2}{*}{$\begin{array}{c}\text { Tempo de } \\
\text { doença até } \\
\text { realização } \\
\text { da biópsia } \\
(\mathrm{m})\end{array}$} & \multirow[b]{2}{*}{$\begin{array}{l}\text { Sinais e } \\
\text { sintomas }\end{array}$} & \multirow[b]{2}{*}{$\begin{array}{l}\text { Força } \\
\text { muscular }\end{array}$} & \multicolumn{5}{|c|}{ Enzimas } & \multicolumn{7}{|c|}{ Biópsia muscular } \\
\hline & & & & & & Aldolase & TGO & TGP & CK & DHL & $\begin{array}{l}\text { Atrofia } \\
\text { perifas- } \\
\text { cicular }\end{array}$ & $\begin{array}{l}\text { Dissociação } \\
\text { miofibrilar }\end{array}$ & $\begin{array}{c}\text { Fibras } \\
\text { necróticas }\end{array}$ & $\begin{array}{c}\text { Fibras em } \\
\text { regene- } \\
\text { ração }\end{array}$ & $\begin{array}{l}\text { Inflamação } \\
\text { perivascular }\end{array}$ & $\begin{array}{l}\text { Inflamação } \\
\text { endomisial }\end{array}$ & $\begin{array}{l}\text { Aumento } \\
\text { tecido } \\
\text { conectivo }\end{array}$ \\
\hline 24 & $F$ & $1 \mathrm{a} 5 \mathrm{~m}$ & 2 & & III & 15 & 64 & 22 & 358 & 943 & $\bar{P}$ & +++ & ++ & +++ & ++ & + & + \\
\hline 25 & $\mathrm{~F}$ & $10 \mathrm{a} 6 \mathrm{~m}$ & 2 & $\mathrm{Ca}$ & III & & 24 & 20 & 113 & 756 & $\mathrm{P}$ & +++ & + & +++ & ++ & + & + \\
\hline 26 & $\mathrm{~F}$ & $6 \mathrm{a} 10 \mathrm{~m}$ & 2 & $\mathrm{G}$ & III & 16 & 40 & 24 & 1173 & 1052 & $P$ & - & - & - & - & - & - \\
\hline 27 & $\mathrm{~F}$ & $8 \mathrm{a}$ & 6 & & IV & & 78 & 54 & 734 & 834 & $P$ & - & + & + & +++ & +++ & - \\
\hline 28 & $\mathrm{~F}$ & $5 \mathrm{a} 8 \mathrm{~m}$ & 4 & PG & II & & 82 & 32 & 605 & & $P$ & + & ++ & +++ & + & ++++ & + \\
\hline 29 & M & $2 \mathrm{a} 4 \mathrm{~m}$ & 2 & & IV & & 200 & 92 & 2670 & 570 & $\mathrm{P}$ & + & ++ & +++ & + & + & + \\
\hline 30 & M & $11 \mathrm{a}$ & 36 & $\mathrm{Ca}$ & IV & & & & 88 & & $\mathrm{P}$ & + & - & - & + & - & - \\
\hline 31 & $\mathrm{~F}$ & $8 \mathrm{a} 6 \mathrm{~m}$ & 1 & & II & & 96 & 41 & 1269 & 881 & $\mathrm{P}$ & + & - & - & + & - & - \\
\hline 32 & F & $9 \mathrm{a} 1 \mathrm{~m}$ & 1 & & IV & 28 & & & 1147 & & $\mathrm{P}$ & + & + & + & + & + & - \\
\hline 33 & $\mathrm{~F}$ & $12 \mathrm{a} 8 \mathrm{~m}$ & 3 & & III & 113 & 550 & & 11640 & 1885 & $\mathrm{P}$ & ++ & ++ & ++ & ++ & ++ & + \\
\hline 34 & M & $7 \mathrm{a}$ & 8 & & IV & & & & 504 & & $\mathrm{P}$ & ++ & + & + & ++ & + & - \\
\hline 35 & $\mathrm{~F}$ & $13 a$ & 6 & & III & & 97 & 84 & 378 & & $\mathrm{P}$ & +++ & +++ & +++ & + & + & - \\
\hline 36 & $\mathrm{~F}$ & $6 \mathrm{a}$ & 4 & & III & & 102 & 283 & 92 & 847 & $\mathrm{P}$ & +++ & +++ & +++ & +++ & ++ & + \\
\hline 37 & M & $4 a$ & 3 & & IV & & 57 & 101 & 205 & & $\mathrm{P}$ & + & + & + & ++ & + & - \\
\hline
\end{tabular}

$\mathrm{C}=$ calcinose, $\mathrm{Ca}=$ cardíaco, $\mathrm{G}=$ gastrointestinal, $\mathrm{P}=$ pulmonar, $\mathrm{U}=$ ulcera cutânea, $\mathrm{P}=$ presente,

$(-)=$ ausência de positividade; $(+)=1$ a $25 \% ;(++)=26$ a $50 \% ;(+++)=51$ a $75 \% ;(++++)=76$ a $100 \%$ de positividade 
Tabela 2: Características terapêuticas e evolutivas dos pacientes com DMJ

\begin{tabular}{|c|c|c|c|c|c|c|c|c|c|c|}
\hline \multirow[b]{2}{*}{ Caso } & \multicolumn{3}{|c|}{ Corticoterapia } & \multirow[b]{2}{*}{ Cloroquina } & \multirow[b]{2}{*}{ Metotrexato } & \multirow[b]{2}{*}{ Ciclosporina } & \multirow[b]{2}{*}{ Ciclofosfamida } & \multirow[b]{2}{*}{$\begin{array}{l}\text { Gamaglobulina } \\
\text { endovenosa }\end{array}$} & \multirow[b]{2}{*}{$\begin{array}{c}\text { Tempo de } \\
\text { seguimento (m) }\end{array}$} & \multirow[b]{2}{*}{$\begin{array}{l}\text { Evolução ao final do } \\
\text { estudo }\end{array}$} \\
\hline & $\begin{array}{c}\text { Anterior } \\
\text { à biópsia }\end{array}$ & $\begin{array}{c}\text { Posterior à } \\
\text { biópsia }\end{array}$ & $\begin{array}{l}\text { Resposta inicial } \\
\quad(4-6 \mathrm{~m})\end{array}$ & & & & & & & \\
\hline 1 & & + & Parcial & + & + & & & & 99 & Remissão \\
\hline 2 & & + & Parcial & & + & & & & 152 & Fora de atividade \\
\hline 3 & & + & Boa & & & & & & 94 & Remissão \\
\hline 4 & + & & Boa & & & & & & 92 & Remissão \\
\hline 5 & & + & Parcial & & + & & & & 152 & Fora de atividade \\
\hline 6 & & + & Parcial & & + & & & & 80 & Remissão \\
\hline 7 & & + & Ruim & + & & + & + & + & 78 & Remissão \\
\hline 8 & & + & Parcial & + & & & & + & 124 & Remissão \\
\hline 9 & & + & Boa & & & & & & 73 & Abandono de seguimento \\
\hline 10 & & + & Parcial & + & + & + & & & 71 & Fora de atividade \\
\hline 11 & + & & Ruim & + & + & + & + & + & 68 & Óbito \\
\hline 12 & & + & Boa & & & & & & 37 & Remissão \\
\hline 13 & + & & Parcial & + & & & & & 68 & Remissão \\
\hline 14 & & + & Boa & & & & & & 73 & Abandono de seguimento \\
\hline 15 & + & & Parcial & & + & & & & 63 & Fora de atividade \\
\hline 16 & & + & Parcial & + & & & & & 60 & Remissão \\
\hline 17 & & + & Parcial & + & & & & & 61 & Remissão \\
\hline 18 & & + & Parcial & & + & & & & 61 & Fora de atividade \\
\hline 19 & & + & Parcial & & + & & & & 60 & Fora de atividade \\
\hline 20 & & + & Boa & & & & & & 60 & Abandono de seguimento \\
\hline 21 & & + & Boa & & & & & & 58 & Remissão \\
\hline 22 & & + & Não aderiu tratamento & & & & & & - & Óbito \\
\hline 23 & & + & Parcial & + & + & & & & 57 & Remissão \\
\hline
\end{tabular}

continua 
continuação Tabela 2

\begin{tabular}{|c|c|c|c|c|c|c|c|c|c|c|}
\hline \multirow[b]{2}{*}{ Caso } & \multicolumn{3}{|c|}{ Corticoterapia } & \multirow[b]{2}{*}{ Cloroquina } & \multirow[b]{2}{*}{ Metotrexato } & \multirow[b]{2}{*}{ Ciclosporina } & \multirow[b]{2}{*}{ Ciclofosfamida } & \multirow[b]{2}{*}{$\begin{array}{l}\text { Gamaglobulina } \\
\text { endovenosa }\end{array}$} & \multirow[b]{2}{*}{$\begin{array}{c}\text { Tempo de } \\
\text { seguimento (m) }\end{array}$} & \multirow[b]{2}{*}{$\begin{array}{l}\text { Evolução ao final do } \\
\text { estudo }\end{array}$} \\
\hline & $\begin{array}{c}\text { Anterior } \\
\text { à biópsia }\end{array}$ & $\begin{array}{l}\text { Posterior à } \\
\text { biópsia }\end{array}$ & $\begin{array}{l}\text { Resposta inicial } \\
\qquad(4-6 \mathrm{~m})\end{array}$ & & & & & & & \\
\hline 24 & & + & Parcial & & + & & & & 57 & Fora de atividade \\
\hline 25 & & + & Boa & & & & & & 58 & Remissão \\
\hline 26 & & + & Parcial & + & & & & & 55 & Remissão \\
\hline 27 & + & & Parcial & & + & & & & 51 & Remissão \\
\hline 28 & & + & Ruim & & + & + & & & 52 & Fora de atividade \\
\hline 29 & + & & Boa & & & & & & 50 & Remissão \\
\hline 30 & & + & Parcial & + & & & & & 51 & Remissão \\
\hline 31 & & + & Boa & & & & & & 61 & Remissão \\
\hline 32 & & + & Parcial & & + & & & & 48 & Fora de atividade \\
\hline 33 & & + & Parcial & + & + & & & & 47 & Fora de atividade \\
\hline 34 & + & & Boa & & & & & & 46 & Remissão \\
\hline 35 & + & & Parcial & + & + & & & & 44 & Fora de atividade \\
\hline 36 & + & & Boa & & & & & & 43 & Remissão \\
\hline 37 & & + & Parcial & & + & & & & 43 & Fora de atividade \\
\hline
\end{tabular}




\section{IMUNOHISTOQUÍMICA}

As expressões de CD4 e CD8 foram identificadas por imunohistoquímica, pela técnica EnVision-AP, descrita a seguir:

1. deixar as lâminas em temperatura ambiente;

2. fixar em acetona gelada a $4^{\circ} \mathrm{C}$ por 10 minutos;

3. lavar em água corrente e depois na água destilada, por 5 minutos, seguida de tampão PBS $(0,01 \mathrm{M}, \mathrm{pH} 7,4)$;

4. bloquear a peroxidase endógena com água oxigenada 10 volumes diluída em metanol volume a volume, 4 banhos de 5 minutos;

5. lavar em água corrente, passar na água destilada e deixar em PBS por 5 minutos;

6. incubar o anticorpo primário diluído em solução de albumina (BSA 1\%) e azida sódica $0,1 \%$ em PBS em câmara úmida por 30 minutos a $37^{\circ} \mathrm{C}$ e depois "overnight" em geladeira $\left(4^{\circ} \mathrm{C}\right)$;

7. lavar em PBS 3 vezes, por 5 minutos cada;

8. incubar com o polímero com a fosfatase alcalina por 30 minutos (Dakkopatts);

9. lavar em PBS 3 vezes, por 5 minutos cada;

10. incubar com o substrato cromógeno fast-red por 10 minutos;

11. lavar em água corrente por 5 minutos;

12. lavar em água destilada;

13. contracorar com Hematoxilina de Harris por 1 minuto;

14. lavar em água corrente; 
15. desidratar em álcool;

16. diafanizar em xilol;

17. montar em meio permanente (Enterllan).

As células CD20 e CD68 foram identificadas por imunohistoquímica, através do sistema $\mathrm{LSAB}+$, cuja técica é descrita a seguir:

1. deixar as lâminas em temperatura ambiente;

2. fixar em acetona gelada a $4^{\circ} \mathrm{C}$ por 10 minutos;

3. lavar em água corrente e depois na água destilada, por 5 minutos, seguida de tampão PBS (0,01M, pH 7,4);

4. bloquear a peroxidase endógena com água oxigenada 10 volumes diluída em metanol volume a volume, 4 banhos de 5 minutos;

5. lavar em água corrente, passar na água destilada e deixar em PBS por 5 minutos;

6. incubar o anticorpo primário diluído em solução de albumina (BSA 1\%) e azida sódica $0,1 \%$ em PBS em câmara úmida por 30 minutos a $37^{\circ} \mathrm{C}$ e depois "overnight" em geladeira $\left(4^{\circ} \mathrm{C}\right)$;

7. lavar em PBS 3 vezes, por 5 minutos cada;

8. incubar o anticorpo secundário anti-imunoglobulina de camundongo, coelho e cabra biotinilada (DAKO, A/S Denmark; código KO690) por 30 minutos a $37^{\circ} \mathrm{C}$;

9. incubar a streptavidina conjugada à peroxidase por 30 minutos a $37^{\circ} \mathrm{C}$ (DAKO, A/S Denmark; código KO690);

10. lavar em PBS 3 vezes, por 5 minutos cada; 
11. revelação da reação com solução cromógena diaminobenzidina (DAB) (3,3`-diaminobenzidina; Sigma Chemical Co, St Louis, MO, USA) \# Preparação do DAB

a) colocar na cuba $1 \mathrm{ml}$ de dimetilsulfóxido

b) dissolver DAB em PBS pré aquecido a $37^{\circ} \mathrm{C}(60 \mu \mathrm{em} 100 \mathrm{ml})$

c) filtrar a solução

d) colocar na cuba e acrescentar $2 \mathrm{ml}$ de água oxigenada 10 vol (3\%)

12. lavar em água corrente por 5 minutos;

13. lavar em água destilada;

14. contracorar com Hematoxilina de Harris por 1 minuto;

15. lavar em água corrente;

16. desidratar em álcool;

17. diafanizar em xilol;

18. montar em meio permanente (Enterllan).

As expressões de MHC-I, MHC-II e C5b-9 foram identificadas por imunohistoquímica, através da técnica de imunoperoxidase StreptABComplex/HRP, descrita a seguir:

1. deixar as lâminas em temperatura ambiente;

2. fixar em acetona a $4^{\circ} \mathrm{C}$ por 10 minutos;

3. lavar em água corrente e depois na água destilada, por 5 minutos, seguida de tampão PBS (0,01M, pH 7,4);

4. bloquear a peroxidase endógena com água oxigenada 10 volumes diluída em metanol volume a volume, 4 banhos de 5 minutos; 
5. lavar em água corrente, passar na água destilada e deixar em PBS por 5 minutos;

6. incubar o anticorpo primário diluído em solução de albumina (BSA 1\%) e azida sódica $0,1 \%$ em PBS em câmara úmida por 30 minutos a $37^{\circ} \mathrm{C}$ e depois “overnight” em geladeira $\left(4^{\circ} \mathrm{C}\right)$;

7. lavar em PBS 3 vezes, por 5 minutos cada;

8. incubar o anticorpo secundário anti-imunoglobulina de camundongo e coelho biotinilado (DAKO, A/S Denmark; código K0492) por 30 minutos a $37^{\circ} \mathrm{C}$;

9. lavar em PBS 3 vezes, por 5 minutos cada;

10. revelar em $\mathrm{DAB}$;

11. lavar em PBS 3 vezes, por 5 minutos cada;

12. lavar em água corrente por 5 minutos;

13. lavar em água destilada;

14. contracorar com Hematoxilina de Harris por 1 minuto;

15. lavar em água corrente;

16. desidratar em álcool;

17. diafanizar em xilol;

18. montar em meio permanente (Enterllan). 


\section{ANÁLISE DA IMUNOHISTOQUÍMICA}

As expressões de CD4 e CD8 foram identificadas por imunohistoquímica, pela técnica EnVision-AP; CD20 e CD68 através do sistema LSAB+; e MHC-I, MHC-II e C5b-9 por imunoperoxidase StreptABComplex/HRP.

As expressões de MHC-I e MHC-II foram analisadas e codificadas semiquantitativemente como: (-): expressão negativa nas fibras e positiva apenas nas células endoteliais; (+): 1 a 10\%; (++): 11 a 25\%; (+++): 26 a 50\%; (++++): 51 a $100 \%$ de fibras com expressão positiva.

As reações com os anticorpos monoclonais para C5b-9, ICAM-1 e VCAM-1 foram analisadas nos vasos endomisiais, vasos perimisiais, capilares e fibras e codificadas semi-quantitativamente como: $(-)$ = ausência de positividade; $(+)=1$ a $25 \% ;(++)=26$ a $50 \% ;(+++)=51$ a $75 \% ;(++++)=76$ a $100 \%$ de positividade nas estruturas analisadas.

As reações com os anticorpos monoclonais para CD4, CD8 e CD20 foram analisados nas regiões endomisial, perimisial e perivascular (perimisial e endomisial) e as células positivas contadas em cada localização.

As células marcadas com o anticorpo monoclonal para CD68 foram analisadas nas regiões endomisial, perimisial e perivascular (perimisial e endomisial) e codificadas semi-quantitativamente como (-) = ausência de células com positividade; $(+)=1$ a $25 \% ;(++)=26$ a $50 \% ;(+++)=51$ a $75 \% ;(++++)=76$ a $100 \%$ de células com positividade nas estruturas analisadas. 
Todas as preparações foram realizadas com controles positivo e negativo em uma única bateria para que a reação de fundo seja a mesma em todas as lâminas.

Todas as reações foram analisadas por dois observadores distintos (AMES e SKNM), em cortes seriados para reação dos anticorpos monoclonais para CD4, CD8, CD20, CD68, C5b-9, MHC-I, MHC-II em dez campos aumentados 200 vezes (Anexos 3,4,5 e 6).

Tabela 3: Anticorpos monoclonais comerciais (Dakopatts) utilizados para imunofenotipagem das células mononucleares e dos antígenos de superfície expressos nos vasos e fibras musculares

\begin{tabular}{|c|c|c|c|}
\hline Anticorpo & Clone & Código & Diluição \\
\hline Linfócito $\mathrm{T}(\mathrm{CD} 4)^{2}$ & OPD4 & DAKO/M 834 & $1: 150$ \\
\hline Linfócito T (CD8) ${ }^{2}$ & C8/ 144B & DAKO/ M 7103 & 1: 200 \\
\hline Macrófago (CD68) ${ }^{1}$ & EBM11 & DAKO/ M 0718 & $1: 1600$ \\
\hline Células B (CD20) ${ }^{1}$ & L26 & DAKO/ M 755 & $1: 200$ \\
\hline $\mathrm{MHC} \mathrm{I}^{3}$ & W6/32 & DAKO/ M 0736 & $1: 100$ \\
\hline $\mathrm{MHC} \mathrm{II}^{3}$ & $\mathrm{CD} 3 / 43$ & DAKO/ M 0775 & $1: 100$ \\
\hline C $5 b-9^{3}$ & $\mathrm{aE} 11$ & DAKO/ M0777 & $1: 200$ \\
\hline
\end{tabular}

\section{Anticorpos secundários:}

${ }^{1} \mathrm{LSAB}^{+}$(DAKO, A/S Denmark; código K0690);

${ }^{2}$ EnVision-AP (Dako EnVision System, alkaline phosphatase; Dakopatts código K4016);

${ }^{3}$ StreptABComplex/HRP-Duet reação imunohistoquímica (StreABComplex/HRP Duet, mouse/rabbit; Dakopatts código K0492) 
As correlações entre MHC-I e II, C5b-9, CD4, CD8, CD20, CD68, ICAM-1 e VCAM-1 foram analisadas conforme a localização da estrutura estudada, incluindo a expressão das fibras musculares, distribuição do infiltrado inflamatório nas regiões endomisial e perimisial e o comprometimento dos vasos de localização endomisial e perimisial.

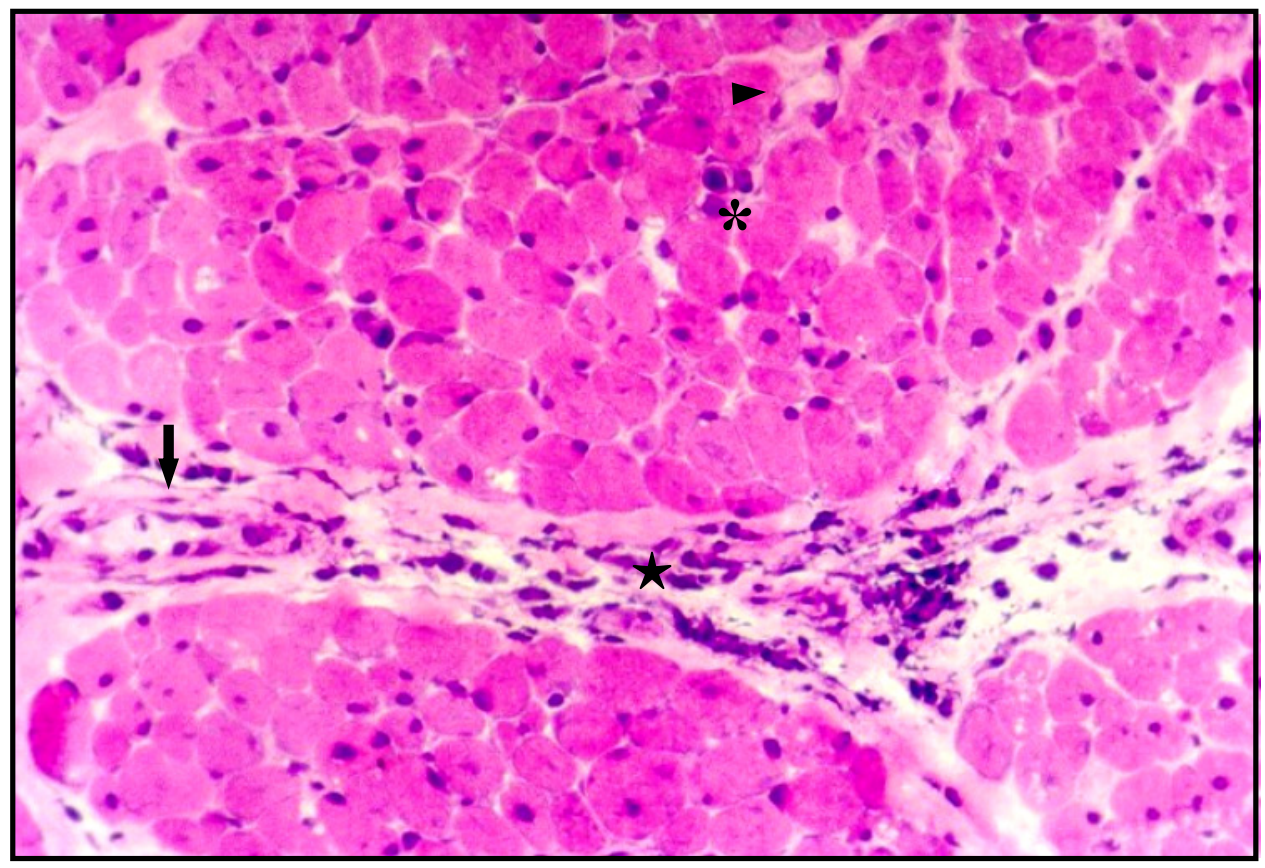

Figura 2: Reação hematoxilina e eosina (HE) de fragmento muscular da DMJ

Vaso localizado em região endomisial ( $\bullet$ ), infiltrado inflamatório em região endomisial $(*)$, vaso localizado em região perimisial $(\rightarrow)$ e infiltrado inflamatório em região perimisial $(\star)$ 


\section{ANÁLISE ESTATÍSTICA}

A análise estatística realizada teve dois objetivos: comparação entre grupos e correlação entre parâmetros quantitativos e qualitativos.

As comparações entre os grupos de interesse em relação às variáveis quantitativas, quando envolviam dois grupos de interesse, foram realizadas pelo teste de Mann-Whitney e quando envolviam três grupos de interesse, pelo teste de Kruskal-Wallis, associado ao teste de comparações múltiplas de Dunn para localização do resultado, quando fosse estatisticamente significante.

As correlações entre os parâmetros quantitativos foram avaliadas pelo coeficiente de correlação por postos de Spearman (rs).

A associação entre variáveis qualitativas foram feitas pelo teste do QuiQuadrado ou teste Exato de Fisher.

O nível de significância adotado foi de $0,05(\alpha=5 \%)$ e os níveis descritivos (p) inferiores foram considerados significantes. 


\section{MHC-I}

\section{Expressão de MHC-I na DMJ}

A expressão de MHC-I foi positiva em 97,3\% dos fragmentos musculares dos pacientes com DMJ.

Gráfico 1: Análise semi-quantitativa da expressão de MHC-I nas fibras de fragmentos musculares de pacientes com DMJ

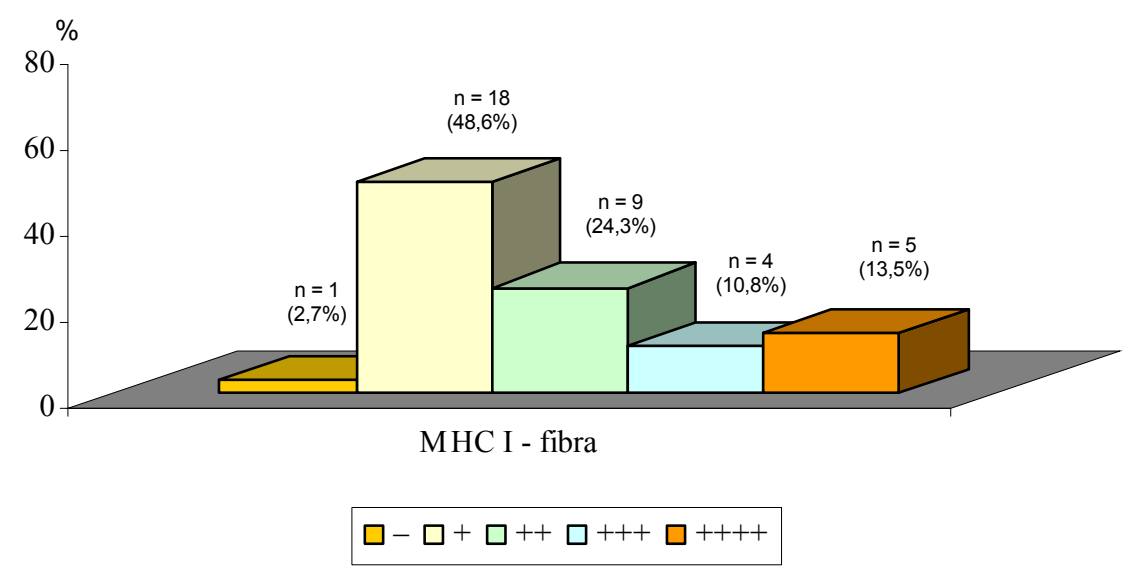

\section{Correlação entre a expressão de MHC-I na DMJ e parâmetros clínicos}

Não houve correlação entre a expressão de MHC-I e sexo $(p=0,686)$, idade $(\mathrm{rs}=0,11 \mathrm{p}=0,509)$, tempo de doença até a biópsia ( $\mathrm{rs}=-0,19 \mathrm{p}=0,250)$, fraqueza muscular ( $r s=0,01 \mathrm{p}=0,956)$, presença de calcinose $(\mathrm{p}=0,849)$ e ulcera cutânea $(\mathrm{p}=0,358)$, comprometimento cardíaco $(\mathrm{p}=0,094)$, pulmonar $(\mathrm{p}=0,668)$ e gastrointestinal $(\mathrm{p}=0,224)$.

\section{Correlação entre a expressão de MHC-I na DMJ e parâmetros laboratoriais}

Não houve correlação entre a expressão de MHC-I e níveis séricos de CK $(\mathrm{rs}=0,12 \mathrm{p}=0,502), \quad$ aldolase $\quad(\mathrm{rs}=0,48 \quad \mathrm{p}=0,152), \quad$ TGO $\quad(\mathrm{rs}=0,03 \quad \mathrm{p}=0,895)$, TGP ( $r s=-0,14 p=0,476)$ e DHL ( $r s=0,26 p=0,176)$. 


\section{Correlação entre a expressão de MHC-I na DMJ e parâmetros histológicos}

Não houve correlação entre a expressão de MHC-I e atrofia perifascicular ( $\mathrm{rs}=0,14 \mathrm{p}=0,400)$, dissociação miofibrilar $(\mathrm{rs}=0,26 \mathrm{p}=0,127)$, fibras necróticas ( $r s=0,25 \mathrm{p}=0,134)$ e em regeneração ( $\mathrm{rs}=0,26 \mathrm{p}=0,125)$, inflamação endomisial $(\mathrm{rs}=0,19 \mathrm{p}=0,261)$ e perivascular $(\mathrm{rs}=0,18 \mathrm{p}=0,293)$ e aumento do tecido conectivo $(\mathrm{rs}=-0,04 \mathrm{p}=0,812)$.

\section{Correlação entre a expressão de MHC-I e terapêutica e evolução}

Não houve correlação entre a expressão de MHC-I e corticoterapia anterior à biópsia muscular $(\mathrm{p}=0,939)$, resposta inicial a corticoterapia $(\mathrm{p}=0,574)$, tratamento utilizado $(p=0,720)$ e evolução $(p=0,888)$.

\section{Correlação entre a expressão de MHC-I na DMJ, DM, PM e distrofia}

Houve maior expressão de MHC-I na DMJ quando comparada à distrofia, e menor quando comparada a PM e DM, que não se diferenciaram $(\mathrm{p}<0,001)$.

Tabela 4: Correlação da análise semi-quantitativa da expressão de MHC-I nas fibras de fragmentos musculares de pacientes com DMJ, DM, PM e distrofia

\begin{tabular}{lccccc}
\hline \multirow{2}{*}{ MHC I } & $\begin{array}{c}\text { DMJ } \\
(\mathrm{n}=37)\end{array}$ & $\begin{array}{c}\text { PM } \\
(\mathrm{n}=8)\end{array}$ & $\begin{array}{c}\text { DM } \\
(\mathrm{n}=5)\end{array}$ & $\begin{array}{c}\text { Distrofia } \\
(\mathrm{n}=4)\end{array}$ & \\
\cline { 2 - 5 } & $(\%)$ & $(\%)$ & $(\%)$ & $(\%)$ & \\
\hline- & 2,7 & 12,5 & 0,0 & 75,0 & \\
+ & 48,6 & 12,5 & 0,0 & 25,0 & \\
++ & 24,3 & 12,5 & 20,0 & 0,0 & \\
+++ & 10,8 & 0,0 & 20,0 & 0,0 & \\
++++ & 13,5 & 62,5 & 60,0 & 0,0 & $\mathrm{p}<0,001$
\end{tabular}

(-): expressão positiva apenas nas células endoteliais; $(+)$ : 1 a 10\%; $(++): 11$ a 25\%; $(+++): 26$ a $50 \% ;(++++): 51$ a $100 \%$ de fibras com expressão positiva.

MHC-II 


\section{Expressão de MHC-II na DMJ}

A expressão de MHC-II foi positiva em 21,6\% dos fragmentos musculares dos pacientes com DMJ.

Gráfico 2: Análise semi-quantitativa da expressão de MHC-II nas fibras de fragmentos musculares de pacientes com DMJ

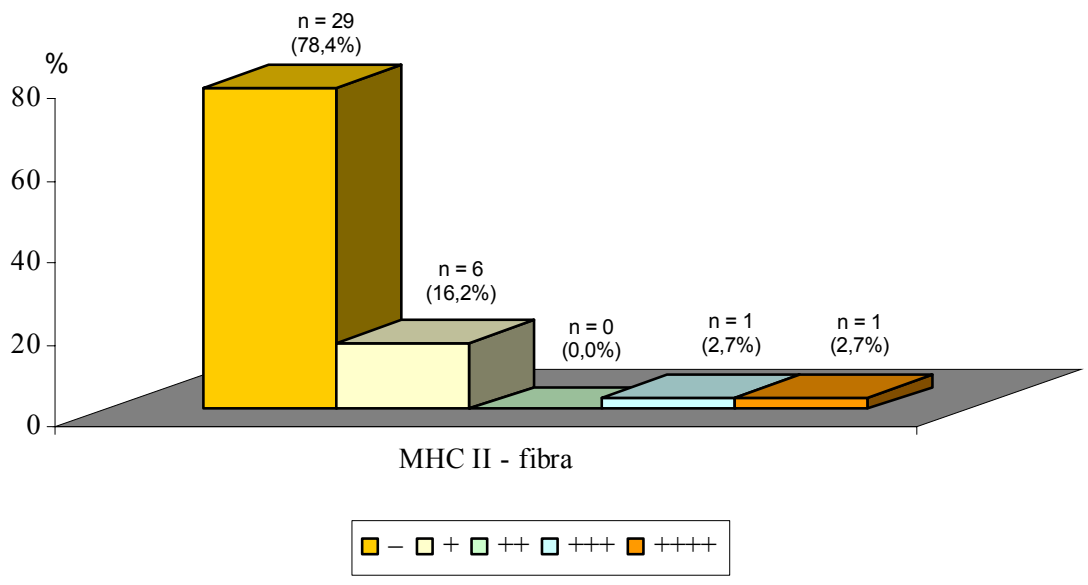

\section{Correlação entre a expressão de MHC-II na DMJ e parâmetros clínicos}

Houve correlação entre a expressão de MHC-II e sexo feminino ( $p=0,047)$. Entretanto, não houve correlação entre a expressão de MHC-II e idade (rs=0,07 $\mathrm{p}=0,689)$, tempo de doença até a biópsia ( $\mathrm{rs}=0,12 \mathrm{p}=0,485)$, fraqueza muscular ( $\mathrm{rs}=-0,15$ $\mathrm{p}=0,370)$, presença de calcinose $(\mathrm{p}=0,459)$ e ulcera cutânea $(\mathrm{p}=0,275)$, comprometimento cardíaco $(\mathrm{p}=0,352)$, pulmonar $(\mathrm{p}=0,252)$ e gastrointestinal $(\mathrm{p}=0,709)$.

\section{Correlação entre a expressão de MHC-II na DMJ e parâmetros laboratoriais}

Houve correlação entre a expressão de MHC-II e níveis séricos de CK ( $r s=0,45$ p=0,008), mas não houve correlação entre a expressão de MHC-II e níveis séricos de aldolase ( $\mathrm{rs}=0,52 \mathrm{p}=0,120)$, TGO ( $\mathrm{rs}=0,26 \mathrm{p}=0,163)$, TGP ( $\mathrm{rs}=0,26$ $\mathrm{p}=0,177)$ e DHL $(\mathrm{rs}=0,24 \mathrm{p}=0,218)$. 


\section{Correlação entre a expressão de MHC-II na DMJ e parâmetros histológicos}

Não houve correlação entre a expressão de MHC-II e atrofia perifascicular ～(rs=0,29 $\mathrm{p}=0,078$ ), dissociação miofibrilar ( $\mathrm{rs}=0,20 \mathrm{p}=0,247)$, fibras necróticas ( $\mathrm{rs}=0,22$ $p=0,205)$ e em regeneração ( $r s=0,15 p=0,398)$, inflamação endomisial ( $r s=0,17 p=0,313)$ e perivascular ( $r s=0,27 \mathrm{p}=0,109)$ e aumento do tecido conectivo ( $\mathrm{rs}=0,29 \mathrm{p}=0,092)$.

\section{Correlação entre a expressão de MHC-II e terapêutica e evolução}

Não houve correlação entre a expressão de MHC-II e corticoterapia anterior à biópsia muscular $(\mathrm{p}=0,416)$, resposta inicial a corticoterapia $(\mathrm{p}=0,617)$, tratamento utilizado $(p=0,880)$ e evolução $(p=0,871)$.

\section{Correlação entre a expressão de MHC-II na DMJ, DM, PM e distrofia}

Houve menor expressão de MHC-II na DMJ e distrofia, que não se diferenciaram, quando comparada a PM e DM, que também não se diferenciaram ( $p<0,001)$.

Tabela 5: Correlação da análise semi-quantitativa da expressão de MHC-II nas fibras de fragmentos musculares de pacientes com DMJ, DM, PM e distrofia

\begin{tabular}{lccccc}
\hline MHC II & DMJ & PM & DM & Distrofia \\
$(\mathrm{n}=37)$ & $(\mathrm{n}=8)$ & $(\mathrm{n}=5)$ & $(\mathrm{n}=4)$ & \\
\cline { 1 - 5 } & $(\%)$ & $(\%)$ & $(\%)$ & $(\%)$ & \\
\hline- & 78,4 & 12,5 & 0,0 & 100,0 & \\
+ & 16,2 & 87,5 & 100,0 & 0,0 & \\
++ & 2,7 & 0,0 & 0,0 & 0,0 & \\
++++ & 2,7 & 0,0 & 0,0 & 0,0 & $\mathrm{p}<0,001$ \\
\hline
\end{tabular}

(-): expressão positiva apenas nas células endoteliais; $(+)$ : 1 a 10\%; $(++): 11$ a 25\%; $(+++): 26$ a 50\%; $(++++): 51$ a $100 \%$ de fibras com expressão positiva. 
Figura 3: Reação imunohistoquímica StreptABCcomplex, para identificação de MHC-I e II na DMJ, DM, PM e distrofia, onde se observa a positividade em marrom $(\longrightarrow)$

[DMJ]: Reação positiva para expressão de MHC-I (A) e MHC-II (B) nas fibras musculares (200X).

[PM]: Reação positiva para expressão de MHC-I (G) e MHC-II (H) nas fibras musculares (200X).

[DM]: Reação positiva para expressão de MHC-I (E) e MHC-II (F) nas fibras musculares (200X).

[distrofia]: Reação negativa para expressão de MHC-I (I) e MHC-II (J) (200X). 
MHC-I

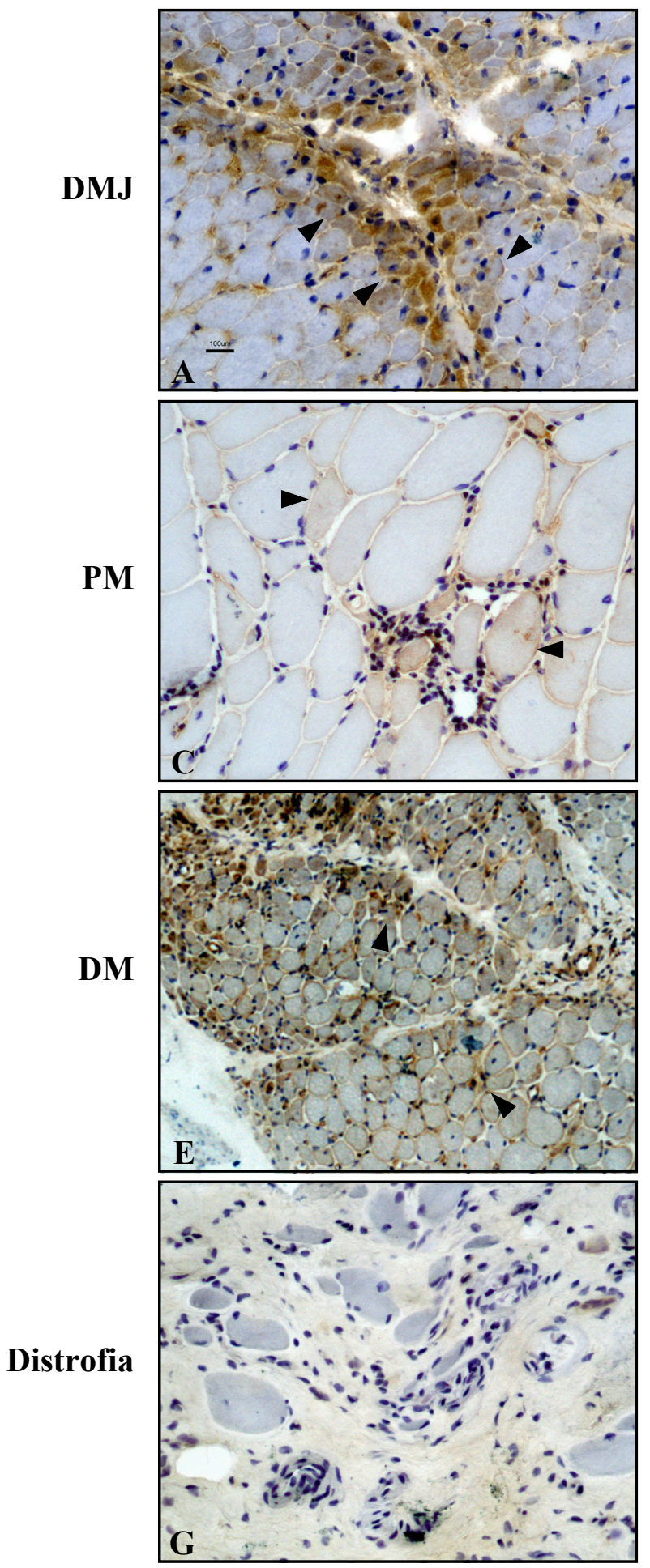

MHC-II
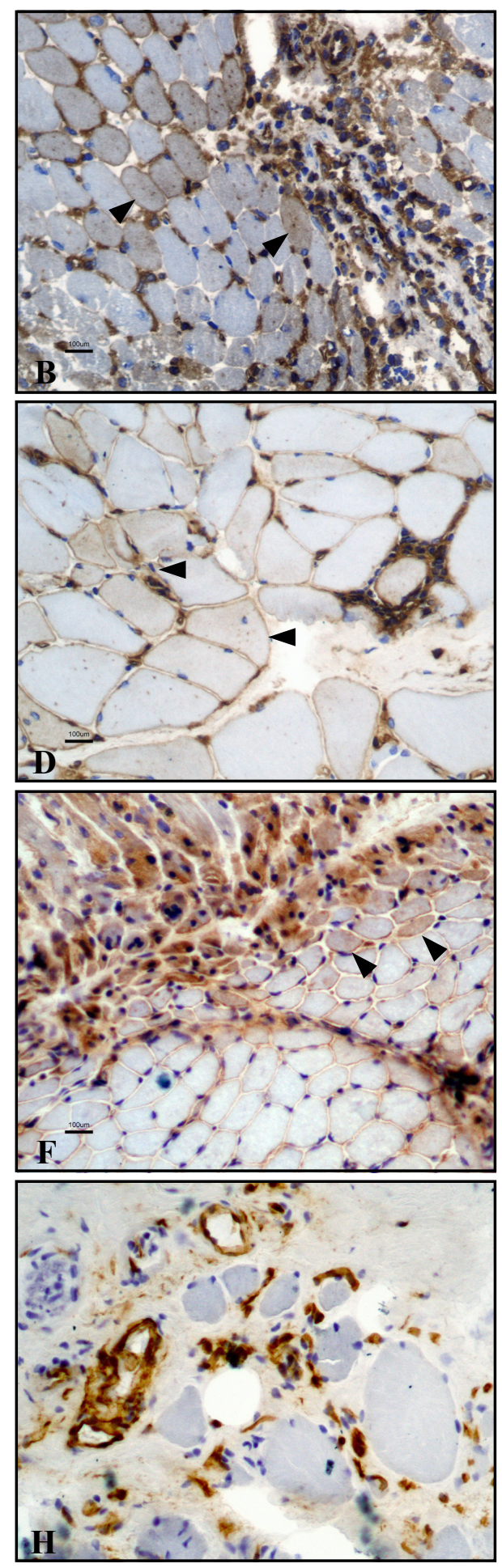
C5b-9

\section{Expressão de C5b-9 na DMJ}

A expressão de C5b-9 foi positiva em $83,8 \%$ dos fragmentos musculares dos pacientes com DMJ.

Houve maior expressão de C5b-9 na região perimisial $\left(\mathrm{p}<0,001^{*}\right)$.

As expressões na região endomisial, capilares e fibras não se diferenciaram.

Gráfico 3 : Análise semi-quantitativa da expressão de C5b-9 na região endomisial, perimisial, capilares e fibras de fragmentos musculares de pacientes com DMJ

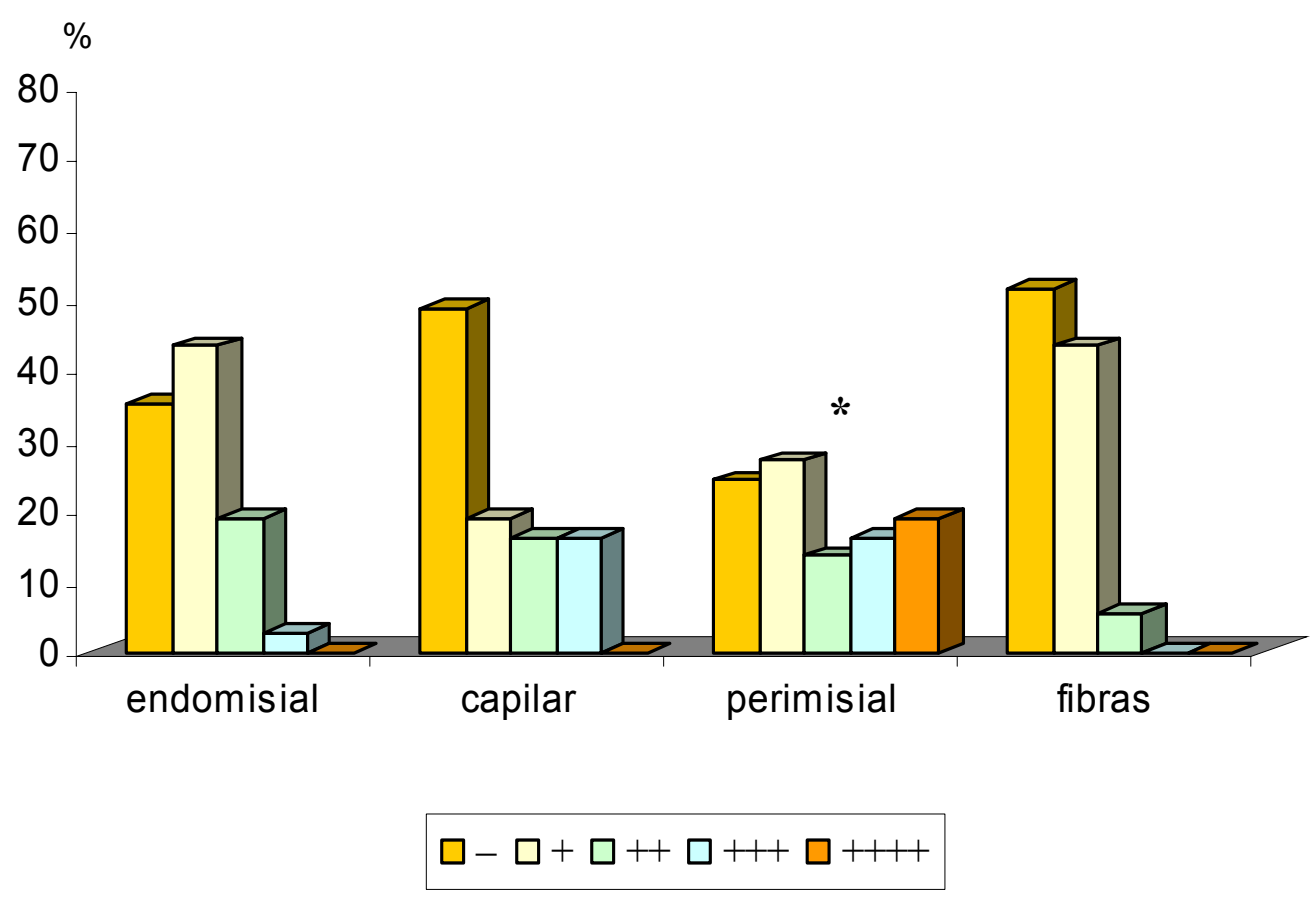


Tabela 6: Análise semi-quantitativa da expressão de C5b-9 na região endomisial, perimisial, capilares e fibras de fragmentos musculares de pacientes com DMJ

\begin{tabular}{lccccccc}
\hline & - & + & ++ & +++ & ++++ & \\
\hline \multicolumn{1}{c}{ C5b-9 } & $\mathrm{n} \%$ & $\mathrm{n} \%$ & $\mathrm{n} \%$ & $\mathrm{n} \%$ & $\mathrm{n} \%$ & \\
\hline Região endomisial & $13(35,1)$ & $16(43,2)$ & $7(18,9)$ & $1(2,7)$ & 0 & \\
Capilares & $18(48,6)$ & $7(18,9)$ & $6(16,2)$ & $6(16,2)$ & 0 & \\
Região perimisial & $9(24,3)$ & $10(27,0)$ & $5(13,5)$ & $6(16,2)$ & $7(18,9)$ & \\
Fibras & $19(51,4)$ & $16(43,2)$ & $2(5,4)$ & 0 & 0 & $\mathrm{p}<0,001$ \\
\hline
\end{tabular}

\section{Correlação entre a expressão de C5b-9 na DMJ e parâmetros clínicos}

Houve correlação entre a expressão de C5b-9 nos vasos da região endomisial $(p=0,006)$ e sexo feminino, embora não se tenha observado correlação entre a expressão nos capilares, vasos da região perimisial e fibras musculares $(p=0,263$; $p=0,575$ e $p=0,671$ respectivamente).

Houve correlação entre a expressão de C5b-9 nos capilares (rs=-0,36 $p=0,028$ ) e fraqueza muscular, mas não houve correlação entre a expressão nos vasos das regiões endomisial e perimisial e fibras musculares $(r s=-0,13 p=0,430 ; r s=-0,24$ $\mathrm{p}=0,156$ e rs $=-0,22 \mathrm{p}=0,199$ respectivamente).

Houve correlação entre a expressão de C5b-9 nos vasos da região endomisial $(p=0,028)$ e presença de calcinose, não houve correlação entre a expressão nos capilares, vasos da região perimisial e fibras musculares $(p=0,129 ; p=0,502$ e $\mathrm{p}=0,660$ respectivamente).

Houve correlação entre a expressão de C5b-9 nos capilares $(p=0,043)$ e comprometimento cardíaco, não houve correlação entre a expressão nos vasos das 
regiões endomisial e perimisial e fibras musculares $(p=0,170 ; p=0,131$ e $p=0,975$ respectivamente).

Houve correlação entre a expressão de C5b-9 nos capilares e fibras musculares $(\mathrm{p}=0,044 \mathrm{e} \mathrm{p}=0,033$ respectivamente) e comprometimento pulmonar, mas não houve correlação entre a expressão nos vasos das regiões endomisiais e perimisiais $(\mathrm{p}=0,651$ e $\mathrm{p}=0,339$ respectivamente $)$.

Não houve correlação entre a expressão de C5b-9 nos vasos das regiões endomisial e perimisial, capilares e fibras e idade ( $r s=-0,12 \mathrm{p}=0,465 ; \mathrm{rs}=-0,11$ $\mathrm{p}=0,531 ; \mathrm{rs}=0,00 \mathrm{p}=0,987$ e $\mathrm{rs}=0,28 \mathrm{p}=0,095$ respectivamente), tempo de doença até a biópsia $(\mathrm{rs}=0,02 \mathrm{p}=0,896 ; \mathrm{rs}=-0,15 \mathrm{p}=0,377$; $\mathrm{rs}=-0,09 \mathrm{p}=0,602$ e $\mathrm{rs}=-0,03 \mathrm{p}=0,861$ respectivamente), presença de úlcera cutânea $(p=0,238 ; p=0,802 ; p=0,104$ e $p=0,362$ respectivamente) e comprometimento gastrointestinal $(p=0,947 ; p=0,569 ; p=0,171$ e $\mathrm{p}=0,457$ respectivamente).

\section{Correlação entre a expressão de C5b-9 na DMJ e parâmetros laboratoriais}

Houve correlação entre a expressão de C5b-9 nos vasos da região endomisial e níveis séricos de aldolase ( $r s=-0,86 \mathrm{p}=0,002)$, não houve correlação entre a expressão nos capilares $(r s=-0,04 \mathrm{p}=0,910)$, vasos da região perimisial $(\mathrm{rs}=0,02$ $\mathrm{p}=0,951)$ e fibras $(\mathrm{rs}=0,04 \mathrm{p}=0,924)$.

Houve correlação entre a expressão de C5b-9 e vasos da região endomisial e níveis séricos de DHL ( $r s=-0,40$ p=0,037), não houve correlação entre a expressão nos capilares $(r s=-0,22 \mathrm{p}=0,265)$, vasos da região perimisial $(\mathrm{rs}=-0,20 \mathrm{p}=0,316)$ e fibras $(\mathrm{rs}=-0,04 \mathrm{p}=0,841)$.

Não houve correlação entre a expressão de C5b-9 nos vasos das regiões endomisial e perimisial, capilares e fibras e níveis séricos de TGO ( $\mathrm{rs}^{\mathrm{s}}=-0,05$ 
$\mathrm{p}=0,776 ; \mathrm{rs}=0,07 \mathrm{p}=0,734 ; \mathrm{rs}=-0,10 \mathrm{p}=0,589$ e $\mathrm{rs}=0,13 \mathrm{p}=0,481$ respectivamente), TGP ( $r s=-0,10 p=0,619 ; r s=-0,13 p=0,497 ; r s=-0,32 p=0,091$ e $r s=-0,08 p=0,692$ respectivamente) e $\mathrm{CK}(\mathrm{rs}=-0,18 \mathrm{p}=0,309 ; \mathrm{rs}=0,33 \mathrm{p}=0,879 ; \mathrm{rs}=-0,11 \mathrm{p}=0,538$ e $\mathrm{rs}=0,14 \mathrm{p}=0,442$ respectivamente).

\section{Correlação entre a expressão de C5b-9 na DMJ e parâmetros histológicos}

Houve correlação entre a expressão de C5b-9 nos capilares, vasos da região perimisial e fibras e dissociação miofibrilar $(\mathrm{rs}=0,34 \mathrm{p}=0,043 ; \mathrm{rs}=0,33 \mathrm{p}=0,048$ e rs $=0,43 \mathrm{p}=0,009$ respectivamente), não houve correlação entre a expressão nos vasos da região endomisial $(\mathrm{rs}=0,19 \mathrm{p}=0,263)$.

Houve correlação entre a expressão de C5b-9 nos vasos da região perimisial e fibras e fibras necróticas ( $\mathrm{rs}=0,32 \mathrm{p}=0,045$ e $\mathrm{rs}=0,36 \mathrm{p}=0,033$ respectivamente), não houve correlação entre a expressão nos vasos da região endomisial e capilares ( $\mathrm{rs}=0,16 \mathrm{p}=0,366$ e $\mathrm{rs}=0,21 \mathrm{p}=0,210$ respectivamente).

Houve correlação entre a expressão de C5b-9 nos vasos da região perimisial e fibras e inflamação endomisial ( $r s=0,34 p=0,043$ e $r s=0,34 p=0,043$ respectivamente), não houve correlação entre a expressão nos vasos da região endomisial e capilares ( $r s=0,22 p=0,197$ e $r s=0,24 p=0,165$ respectivamente).

Houve correlação entre a expressão de C5b-9 nas fibras e fibras em regeneração ( $r s=0,42$ p=0,012), não houve correlação entre a expressão nos vasos das regiões endomisial e perimisial e capilares $(r s=0,08 p=0,635 ; r s=0,24 p=0,159$ e $\mathrm{rs}=0,22 \mathrm{p}=0,201$ respectivamente).

Houve correlação entre a expressão de C5b-9 nos vasos da região perimisial e aumento do tecido conectivo na histologia muscular ( $r s=-0,39$ 
$\mathrm{p}=0,019)$, não houve correlação entre a expressão nos vasos da região endomisial, capilares e fibras $(r s=-0,01 \quad \mathrm{p}=0,955 ; \mathrm{rs}=0,19 \mathrm{p}=0,269$ e $\mathrm{rs}=0,11 \mathrm{p}=0,514$ respectivamente).

Não houve correlação entre a expressão de C5b-9 nos vasos das regiões endomisial e perimisial, capilares e fibras e atrofia perifascicular ( $r s=0,20 p=0,233$; $\mathrm{rs}=0,22 \mathrm{p}=0,183 ; \mathrm{rs}=0,16 \mathrm{p}=0,347$ e $\mathrm{rs}=0,16 \mathrm{p}=0,348$ respectivamente) e inflamação perivascular $(r s=0,10 p=0,557 ; r s=0,25 p=0,142 ; r s=0,07 p=0,706$ e $r s=0,24 p=0,156$ respectivamente).

\section{Correlação entre a expressão de C5b-9 e terapêutica e evolução}

Houve correlação entre a expressão de C5b-9 nas fibras e corticoterapia anterior à biópsia muscular ( $\mathrm{p}=0,044)$, não houve correlação entre a expressão nos vasos das regiões endomisial $(p=0,718)$ e perimisial $(p=1,000)$ e capilares $(\mathrm{p}=0,733)$.

Houve correlação entre a expressão de C5b-9 nos capilares e corticoterapia associada a duas ou mais medicações $(p=0,037)$, não houve correlação entre a expressão nos vasos das regiões endomisial $(p=0,301)$ e perimisial $(p=0,510)$ e fibras $(\mathrm{p}=0,067)$.

Não houve correlação entre a expressão de C5b-9 nos vasos das regiões endomisial e perimisial, capilares e fibras e resposta inicial a corticoterapia $(\mathrm{p}=0,099 ; \mathrm{p}=0,081 ; \mathrm{p}=0,607$ e $\mathrm{p}=0,324$ respectivamente) e evolução ( $\mathrm{p}=0,427$; $p=0,264 ; p=0,709$ e $p=1,000$ respectivamente). 
Tabela 7: Correlações positivas da análise semi-quantitativa da expressão de C5b-9 nos vasos das regiões endomisial e perimisial, capilares e fibras de fragmentos musculares de pacientes com DMJ com características clínicas, laboratoriais, histológicas, terapêuticas e evolutivas

\section{C5b-9}

\begin{tabular}{|c|c|c|c|c|}
\hline & $\begin{array}{c}\text { Região } \\
\text { perimisial }\end{array}$ & $\begin{array}{c}\text { Região } \\
\text { endomisial }\end{array}$ & Capilares & Fibras \\
\hline Sexo feminino & & $p=0,006$ & & \\
\hline Fraqueza muscular & & & $\begin{array}{l}\mathrm{rs}=-0,36 \\
\mathrm{p}=0,028\end{array}$ & \\
\hline Calcinose & & $p=0,028$ & & \\
\hline Comprometimento cardíaco & & & $\mathrm{p}=0,043$ & \\
\hline Comprometimento pulmonar & & & $\mathrm{p}=0,044$ & $\mathrm{p}=0,033$ \\
\hline DHL & & $\begin{array}{l}\mathrm{rs}=-0,40 \\
\mathrm{p}=0,037\end{array}$ & & \\
\hline Aldolase & & $\begin{array}{l}\mathrm{rs}=-0,86 \\
\mathrm{p}=0,002\end{array}$ & & \\
\hline Dissociação miofibrilar & $\begin{array}{l}\mathrm{rs}=0,33 \\
\mathrm{p}=0,048\end{array}$ & & $\begin{array}{l}\mathrm{rs}=0,34 \\
\mathrm{p}=0,043\end{array}$ & $\mathrm{p}=0,009$ \\
\hline Fibras necróticas & $\begin{array}{l}\mathrm{rs}=0,32 \\
\mathrm{p}=0,045\end{array}$ & & & $\begin{array}{l}\mathrm{rs}=0,36 \\
\mathrm{p}=0,033\end{array}$ \\
\hline Fibras em regeneração & & & & $\begin{array}{l}\mathrm{rs}=0,42 \\
\mathrm{p}=0,012\end{array}$ \\
\hline Inflamação endomisial & $\begin{array}{l}\mathrm{rs}=0,34 \\
\mathrm{p}=0,043\end{array}$ & & & $\begin{array}{l}\mathrm{rs}=0,34 \\
\mathrm{p}=0,043\end{array}$ \\
\hline Aumento tecido conectivo & $\begin{array}{l}\mathrm{rs}=-0,39 \\
\mathrm{p}=0,019\end{array}$ & & & \\
\hline Corticoterapia pré biópsia & & & & $\mathrm{p}=0,044$ \\
\hline $\begin{array}{l}\text { Corticoterapia associada a duas } \\
\text { ou mais medicações }\end{array}$ & & & $p=0,037$ & \\
\hline
\end{tabular}




\section{Correlação entre a expressão de C5b-9 na DMJ, DM, PM e distrofia}

Houve maior expressão de C5b-9 nos vasos da região perimisial na DMJ, quando comparado a DM, PM e distrofia $(\mathrm{p}<0,001)$ e menor expressão de C5b-9 nas fibras na distrofia, quando comparado a DMJ, DM e PM $(p=0,050)$.

Não houve diferença na expressão de C5b-9 nos vasos da região endomisial e capilar na DMJ, DM, PM e distrofia ( $\mathrm{p}=0,084$ e $\mathrm{p}=0,786$ respectivamente).

Tabela 8: Correlação da análise semi-quantitativa da expressão de C5b-9 nos vasos das regiões endomisial e perimisial, capilares e fibras de fragmentos musculares de pacientes com DMJ, DM, PM e distrofia

\begin{tabular}{llccccc}
\hline \multirow{2}{*}{ C5b-9 } & & DMJ & PM & DM & Distrofia & \\
& & $(\mathrm{n}=37)$ & $(\mathrm{n}=8)$ & $(\mathrm{n}=5)$ & $(\mathrm{n}=4)$ & \\
\cline { 3 - 6 } Região & - & 35,1 & 50,0 & 40,0 & 100,0 & \\
endomisial & + & 43,2 & 50,0 & 60,0 & 0,0 & \\
& ++ & 18,9 & 0,0 & 0,0 & 0,0 & \\
& +++ & 2,7 & 0,0 & 0,0 & 0,0 & $\mathrm{p}=0,084$ \\
\hline Capilares & - & 48,6 & 25,0 & 0,0 & 50,0 & \\
& + & 18,9 & 50,0 & 80,0 & 25,0 & \\
& ++ & 16,2 & 25,0 & 20,0 & 25,0 & \\
\hline Região & + & 16,2 & 0,0 & 0,0 & 0,0 & $\mathrm{p}=0,786$ \\
perimisial & + & 24,3 & 100,0 & 100,0 & 100,0 & \\
& +++ & 27,0 & 0,0 & 0,0 & 0,0 & \\
& +++ & 13,5 & 0,0 & 0,0 & 0,0 & \\
& ++++ & 16,2 & 0,0 & 0,0 & 0,0 & \\
\hline Fibras & - & 18,9 & 0,0 & 0,0 & 0,0 & $\mathrm{p}<0,001$ \\
\hline & + & 51,4 & 37,5 & 20,0 & 100,0 & \\
& ++ & 43,2 & 50,0 & 40,0 & 0,0 & \\
\hline
\end{tabular}

$(-)$ : ausência de positividade; $(+)=1$ a $25 \% ;(++)=26$ a $50 \% ;(+++)=51$ a $75 \%$; $(++++)=76$ a $100 \%$ de positividade nas estruturas analisadas. 

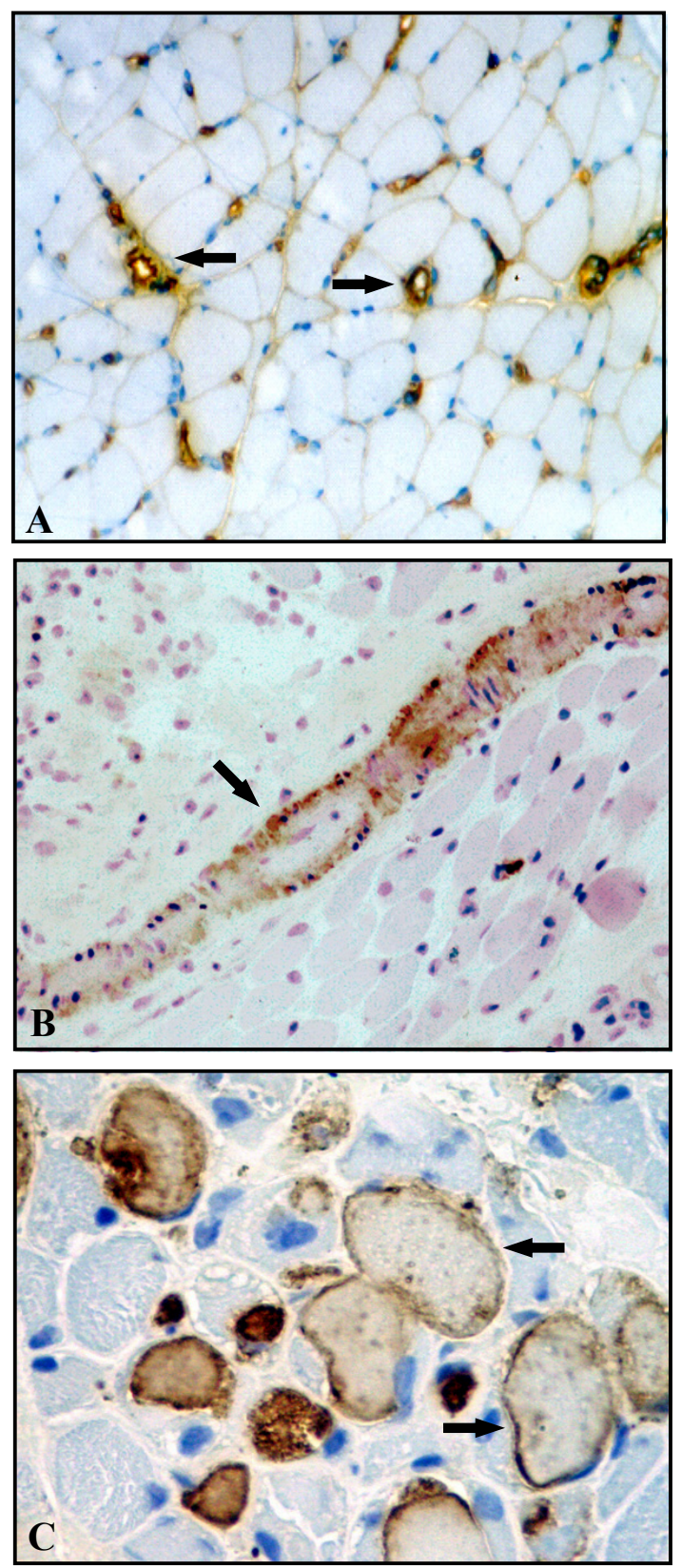

Figura 4: Reação imunohistoquímica StreptABCcomplex, para identificação de C5b-9 na DMJ, onde se observa a positividade em marrom

Reação positiva para expressão de C5b-9 $(\rightarrow$ ) nos capilares $(A)$, nos vasos da região perimisial (B) e fibras musculares (C). 


\section{CD4}

\section{Expressão de CD4 na DMJ}

A expressão de CD4 foi positiva em $81,1 \%$ dos fragmentos musculares dos pacientes com DMJ.

Houve maior expressão de CD4 em células nas regiões endomisial e perimisial (que não se diferenciaram) quanto à expressão nas células da região perivascular (endomisial e perimisial) (que também não se diferenciaram) $\left(\mathrm{p}<0,001^{*}\right)$.

Gráfico 4: Análise quantitativa de células CD4 nas regiões endomisial, perimisial e perivascular (endomisial e perimisial) de fragmentos musculares de pacientes com DMJ

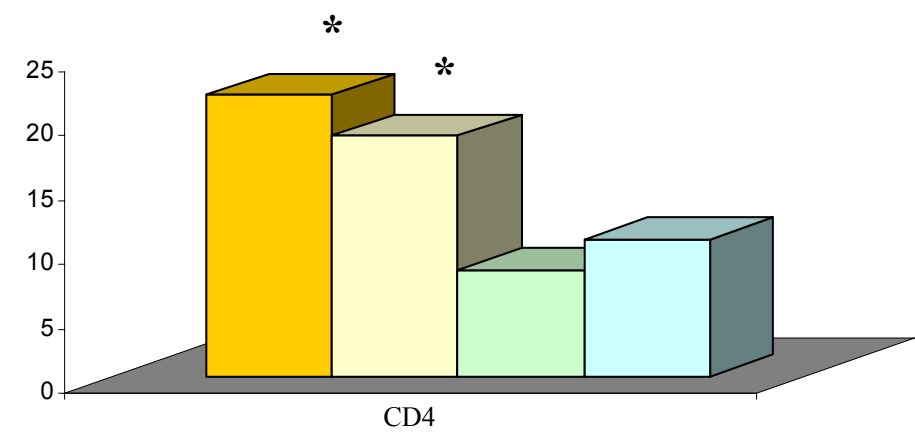

$\square$ endomisial $\square$ perimisial $\square$ perivascular endomisial $\square$ perivascular perimisial

Tabela 9: Análise quantitativa de células CD4 nas regiões endomisial, perimisial e perivascular (endomisial e perimisial) de fragmentos musculares de pacientes com DMJ

\begin{tabular}{lccccc}
\hline \multicolumn{5}{c}{ Expressão de CD4 } \\
\hline Região & média & dp & mediana & mínimo & máximo \\
\hline Endomisial & 21,89 & 40,36 & 4 & 0 & 149 \\
Perimisial & 18,68 & 46,32 & 3 & 0 & 209 \\
Perivascular endomisial & 8,27 & 27,99 & 0 & 0 & 150 \\
Perivascular perimisial & 10,68 & 44,01 & 0 & 0 & 265 \\
\hline
\end{tabular}




\section{Correlação entre a expressão de CD4 na DMJ e parâmetros clínicos}

Houve correlação entre a expressão de células CD4 total ( $r s=-0,34 p=0,020)$, nas regiões endomisial $(\mathrm{rs}=-0,38 \mathrm{p}=0,041)$ e perimisial $(\mathrm{rs}=-0,38 \mathrm{p}=0,021)$ e fraqueza muscular, mas não houve correlação entre a quantidade de células CD4 na região perivascular (endomisial e perimisial) $(\mathrm{rs}=-0,25 \mathrm{p}=0,133$ e $\mathrm{rs}=-0,28 \mathrm{p}=0,094$ respectivamente) .

Não houve correlação entre a expressão de células CD4 total, nas regiões endomisial, perimisial e perivascular (endomisial e perimisial) e sexo $(p=0,280$; $\mathrm{p}=0,182 ; \mathrm{p}=0,403 ; \mathrm{p}=0,719$ e $\mathrm{p}=0,733$ respectivamente), idade ( $\mathrm{rs}=0,03 \mathrm{p}=0,843$;

$\mathrm{rs}=-0,01 \quad \mathrm{p}=0,961 ; \quad \mathrm{rs}=0,06 \quad \mathrm{p}=0,726 ; \quad \mathrm{rs}=0,06 \quad \mathrm{p}=0,717 \quad$ e $\quad \mathrm{rs}=0,03 \quad \mathrm{p}=0,842$ respectivamente), tempo de doença até biópsia ( $\mathrm{rs}=0,11 \mathrm{p}=0,536 ; \mathrm{rs}=0,14 \mathrm{p}=0,411$; $\mathrm{rs}=0,13 \mathrm{p}=0,446 ; \mathrm{rs}=0,00 \mathrm{p}=0,999$ e $\mathrm{rs}=0,09 \mathrm{p}=0,614$ respectivamente), presença de calcinose $(p=0,683 ; p=0,290 ; p=0,857 ; p=0,710$ e $p=0,347$ respectivamente $)$ e úlcera cutânea $(\mathrm{p}=0,231 ; \mathrm{p}=0,342 ; \mathrm{p}=0,188 ; \mathrm{p}=0,321$ e $\mathrm{p}=0,180$ respectivamente), comprometimento pulmonar $(\mathrm{p}=0,738 ; \mathrm{p}=0,892 ; \mathrm{p}=0,298 ; \mathrm{p}=0,446$ e $\mathrm{p}=0,129$ respectivamente), cardíaco $(\mathrm{p}=0,685 ; \mathrm{p}=0,135 ; \mathrm{p}=0,571 ; \mathrm{p}=0,689$ e $\mathrm{p}=0,902)$ e gastrintestinal $(p=0,231 ; p=0,342 ; p=0,188 ; p=0,321 e p=0,180$ respectivamente).

\section{Correlação entre a expressão de CD4 na DMJ e parâmetros laboratoriais}

Houve correlação entre a expressão de células CD4 total ( $\mathrm{rs}=0,42 \mathrm{p}=0,011)$, nas regiões endomisial $(\mathrm{rs}=0,41 \mathrm{p}=0,012)$, perimisial $(\mathrm{rs}=0,35 \mathrm{p}=0,032)$, perivascular endomisial $(r s=0,44 \mathrm{p}=0,006)$ e perivascular perimisial $(\mathrm{rs}=0,38 \mathrm{p}=0,021)$ e níveis séricos de CK. 
Não houve correlação entre a expressão de células CD4 total, nas regiões endomisial, perimisial e perivascular (endomisial e perimisial) e níveis séricos de TGO $(\mathrm{rs}=-0,11 \mathrm{p}=0,549 ; \mathrm{rs}=-0,02 \mathrm{p}=0,901 ; \mathrm{rs}=-0,15 \mathrm{p}=0,417 ; \mathrm{rs}=-0,10 \mathrm{p}=0,615$ e $\mathrm{rs}=0,01$ $\mathrm{p}=0,942$ respectivamente), TGP $(\mathrm{rs}=-0,24 \mathrm{p}=0,210 ; \mathrm{rs}=-0,14 \mathrm{p}=0,466 ; \mathrm{rs}=-0,22$ $\mathrm{p}=0,253 ; \mathrm{rs}=-0,27 \mathrm{p}=0,163$ e $\mathrm{rs}=-0,13 \mathrm{p}=0,519)$, aldolase $(\mathrm{rs}=0,54 \mathrm{p}=0,104 ; \mathrm{rs}=0,35$ $\mathrm{p}=0,325 ; \mathrm{rs}=0,53 \mathrm{p}=0,115 ; \mathrm{rs}=0,63 \mathrm{p}=0,073$ e $\mathrm{rs}=0,41 \mathrm{p}=0,245$ respectivamente) e DHL $(\mathrm{rs}=0,20 \mathrm{p}=0,299 ; \mathrm{rs}=0,19 \mathrm{p}=0,322 ; \mathrm{rs}=0,26 \mathrm{p}=0,176 ; \mathrm{rs}=0,07 \mathrm{p}=0,736$ e $\mathrm{rs}=0,05$ $\mathrm{p}=0,797$ respectivamente).

\section{Correlação entre a expressão de CD4 na DMJ e parâmetros histológicos}

Houve correlação entre a quantidade de células CD4 na região perivascular (endomisial e perimisial) $(\mathrm{rs}=0,40 \mathrm{p}=0,014$ e $\mathrm{rs}=0,40 \mathrm{p}=0,015$ respectivamente) e fibras necróticas, não houve correlação entre a expressão total e nas regiões endomisial e perimisial $(r s=0,24 p=0,151 ; r s=0,21 p=0,222$ e $r s=0,26 p=0,127$ respectivamente).

Houve correlação entre a expressão de células CD4 nas regiões perimisial e perivascular endomisial $(\mathrm{rs}=0,40 \mathrm{p}=0,014$ e $\mathrm{rs}=0,33 \mathrm{p}=0,046$ respectivamente) e inflamação perivascular, não houve correlação entre a expressão total e nas regiões endomisial e perivascular perimisial $(r s=0,30 \mathrm{p}=0,072 ; \mathrm{rs}=0,28 \mathrm{p}=0,088$ e $\mathrm{rs}=0,29$ $\mathrm{p}=0,083$ respectivamente).

Houve correlação entre a expressão de células CD4 total e nas regiões endomisial, perimisial, perivascular (endomisial e perimisial) e inflamação endomisial ( $r s=0,40 p=0,015 ; r s=0,39 p=0,018 ; r s=0,47 p=0,003 ; r s=0,55 p<0,001$ e $\mathrm{rs}=0,49 \mathrm{p}=0,002$ respectivamente). 
Houve correlação entre a expressão de células CD4 perimisial e perivascular (endomisial e perimisial) $(\mathrm{rs}=0,32 \mathrm{p}=0,042 ; \mathrm{rs}=0,32 \mathrm{p}=0,045 \mathrm{e}$ $\mathrm{rs}=0,33 \mathrm{p}=0,040$ respectivamente) e aumento do tecido conectivo, não houve correlação entre a expressão total e quantidade de células na região endomisial ( $\mathrm{rs}=0,29 \mathrm{p}=0,085$ e $\mathrm{rs}=0,24 \mathrm{p}=0,152$ respectivamente).

Não houve correlação entre a expressão de células CD4 total e nas regiões endomisial, perimisial, perivascular (endomisial e perimisial) e atrofia perifascicular $(\mathrm{rs}=-0,22 \mathrm{p}=0,192 ; \mathrm{rs}=-0,24 \mathrm{p}=0,157 ; \mathrm{rs}=-0,21 \mathrm{p}=0,129 ; \mathrm{rs}=-0,16 \mathrm{p}=0,331$ e $\mathrm{rs}=-0,17$ $\mathrm{p}=0,306$ respectivamente) e dissociação miofibrilar ( $\mathrm{rs}=0,10 \mathrm{p}=0,564 ; \mathrm{rs}=0,05 \mathrm{p}=0,765$; $r s=0,14 p=0,423 ; r s=0,15 p=0,364$ e $r s=0,21 p=0,206)$ e fibras em regeneração ( $r s=0,10$ $\mathrm{p}=0,542 ; \mathrm{rs}=0,06 \mathrm{p}=0,728 ; \mathrm{rs}=0,18 \mathrm{p}=0,276 ; \mathrm{rs}=0,31 \mathrm{p}=0,062$ e $\mathrm{rs}=0,27 \mathrm{p}=0,112$ respectivamente).

\section{Correlação entre a expressão de CD4 e terapêutica e evolução}

Não houve correlação entre a expressão de células CD4 total e nas regiões endomisial, perimisial e perivascular (endomisial e perimisial) e corticoterapia anterior à biópsia muscular $(p=0,248 ; p=0,462 ; p=0,176 ; p=0,518$ e $p=0,681$ respectivamente), resposta inicial a corticoterapia $(p=0,397 ; p=0,362 ; p=0,478$; $\mathrm{p}=0,687$ e $\mathrm{p}=0,794$ respectivamente $)$, tratamento utilizado $(\mathrm{p}=0,759 ; \mathrm{p}=0,757$; $p=0,266 ; p=0,095$ e $p=0,157$ respectivamente) e evolução ( $p=0,710 ; p=0,796$; $\mathrm{p}=0,512 ; \mathrm{p}=0,483$ e $\mathrm{p}=0,615$ respectivamente). 
Tabela 10: Correlações positivas da análise quantitativa de células CD4 nas regiões endomisial, perimisial e perivascular (endomisial e perimisial) de fragmentos musculares de pacientes com DMJ com características clínicas, laboratoriais, histologicas, terapêuticas e evolutivas

\begin{tabular}{llllll}
\hline & \multicolumn{5}{c}{ CD4 } \\
\cline { 2 - 6 } & Total & $\begin{array}{c}\text { Região } \\
\text { endomisial }\end{array}$ & $\begin{array}{c}\text { Região } \\
\text { perimisial }\end{array}$ & $\begin{array}{c}\text { Região } \\
\text { perivascular } \\
\text { endomisial }\end{array}$ & $\begin{array}{c}\text { Região } \\
\text { perivascular } \\
\text { perimisial }\end{array}$ \\
\hline Fraqueza muscular & $\mathrm{rs}=-0,34$ & $\mathrm{rs}=-0,38$ & $\mathrm{rs}=-0,38$ & & \\
& $\mathrm{p}=0,020$ & $\mathrm{p}=0,041$ & $\mathrm{p}=0,021$ & & \\
\hline CK & $\mathrm{rs}=0,42$ & $\mathrm{rs}=0,41$ & $\mathrm{rs}=0,35$ & $\mathrm{rs}=0,44$ & $\mathrm{rs}=0,38$ \\
& $\mathrm{p}=0,011$ & $\mathrm{p}=0,012$ & $\mathrm{p}=0,032$ & $\mathrm{p}=0,006$ & $\mathrm{p}=0,021$ \\
\hline Fibras necróticas & & & & $\mathrm{rs}=0,40$ & $\mathrm{rs}=0,40$ \\
& & & & $\mathrm{p}=0,014$ & $\mathrm{p}=0,015$ \\
\hline Inflamação endomisial & $\mathrm{rs}=0,40$ & $\mathrm{rs}=0,39$ & $\mathrm{rs}=0,47$ & $\mathrm{rs}=0,55$ & $\mathrm{rs}=0,49$ \\
& $\mathrm{p}=0,015$ & $\mathrm{p}=0,018$ & $\mathrm{p}=0,003$ & $\mathrm{p}<0,001$ & $\mathrm{p}=0,002$ \\
\hline Inflamação perivascular & & & $\mathrm{rs}=0,40$ & $\mathrm{rs}=0,33$ & \\
\hline \multirow{2}{*}{ Aumento tecido conectivo } & & & $\mathrm{p}=0,014$ & $\mathrm{p}=0,046$ & \\
\hline
\end{tabular}

\section{Correlação entre a expressão de CD4 na DMJ, DM, PM e distrofia}

Houve maior expressão de células CD4 na região perimisial na DMJ quando comparado à DM, PM e distrofia $(\mathrm{p}<0,001)$.

Não houve diferença entre a expressão de células CD4 nas regiões endomisial e perivascular (endomisial e perivascular) na DMJ, DM, PM e distrofia ( $p=0,367$; $p=0,511$ e $p=0,154$ respectivamente). 
Tabela 11: Correlação da análise quantitativa de células CD4 nas regiões endomisial, perimisial e perivascular (endomisial e perimisial) de fragmentos musculares de pacientes com DMJ, DM, PM e distrofia

\begin{tabular}{lccccc}
\hline \multicolumn{1}{c}{ CD4 } & DMJ & PM & DM & Distrofia & \\
& $(\mathrm{n}=37)$ & $(\mathrm{n}=8)$ & $(\mathrm{n}=5)$ & $(\mathrm{n}=4)$ & \\
& média $(\mathrm{dp})$ & media $(\mathrm{dp})$ & média $(\mathrm{dp})$ & média $(\mathrm{dp})$ & \\
& mediana & mediana & mediana & mediana & \\
\hline Endomisial & $21,9(40,4)$ & $40,4(44,7)$ & $23,6(38,9)$ & $19,3(30,1)$ & \\
& 4 & 15 & 5 & 6,5 & $\mathrm{p}=0,367$ \\
\hline Perimisial & $18,7(46,3)$ & 0 & 0 & 0 & \\
& 3 & 0 & 0 & 0 & $\mathrm{p}<0,001$ \\
\hline Perivascular endomisial & $8,3(28,0)$ & $0,8(1,5)$ & $2,6(5,8)$ & $7,0(8,1)$ & \\
& 0 & 0 & 0 & 7 & $\mathrm{p}=0,511$ \\
\hline Perivascular perimisial & $10,7(44,0)$ & $0,4(1,1)$ & 0 & $5,8(11,5)$ & \\
& 0 & 0 & 0 & 0 & $\mathrm{p}=0,154$ \\
\hline
\end{tabular}
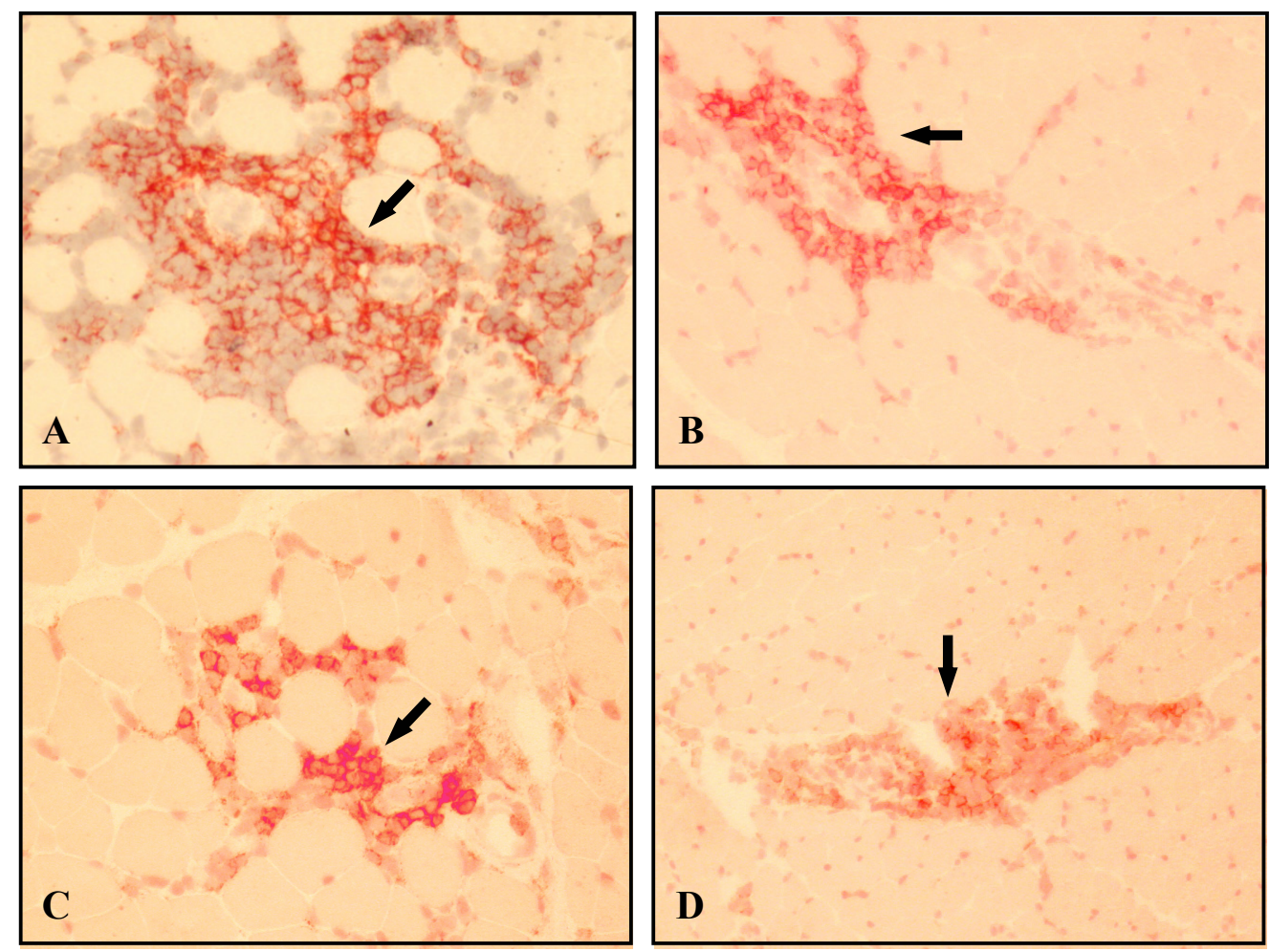

Figura 5: Reação imunohistoquímica EnVision-AP para identificação de células CD4 na DMJ, onde se observa a positividade em vermelho $(\rightarrow)$

Reação positiva para expressão de células CD4 nas regiões endomisial (A), perimisial (B) e perivascular endomisial (C) e perimisial (D) (200X). 


\section{CD8}

\section{Expressão de CD8 na DMJ}

A expressão de células CD8 foi positiva em 86,5\% dos fragmentos musculares dos pacientes com DMJ.

Houve maior expressão de células $\mathrm{CD} 8$ em região endomisial quanto à expressão nas regiões perimisial e perivascular (endomisial e perimisial) (que não se diferenciaram) $(\mathrm{p}<0,001 *)$.

Gráfico 5 : Análise quantitativa de células CD8 nas regiões endomisial, perimisial e perivascular (endomisial e perimisial) de fragmentos musculares de pacientes com DMJ

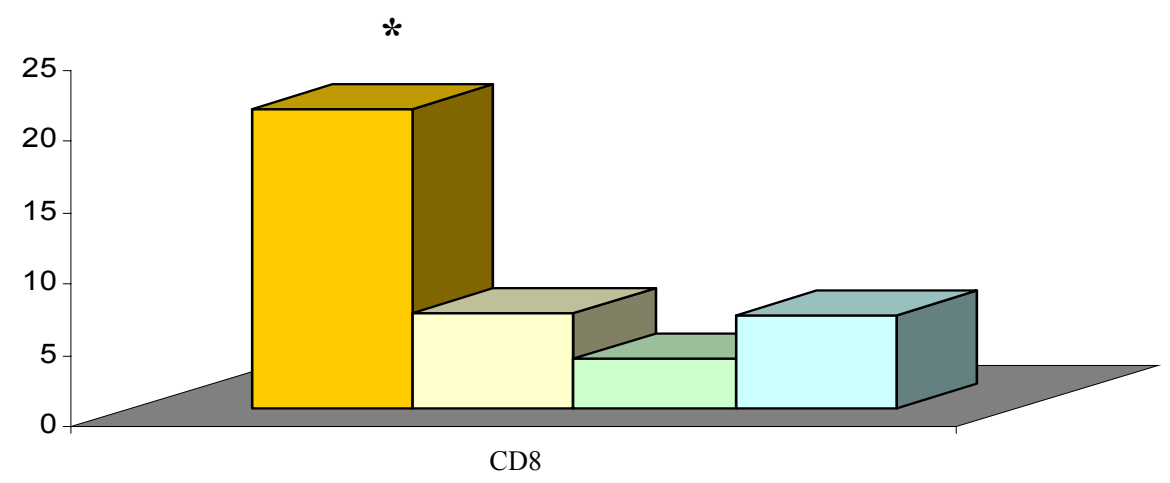

$\square$ endomisial $\square$ perimisial $\square$ perivascular endomisial $\square$ perivascular perimisial

Tabela 12: Análise quantitativa de células CD8 nas regiões endomisial, perimisial e perivascular (endomisial e perimisial) de fragmentos musculares de pacientes com DMJ

\begin{tabular}{lccccc}
\hline Região & \multicolumn{5}{c}{ Expressão de CD8 } \\
\cline { 2 - 6 } & média & dp & mediana & mínimo & máximo \\
\hline Endomisial & 21,00 & 36,26 & 9 & 0 & 184 \\
Perimisial & 6,65 & 12,00 & 2 & 0 & 50 \\
Perivascular endomisial & 3,46 & 7,40 & 0 & 0 & 40 \\
Perivascular perimisial & 6,54 & 25,65 & 0 & 0 & 153 \\
\hline
\end{tabular}




\section{Correlação entre a expressão de CD8 na DMJ e parâmetros clínicos}

Não houve correlação entre a expressão de células CD8 total e nas regiões endomisial, perimisial e perivascular (endomisial e perimisial) e sexo $(\mathrm{p}=0,732$; $\mathrm{p}=0,797 ; \mathrm{p}=0,172 ; \mathrm{p}=0,823 ; \mathrm{p}=0,609$ respectivamente), idade ( $\mathrm{rs}=-0,09 \mathrm{p}=0,225$; $r s=-0,11 \quad \mathrm{p}=0,926 ; \quad \mathrm{rs}=0,02 \quad \mathrm{p}=0,291 ; \quad \mathrm{rs}=-0,18 \quad \mathrm{p}=0,993 \quad$ e $\quad \mathrm{rs}=0,00 \quad \mathrm{p}=0,580$ respectivamente); tempo de doença até biópsia ( $r s=0,04 \mathrm{p}=0,817$; $r \mathrm{~s}=-0,02 \mathrm{p}=0,889$; $\mathrm{rs}=0,12 \mathrm{p}=0,492 ; \mathrm{rs}=-0,05 \mathrm{p}=0,751$ e $\mathrm{rs}=-0,20 \mathrm{p}=0,242$ respectivamente), fraqueza muscular $(r s=-0,15 p=0,391 ; r s=-0,22 p=0,193 ; r s=-0,19 p=0,261 ; r s=-0,15 p=0,366$ e $r s=-0,06 p=0,734$ respectivamente), presença de calcinose $(p=0,501 ; p=0,499$; $p=0,925 ; p=0,602$ e $p=0,515$ respectivamente) e úlcera cutânea $(p=0,458 ; p=0,215$; $\mathrm{p}=0,913 ; \mathrm{p}=0,345$ e $\mathrm{p}=0,636$ respectivamente), comprometimento pulmonar $(\mathrm{p}=0,213 ; \mathrm{p}=0,182 ; \mathrm{p}=0,813 ; \mathrm{p}=0,383$ e $\mathrm{p}=0,385$ respectivamente $)$, cardíaco $(p=0,697 ; p=0,451 ; p=0,162 ; p=0,649$ e $p=0,677$ respectivamente) e gastrointestinal $(p=0,458 ; p=0,215 ; p=0,913 ; p=0,345$ e $p=0,636$ respectivamente).

\section{Correlação entre a expressão de CD8 na DMJ e parâmetros laboratoriais}

Não houve correlação entre a expressão de células CD8 total e nas regiões endomisial, perimisial e perivascular (endomisial e perimisial) e níveis séricos de CK $(\mathrm{rs}=0,23 \mathrm{p}=0,198 ; \mathrm{rs}=0,24 \mathrm{p}=0,174 ; \mathrm{rs}=0,04 \mathrm{p}=0,829 ; \mathrm{rs}=0,25 \mathrm{p}=0,159$ e $\mathrm{rs}=0,16$ $\mathrm{p}=0,365$ respectivamente), TGO $(\mathrm{rs}=0,01 \mathrm{p}=0,972 ; \mathrm{rs}=0,02 \mathrm{p}=0,927 ; \mathrm{rs}=-0,13 \mathrm{p}=0,510$; $\mathrm{rs}=0,22 \mathrm{p}=0,235$ e $\mathrm{rs}=0,19 \mathrm{p}=0,317$ respectivamente), TGP $(\mathrm{rs}=-0,14 \mathrm{p}=0,479 ; \mathrm{rs}=-0,08$ $\mathrm{p}=0,675 ; \mathrm{rs}=-0,27 \mathrm{p}=0,150 ; \mathrm{rs}=0,09 \mathrm{p}=0,640$ e $\mathrm{rs}=0,03 \mathrm{p}=0,871$ respectivamente), aldolase $(r s=0,16 p=0,655 ; r s=0,17 p=0,636 ; r s=0,06 p=0,872 ; r s=0,42 p=0,231$ e $\mathrm{rs}=0,43 \mathrm{p}=0,219$ respectivamente) e DHL ( $\mathrm{rs}=0,04 \mathrm{p}=0,852 ; \mathrm{rs}=-0,15 \mathrm{p}=0,433 ; \mathrm{rs}=0,14$ $\mathrm{p}=0,476 ; \mathrm{rs}=0,30 \mathrm{p}=0,117$ e $\mathrm{rs}=0,37 \mathrm{p}=0,076$ respectivamente). 


\section{Correlação entre a expressão de CD8 na DMJ e parâmetros histológicos}

Houve correlação entre a expressão de células CD8 total ( $r s=0,38 p=0,022)$ e presença de células $\mathrm{Cd} 8$ na região endomisial $(\mathrm{rs}=0,36 \mathrm{p}=0,027)$ e dissociação miofibrilar, não houve correlação entre a expressão destas células nas regiões perimisial $(\mathrm{rs}=0,15 \mathrm{p}=0,392)$, perivascular endomisial $(\mathrm{rs}=0,04 \mathrm{p}=0,835)$ e perimisial ( $\mathrm{rs}=0,20 \mathrm{p}=0,239)$.

Houve correlação entre a expressão de células CD8 total ( $r s=0,49 \mathrm{p}=0,002)$ e quantidade destas células nas regiões endomisial $(\mathrm{rs}=0,50 \mathrm{p}=0,001)$ e fibras necróticas, não houve correlação entre a expressão destas células nas regiões perimisial $(\mathrm{rs}=0,18 \mathrm{p}=0,283)$, perivascular endomisial $(\mathrm{rs}=0,12 \mathrm{p}=0,478)$ e perimisial $(\mathrm{rs}=0,30 \mathrm{p}=0,073)$.

Houve correlação entre a expressão de células CD8 total ( $r s=0,48$ p=0,003), presença destas células nas regiões endomisial $(\mathrm{rs}=0,42 \mathrm{p}=0,009)$ e perivascular perimisial ( $r s=0,36$ p=0,027) e fibras em regeneração, não houve correlação entre a expressão destas células nas regiões perimisial ( $\mathrm{rs}=0,27 \mathrm{p}=0,113)$ e perivascular endomisial ( $\mathrm{rs}=0,17 \mathrm{p}=0,324)$.

Houve correlação entre a expressão de células $C D 8$ total $(r s=0,39 \mathrm{p}=0,016)$ e células CD8 na região perimisial ( $\mathrm{rs}=0,40 \mathrm{p}=0,015)$ e inflamação perivascular, não houve correlação entre a expressão de CD8 nas regiões endomisial (rs=0,23 $\mathrm{p}=0,163)$, perivascular endomisial $(\mathrm{rs}=0,01 \mathrm{p}=0,943)$ e perimisial $(\mathrm{rs}=0,12 \mathrm{p}=0,469)$.

Houve correlação entre a expressão de células CD8 total ( $\mathrm{rs}=0,42 \mathrm{p}=0,010)$, presença destas células nas regiões endomisial ( $\mathrm{rs}=0,35 \mathrm{p}=0,037)$ e perimisial ( $\mathrm{rs}=0,44$ $\mathrm{p}=0,006)$ e inflamação endomisial, não houve com a expressão de células CD8 nas regiões perivascular endomisial $(\mathrm{rs}=0,11 \mathrm{p}=0,513)$ e perimisial $(\mathrm{rs}=0,14 \mathrm{p}=0,403)$.

Não houve correlação entre a expressão de células CD8 total e nas regiões endomisial, perimisial e perivascular (endomisial e perimisial) e atrofia perifascicular $(\mathrm{rs}=-0,11 \mathrm{p}=0,519 ; \mathrm{rs}=-0,14 \mathrm{p}=0,405 ; \mathrm{rs}=-0,04 \mathrm{p}=0,807 ; \mathrm{rs}=-0,19 \mathrm{p}=0,267$ e $\mathrm{rs}=-0,14$ 
$\mathrm{p}=0,427$ respectivamente) e aumento do tecido conectivo $(\mathrm{rs}=0,27 \mathrm{p}=0,112 ; \mathrm{rs}=0,18$ $p=0,287 ; r s=0,23 p=0,177 ; r s=0,10 p=0,549$ e $r s=0,07 p=0,671)$.

\section{Correlação entre a expressão de CD8 e terapêutica e evolução}

Houve correlação entre a expressão de CD8 total $(\mathrm{p}=0,036)$ e células CD8 região endomisial $(p=0,008)$ e corticoterapia anterior à biópsia muscular, não houve correlação entre a expressão destas células nas regiões perimisial $(p=0,777)$, perivascular endomisial $(\mathrm{p}=0,893)$ e perimisial $(\mathrm{p}=0,760)$.

Não houve correlação entre a expressão de CD8 total e quantidade destas células nas regiões endomisial, perimisial e perivascular (endomisial e perimisial) e resposta inicial a corticoterapia $(p=0,549 ; p=0,498 ; p=0,628 ; p=0,603$ e $p=0,929$ respectivamente), tratamento utilizado $(\mathrm{p}=0,783 ; \mathrm{p}=0,407 ; \mathrm{p}=0,279 ; \mathrm{p}=0,793$ e $p=0,888$ respectivamente) e evolução $(p=0,907 ; p=0,770 ; p=1,000 ; p=0,183$ e $\mathrm{p}=0,566$ respectivamente).

Tabela 13: Correlações positivas da análise quantitativa de células CD8 nas regiões endomisial, perimisial e perivascular (endomisial e perimisial) de fragmentos musculares de pacientes com DMJ com características clínicas, laboratoriais, histologicas, terapêuticas e evolutivas

\begin{tabular}{lcllll}
\hline & \multicolumn{5}{c}{ CD8 } \\
\cline { 2 - 5 } & Total & Endomisial & Perimisial & $\begin{array}{c}\text { Perivascular } \\
\text { endomisial }\end{array}$ & $\begin{array}{c}\text { Perivascular } \\
\text { perimisial }\end{array}$ \\
\hline $\begin{array}{l}\text { Dissociação } \\
\text { miofibrilar }\end{array}$ & $\mathrm{rs}=0,38$ & $\mathrm{rs}=0,36$ & & & \\
\hline Fibras necróticas & $\mathrm{rs}=0,022$ & $\mathrm{p}=0,49$ & $\mathrm{rs}=0,027$ & & \\
\hline Fibras em & $\mathrm{rs}=0,002$ & $\mathrm{p}=0,001$ & & $\mathrm{rs}=0,36$ \\
regeneração & $\mathrm{p}=0,003$ & $\mathrm{p}=0,42$ & & $\mathrm{p}=0,027$ \\
\hline Inflamação & $\mathrm{rs}=0,42$ & $\mathrm{rs}=0,35$ & $\mathrm{rs}=0,44$ & \\
endomisial & $\mathrm{p}=0,010$ & $\mathrm{p}=0,037$ & $\mathrm{p}=0,006$ & \\
\hline Inflamação & $\mathrm{rs}=0,39$ & & $\mathrm{rs}=0,40$ & \\
perivascular & $\mathrm{p}=0,016$ & & $\mathrm{p}=0,015$ & \\
\hline Corticoterapia pré & & & & & \\
biópsia & $\mathrm{p}=0,036$ & $\mathrm{p}=0,008$ & & \\
\hline
\end{tabular}




\section{Correlação da expressão de CD8 na DMJ, DM, PM e distrofia}

Houve maior expressão de CD8 na região perimisial na DMJ, quando comparado à DM, PM e distrofia $(p=0,026)$.

Não houve diferença entre a expressão de CD8 nas regiões endomisial $(p=0,379)$ perivascular endomisial $(p=0,139)$ e perimisial $(p=0,110)$ na DMJ, DM, PM e distrofia.

Tabela 14: Correlação da análise quantitativa de células CD8 nas regiões endomisial, perimisial e perivascular (endomisial e perimisial) de fragmentos musculares de pacientes com DMJ, DM, PM e distrofia

\begin{tabular}{|c|c|c|c|c|c|}
\hline \multirow[t]{3}{*}{ CD8 } & $\begin{array}{c}\text { DMJ } \\
(\mathrm{n}=37)\end{array}$ & $\begin{array}{c}\mathbf{P M} \\
(\mathrm{n}=8)\end{array}$ & $\begin{array}{c}\mathbf{D M} \\
(\mathrm{n}=5)\end{array}$ & $\begin{array}{c}\text { Distrofia } \\
(\mathrm{n}=4)\end{array}$ & \\
\hline & $\begin{array}{l}\text { média } \\
\text { (dp) }\end{array}$ & $\begin{array}{l}\text { média } \\
(\mathrm{dp})\end{array}$ & $\begin{array}{l}\text { média } \\
\text { (dp) }\end{array}$ & $\begin{array}{l}\text { média } \\
(\mathrm{dp})\end{array}$ & \\
\hline & mediana & mediana & mediana & mediana & \\
\hline \multirow[t]{2}{*}{ endomisial } & $\begin{array}{c}21,0 \\
(36,3)\end{array}$ & $\begin{array}{c}78,9 \\
(108,3)\end{array}$ & $\begin{array}{c}15,6 \\
(22,7)\end{array}$ & $\begin{array}{c}67,5 \\
(87,4)\end{array}$ & $\mathrm{p}=0,379$ \\
\hline & 9 & 29,5 & 0 & 42,5 & \\
\hline \multirow[t]{2}{*}{ perimisial } & $\begin{array}{c}6,7 \\
(12,0)\end{array}$ & $\begin{array}{c}1,3 \\
(3,5)\end{array}$ & $\begin{array}{c}0,0 \\
(0,0)\end{array}$ & $\begin{array}{c}0,0 \\
(0,0)\end{array}$ & $\mathrm{p}=0,026$ \\
\hline & 2 & 0 & 0 & 0 & \\
\hline \multirow[t]{2}{*}{$\begin{array}{l}\text { perivascular } \\
\text { endomisial }\end{array}$} & $\begin{array}{c}3,5 \\
(7,4)\end{array}$ & $\begin{array}{c}5,1 \\
(7,3)\end{array}$ & $\begin{array}{c}0,0 \\
(0,0)\end{array}$ & $\begin{array}{c}22,0 \\
(26,4)\end{array}$ & $\mathrm{p}=0,139$ \\
\hline & 0 & 3,5 & 0 & 17,5 & \\
\hline \multirow[t]{2}{*}{$\begin{array}{l}\text { perivascular } \\
\text { perimisial }\end{array}$} & $\begin{array}{c}6,5 \\
(25,7)\end{array}$ & $\begin{array}{c}0,0 \\
(0,0)\end{array}$ & $\begin{array}{c}7,0 \\
(15,7)\end{array}$ & $\begin{array}{c}0,0 \\
(0,0)\end{array}$ & $\mathrm{p}=0,110$ \\
\hline & 0 & 0 & 0 & 0 & \\
\hline
\end{tabular}



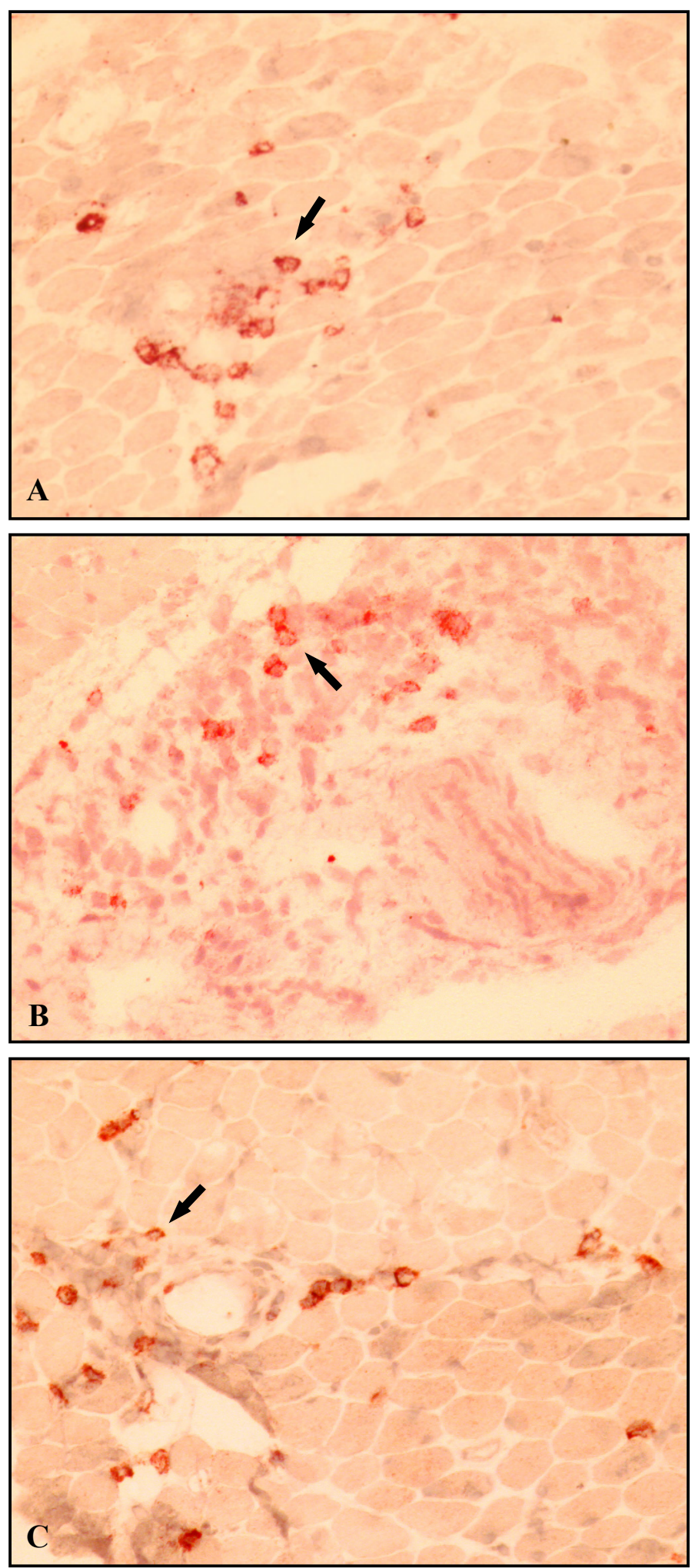

Figura 6: Reação imunohistoquímica EnVision-AP para identificação de células CD8 na DMJ, onde se observa a positividade em vermelho $(\rightarrow)$

Reação positiva para expressão de células CD8 nas regiões endomisial (A), perimisial (B) e perivascular perimisial (C). 


\section{Expressão de CD20 na DMJ}

A expressão de CD20 foi positiva em $62,2 \%$ dos fragmentos musculares dos pacientes com DMJ.

Não houve diferença entre a expressão de células CD20 nas regiões endomisial, perimisial e perivascular (endomisial e perimisial) na $\mathrm{DMJ}(\mathrm{p}=0,101)$.

Gráfico 6 : Análise quantitativa de células CD20 nas regiões endomisial, perimisial e perivascular (endomisial e perimisial) de fragmentos musculares de pacientes com DMJ

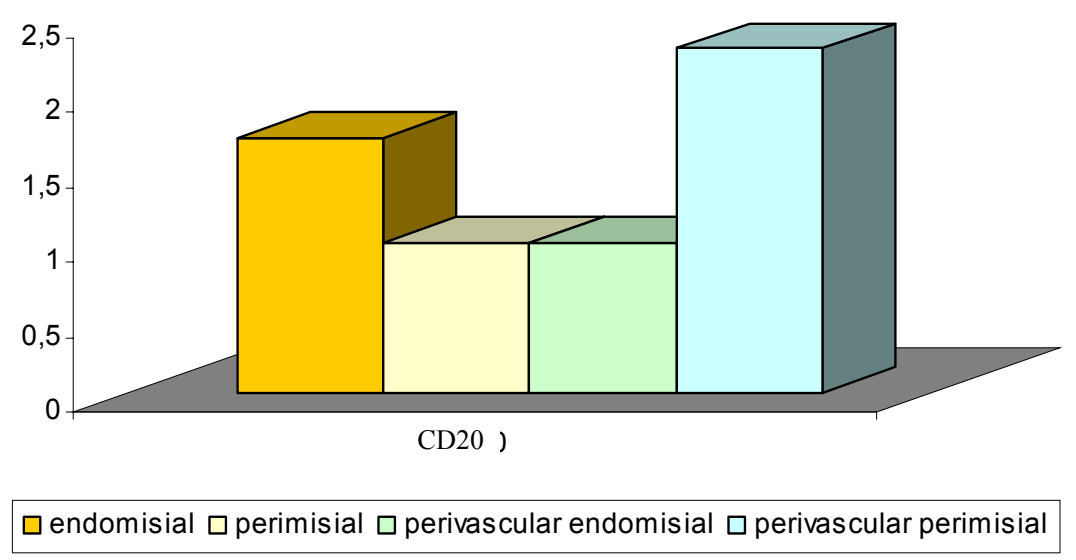

Tabela 15: Análise quantitativa de células CD20 nas regiões endomisial, perimisial e perivascular (endomisial e perimisial) de fragmentos musculares de pacientes com DMJ

\begin{tabular}{lccccc}
\hline \multirow{2}{*}{ Região } & \multicolumn{5}{c}{ CD20 } \\
\cline { 2 - 6 } & média & $\mathrm{dp}$ & mediana & mínimo & máximo \\
\hline Endomisial & 1,70 & 2,89 & 1 & 0 & 16 \\
Perimisial & 0,97 & 3,80 & 0 & 0 & 21 \\
Perivascular endomisial & 0,95 & 2,31 & 0 & 0 & 9 \\
Perivascular perimisial & 2,32 & 9,10 & 0 & 0 & 48 \\
\hline
\end{tabular}




\section{Correlação entre a expressão de CD20 na DMJ e parâmetros clínicos}

Houve correlação entre a expressão de células CD20 na região perimisial ( $p=0,031)$ e sexo masculino, não houve correlação entre a expressão total de CD20 $(p=0,448)$ e nas regiões endomisial $(p=0,761)$, perivascular endomisial $(p=0,663)$ e perimisial $(\mathrm{p}=0,114)$.

Não houve correlação entre a expressão de células CD20 total e nas regiões endomisial, perimisial e perivascular (endomisial e perimisial) e idade ( $\mathrm{rs}=-0,28$ $p=0,190 ; r s=-0,20 p=0,225 ; r s=-0,06 p=0,748 ; r s=-0,09 p=0,581$ e $r s=-0,13 p=0,461$ respectivamente), tempo de doença até a biópsia ( $r s=0,08 \mathrm{p}=0,623 ; \mathrm{rs}=0,05 \mathrm{p}=0,773$; $\mathrm{rs}=0,03 \mathrm{p}=0,851 ; \mathrm{rs}=0,03 \mathrm{p}=0,884$ e $\mathrm{rs}=0,11 \mathrm{p}=0,520$ respectivamente), fraqueza muscular $(r s=-0,13 p=0,432 ; r s=-0,07 p=0,684 ; r s=-0,25 p=0,132 ; r s=-0,08 p=0,655$ e $r s=-0,27 p=0,101$ respectivamente), presença de calcinose $(p=0,547 ; p=0,404$; $\mathrm{p}=0,948 ; \mathrm{p}=0,384$ e $\mathrm{p}=0,743$ respectivamente) e úlcera cutânea $(\mathrm{p}=0,444 ; 0,812$; 0,$156 ; 0,681$ e 0,119 respectivamente), comprometimento pulmonar ( $\mathrm{p}=0,682$; $\mathrm{p}=0,475 ; \mathrm{p}=0,682 ; \mathrm{p}=0,914$ e $\mathrm{p}=0,747$ respectivamente $)$, cardíaco $(\mathrm{p}=0,207$; $p=0,620 ; p=0,256 ; p=0,739$ e $p=0,374$ respectivamente) e gastrointestinal $(p=0,444$; $\mathrm{p}=0,812 ; \mathrm{p}=0,156 ; \mathrm{p}=0,681$ e $\mathrm{p}=0,119$ respectivamente).

\section{Correlação entre a expressão de CD20 e parâmetros laboratoriais}

Não houve correlação entre a expressão de CD20 total e nas regiões endomisial, perimisial e perivascular (endomisial e perimisial) e níveis séricos de CK $(r s=-0,09 p=0,624 ; r s=-0,09 p=0,611 ; r s=0,01 p=0,966 ; r s=0,04 p=0,839$ e $r s=-0,04$ $\mathrm{p}=0,838$ respectivamente), TGO $(\mathrm{rs}=-0,09 \mathrm{p}=0,625 ; \mathrm{rs}=-0,03 \mathrm{p}=0,885 ; \mathrm{rs}=-0,20$ $\mathrm{p}=0,298 ; \mathrm{rs}=-0,15 \mathrm{p}=0,431$ e $\mathrm{rs}=-0,06 \mathrm{p}=0,754$ respectivamente), TGP ( $\mathrm{rs}=-0,13$ 
$p=0,497 ; r s=0,02 p=0,913 ; r s=-0,33 p=0,078 ; r s=-0,23 p=0,223$ e $r s=-0,18 p=0,341$ respectivamente) e aldolase ( $r s=-0,08 p=0,820 ; r s=0,21 p=0,557 ; r s=-0,52 p=0,120$; $r s=-0,34 p=0,339$ e $r s=-0,52 p=0,120$ respectivamente).

Houve correlação entre a expressão de CD20 na região perimisial e níveis séricos de DHL ( $r=-0,45$ p=0,017), não houve correlação entre a expressão total $(\mathrm{rs}=-0,24 \mathrm{p}=0,214)$ e nas regiões endomisial $(\mathrm{rs}=-0,08 \mathrm{p}=0,699)$, perivascular endomisial ( $r s=-0,10 p=0,626)$ e perimisial $(r s=-0,32 p=0,100)$.

\section{Correlação entre a expressão de CD20 e parâmetros histológicos}

Houve correlação entre a expressão de CD20 total $(r s=0,38 p=0,021)$ e presença destas células na região endomisial $(\mathrm{rs}=0,40 \mathrm{p}=0,015)$ e fibras necróticas, não houve correlação entre a expressão destas células nas regiões perimisial ( $r s=0,15$ $\mathrm{p}=0,377)$ e perivascular endomisial $(\mathrm{rs}=0,23 \mathrm{p}=0,173)$ e perimisial $(\mathrm{rs}=0,12 \mathrm{p}=0,479)$.

Houve correlação entre a expressão de $\mathrm{CD} 20$ total $(\mathrm{rs}=0,44 \mathrm{p}=0,007)$ e nas regiões endomisial $(r s=0,52 \mathrm{p}=0,001)$ e perivascular endomisial $(\mathrm{rs}=0,35 \mathrm{p}=0,033)$ e fibras em regeneração, não houve correlação entre a expressão destas células nas regiões perimisial $(r s=0,04 p=0,800)$ e perivascular perimisial $(r s=0,02 p=0,913)$.

Houve correlação entre a expressão de $\operatorname{CD} 20$ total $(r s=0,50 p=0,002)$ e quantidade destas células na região endomisial ( $\mathrm{rs}=0,55 \mathrm{p}<0,001)$ e inflamação endomisial, não houve correlação entre a expressão nas regiões perimisial e perivascular (endomisial e perimisial) $(r \mathrm{~s}=0,22 \mathrm{p}=0,195 ; \mathrm{rs}=0,21 \mathrm{p}=0,205$ e $\mathrm{rs}=0,18$ $\mathrm{p}=0,284$ respectivamente).

Houve correlação entre a expressão de CD20 total e células na região endomisial ( $\mathrm{rs}=0,41 \mathrm{p}=0,012$ e $\mathrm{rs}=0,50 \mathrm{p}=0,002$ respectivamente) e inflamação 
perivascular, não houve correlação entre a expressão de células CD20 nas regiões perimisial e perivascular (endomisial e perimisial) $(\mathrm{rs}=0,07 \mathrm{p}=0,673 ; \mathrm{rs}=0,11$ $\mathrm{p}=0,532$ e rs $=0,11 \mathrm{p}=0,502$ respectivamente).

Houve correlação entre a expressão de CD20 total e nas regiões endomisial, perimisial e perivascular (endomisial e perimisial) e aumento do tecido conectivo $(\mathrm{rs}=0,62 \mathrm{p}<0,001 ; \mathrm{rs}=0,56 \mathrm{p}<0,001 ; \mathrm{rs}=0,34 \mathrm{p}=0,042 ; \mathrm{rs}=0,32 ; \mathrm{p}=0,046$ e $\mathrm{rs}=0,36$ $\mathrm{p}=0,030$ respectivamente)

Não houve correlação entre a expressão de CD20 total e nas regiões endomisial, perimisial e perivascular (endomisial e perimisial) e atrofia perifascicular $(\mathrm{rs}=0,19 \mathrm{p}=0,273 ; \mathrm{rs}=0,18 \mathrm{p}=0,287 ; \mathrm{rs}=0,06 \mathrm{p}=0,734 ; \mathrm{rs}=0,09 \mathrm{p}=0,583$ e $\mathrm{rs}=0,07 \mathrm{p}=0,699$ respectivamente) e dissociação miofibrilar ( $\mathrm{rs}=0,21 \mathrm{p}=0,224$; $\mathrm{rs}=0,27 \quad \mathrm{p}=0,108 ; \quad \mathrm{rs}=0,00 \quad \mathrm{p}=0,979 ; \quad \mathrm{rs}=0,06 \quad \mathrm{p}=0,734 \quad \mathrm{e} \quad \mathrm{rs}=0,04 \quad \mathrm{p}=0,805$ respectivamente).

\section{Correlação entre a expressão de CD20 na DMJ e terapêutica e evolução}

Houve correlação entre a expressão de $\operatorname{CD} 20 \quad(\mathrm{p}=0,032)$ na região perivascular perimisial e corticoterapia anterior à biópsia muscular, não houve correlação entre CD20 total e nas regiões endomisial, perimisial e perivascular endomisial $(p=0,139 ; p=0,266 ; p=0,168$ e $p=0,888)$.

Não houve correlação entre a expressão de CD20 total e nas regiões endomisial, perimisial e perivascular (endomisial e perimisial) e resposta inicial a corticoterapia $(p=0,522 ; p=0,723 ; p=0,075 ; p=0,260$ e $p=0,230)$, tratamento utilizado $(p=0,527 ; p=0,607 ; p=0,157 ; p=0,671$ e $p=0,655)$ e evolução $(p=0,810 ; p=0,984$; $p=0,520 ; p=0,980$ e $p=0,926)$. 
Tabela 16: Correlações positivas da análise quantitativa de células CD20 nas regiões endomisial, perimisial e perivascular (endomisial e perimisial) de fragmentos musculares de pacientes com DMJ com características clínicas, laboratoriais, histológicas, terapêuticas e evolutivas

\section{CD20}

\begin{tabular}{cccc}
\hline Total Endomisial Perimisial & $\begin{array}{c}\text { Perivascular } \\
\text { endomisial }\end{array}$ & $\begin{array}{c}\text { Perivascular } \\
\text { perimisial }\end{array}$ \\
\hline
\end{tabular}

\begin{tabular}{|c|c|c|c|c|c|}
\hline \multicolumn{3}{|l|}{ Sexo masculino } & \multicolumn{3}{|l|}{$\mathrm{p}=0,031$} \\
\hline DHL & & & $\begin{array}{l}\mathrm{rs}=-0,45 \\
\mathrm{p}=0,017\end{array}$ & & \\
\hline Fibras necróticas & $\begin{array}{r}\mathrm{rs}=0,38 \\
\mathrm{p}=0,021\end{array}$ & $\begin{array}{l}\mathrm{rs}=0,40 \\
\mathrm{p}=0,015\end{array}$ & & & \\
\hline $\begin{array}{l}\text { Fibras em } \\
\text { regeneração }\end{array}$ & $\begin{array}{r}\mathrm{rs}=0,44 \\
\mathrm{p}=0,007\end{array}$ & $\begin{array}{l}\mathrm{rs}=0,52 \\
\mathrm{p}=0,001\end{array}$ & & $\begin{array}{l}\mathrm{rs}=0,35 \\
\mathrm{p}=0,033\end{array}$ & \\
\hline $\begin{array}{l}\text { Inflamação } \\
\text { endomisial }\end{array}$ & $\begin{array}{r}\mathrm{rs}=0,50 \\
\mathrm{p}=0,002\end{array}$ & $\begin{array}{l}\mathrm{rs}=0,55 \\
\mathrm{p}<0,001\end{array}$ & & & \\
\hline $\begin{array}{l}\text { Inflamação } \\
\text { perivascular }\end{array}$ & $\begin{array}{r}\mathrm{rs}=0,41 \\
\mathrm{p}=0,012\end{array}$ & $\begin{array}{l}\mathrm{rs}=0,50 \\
\mathrm{p}=0,002\end{array}$ & & & \\
\hline $\begin{array}{l}\text { Aumento tecido } \\
\text { conectivo }\end{array}$ & $\begin{array}{r}\mathrm{rs}=0,62 \\
\mathrm{p}<0,001\end{array}$ & $\begin{array}{l}\mathrm{rs}=0,56 \\
\mathrm{p}<0,001\end{array}$ & $\begin{array}{l}\mathrm{rs}=0,34 \\
\mathrm{p}=0,042\end{array}$ & $\begin{array}{l}\mathrm{rs}=0,32 \\
\mathrm{p}=0,046\end{array}$ & $\begin{array}{l}\mathrm{rs}=0,36 \\
\mathrm{p}=0,030\end{array}$ \\
\hline $\begin{array}{l}\text { Corticoterapia pré } \\
\text { biópsia }\end{array}$ & & & & & $\mathrm{p}=0,032$ \\
\hline
\end{tabular}




\section{Correlação entre a expressão de CD20 na DMJ, DM, PM e distrofia}

Não houve diferença entre a expressão de células CD20 nas regiões endomisial $(\mathrm{p}=0,861)$, perimisial $(\mathrm{p}=0,584)$, perivascular endomisial $(\mathrm{p}=0,733)$ e perimisial $(\mathrm{p}=0,661)$ na DMJ, DM, PM e distrofia.

Tabela 17: Correlação da análise quantitativa de células CD20 nas regiões endomisial, perimisial e perivascular (endomisial e perimisial) de fragmentos musculares de pacientes com DMJ, DM, PM e distrofia

\begin{tabular}{|c|c|c|c|c|c|}
\hline \multirow[t]{3}{*}{ CD20 } & $\begin{array}{c}\text { DMJ } \\
(\mathrm{n}=37)\end{array}$ & $\begin{array}{c}P M \\
(n=8)\end{array}$ & $\begin{array}{c}\mathrm{DM} \\
(\mathrm{n}=5)\end{array}$ & $\begin{array}{c}\text { Distrofia } \\
(\mathrm{n}=4)\end{array}$ & \\
\hline & $\begin{array}{l}\text { média } \\
(\mathrm{dp})\end{array}$ & $\begin{array}{l}\text { média } \\
\text { (dp) }\end{array}$ & $\begin{array}{l}\text { média } \\
\text { (dp) }\end{array}$ & $\begin{array}{l}\text { média } \\
(\mathrm{dp})\end{array}$ & \\
\hline & mediana & mediana & mediana & mediana & \\
\hline \multirow[t]{3}{*}{ endomisial } & 1,7 & 9,0 & 14,0 & 2,0 & \\
\hline & $(2,9)$ & $(21,9)$ & $(30,8)$ & $(4,0)$ & \\
\hline & 1 & 1 & 0 & 0 & $\mathrm{p}=0,861$ \\
\hline \multirow[t]{3}{*}{ perimisial } & 1,0 & 0,0 & 0,0 & 0,0 & \\
\hline & $(3,8)$ & $(0,0)$ & $(0,0)$ & $(0,0)$ & \\
\hline & 0 & 0 & 0 & 0 & $\mathrm{p}=0,584$ \\
\hline \multirow[t]{3}{*}{ perivascular endomisial } & 1,0 & 4,4 & 2,6 & 0,0 & \\
\hline & $(2,3)$ & $(9,9)$ & $(5,8)$ & $(0,0)$ & \\
\hline & 0 & 0 & 0 & 0 & $\mathrm{p}=0,733$ \\
\hline perivascular & 2,3 & 6,3 & 3,2 & 0,0 & \\
\hline \multirow[t]{2}{*}{ perimisial } & $(9,1)$ & $(15,8)$ & $(7,2)$ & $(0,0)$ & \\
\hline & 0 & 0 & 0 & 0 & $p=0,661$ \\
\hline
\end{tabular}



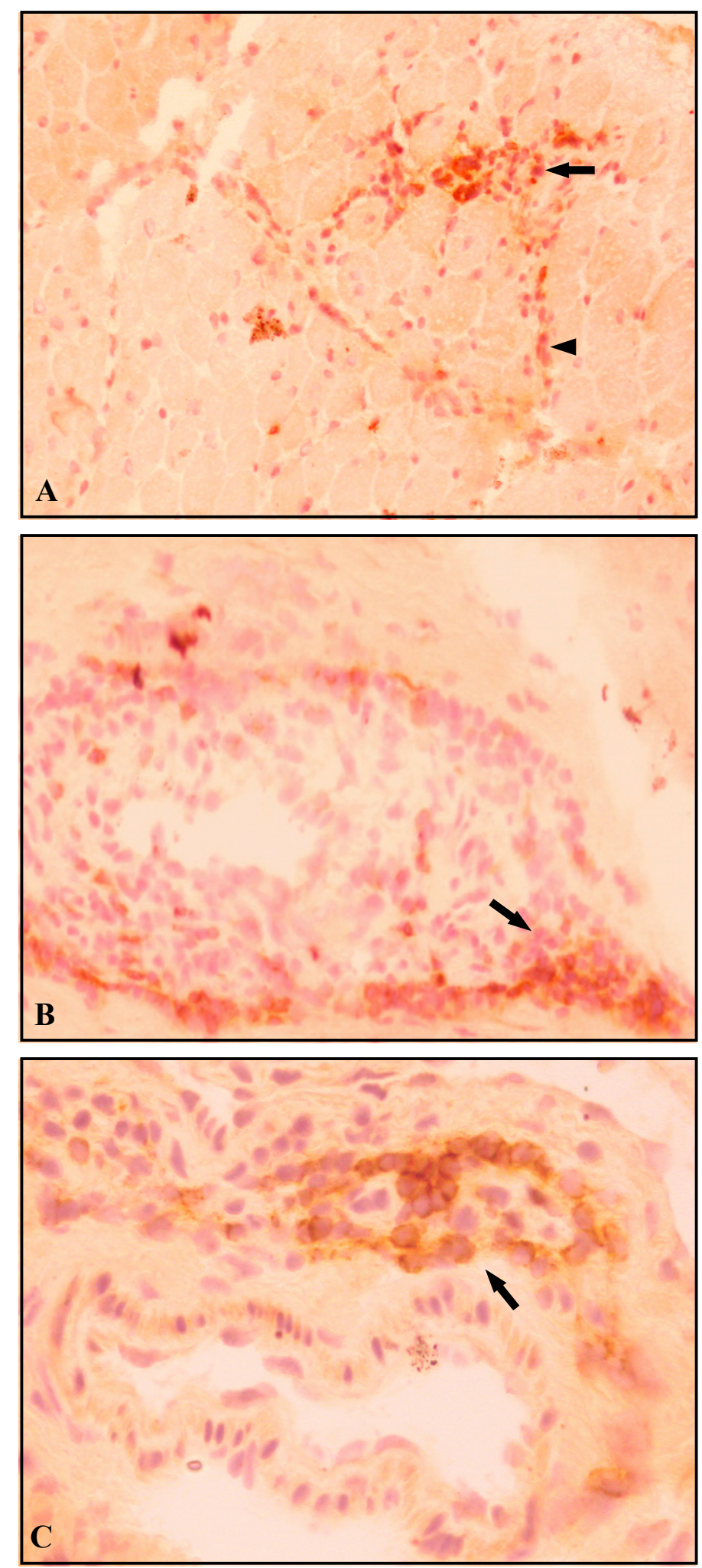

Figura 7: Reação imunohistoquímica LSAB+ para identificação de células CD20 na DMJ, onde se observa a positividade em vermelho

Reação positiva para expressão de CD20 na região endomisial $(\bullet)$ e perivascular endomisial $(\rightarrow)(\mathrm{A})$, perimisial $(\rightarrow)(\mathrm{B})$ e perivascular perimisial $\rightarrow)(\mathrm{C})$. 


\section{CD68}

\section{Expressão de CD68 na DMJ}

A expressão de CD68 foi positiva em 97,2\% dos fragmentos musculares dos pacientes com DMJ.

Houve maior expressão nas regiões perimisial e perivascular perimisial (que não se diferenciaram), seguida da região endomisial, que apresentou maior expressão que a região perivascular endomisial $\left(\mathrm{p}<0,001^{*}\right)$.

Gráfico 7: Análise semi-quantitativa da expressão de células CD68 nas regiões endomisial, perimisial e perivascular (endomisial e perimisial) de fragmentos musculares de pacientes com DMJ

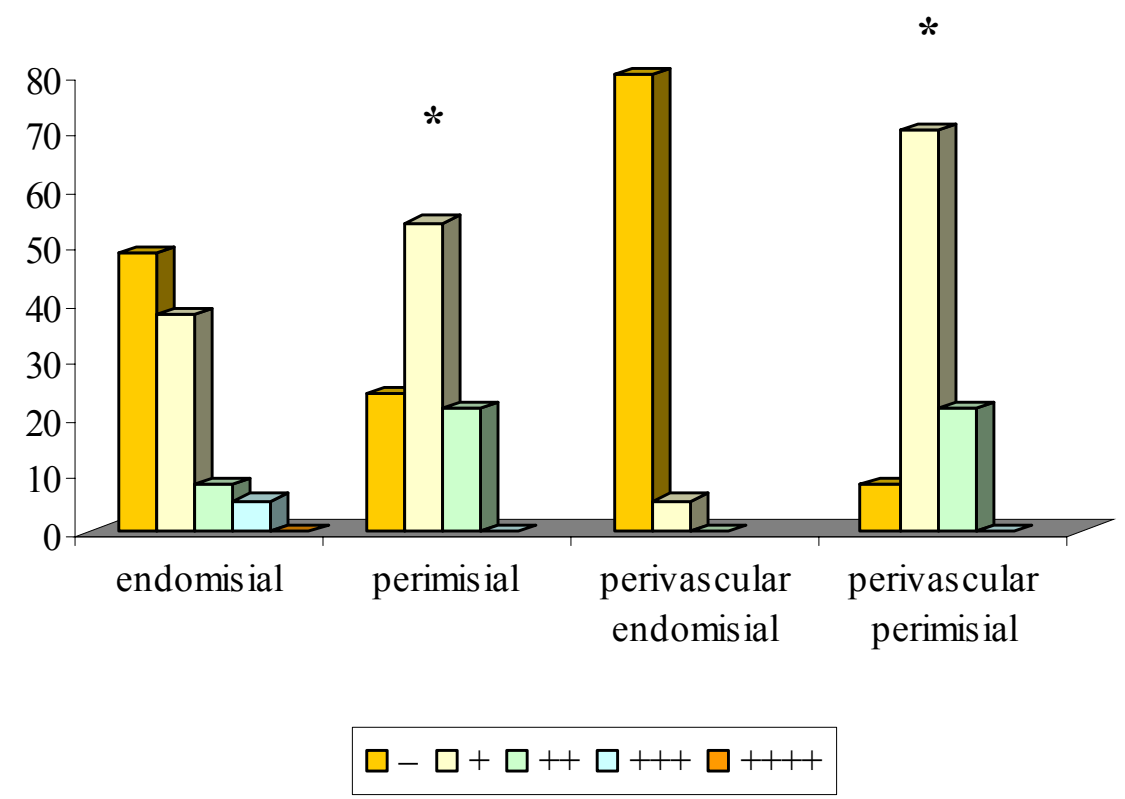


Tabela 18: Análise semi-quantitativa da expressão de células CD68 nas regiões endomisial, perimisial e perivascular (endomisial e perimisial) de fragmentos musculares de pacientes com DMJ

\begin{tabular}{|c|c|c|c|c|c|c|c|}
\hline \multirow[t]{3}{*}{ CD68 } & \multicolumn{7}{|c|}{ Região } \\
\hline & \multicolumn{2}{|c|}{ Endomisial } & \multicolumn{2}{|c|}{ Perimisial } & \multicolumn{2}{|c|}{$\begin{array}{c}\text { Perivascular } \\
\text { endomisial }\end{array}$} & $\begin{array}{c}\text { Perivascular } \\
\text { perimisial }\end{array}$ \\
\hline & $\mathrm{n}$ & $(\%)$ & $\mathrm{n}$ & $(\%)$ & $\mathrm{n}$ & $(\%)$ & $\mathrm{n} \quad(\%)$ \\
\hline$-(0)$ & 18 & $(48,6)$ & 9 & $(24,3)$ & 35 & $(94,6)$ & $3(8,1)$ \\
\hline$+(1)$ & 14 & $(37,8)$ & 20 & $(54,1)$ & 2 & $(5,4)$ & $26 \quad(70,3)$ \\
\hline$++(2)$ & 3 & $(8,1)$ & 8 & $(21,6)$ & 0 & $(0,0)$ & $8 \quad(21,6)$ \\
\hline$+++(3)$ & 2 & $(5,4)$ & 0 & $(0,0)$ & 0 & $(0,0)$ & $0 \quad(0,0)$ \\
\hline
\end{tabular}

\section{Correlação entre a expressão de CD68 e parâmetros clínicos}

Houve correlação entre a expressão de CD68 na região perivascular endomisial e idade ( $r s=0,35 \mathrm{p}=0,035)$, não houve correlação entre a expressão nas regiões endomisial $(r s=-0,19 \mathrm{p}=0,251)$, perimisial $(\mathrm{rs}=0,01 \mathrm{p}=0,948)$, perivascular perimisial ( $\mathrm{rs}=0,21 \mathrm{p}=0,205)$.

Houve correlação entre a expressão de CD68 na região endomisial e fraqueza muscular (rs=-0,33 p=0,049), não houve correlação entre a expressão nas regiões perimisial $(\mathrm{rs}=-0,24 \mathrm{p}=0,157)$, perivascular endomisial $(\mathrm{rs}=-0,27 \mathrm{p}=0,103)$ e perimisial $(\mathrm{rs}=-0,16 \mathrm{p}=0,354)$.

Não houve correlação entre a expressão de CD68 nas regiões endomisial, perimisial, perivascular (endomisial e perimisial) e sexo $(\mathrm{p}=0,574 ; \mathrm{p}=0,677$; $\mathrm{p}=0,383 ; \mathrm{p}=0,815$ respectivamente), tempo de doença até a biópsia ( $\mathrm{rs}=-0,04$ $\mathrm{p}=0,832 ; \mathrm{rs}=-0,23 \mathrm{p}=0,180 ; \mathrm{rs}=-0,04 \mathrm{p}=0,816$ e $\mathrm{rs}=-0,15 \mathrm{p}=0,391$ respectivamente), presença de calcinose $(p=0,404 ; p=0,122 ; p=0,416$ e $p=0,808$ respectivamente $)$ e ulcera cutânea $(p=0,591 ; p=0,499 ; \quad p=0,618$ e $p=0,542$ respectivamente), 
comprometimento cardíaco $(p=0,445 ; p=0,424 ; p=0,670$ e $p=0,603$ respectivamente), pulmonar $(\mathrm{p}=0,061 ; \mathrm{p}=0,922 ; \mathrm{p}=0,126 \mathrm{e} \mathrm{p}=0,234$ respectivamente) e gastrointestinal $(p=0,190 ; p=0,600 ; p=0,189$ e $p=0,918$ respectivamente $)$.

\section{Correlação entre a expressão de CD68 na DMJ e parâmetros laboratoriais}

Não houve correlação entre a expressão de CD68 nas regiões endomisial, perimisial e perivascular (endomisial e perimisial) e níveis séricos de aldolase $(\mathrm{rs}=0,00 \mathrm{p}=1,000 ; \quad \mathrm{rs}=0,22 \mathrm{p}=0,545 ; \quad \mathrm{rs}=0,52 \mathrm{p}=0,120$ e $\mathrm{rs}=0,55 \quad \mathrm{p}=0,102$ respectivamente), TGO ( $r s=0,04 p=0,828 ; r s=0,06 p=0,769 ; r s=0,09 p=0,626$ e $\mathrm{rs}=0,25 \mathrm{p}=0,178$ respectivamente), TGP $(\mathrm{rs}=0,07 \mathrm{p}=0,724 ; \mathrm{rs}=0,10 \mathrm{p}=0,624$; $\mathrm{rs}=-0,23 \mathrm{p}=0,239$ e $\mathrm{rs}=0,22 \mathrm{p}=0,246$ respectivamente), $\mathrm{CK}$ ( $\mathrm{rs}=0,11 \mathrm{p}=0,545$; $\mathrm{rs}=0,09 \mathrm{p}=0,608 ; \mathrm{rs}=0,27 \mathrm{p}=0,133$ e $\mathrm{rs}=0,15 \mathrm{p}=0,408$ respectivamente), DHL $(r s=-0,20 p=0,299 ; \quad r s=0,14 \quad p=0,493 ; \quad r s=0,09 p=0,664$ e $r s=-0,02 \quad p=0,914$ respectivamente).

\section{Correlação entre a expressão de CD68 na DMJ e parâmetros histológicos}

Houve correlação entre a expressão de CD68 na região perimisial e dissociação miofibrilar ( $r$ = $=0,33$ p=0,049), não houve correlação entre a expressão nas regiões endomisial ( $\mathrm{rs}=0,24 \mathrm{p}=0,163)$ e perivascular endomisial $(\mathrm{rs}=0,21$ $\mathrm{p}=0,228)$ e perimisial $(\mathrm{rs}=0,28 \mathrm{p}=0,098)$.

Houve correlação entre a expressão de CD68 nas regiões endomisial (rs=0,51 $\mathrm{p}=0,001)$, perimisial $(\mathrm{rs}=0,43 \mathrm{p}=0,008)$ e perivascular perimisial $(\mathrm{rs}=0,41 \mathrm{p}=0,014) \mathrm{e}$ fibras necróticas, não houve correlação entre a expressão na região perivascular endomisial ( $\mathrm{rs}=0,24 \mathrm{p}=0,165)$. 
Houve correlação entre a expressão de CD68 nas regiões endomisial (rs=0,45 $\mathrm{p}=0,006)$, perimisial $(\mathrm{rs}=0,42 \mathrm{p}=0,011)$ e perivascular perimisial $(\mathrm{rs}=0,36 \mathrm{p}=0,033)$ e fibras em regeneração, não houve correlação entre a expressão na região perivascular endomisial ( $\mathrm{rs}=0,15 \mathrm{p}=0,394)$.

Houve correlação entre a expressão de CD68 nas regiões endomisial (rs=0,49 $\mathrm{p}=0,002)$ e perivascular endomisial ( $\mathrm{rs}=0,34 \mathrm{p}=0,045)$ e inflamação endomisial, não houve correlação entre a expressão nas regiões perimisial ( $r=0,17 \mathrm{p}=0,330)$ e perivascular perimisial $(\mathrm{rs}=0,17 \mathrm{p}=0,313)$.

Não houve correlação entre a expressão de CD68 nas regiões endomisial, perimisial e perivascular (endomisial e perimisial) e atrofia perifascicular $(\mathrm{rs}=-0,11$ $\mathrm{p}=0,512 ; \mathrm{rs}=-0,01 \mathrm{p}=0,960 ; \mathrm{rs}=0,04 \mathrm{p}=0,815$ e $\mathrm{rs}=0,05 \mathrm{p}=0,775$ respectivamente), inflamação perivascular $(\mathrm{rs}=0,24 \mathrm{p}=0,159 ; \mathrm{rs}=0,17 \mathrm{p}=0,321 ; \mathrm{rs}=0,28 \mathrm{p}=0,096 \mathrm{e}$ $\mathrm{rs}=0,06 \mathrm{p}=0,720$ respectivamente) e aumento do tecido conectivo ( $\mathrm{rs}=0,14 \mathrm{p}=0,430$ $\mathrm{rs}=0,12 \mathrm{p}=0,480 ; \mathrm{rs}=0,30 \mathrm{p}=0,074$ e $\mathrm{rs}=0,22 \mathrm{p}=0,202$ respectivamente).

\section{Correlação entre a expressão de CD68 na DMJ e terapêutica e evolução}

Houve correlação entre a expressão de CD68 na região endomisial e corticoterapia anterior a biópsia muscular $(\mathrm{p}=0,006)$, não houve correlação entre a expressão nas regiões perimisial $(p=0,210)$, perivascular endomisial $(p=0,391)$ e perimisial $(p=0,171)$.

Houve correlação entre a expressão de CD68 na região endomisial $(p=0,032)$ e tratamento utilizado, não houve correlação entre a expressão nas regiões perimisial $(p=0,301)$, perivascular endomisial $(p=0,157)$ e perimisial $(p=0,081)$. 
Não houve correlação entre a expressão de CD68 nas regiões endomisial, perimisial e perivascular (endomisial e perimisial) e resposta inicial a corticoterapia $(p=0,788 ; p=0,367 ; p=0,684$ e $p=0,643$ respectivamente) e evolução ( $p=0,458$; $p=0,425 ; p=0,711$ e $p=0,944$ respectivamente).

Tabela 19: Correlações positivas da análise semi-quantitativa de células CD68 nas regiões endomisial, perimisial e perivascular (endomisial e perimisial) de fragmentos musculares de pacientes com DMJ com características clínicas, laboratoriais, histologicas, terapêuticas e evolutivas

\begin{tabular}{|c|c|c|c|c|}
\hline & \multicolumn{4}{|c|}{ CD68 } \\
\hline & Endomisial & Perimisial & $\begin{array}{c}\text { Perivascular } \\
\text { endomisial }\end{array}$ & $\begin{array}{c}\text { Perivascular } \\
\text { perimisial }\end{array}$ \\
\hline Idade & & & $\begin{array}{l}\mathrm{rs}=0,35 \\
\mathrm{p}=0,035\end{array}$ & \\
\hline Fraqueza muscular & $\begin{array}{l}\mathrm{rs}=-0,33 \\
\mathrm{p}=0,049\end{array}$ & & & \\
\hline Dissociação miofibrilar & & $\begin{array}{l}\mathrm{rs}=0,33 \\
\mathrm{p}=0,049\end{array}$ & & \\
\hline Fibras necróticas & $\begin{array}{l}\mathrm{rs}=0,51 \\
\mathrm{p}=0,001\end{array}$ & $\begin{array}{l}\mathrm{rs}=0,43 \\
\mathrm{p}=0,008\end{array}$ & & $\begin{array}{l}\mathrm{rs}=0,41 \\
\mathrm{P}=0,014\end{array}$ \\
\hline Fibras em regeneração & $\begin{array}{l}\mathrm{rs}=0,45 \\
\mathrm{p}=0,006\end{array}$ & $\begin{array}{l}\mathrm{rs}=0,42 \\
\mathrm{p}=0,011\end{array}$ & & $\begin{array}{l}\mathrm{rs}=0,36 \\
\mathrm{p}=0,033\end{array}$ \\
\hline Inflamação endomisial & $\begin{array}{l}\mathrm{rs}=0,49 \\
\mathrm{p}=0,002\end{array}$ & & $\begin{array}{l}\mathrm{rs}=0,34 \\
\mathrm{p}=0,045\end{array}$ & \\
\hline Corticoterapia pré biópsia & $\mathrm{p}=0,006$ & & & \\
\hline $\begin{array}{l}\text { Corticoterapia associada a duas } \\
\text { ou mais medicações }\end{array}$ & $\mathrm{p}=0,032$ & & & \\
\hline
\end{tabular}



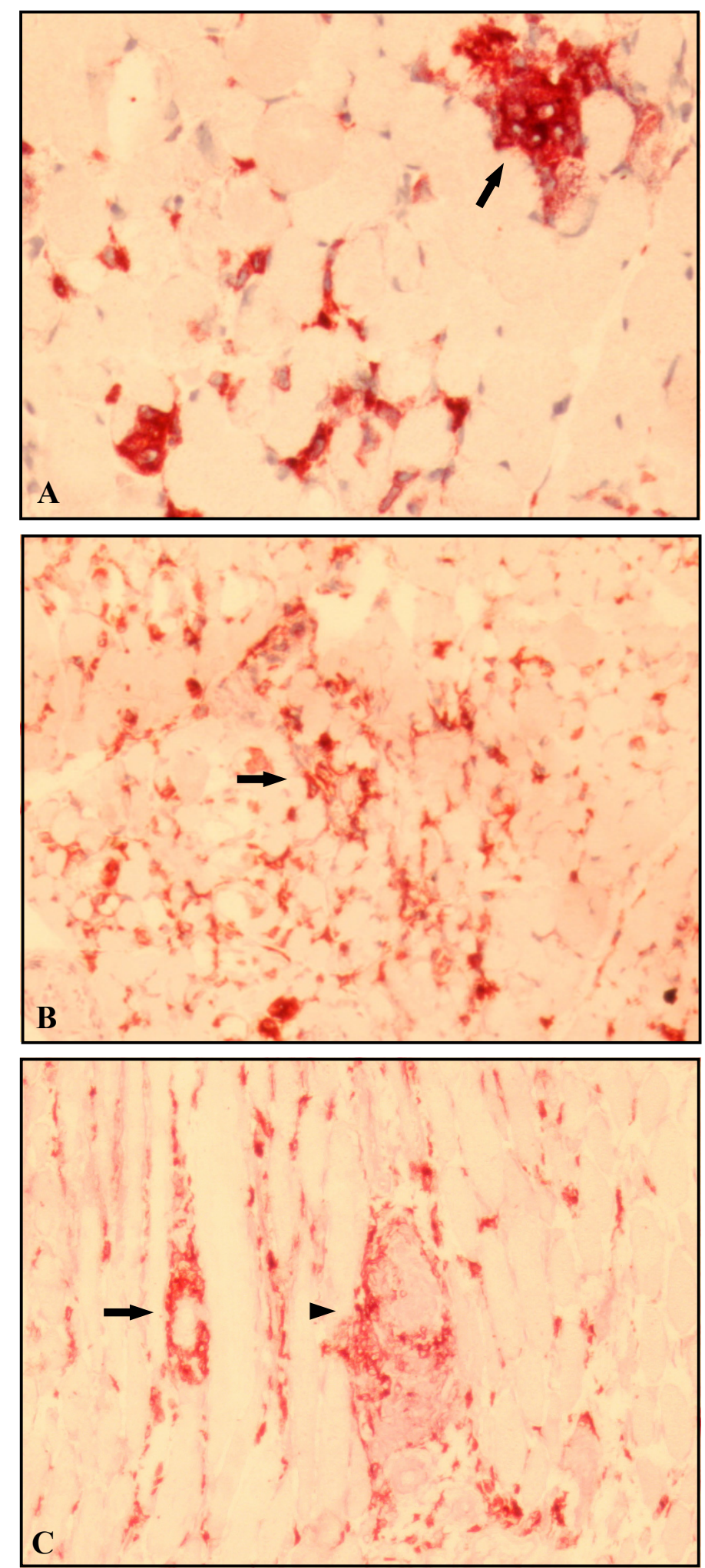

Figura 8: Reação imunohistoquímica LSAB+ para identificação de células CD68 na DMJ, onde se observa a positividade em vermelho

Reação positiva para expressão de CD68 na região endomisial $(\rightarrow)(\mathrm{A})$, perivascular endomisial perimisial $(\rightarrow)(B)$, perimisial $(\rightarrow)$ e perivascular perimisial $(\bullet)(C)$. 


\section{Correlação entre a expressão de CD68 na DMJ, DM, PM e distrofia}

Houve maior expressão de CD68 na região endomisial na DM, quando comparada a DMJ, PM e distrofia. $(p=0,004)$.

Houve menor expressão de CD68 na região perivascular endomisial na DMJ, quando comparada a DM, PM e distrofia. $(p=0,002)$.

Não houve diferença entre a expressão de CD68 nas regiões perimisial e perivascular perimisial na DMJ, DM, PM e distrofia $(p=0,440$ e $p=0,476$ respectivamente).

Tabela 20: Correlação da análise semi-quantitativa de células CD68 nas regiões endomisial, perimisial e perivascular (endomisial e perimisial) de fragmentos musculares de pacientes com DMJ, DM, PM e distrofia

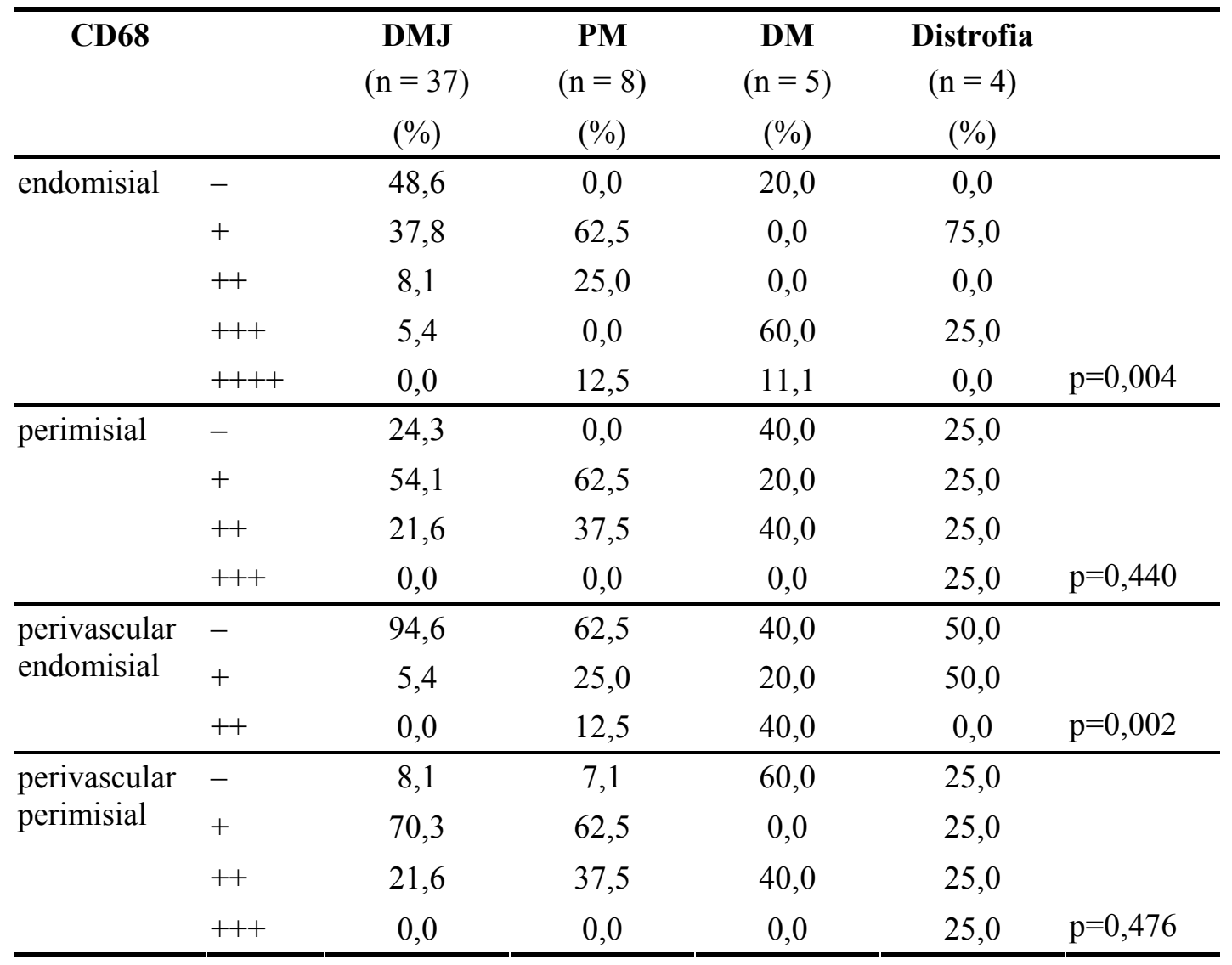


Correlações entre MHC I e II, C5b-9, CD4, CD8, CD4+CD8, CD20, CD68, ICAM-1 e VCAM-1

\section{Correlação entre a expressão de MHC-I e CD4}

Não houve correlação entre a expressão de MHC-I nas fibras e CD4 nas regiões endomisial $(r s=0,18 \mathrm{p}=0,301)$ e perivascular endomisial $(\mathrm{rs}=0,39 \mathrm{p}=0,017)$.

\section{Correlação entre a expressão de MHC-I e CD8}

Não houve correlação entre a expressão de MHC-I nas fibras e CD8 nas regiões endomisial ( $r s=0,30 p=0,074)$ e perivascular endomisial $(r s=0,19 p=0,255)$.

\section{Correlação entre a expressão de MHC-I e CD4 + CD8}

Houve correlação entre a expressão de MHC-I nas fibras e CD4 + CD8 nas regiões endomisial ( $r s=0,37 \mathrm{p}=0,025)$ e perivascular endomisial $(\mathrm{rs}=0,44 \mathrm{p}=0,007)$.

\section{Correlação entre a expressão de MHC-I e CD20}

Não houve correlação entre a expressão de MHC-I nas fibras e CD20 nas regiões endomisial $(r s=0,16 p=0,335)$ e perivascular endomisial $(r s=0,22 p=0,198)$.

\section{Correlação entre a expressão de MHC-II e CD4}

Houve correlação entre a expressão de MHC-II nas fibras e CD4 nas regiões endomisial $(r s=0,44 p=0,006)$ e perivascular endomisial $(r s=0,42 p=0,009)$. 


\section{Correlação entre a expressão de MHC-II e CD8}

Não houve correlação entre a expressão de MHC-II nas fibras e CD8 nas regiões endomisial ( $r s=0,32 \mathrm{p}=0,061)$ e perivascular endomisial $(\mathrm{rs}=0,12 \mathrm{p}=0,477)$.

\section{Correlação entre a expressão de MHC-II e CD20}

Não houve correlação entre a expressão de MHC-II nas fibras e CD20 nas regiões endomisial ( $r s=0,17 \mathrm{p}=0,317)$ e perivascular endomisial $(\mathrm{rs}=0,08 \mathrm{p}=0,660)$.

\section{Correlação entre a expressão de MHC-II e CD4 + CD8}

Houve correlação entre a expressão de MHC-II nas fibras e CD4 + CD8 nas regiões endomisial $(r s=0,46 p=0,004)$ e perivascular endomisial $(r s=0,43 p=0,009)$.

\section{Correlação entre a expressão de C5b-9 e CD4}

Não houve correlação entre a expressão de C5b-9 nas fibras, capilares e vasos endomisiais e CD4 na região endomisial ( $r s=0,04 p=0,831$; $r s=-0,18 p=0,276$ e rs=$0,21 \mathrm{p}=0,205$ respectivamente) e perivascular endomisial $(\mathrm{rs}=0,08 \mathrm{p}=0,630 ; \mathrm{rs}=0,04$ $p=0,829 ; p=-0,05 p=0,781$ respectivamente), C5b-9 nos vasos perimisiais e CD4 nas regiões perimisial $(r s=0,06 \mathrm{p}=0,715)$ e perivascular perimisial $(\mathrm{rs}=0,07 \mathrm{p}=0,695)$.

\section{Correlação entre a expressão de C5b-9 e CD8}

Houve correlação entre a expressão de C5b-9 nas fibras e capilares e CD8 na região endomisial ( $r s=0,43 p=0,009$ e $r s=-0,42 p=0,010)$, não houve correlação na região perivascular endomisial $\quad(\mathrm{rs}=0,24 \quad \mathrm{p}=0,150 \quad \mathrm{e} \quad \mathrm{rs}=0,23 \quad \mathrm{p}=0,179$ respectivamente). 
Houve correlação entre a expressão de C5b-9 nos vasos perimisiais e CD8 nas regiões perimisial $(\mathrm{rs}=0,48 \mathrm{p}=0,003)$ e perivascular perimisial $(\mathrm{rs}=-0,10$ $\mathrm{p}=0,553)$.

Não houve correlação entre a expressão de C5b-9 nos vasos endomisiais e CD8 nas regiões endomisial ( $\mathrm{rs}=0,10 \mathrm{p}=0,562)$ e perivascular endomisial $(\mathrm{rs}=-0,13$ $\mathrm{p}=0,441)$

\section{Correlação entre a expressão de C5b-9 e CD4 + CD8}

Não houve correlação entre a expressão de C5b-9 nas fibras, capilares e vasos endomisiais e CD4 + CD8 na região endomisial ( $r s=0,32 p=0,067 ; r s=0,14 p=0,405$ e $\mathrm{rs}=-0,17 \mathrm{p}=0,316$ respectivamente) e perivascular endomisial $(\mathrm{rs}=023 \mathrm{p}=0,171$; $\mathrm{rs}=0,09 \mathrm{p}=0,612$ e $\mathrm{rs}=-0,16 \mathrm{p}=0,348$ respectivamente).

Não houve correlação entre a expressão de C5b-9 nos vasos perimisiais e $\mathrm{CD} 4+\mathrm{CD} 8$ nas regiões perimisial $(\mathrm{rs}=0,28 \mathrm{p}=0,100)$ e perivascular perimisial $(\mathrm{rs}=0,04 \mathrm{p}=0,807)$.

\section{Correlação entre a expressão de C5b-9 e CD20}

Não houve correlação entre a expressão de C5b-9 nas fibras, capilares e vasos endomisiais e CD20 na região endomisial ( $r s=-0,06 \mathrm{p}=0,739$; $r \mathrm{~s}=0,12 \mathrm{p}=0,492$ e rs $=$ $0,05 \mathrm{p}=0,761$ respectivamente) e perivascular endomisial $(\mathrm{rs}=0,06 \mathrm{p}=0,711 ; \mathrm{rs}=0,15$ $\mathrm{p}=0,388$ e $\mathrm{rs}=-0,17 \mathrm{p}=0,322$ respectivamente).

Não houve correlação entre a expressão de C5b-9 nos vasos perimisiais e CD20 nas regiões perimisial $(r s=0,21 \mathrm{p}=0,224)$ e perivascular perimisial $(\mathrm{rs}=0,22$ $\mathrm{p}=0,203)$. 


\section{Correlação entre a expressão de CD68 e CD4}

Não houve correlação entre a expressão de CD68 e CD4 nas regiões endomisial ( $r s=0,00 \mathrm{p}=0,994)$, perimisial $(\mathrm{rs}=0,01 \mathrm{p}=0,951)$, perivascular endomisial $(\mathrm{rs}=0,41 \mathrm{p}=0,012)$ e perimisial $(\mathrm{rs}=0,15 \mathrm{p}=0,382)$.

\section{Correlação entre a expressão de CD68 e CD8}

Não houve correlação entre a expressão de CD68 e CD8 nas regiões endomisial $(\mathrm{rs}=0,00 \mathrm{p}=0,994)$, perimisial $\quad(\mathrm{rs}=-0,01 \quad \mathrm{p}=0,938)$, perivascular endomisial ( $r s=-0,07 p=0,693)$ e perimisial $(r s=0,16 p=0,349)$.

\section{Correlação entre a expressão de CD68 e CD4 + CD8}

Houve correlação entre a expressão de CD68 e CD4 + CD8 na região perivascular endomisial ( $\mathrm{rs}=0,33 \mathrm{p}=0,043)$, não houve correlação entre a expressão nas regiões endomisial ( $\mathrm{rs}=0,31 \mathrm{p}=0,058)$, perimisial $(\mathrm{rs}=-0,06 \mathrm{p}=0,733)$ e perivascular perimisial $(\mathrm{rs}=0,19 \mathrm{p}=0,252)$.

\section{Correlação entre a expressão de CD68 e CD20}

Não houve correlação entre a expressão de CD68 e CD20 nas regiões endomisial ( $\mathrm{rs}=0,11 \mathrm{p}=0,530)$, perimisial $(\mathrm{rs}=0,15 \mathrm{p}=0,384)$, perivascular endomisial $(\mathrm{rs}=-0,13 \mathrm{p}=0,429)$ e perimisial $(\mathrm{rs}=0,22 \mathrm{p}=0,202)$.

\section{Correlação entre a expressão de ICAM-1 e CD4}

Houve correlação entre a expressão de ICAM-1 nos vasos endomisiais e capilares e CD4 na região perivascular endomisial ( $r s=-0,44 p=0,007$ e $r s=-0,43$ $\mathrm{p}=0,008$ respectivamente), ICAM-1 nos capilares e CD4 nas regiões endomisial 
$(\mathrm{rs}=-0,44 \mathrm{p}=0,007), \mathrm{ICAM}-1$ nos vasos perimisiais e CD4 na região perimisial ( $\mathrm{rs}=-$ $0,42 \mathrm{p}=0,010)$ e perivascular perimisial $(\mathrm{rs}=-0,37 \mathrm{p}=0,026)$.

Não houve correlação entre ICAM-1 nos vasos endomisiais e CD4 na região endomisial ( $\mathrm{rs}=-0,20 \mathrm{p}=0,230)$.

\section{Correlação entre a expressão de ICAM-1 e CD8}

Não houve correlação entre a expressão de ICAM-1 nos vasos endomisiais e capilares e CD8 na região perivascular endomisial ( $r s=0,14 \mathrm{p}=0,418$ e $\mathrm{rs}=-0,19$ $\mathrm{p}=0,270$ respectivamente), ICAM-1 nos vasos endomisiais e CD8 na região endomisial ( $r s=-0,19 \mathrm{p}=0,263)$, ICAM-1 nos capilares e CD8 na região endomisial $(\mathrm{rs}=-0,03 \mathrm{p}=0,852)$, ICAM-1 nos vasos perimisiais e CD8 na região perimisial $(\mathrm{rs}=0,03 \mathrm{p}=0,858)$ e perivascular perimisial $(\mathrm{rs}=-0,10 \mathrm{p}=0,561)$.

\section{Correlação entre a expressão de ICAM-1 e CD4 + CD8}

Houve correlação entre a expressão de ICAM-1 nos capilares e CD4 + CD8 na região perivascular endomisial ( $\mathrm{rs}=-0,37 \mathrm{p}=0,026$ respectivamente).

Não houve entre ICAM-1 nos vasos endomisiais e CD4 + CD8 nas regiões perivascular endomisial ( $r s=-0,23 p=0,176)$ e endomisial ( $r s=-0,12 p=0,466)$, ICAM-1 nos capilares e CD4 + CD8 na região endomisial ( $r s=-0,24 p=0,160)$, ICAM-1 nos vasos perimisiais e CD4 $+\mathrm{CD} 8$ nas regiões perimisial $(\mathrm{rs}=-0,24 \mathrm{p}=0,162)$ e perivascular perimisial $(\mathrm{rs}=-0,21 \mathrm{p}=0,223)$. 


\section{Correlação entre a expressão de ICAM-1 e CD20}

Não houve correlação entre a expressão de ICAM-1 nos vasos endomisiais e capilares e CD20 na região perivascular endomisial ( $r s=0,12 p=0,499$ e $r s=-0,16$ $\mathrm{p}=0,256$ respectivamente), ICAM-1 nos vasos endomisiais e CD20 na região endomisial ( $r s=-0,05 \mathrm{p}=0,761)$, ICAM-1 nos capilares e CD20 na região endomisial ( $r s=0,24 \mathrm{p}=0,153)$, ICAM-1 nos vasos perimisiais e CD20 na região perimisial $(\mathrm{rs}=0,11 \mathrm{p}=0,514)$ e perivascular perimisial $(\mathrm{rs}=0,16 \mathrm{p}=0,348)$.

\section{Correlação entre a expressão de VCAM-1 e CD4}

Não houve correlação entre a expressão de VCAM-1 nos vasos endomisiais e capilares e CD4 na região perivascular endomisial ( $r s=0,06 \mathrm{p}=0,716$ e $\mathrm{rs}=0,02$ $\mathrm{p}=0,913$ respectivamente), VCAM-1 nos capilares e CD4 na região endomisial $(\mathrm{rs}=0,14 \mathrm{p}=0,402)$, VCAM-1 nos vasos endomisiais e CD4 na região endomisial $(\mathrm{rs}=0,22 \mathrm{p}=0,188), \mathrm{VCAM}-1$ nos vasos perimisiais e CD4 na região perimisial $(\mathrm{rs}=0,15 \mathrm{p}=0,385)$.

\section{Correlação entre a expressão de VCAM-1 e CD8}

Não houve correlação entre a expressão de VCAM-1 nos vasos endomisiais e capilares e CD8 na região perivascular endomisial $(r s=0,07 \mathrm{p}=0,667$ e $\mathrm{rs}=0,03$ $\mathrm{p}=0,858$ respectivamente), VCAM-1 nos capilares e CD8 na região endomisial ( $r s=-0,07 \mathrm{p}=0,692), \mathrm{VCAM}-1$ nos vasos endomisiais e CD8 na região endomisial $(\mathrm{rs}=0,16 \mathrm{p}=0,335), \mathrm{VCAM}-1$ nos vasos perimisiais e $\mathrm{CD} 8$ na região perimisial $(\mathrm{rs}=0,11 \mathrm{p}=0,524)$. 


\section{Correlação entre a expressão de VCAM-1 e CD4 + CD8}

Não houve correlação entre a expressão de VCAM-1 nos vasos endomisiais e capilares e CD4 + CD8 na região perivascular endomisial ( $r s=0,03$ p=0,866 e $\mathrm{rs}=-0,02 \mathrm{p}=0,919$ respectivamente), VCAM-1 nos capilares e CD4 + CD8 na região endomisial ( $r s=0,00 \mathrm{p}=1,000), \mathrm{VCAM}-1$ nos vasos endomisiais e CD4 + CD8 na região endomisial ( $r \mathrm{~s}=0,05 \mathrm{p}=0,757)$, VCAM-1 nos vasos perimisiais e CD4 + CD8 na região perimisial ( $\mathrm{rs}=0,18 \mathrm{p}=0,288)$.

\section{Correlação entre a expressão de VCAM-1 e CD20}

Não houve correlação entre a expressão de VCAM-1 nos vasos endomisiais e capilares e $\mathrm{CD} 20$ na região perivascular endomisial $(\mathrm{rs}=0,19 \mathrm{p}=0,251$ e $\mathrm{rs}=-0,13$ $\mathrm{p}=0,429$ respectivamente), VCAM-1 nos capilares e CD20 na região endomisial $(\mathrm{rs}=0,24 \mathrm{p}=0,153)$, VCAM-1 nos vasos endomisiais e CD20 na região endomisial ( $\mathrm{rs}=0,01 \mathrm{p}=0,973)$, VCAM-1 nos vasos perimisiais e CD20 na região perimisial $(\mathrm{rs}=-0,18 \mathrm{p}=0,280)$.

\section{Correlação entre a expressão de CD4 e CD8}

Houve correlação entre a expressão de CD4 e CD8 total ( $r s=0,36$ p=0,028), nas regiões perimisial $(\mathrm{rs}=0,40 \mathrm{p}=0,013)$ e perivascular perimisial $(\mathrm{rs}=0,44 \mathrm{p}=0,007)$, não houve correlação entre a expressão nas regiões endomisial ( $r s=0,29$ p=0,086) e perivascular endomisial $(\mathrm{rs}=0,29 \mathrm{p}=0,084)$.

\section{Correlação entre a expressão de CD20 e CD4 + CD8}

Houve correlação entre a expressão de CD20 e CD4 + CD8 total (rs=0,41 $\mathrm{p}=0,011)$ e na região perivascular endomisial $(\mathrm{rs}=0,46 \mathrm{p}=0,004)$, não houve 
correlação entre a expressão nas regiões endomisial $(r s=0,27 \mathrm{p}=0,102)$, perimisial $(\mathrm{rs}=0,22 \mathrm{p}=0,189)$ e perivascular perimisial $(\mathrm{rs}=0,25 \mathrm{p}=0,138)$.

\section{Correlações positivas entre MHC-I e II, C5b-9, Cd4, CD8, CD4 + CD8, Cd20, CD68, ICAM-1 e VCAM-1}

Houve correlação entre MHC-I e CD4 + CD8 nas regiões endomisial (rs=0,37 $\mathrm{p}=0,025)$ e perivascular endomisial ( $\mathrm{rs}=0,44 \mathrm{p}=0,007)$, MHC-II e CD4 nas regiões endomisial ( $r s=0,44 \mathrm{p}=0,006)$ e perivascular endomisial $(\mathrm{rs}=0,42 \mathrm{p}=0,009)$, MHC-II e CD4 + CD8 nas regiões endomisial ( $\mathrm{rs}=0,46 \mathrm{p}=0,004)$ e perivascular endomisial ( $r s=0,43 p=0,009), C 5 b-9$ nas fibras e capilares e CD8 na região endomisial ( $r s=0,43$ $\mathrm{p}=0,009$ e $\mathrm{rs}=-0,42 \mathrm{p}=0,010), \mathrm{C} 5 \mathrm{~b}-9$ nos vasos perimisiais e CD8 na região perimisial $(r s=0,48 p=0,003)$ e perivascular perimisial $(r s=-0,10 p=0,553), C D 4$ e CD8 total $(r s=0,36 p=0,028)$, nas regiões perimisial $(r s=0,40 p=0,013)$ e perivascular perimisial $(\mathrm{rs}=0,44 \mathrm{p}=0,007), \mathrm{CD} 20$ e $\mathrm{CD} 4+\mathrm{CD} 8$ total $(\mathrm{rs}=0,41 \mathrm{p}=0,011)$ e na região perivascular endomisial $(\mathrm{rs}=0,46 \mathrm{p}=0,004), \mathrm{CD} 68$ e $\mathrm{CD} 4+\mathrm{CD} 8$ na região perivascular endomisial ( $\mathrm{rs}=0,33 \mathrm{p}=0,043)$, ICAM-1 nos vasos endomisiais e capilares e CD4 na região perivascular endomisial ( $r s=-0,44 p=0,007$ e $r s=-0,43$ $\mathrm{p}=0,008$ respectivamente), ICAM- 1 nos capilares e CD4 na região endomisial ( $r s=-0,44 \mathrm{p}=0,007)$, ICAM-1 nos vasos perimisiais e CD4 nas regiões perimisial $(\mathrm{rs}=-0,42 \mathrm{p}=0,010)$ e perivascular perimisial $(\mathrm{rs}=-0,37 \mathrm{p}=0,026)$, ICAM-1 nos capilares e CD4 + CD8 na região perivascular endomisial ( $r s=-0,37 p=0,026$ respectivamente), $\mathrm{CD} 4$ e $\mathrm{CD} 8$ total $(\mathrm{rs}=0,36 \mathrm{p}=0,028)$, nas regiões perimisial $(\mathrm{rs}=0,40 \mathrm{p}=0,013)$ e perivascular perimisial $(\mathrm{rs}=0,44 \mathrm{p}=0,007), \mathrm{CD} 20$ e CD4 + CD8 total $(r s=0,41 \mathrm{p}=0,011)$ e na região perivascular endomisial $(\mathrm{rs}=0,46 \mathrm{p}=0,004)$. 
Tabela 21: Resumo da expressão, localização e correlações positivas de MHC-I e II, C5b-9, CD4, CD8, CD20 e CD68

\begin{tabular}{|c|c|c|c|c|c|c|c|c|}
\hline & $\begin{array}{l}\text { Positividade } \\
\text { de expressão } \\
\text { na DMJ (\%) }\end{array}$ & $\begin{array}{l}\text { Localização } \\
\text { preferencial na } \\
\text { DMJ }\end{array}$ & $\begin{array}{l}\text { Correlação com } \\
\text { expressão na DM, PM e } \\
\text { distrofia }\end{array}$ & $\begin{array}{l}\text { Correlação com } \\
\text { características } \\
\text { clínicas }\end{array}$ & $\begin{array}{l}\text { Correlação com } \\
\text { características } \\
\text { laboratoriais }\end{array}$ & $\begin{array}{l}\text { Correlação com } \\
\text { características } \\
\text { histológicas }\end{array}$ & $\begin{array}{l}\text { Correlação com } \\
\text { terapêutica e } \\
\text { evolução }\end{array}$ & $\begin{array}{l}\text { Correlação com } \\
\text { outros marcadores }\end{array}$ \\
\hline \multirow[t]{2}{*}{ MHC-I } & 97,3 & fibras & & & & - & - & $\mathrm{CD} 4+\mathrm{CD} 8$ \\
\hline & & & $\mathrm{PM}=\mathrm{DM}>\mathrm{DMJ}>$ distrofia & - & - & & & \\
\hline \multirow[t]{2}{*}{ MHC-II } & 21,6 & fibras & & & & - & - & CD4 \\
\hline & & & $\mathrm{PM}=\mathrm{DM}>\mathrm{DMJ}=$ distrofia & sexo feminino & CK & & & $\mathrm{CD} 4+\mathrm{CD} 8$ \\
\hline \multirow[t]{2}{*}{ C5b-9 } & 83,8 & & & sexo feminino, & & dissociação miofibrilar, fibras & corticoterapia associada & CD8 \\
\hline & & perimisial & > DMJ (perimisial) & $\begin{array}{l}\text { fraqueza muscular, } \\
\text { calcinose, comp. } \\
\text { cardíaco e pulmonar }\end{array}$ & aldolase, DHL & $\begin{array}{l}\text { necróticas e em regeneração, } \\
\text { inflamação endomisial, } \\
\text { aumento do tecido conectivo }\end{array}$ & $\begin{array}{l}\text { a } 2 \text { ou mais medicações, } \\
\text { corticoterapia pré- } \\
\text { biópsia }\end{array}$ & $\mathrm{CD} 4+\mathrm{CD} 8$ \\
\hline \multirow[t]{4}{*}{ CD4 } & 81,1 & & & fraqueza muscular & $\mathrm{CK}$ & fibras necróticas, inflamação & - & MHC-II \\
\hline & & & & & & endomisial e perivascular, & & C5B-9 \\
\hline & & & & & & & & CD8 \\
\hline & & endomisial e & $>\mathrm{DMU}$ (nerimisiol) & & & & & ICAM-1 \\
\hline \multirow[t]{2}{*}{ CD8 } & 86,5 & & & - & - & dissociação miofibrilar, fibras & corticoterapia pré- & C5B-9 \\
\hline & & endomisial & > DMJ (perimisial) & & & $\begin{array}{l}\text { necróticas e em regeneração, } \\
\text { inflamação endomisial e } \\
\text { perivascular }\end{array}$ & biópsia & CD4 \\
\hline CD20 & 62,2 & sem diferença & sem diferença & sexo masculino & DHL & $\begin{array}{l}\text { fibras necróticas e em } \\
\text { regeneração, inflamação } \\
\text { endomisial e perivascular, } \\
\text { aumento do tecido conectivo }\end{array}$ & $\begin{array}{l}\text { corticoterapia pré- } \\
\text { biópsia }\end{array}$ & $\mathrm{CD} 4+\mathrm{CD} 8$ \\
\hline CD68 & 97,2 & $\begin{array}{l}\text { perimisial e } \\
\text { perivascular } \\
\text { perimisial }\end{array}$ & > DM (endomisial) & $\begin{array}{l}\text { idade, fraqueza } \\
\text { muscular }\end{array}$ & - & $\begin{array}{l}\text { dissociação miofibrilar, fibras } \\
\text { necróticas e em regeneração, } \\
\text { inflamação endomisial }\end{array}$ & $\begin{array}{l}\text { corticoterapia associada } \\
\text { a } 2 \text { ou mais medicações, } \\
\text { corticoterapia pré- } \\
\text { biópsia }\end{array}$ & $\mathrm{CD} 4+\mathrm{CD} 8$ \\
\hline
\end{tabular}




\section{DISCUSSÃO}


A maioria dos estudos envolvendo mecanismos patogênicos das MII tem o seu foco na resposta imune, particularmente, nos possíveis mecanismos de dano à fibra muscular.

Observações clínicas e histopatológicas demonstraram que o dano à fibra muscular não é a única causa de fraqueza muscular, conforme se observa através de falhas encontradas nas correlações entre os indicadores de dano à fibra muscular: níveis séricos das enzimas musculares, alterações histológicas e intensidade dos sintomas clínicos (KROLL et al, 1986; SALLUM et al, 2002; LUNDBERG e DASTMALCHI, 2002).

Fibras musculares, vasos sanguíneos e células inflamatórias são possivelmente os componentes do tecido muscular envolvidos nos mecanismos patogênicos. Estas estruturas podem expressar moléculas que se relacionem com o desenvolvimento das características clínicas, laboratoriais, histológicas, terapêuticas e evolutivas da doença.

\section{EXPRESSÃO DE MHC-I e II}

Os resultados deste estudo mostraram expressão de MHC-I positiva em 97,2\% dos casos de DMJ, com tendência à maior expressão de MHC-I na DMJ, quando comparada à distrofia, e menor, quando comparada a PM e DM, que não se 
diferenciaram $(\mathrm{p}<0,001)$. Enquanto que a expressão de MHC-II foi positiva em apenas 21,6\% dos casos de DMJ e apresentou correlacão com sexo feminino e níveis séricos mais elevados de CK. Observou-se menor expressão de MHC-II na DMJ e distrofia, que não se diferenciaram, quando comparada a PM e DM, que também não se diferenciaram $(\mathrm{p}<0,001)$.

Os antígenos de histocompatibilidade foram inicialmente descritos e caracterizados em transplantes. A seguir, tornou-se claro que estas glicoproteinas desempenhavam papel importante na imunidade. As moléculas do complexo maior de histocompatibidade ligam-se aos antígenos e os apresentam aos linfócitos T. Os antígenos ligados às moléculas de classe I são normalmente reconhecidos por células $\mathrm{T}$ citotóxicas (CD8+) enquanto que os ligados à classe II são reconhecidos por células T helper (CD4+). Antígenos de classe I apresentam uma ampla distribuição tecidual, enquanto que os de classe II tem uma distribuição limitada, expressas basicamente nas células pertencentes ao sistema imune, consideradas apresentadoras de antígenos, como macrófagos, células $\mathrm{B}$, células dendríticas e células de Langerhans (HOHFELD e ENGEL, 1990).

Sob condições fisiológicas, fibras musculares maduras não expressam MHC-I ou II (ROWE et al, 1983; DAAR et al, 1984; ISENBERG et al, 1986; KARPATI et al, 1988; ZUK e FLETCHER, 1988; MCDOUALL et al, 1989; EMSLIE-SMITH et al, 1989; INUKAI et al, 2000; ENGLUND et al, 2001).

Estudos realizados em biópsias de miopatias inflamatórias “in vivo" e experimentos com culturas de mioblastos "in vitro" demonstraram que estas moléculas do MHC estão presentes em fragmentos patológicos ou induzidas em células musculares “in vitro” (NAGARAJU et al, 2000; MARINO et al, 2001). 
$\mathrm{Na}$ musculatura normal, células satélites rodeiam as fibras musculares. Quando acontece uma lesão, elas se transformam em células em regeneração que expressam MHC-I e II na sua superfície (BARTOCCIONI et al, 1994), possivelmente em resposta às citocinas que estão presentes no processo inflamatório. Mioblastos "in vitro" apresentam respostas semelhantes (HOHFELD e ENGEL, 1990; LUNDBERG, 2001).

A regulação da expressão muscular de MHC-I e II (KROEMER et al, 1991) pode decorrer da produção local de TNF-alfa e IFN-gama no infiltrado inflamatório. Estudos anteriores demonstraram que IFN-gama pode induzir mioblastos humanos “in vitro" a sintetizar MHC-II (HOHFELD e ENGEL, 1990; MANTEGAZZA et al, 1991; LINDBERG et al, 1995). Um relato de caso de uma paciente do sexo feminino que desenvolveu miosite como efeito colateral de tratamento com TNF-alfa fornece evidências que o TNF-alfa regule o MHC-I no tecido músculo-esquelético humano (HENGSTMAN et al, 2000)

A expressão de MHC-I foi observada nas fibras musculares de pacientes adultos portadores de miopatias inflamatórias (DM, PM e MCI) (ROWE et al, 1983; ISENBERG et al, 1986; KARPATI et al, 1988; MCDOUALL et al, 1989; EMSLIESMITH et al, 1989; KALOVIDOURUS, 1991; BARTOCCIONI et al, 1994; LINDBERG et al, 1995; FLADBY et al, 1997; ENGLUND et al, 2001), assim como na faixa etária pediátrica evidenciada na DMJ (EMSLIE-SMITH et al, 1989; MCDOUALL et al, 1989; TOPALOGLU et al, 1997; LI et al, 2004).

Poucos estudos avaliaram a expressão de MHC-I e II na DMJ. MCDOUALL em 1989, estudou 200 fragmentos musculares de pacientes com doenças musculares, sendo 23 casos de DMJ e observou intensa expressão de MHC-I e ausência de 
expressão de MHC-II, na DMJ, assim como nas outras miopatias inflamatórias (PM, DM e MCI) e distrofias musculares ligadas ao X.

Alguns estudos sugerem que MHC-I possa ser um marcador diagnóstico das MII. Observou-se na DMJ, uma maior expressão do MHC-I, na ausência de alterações histológicas (TOPALOGLU et al, 1997), nas fases iniciais da doença, anteriormente ao aparecimento do infiltrado inflamatório e da lesão muscular (LI et al, 2004), assim como nos adultos portadores de PM e DM que apresentavam fraqueza muscular e ausência de infiltrado inflamatório (ENGLUND et al, 2002). Nos ratos houve o desenvolvimento de características clínicas, bioquímicas e histológicas de PM, após regulação do MHC-I (NAGARAJU et al, 2000).

NYBERG et al (2000) também encontraram aumento da expressão de MHC-I em pacientes portadores de PM e DM que estavam sendo tratados com terapia imunossupressora, mas persistiam com fraqueza muscular.

KARPATI et al (1988), MCDOUALL et al (1989), EMSLIE-SMITH et al (1989) observaram que a expressão do MHC-I na DM, localizou-se na região perifascular e áreas com depleção capilar, podendo sugerir que a isquemia seja uma reação não especifica de estresse celular. Enquanto que na PM foi observada maior expressão nas fibras em regeneração (NYBERG et al, 2000).

VAN DER PAS et al (2004) estudaram 61 pacientes adultos portadores de MII e concluíram que a positividade de expressão do MHC-I apresenta uma sensibilidade de $78 \%$ e especificidade de $95 \%$ para este diagnóstico.

A expressão do MHC-II não está presente nas fibras musculares normais (DAAR et al, 1984; ENGLUND et al, 2001), em contraste com culturas de 
mioblastos (CIFUENTES-DIAZ et al, 1992) onde se observou a sua ação como célula apresentadora de antígeno (GOEBELS et al, 1992).

Os resultados da expressão de MHC-II foram bastante conflitantes nos diferentes estudos. Alguns autores (ROWE et al, 1983; OLSSON et al, 1985; BARTOCCIONI et al, 1994; LINDBERG et al, 1995; INUKAI et al, 2000; ENGLUND et al, 2001) detectaram o antígeno DR nas fibras musculares de pacientes com PM e DM. Achado não confirmado por outros pesquisadores (KARPATI et al, 1988; MCDOUALL et al, 1989). Quando a expressão de MHC II foi observada, os estudos mostraram resultados distintos, desde baixa expressão na PM, DM e MCI, localizada em fibras pequenas e em regeneração, até uma expressão em todos os casos de PM, localizada próxima ao infiltrado mononuclear (BARTOCCIONI et al, 1994; LINDBERG et al, 1995). NYBERG et al (2000) e ENGLUND et al (2001) relataram achados distintos quanto à diferença na expressão de MHC-I e II na PM e DM. A expressão nas distrofias musculares também apresentou resultados conflitantes (ROWE et al, 1983; APPLEYARD et al, 1985; ISENBERG et al, 1986; ZUK e FLETCHER, 1988; MCDOUALL et al, 1989; LINDBERG et al, 1995; ENGLUND et al, 2001), negativa ou positiva, localizada nas áreas adjacentes ao infiltrado inflamatório e / ou na evidência de dano da fibra muscular (ISENBERG et al, 1986), ou apenas nos vasos sanguíneos (LINDBERG et al, 1995).

Segundo WEDDERBURN e LI (2004), o valor da expressão do MHC-I e II na doença na faixa etária pediátrica é desconhecido, uma vez que a positividade destes marcadores é menor quando comparado com adultos. No presente estudo também observou-se uma tendência a maior expressão de MHC-I e II na PM e DM, quando comparado a DMJ. Talvez uma casuística maior na população adulta possa 
esclarecer se existe esta diferença. De qualquer modo, a positividade em 97,2\% dos casos foi relevante. Ampliando a nossa casuística para 46 casos de DMJ (dados ainda não publicados), observamos uma maior expressão de MHC-I nos pacientes com tempo de doença até a realização da biópsia menor que dois meses, enfatizando a importância do MHC-I como marcador diagnóstico e possivelmente contribuindo para o desenvolvimento da sintomatologia da DMJ.

Ainda não está definido como o MHC pode afetar a função muscular, mas é possível que a produção de grandes quantidades de MHC nas fibras musculares possa bloquear a produção de proteínas contráteis pelo retículo endoplasmático e afetar a força muscular (LUNDBERG, 2001).

\section{EXPRESSÃO DE C5b-9}

A expressão de C5b-9 esteve presente em 84\% dos casos, apresentando maior positividade nos vasos da região perimisial. Esta positividade correlacionou-se com o sexo feminino, fraqueza muscular, calcinose, comprometimento cardíaco e pulmonar, níveis séricos mais elevados de DHL e aldolase, presença de dissociação miofibrilar, fibras necróticas e em regeneração, inflamação endomisial e aumento do tecido conectivo na histologia muscular, e ainda a necessidade da utilização de duas outras medicações complementares a corticoterapia. A utilização de corticoterapia anteriormente à biópsia muscular não interferiu na positividade desta reação. Houve maior expressão nos vasos da região perimisial na DMJ quando comparado a PM, DM e distrofia. 
KISSEL (1991) confirmou que C5b-9 seria um evento precoce na fisiopatologia da DM, observando uma maior expressão de C5b-9, quanto menor o tempo de doença até a realização da biópsia muscular associada à presença de dissociação miofibrilar (alteração histológica observada inicialmente na evolução da lesão isquêmica da fibra muscular) e menor expressão nos fascículos com atrofia perifascicular.

BANKER e VICTOR (1966), BANKER (1974, 1975) descreveram a importância da microvasculatura, especialmente arteriolar, envolvendo a pele, trato gastrointestinal, SNC e musculatura. A lesão se inicia com edema endotelial nos capilares e pequenas arteríolas. Se o edema for intenso pode levar a obstrução mecânica do vaso, sendo a lesão final, a oclusão trombótica com subseqüente infarto da região adjacente. Estes achados sugerem que o endotélio seja o alvo para os anticorpos e/ou eventos celulares mediados. Trombose arteriolar foi observada ocasionalmente nos adultos, mas freqüentemente em crianças.

Em 1972, WHITAKER e ENGEL, encontraram depósitos granulares de imunoglobulinas e C3, isolados ou em combinação em 9 de 11 pacientes com DMJ e três de 12 com DM. Foi proposto que uma vasculopatia imune mediada fosse um importante mecanismo de dano muscular.

KISSEL et al (1986), observaram a expressão de C5b-9 em 10 de 12 pacientes com DMJ (83\%) e cinco de 19 (26\%) pacientes com DM. Na DMJ, a expressão localizou-se nas fibras musculares necróticas, arteríolas endomisiais e perimisiais e capilares. Na DM, a positividade foi observada apenas nos casos que apresentavam lesão isquêmica em fase inicial. Estes achados sugeriram um papel primário para C5b-9 no dano microvascular da DMJ e que nos pacientes adultos 
ocorreria ativação do complemento na fase inicial da doença, sendo este substituído no curso da doença por outro mecanismo imune.

Em 1987, SEWRY et al, já havia demonstrado a localização de C8 e C9 na superfície de fibras musculares necróticas e não necróticas e nos vasos sanguíneos na PM, DM e distrofia. Estes autores indicam que a ligação do complemento seja um evento inicial ao dano muscular, anterior a necrose, mas sugerindo que não seja específica da DM como relatado por KISSEL, 1991.

Por sua vez, EMSLIE-SMITH e ENGEL (1990), encontraram positividade ao C5b-9 em 10 de 10 pacientes com DM inicial e seis de sete com DM avançada, sugerindo que este marcador participa da DM tanto na fase inicial como avançada.

EMSLIE-SMITH e ENGEL (1990), também observaram depleção capilar na musculatura de pacientes com $\mathrm{DM}$ que não apresentavam fraqueza e não apresentavam alterações patológicas suficientes para o diagnóstico. $O$ fato da depleção capilar preceder a alteração estrutural e o aparecimento de inflamação confirma que os capilares sejam o alvo inicial na doença.

Enfatizando a diferença na fisiopatologia entre as MII (PM, DM e MCI), EMSLIE-SMITH e ENGEL (1990) não observaram depleção capilar na PM e MCI. Estes achados foram também confirmados por CASADEMONT (1990) e ESTRUCH et al (1992).

Conclui-se que a doença começa quando anticorpos na circulação ativam C3, formando $\mathrm{C} 3 \mathrm{~b}$ e $\mathrm{C} 4 \mathrm{~b}$, determinando a formação do C3bNEO e C5b-9, sendo ambos depositados na microvasculatura endomisial. O depósito do C5b-9 nos capilares provoca uma necrose destes, resultando em uma diminuição do seu número e dilatação dos restantes em uma tentativa de compensação da perfusão. Vasos de 
maior calibre também são afetados, levando a destruição da fibra muscular, microinfartos e inflamação. A atrofia perifascicular é um reflexo da hipoperfusão (DALAKAS，1991; DALAKAS，1995; LUNDBERG，2001; WARGULA，2003; DALAKAS, 2004).

O envolvimento dos vasos sanguíneos pode afetar a perfusão muscular levando a um distúrbio do metabolismo muscular que pode parcialmente explicar os sintomas clínicos. O papel dos vasos sanguíneos foi previamente explicado na DM. O estudo de pacientes com PM e MCI demonstrou células endoteliais que expressavam Il-1 $\alpha$ (LUNDBERG et al, 1997), localizadas em vasos de pequeno e médio calibre, em áreas com ou sem infiltrado inflamatório, indicando também envolvimento da microvasculatura no processo inflamatório da PM e MCI e não apenas da DM. Alterações fenotípicas dos capilares também foram evidentes em pacientes com PM e DM após três meses de corticoterapia, apesar da resolução do infiltrado inflamatório (LUNDBERG et al, 2000) e se correlacionaram com a persistência da diminuição da força muscular, não se observando a mesma correlação com o infiltrado inflamatório (LUNDBERG et al, 2001).

Corroborando a importância do complemento na patogênese da DMJ, GONÇALVES et al $(2002,2004)$ estudando a expressão de CD59, proteína que atua impedindo a formação do C5b-9, encontraram diminuição da expressão nos pacientes com DMJ, sugerindo que a ação do complemento esteja favorecida nesta doença.

No presente estudo, a observação da expressão de C5b-9 em 84\% dos casos, associada à maior positividade nos vasos da região perimisial, correlacionada às características clínicas (intensidade da fraqueza muscular, calcinose, comprometimento cardíaco e pulmonar, níveis séricos mais elevados de DHL e 
aldolase) e terapêuticas (necessidade da utilização de duas outras medicações, em adição a corticoterapia), sugestivas de pior prognóstico. Assim como, a correlação com as características histológicas iniciais e evolutivas (presença de dissociação miofibrilar, fibras necróticas e em regeneração, inflamação endomisial e aumento do tecido conecutivo) e ainda maior expressão nos vasos da região perimisial em comparação a PM, DM e distrofia; enfatizam a importância de C5b-9 na fisiopatologia da DMJ em todas as fases da doença e corroboram a diferença existente na fisiopatologia desta miopatia inflamatória.

A participação do complemento na DMJ é notória, contudo o mecanismo pelo qual este é ativado ainda é desconhecido. É Desconhecido se a ativação ocorre pela ligação do anticorpo ao componente microvascular (via clássica) ou se é resultado de uma alteração no componente celular vascular (via alternativa), ou ainda se a presença do C5b-9 está na forma de imunocomplexos formados no componente intravascular e depositado na parede do capilar (EMSLIE-SMITH e ENGEL, 1990; GREENBERG e AMATO, 2004).

A ativação e depósito do complemento é provavelmente responsável pela indução de citocinas que irão regular a expressão das moléculas de adesão ICAM-1 e VCAM-1 nas células endoteliais e facilitar a saída dos linfócitos ativados para os espaços endomisiais e perimisiais. Os resultados previamente publicados da presente casuística demonstraram uma maior expressão de ICAM-1 nas células endoteliais, particularmente de capilares, corroborando a participação preponderante do vaso na fisiopatologia da lesão muscular na DMJ (SALLUM et al, 2004). 


\section{CÉLULAS INFLAMATÓRIAS}

Aumento da expressão de MHC-I e II nas células musculares e células inflamatórias é um pré-requisito para apresentação do antígeno enfatizando o papel das células T nas MII.

Os linfócitos são componentes do infiltrado inflamatório das MII. Inicialmente, acreditou-se que fizessem parte de uma resposta inespecífica à lesão muscular. Atualmente está claro que participam da patogênese destas doenças (MASTAGLIA e CURRIE, 1971; NICK et al, 1971).

Neste estudo, a presença de linfócitos CD4 (81,1\% de positividade), CD8 (86,5\% de positividade), CD20 (62,2\% de positividade) e CD68 (97,2\% de positividade) correlacionaram-se com o grau de inflamação observada na histologia muscular. A presença de CD4 e CD68 também se correlacionaram com a intensidade de fraqueza muscular, e laboratorialmente, CD4 correlacionou-se com níveis elevados de CK e CD20 com DHL. Na DMJ observou-se maior expressão de CD4 e CD8 e tendência a menor expressão de CD68 em comparação à DM e PM. Não houve diferença quanto à expressão de CD20.

ENGEL e ARAHATA (1984) estudando a expressão das células inflamatórias nas miopatias inflamatórias, com uma casuística de seis casos de DMJ, sete DM, quinze PM e onze casos de distofia de Duchenne, observaram que, em cada doença e localização estudadas, as células T encontraram-se em maior número que as células $\mathrm{B}$ e macrófagos, exceto na região perivascular da DM, onde as células B foram encontradas em maior número. Células $\mathrm{T}$ estavam em maior porcentagem na região endomisial, células B na perivascular e macrófagos em porcentagens iguais nas diferentes regiões. 
Outros estudos, com casuísticas menores, avaliaram a expressão no tecido muscular de pacientes adultos portadores de MII e demostraram resultados divergentes: predomínio de células CD4 na PM não tratada (ROWE et al, 1983), predomínio de células CD8 e macrófagos na PM e DM (LEMOINE et al, 1986) e ainda, predomínio de linfócitos $\mathrm{B}$ e células CD4 nas regiões perimisial e perifascicular na DM, enquanto que na PM, o infiltrado era constituído de células CD8 (IANNONE et al, 1996).

Na PM e DM, macrófagos pró-inflamatórios CD68 positivos que expressam MRP8 e MRP14, invadem fibras musculares não necróticas juntamente com células T ativadas. Estes macrófagos purificados inibem a proliferação de mioblastos e induzem a apoptose, sendo portanto considerados miocitotóxicos (SEELINGER et al, 2003).

ROSTASY et al (2004) demonstraram que a DM e a PM apresentam um padrão característico de diferenciação e distribuição do macrófago. $\mathrm{Na} \mathrm{PM}$, ocorria uma ativação precoce do macrófago, localizada no endomísio e na DM, ativação tardia, localizada no perimísio. Demonstrou-se outrossim que o corticóide não interfere nesta expressão.

CHIU et al (1981), também relataram que o tratamento com corticóide não altera a distribuição das células T CD4 e CD8.

Quando analisada a expressão destas células no sangue periférico, a maioria dos estudos demonstrou diminuição dos linfócitos T na DM, PM e MCI, e aumento dos linfócitos B na DM (BEHAN e BEHAN, 1984; 1985; RAMIREZ et al, 1986; MILLER et al, 1990; KIKUCHI et al, 2001). No entanto, IYER et al (1983) não encontraram diferença na distribuição das células T em seis casos de PM e um caso de DMJ, quando comparado com controles normais e VIGUIER et al (2003) 
encontraram baixos níveis de células T (CD4 e CD8) e células B em pacientes com DM e diminuição destes níveis após introdução de corticoterapia.

$\mathrm{Na} \mathrm{DM}$, apesar do evidente infiltrado perivascular e perimisial de células $\mathrm{B}$ e células CD4, não está claro se células B intramusculares ou seus sucessores maduros, plasmoblastos e células plasmáticas, produzem imunoglobulinas ou apresentam antígenos ou se células CD4 vistas em associação, são células antígeno específicas e servem para ativar as células B. Enquanto que na PM e MCI, a identificação de subtipos de células $\mathrm{T}$ e análises moleculares dos receptores de células $\mathrm{T}$ auxiliaram no entendimento da especificidade antigênica da resposta (ENGEL e ARAHATA, 1984; VAN DER MEULEN et al, 2002; HOFBAUER et al, 2003; GREENBERG e AMATO, 2004).

No tecido muscular de pacientes com DMJ, BRESNAN et al (1986) observaram predomínio de células CD4 concomitante a diminuição do nível sérico de CD8 em dois casos com doença ativa, com normalização na remissão; MILLER et al (1987) encontraram menor relação CD4/CD8 em quatro de cinco casos que apresentavam doença com característica de maior gravidade e MCDOUALL et al (1990) estudando 21 casos de DMJ e 9 distrofias, relataram predomínio de células CD4 e macrófagos nas duas doenças.

$\mathrm{Na}$ análise do sangue periférico, em pacientes com DMJ em atividade da doença, foi observado diminuição do número total de linfócitos e aumento da porcentagem de células B (O'GORMAN et al, 1995) e correlação da atividade da doença com a porcentagem de células B e ausência de correlação com células CD4 e CD8 (PACHMAN, 1994; EISENSTEIN et al, 1997). Enquanto que ISHIDA et al (1993) não demonstraram diferença na doença ativa ou não. 
Embora o infiltrado inflamatório seja característico das MII, os resultados destes estudos anteriores sugerem que exista etiologia e mecanismos patogênicos específicos para cada subgrupo (PM, DM e MCI).

As características histopatológicas da PM e MCI evidenciam que as fibras musculares são rodeadas, invadidas e destruídas por células inflamatórias mononucleares. A maioria destas células são linfócitos T, maioria $\mathrm{CD} 8+$, fenótipo MHC-I, falando a favor de um processo citotóxico mediado por célula T. Na DM, especialmente na DMJ, a reação inflamatória celular parece ser menos importante.

O significado e a correlação clínica do infiltrado inflamatório na DMJ ainda necessitam ser estabelecidos (WEDDERBURN e LI, 2004). No presente estudo, observou-se presença de CD4 e CD8 preponderantes nas regiões endomisial e perimisial, onde se correlacionaram com a expressão de C5b-9 e, interessantemente, a presença de CD4, à marcação de MHC tanto de classe I como II e ICAM-1. A presença e distribuição dos macrófagos foi paralela à distribuição de CD4 e CD8. Por outro lado, a quantidade de células CD20 foi menor e a sua distribuição foi pouco específica. Conjuntamente os achados permitem sugerir que apesar do vaso apresentar papel preponderante no mecanismo fisiopatológico da DMJ, a lesão na fibra muscular envolve a expressão de moléculas MHC nestas fibras particularmente de classe I e atração de linfócitos CD4 e CD8 mediando imunopatogenia celular.

A análise da expressão destes diferentes marcadores celulares inflamatórios, de fibra muscular e endotelial permite especular uma seqüência de eventos imunopatológicos na DMJ. Dois eventos iniciais importantes cuja seqüência ainda não está clara.

A formação do complexo C5b-9 atravessa a parede das células endoteliais e este depósito leva a destruição e redução do número de capilares resultando em 
isquemia que se traduz morfologicamente pela presença de atrofia perifascicular. Há ativação de molécula de adesão, particularmente de ICAM-1 nos capilares, que facilita a migração de linfócitos T, B e macrófagos. Nota-se predomínio de células T (CD4 e CD8) na região endomisial.

Por outro lado, a expressão de MHC classe I nas fibras musculares, a ativação e atração de células inflamatórias citotóxicas e macrófagos para adicionalmente promover o dano muscular.

Além da necessidade de se diferenciar a cronologia precisa destas ativações, igualmente importante é a determinação do papel de imuno-efetores e moduladores concomitantemente a estes mecanismos.

O modelo animal singênico (NAGARAJU et al, 2000) e a metodologia de análise de expressão gênica em larga escala por "microarrays" (HAN et al, 2003; SANOUDOU et al, 2004; GREENBERG et al, 2005) permitirão reconhecer outros parâmetros envolvidos neste complexo mecanismo etiopatogênico e definir novos fatores preditivos de evolução, prognóstico e alvos terapêuticos para esta doença.

Apesar dos números não comparáveis das casuísticas, os resultados deste estudo apontam para a participação preferencial da imunidade celular na PM, humoral na DM e de ambos os sistemas imunes na DMJ.

Diferenças de expressão de MHC-I e II, C5b-9, CD4, CD8 e CD68 na DMJ, DM e PM, sugere a participação das imunidades celular e humoral em proporções distintas na fisiopatologia da doença na faixa etária pediátrica (DMJ) e no adulto (PM e DM).

Em relação a DMJ, a alta freqüência de MHC-I, C5b-9, CD4, CD8 e CD68, poderão possibilitar a utilização destes parâmetros para elaboração de um escore para determinação de gravidade da doença, fator preditivo de prognóstico e portanto demanda terapêutica. 
1. O infiltrado inflamatório na DMJ foi constituído predominantemente de linfócitos CD8 (86\%) e CD4 (81\%). E em menor quantidade de linfócitos CD20 (62\%). Infiltrado de macrófagos (CD68) foi evidenciado em 97\% dos casos.

2. A expressão do complexo de ataque à membrana (C5b-9) foi observada em $84 \%$ dos casos e a expressão de MHC-I e II foi evidenciada em 97\% e 22\%, respectivamente.

3. Na DMJ observou-se maior expressão de C5b-9, CD4 e CD8 e menor expressão de MHC-I e II em comparação à DM e PM. A expressão destes marcadores foi sempre menor na distrofia.

4. Houve correlação da expressão de MHC-II, C5b-9, CD4 e CD20 com níveis séricos das enzimas musculares (CK, aldolase e DHL) e com alterações histológicas correspondentes à intensidade da lesão muscular e da atividade inflamatória no músculo com C5b-9, CD4, CD8, CD20 e CD68.

5. Houve correlação da marcação de ICAM-1 com presença de células CD4.

6. A análise conjunta dos marcadores no presente estudo permite concluir:

a. Diferenças de expressão de MHC-I e II, C5b9, CD4, CD8, CD68 na DMJ, DM e PM, sugeriu a participação das imunidades celular e humoral em proporções distintas na fisiopatologia da doença na faixa etária pediátrica (DMJ) e na doença do adulto (DM e PM). 
b. Alta positividade de expressão de MHC-I, C5b9, CD4, CD8 e CD68, a correlação destes marcadores entre si e com ICAM-1, e a correlação com características clínicas, laboratoriais, histológicas e terapêuticas, ressaltaram a participação destes marcadores no mecanismo fisiopatológico da DMJ.

c. A correlação da expressão de CD4, CD8, CD20 e CD68 com características histológicas indicou que possam ser considerados marcadores diagnósticos da DMJ.

d. A correlação da expressão de C5b-9 com várias características clínicas, laboratoriais, histológicas e terapêuticas, especialmente características de pior prognóstico (presença de calcinose, comprometimento cardíaco e pulmonar, necessidade da utilização de corticoterapia associada a 2 ou mais medicações), sugeriu que possa ser considerado marcador prognóstico da DMJ.

e. Apesar da baixa positividade de expressão de CD20 e MHC-II, a correlação com características clínicas, laboratoriais, histológicas e terapêuticas da doença, sugeriu a participação no mecanismo fisiopatológico da DMJ. 


\section{Anexo 1}

\begin{tabular}{|c|c|c|c|c|c|}
\hline \multicolumn{6}{|c|}{ DADOS DOS PACIENTES } \\
\hline No & NOME & REGISTRO & BIÓPSIA & SEXO & $\begin{array}{c}\text { DATA DE } \\
\text { NASCIMENTO }\end{array}$ \\
\hline 1 & C.C.L. & $6057266 \mathrm{i}$ & 1756 & Fem & $17 / 5 / 1989$ \\
\hline 2 & A.S.O. & $6036649 \mathrm{~b}$ & 1767 & Masc & $02 / 07 / 88$ \\
\hline 3 & G.S.S. & $6058615 d$ & 1784 & Fem & $15 / 11 / 98$ \\
\hline 4 & N.P.S. & $3135018 c$ & 1811 & Fem & $20 / 10 / 86$ \\
\hline 5 & A.S.O. & $6036649 \mathrm{~b}$ & 1878 & Masc & 02/07/88 \\
\hline 6 & N.L.G.N. & $3192701 \mathrm{~h}$ & 1903 & Fem & $28 / 04 / 93$ \\
\hline 7 & L.F.L. & $6066270 \mathrm{k}$ & 1904 & Fem & $27 / 09 / 87$ \\
\hline 8 & J.F.X. & $6042905 i$ & 1915 & Masc & $23 / 11 / 84$ \\
\hline 9 & P.U.C. & $3212999 f$ & 1937 & Fem & $09 / 02 / 93$ \\
\hline 10 & S.T.S.P. & $6069552 \mathrm{j}$ & 1972 & Masc & $05 / 03 / 96$ \\
\hline 11 & B.J.C. & $3228079^{a}$ & 1980 & Fem & $17 / 04 / 92$ \\
\hline 12 & J.D.S. & $6070110 b$ & 1993 & Masc & $20 / 09 / 84$ \\
\hline 13 & E.O.P. & $3232947 k$ & 1997 & Fem & $15 / 03 / 92$ \\
\hline 14 & P.U.C. & $3212999 f$ & 2033 & Fem & $09 / 02 / 93$ \\
\hline 15 & C.S.F. & $3257496 b$ & 2088 & Fem & $22 / 02 / 94$ \\
\hline 16 & T.B.P. & $3240378 \mathrm{~g}$ & 2106 & Fem & $23 / 03 / 89$ \\
\hline 17 & P.H.S.S. & $6074215 f$ & 2116 & Masc & $22 / 04 / 91$ \\
\hline 18 & B.N.V. & $6074684 c$ & 2127 & Fem & 04/07/98 \\
\hline 19 & A.C.M. & $6074319 i$ & 2135 & Fem & $22 / 10 / 89$ \\
\hline 20 & J.F.S. & $6075439 \mathrm{e}$ & 2146 & Fem & $12 / 03 / 90$ \\
\hline 21 & A.O.F. & $6074765 d$ & 2152 & Fem & $30 / 10 / 90$ \\
\hline 22 & S.R.B. & $6075747 c$ & 2158 & Fem & $24 / 12 / 89$ \\
\hline 23 & S.L.B.O. & $6076033 \mathrm{k}$ & 2162 & Fem & $30 / 01 / 91$ \\
\hline 24 & C.R.S. & $6076199 \mathrm{e}$ & 2165 & Fem & $28 / 05 / 97$ \\
\hline 25 & C.M.S. & $6077628 b$ & 2198 & Fem & $24 / 11 / 88$ \\
\hline 26 & T.A.S. & $6080618^{a}$ & 2225 & Fem & $11 / 09 / 92$ \\
\hline 27 & M.S.O. & $6079062 j$ & 2229 & Fem & $03 / 02 / 91$ \\
\hline 28 & C.C. & $6083227 \mathrm{k}$ & 2243 & Fem & $17 / 10 / 93$ \\
\hline 29 & G.O.B. & $6081693 \mathrm{j}$ & 2255 & Masc & $20 / 03 / 97$ \\
\hline 30 & L.N.A. & $3307816 \mathrm{k}$ & 2265 & Masc & $06 / 12 / 84$ \\
\hline 31 & P.B.S. & 690897SC & 2283 & Fem & $06 / 05 / 91$ \\
\hline 32 & S.A.S. & $6090329 c$ & 2286 & Fem & $20 / 10 / 90$ \\
\hline 33 & J.A.B.S. & SC & 2291 & Fem & $28 / 03 / 86$ \\
\hline 34 & M.J.C.S. & SC & 2362 & Masc & $01 / 11 / 92$ \\
\hline 35 & C.R.S. & SC & 2370 & Fem & $12 / 01 / 88$ \\
\hline 36 & B.T.N.P. & SC & 2395 & Fem & $24 / 11 / 93$ \\
\hline 37 & R.C.S. & SC & 2414 & Masc & $08 / 07 / 96$ \\
\hline
\end{tabular}


Anexo 2

\section{PROTOCOLO}

\section{IDENTIFICAÇÃO}

Nome:

Registro:

Endereço:

Telefone:

Raça:

Sexo:

Idade:

Data de nascimento:

\section{CRONOLOGIA}

Data do início dos sintomas:

Data do início do tratamento:

Data do início do acompanhamento :

\section{CRITÉRIOS DIAGNÓSTICOS DE DM/PM}

Fraqueza muscular proximal

Aumento de enzimas musculares: $\mathrm{CPK}$

Aldolase

TGO

TGP

Eletromiografia:

DHL

Biópsia muscular:

Lesões cutâneas: Heliotropo

Gottron

\section{SINTOMATOLOGIA}

Queixa principal:

HPMA: 
EXAME FÍSICO

Força muscular: grau

Lesões cutâneas:

Vasculites:

Outros:

\section{COMPROMETIMENTO DE OUTROS ÓRGÃOS E SISTEMAS}

Coração:

Pulmão:

Osteoarticular:

Ocular:

Gastro-

intestinal:

Outros:

TRATAMENTO

RESULTADO

DOSE PERÍODO

Prednisona

Ciclosporina

Ciclofosfamida

Metotrexato

Outros

\section{LABORATÓRIO}

Hemograma:

VHS:

FAN:

PCR: anti-DNA:

Jo-1:

Complemento:

Enzimas musculares:
Ro:

La:

Sc1-70:

FR:

Fator VIII: 
EXAMES COMPLEMENTARES

RX:

ECO:

MAPEAMENTO:

PROVA FUNÇÃO PULMONAR:

OUTROS:

BIÓPSIA

ELETRONEUROMIOGRAFIA 
Anexo 3: Análise quantitativa de CD4, CD8 e CD20 na DMJ

\begin{tabular}{|c|c|c|c|c|c|c|c|c|c|c|c|c|c|c|c|}
\hline \multirow[b]{2}{*}{ Caso } & \multicolumn{5}{|c|}{ CD4 } & \multicolumn{5}{|c|}{ CD8 } & \multicolumn{5}{|c|}{ CD20 } \\
\hline & $\begin{array}{l}\text { Endo- } \\
\text { misial }\end{array}$ & $\begin{array}{l}\text { Peri- } \\
\text { misial }\end{array}$ & $\begin{array}{c}\text { Peri- } \\
\text { vascular } \\
\text { endomisial }\end{array}$ & $\begin{array}{c}\text { Peri- } \\
\text { vascular } \\
\text { perimisial }\end{array}$ & Total & $\begin{array}{l}\text { Endo- } \\
\text { misial }\end{array}$ & $\begin{array}{l}\text { Peri- } \\
\text { misial }\end{array}$ & $\begin{array}{c}\text { Peri- } \\
\text { vascular } \\
\text { endomisial }\end{array}$ & $\begin{array}{c}\text { Peri- } \\
\text { vascular } \\
\text { perimisial }\end{array}$ & Total & $\begin{array}{l}\text { Endo- } \\
\text { misial }\end{array}$ & $\begin{array}{l}\text { Peri- } \\
\text { misial }\end{array}$ & $\begin{array}{c}\text { Peri- } \\
\text { vascular } \\
\text { endomisial }\end{array}$ & $\begin{array}{c}\text { Peri- } \\
\text { vascular } \\
\text { perimisial }\end{array}$ & Total \\
\hline 1756 & 1 & 3 & 1 & 0 & 5 & 6 & 8 & 0 & 0 & 14 & 6 & 0 & 0 & 0 & 6 \\
\hline 1767 & 0 & 2 & 0 & 0 & 2 & 0 & 27 & 0 & 0 & 27 & 3 & 0 & 0 & 0 & 3 \\
\hline 1784 & 15 & 5 & 87 & 265 & 372 & 184 & 0 & 0 & 153 & 337 & 16 & 0 & 6 & 0 & 22 \\
\hline 1811 & 120 & 49 & 10 & 5 & 184 & 104 & 2 & 0 & 0 & 106 & 5 & 21 & 0 & 48 & 74 \\
\hline 1878 & 6 & 3 & 2 & 1 & 12 & 3 & 0 & 3 & 0 & 6 & 3 & 0 & 9 & 0 & 12 \\
\hline 1903 & 134 & 8 & 0 & 0 & 142 & 0 & 0 & 0 & 0 & 0 & 1 & 0 & 0 & 0 & 1 \\
\hline 1904 & 0 & 2 & 0 & 2 & 4 & 4 & 0 & 0 & 0 & 4 & 0 & 0 & 0 & 0 & 0 \\
\hline 1915 & 12 & 1 & 0 & 0 & 13 & 23 & 0 & 0 & 0 & 23 & 0 & 0 & 0 & 0 & 0 \\
\hline 1937 & 110 & 123 & 3 & 3 & 239 & 20 & 3 & 5 & 1 & 29 & 0 & 0 & 0 & 0 & 0 \\
\hline 1972 & 4 & 6 & 3 & 6 & 19 & 8 & 3 & 1 & 0 & 12 & 0 & 2 & 0 & 2 & 4 \\
\hline 1980 & 2 & 5 & 1 & 2 & 10 & 44 & 3 & 4 & 1 & 52 & 2 & 0 & 0 & 0 & 2 \\
\hline 1993 & 9 & 4 & 2 & 1 & 16 & 4 & 17 & 0 & 0 & 21 & 1 & 3 & 2 & 2 & 8 \\
\hline 1997 & 6 & 0 & 0 & 0 & 6 & 20 & 0 & 0 & 0 & 20 & 0 & 0 & 0 & 0 & 0 \\
\hline 2033 & 2 & 0 & 0 & 0 & 2 & 0 & 0 & 0 & 0 & 0 & 1 & 0 & 0 & 0 & 1 \\
\hline 2088 & 11 & 0 & 0 & 0 & 11 & 17 & 8 & 2 & 1 & 28 & 3 & 0 & 0 & 29 & 32 \\
\hline 2106 & 3 & 4 & 0 & 0 & 7 & 4 & 0 & 6 & 0 & 10 & 1 & 0 & 0 & 0 & 1 \\
\hline 2116 & 73 & 164 & 20 & 36 & 293 & 100 & 49 & 40 & 18 & 207 & 1 & 0 & 0 & 0 & 1 \\
\hline 2127 & 33 & 27 & 2 & 3 & 65 & 21 & 0 & 10 & 0 & 31 & 0 & 0 & 0 & 0 & 0 \\
\hline 2135 & 2 & 1 & 0 & 1 & 4 & 9 & 0 & 3 & 3 & 15 & 0 & 0 & 0 & 0 & 0 \\
\hline 2146 & 3 & 5 & 0 & 0 & 8 & 0 & 0 & 0 & 0 & 0 & 0 & 0 & 0 & 0 & 0 \\
\hline 2152 & 0 & 0 & 0 & 0 & 0 & 0 & 0 & 0 & 0 & 0 & 0 & 0 & 0 & 0 & 0 \\
\hline 2158 & 10 & 6 & 2 & 1 & 19 & 16 & 8 & 3 & 1 & 28 & 1 & 0 & 1 & 0 & 2 \\
\hline 2162 & 27 & 23 & 5 & 3 & 58 & 10 & 9 & 0 & 0 & 19 & 1 & 0 & 0 & 0 & 1 \\
\hline 2165 & 0 & 0 & 0 & 0 & 0 & 18 & 8 & 1 & 36 & 63 & 1 & 0 & 1 & 0 & 2 \\
\hline 2198 & 0 & 5 & 0 & 0 & 5 & 15 & 10 & 7 & 1 & 33 & 2 & 0 & 2 & 0 & 4 \\
\hline 2225 & 15 & 6 & 0 & 0 & 21 & 0 & 0 & 0 & 0 & 0 & 0 & 0 & 0 & 0 & 0 \\
\hline 2229 & 33 & 209 & 6 & 45 & 293 & 15 & 50 & 10 & 13 & 88 & 3 & 0 & 9 & 0 & 12 \\
\hline 2243 & 20 & 11 & 6 & 4 & 41 & 39 & 9 & 16 & 4 & 68 & 4 & 0 & 4 & 0 & 8 \\
\hline 2255 & 0 & 0 & 0 & 0 & 0 & 20 & 5 & 14 & 4 & 43 & 1 & 10 & 1 & 5 & 17 \\
\hline 2265 & 0 & 1 & 0 & 0 & 1 & 0 & 8 & 0 & 1 & 9 & 0 & 0 & 0 & 0 & 0 \\
\hline
\end{tabular}




\begin{tabular}{|c|c|c|c|c|c|c|c|c|c|c|c|c|c|c|c|}
\hline \multirow[b]{2}{*}{ Caso } & \multicolumn{5}{|c|}{ CD4 } & \multicolumn{5}{|c|}{ CD8 } & \multicolumn{5}{|c|}{ CD20 } \\
\hline & $\begin{array}{l}\text { Endo- } \\
\text { misial }\end{array}$ & $\begin{array}{l}\text { Peri- } \\
\text { misial }\end{array}$ & $\begin{array}{c}\text { Peri- } \\
\text { vascular } \\
\text { endomisial }\end{array}$ & $\begin{array}{c}\text { Peri- } \\
\text { vascular } \\
\text { perimisial }\end{array}$ & Total & $\begin{array}{l}\text { Endo- } \\
\text { misial }\end{array}$ & $\begin{array}{l}\text { Peri- } \\
\text { misial }\end{array}$ & $\begin{array}{c}\text { Peri- } \\
\text { vascular } \\
\text { endomisial }\end{array}$ & $\begin{array}{c}\text { Peri- } \\
\text { vascular } \\
\text { perimisial }\end{array}$ & Total & $\begin{array}{l}\text { Endo- } \\
\text { misial }\end{array}$ & $\begin{array}{l}\text { Peri- } \\
\text { misial }\end{array}$ & $\begin{array}{c}\text { Peri- } \\
\text { vascular } \\
\text { endomisial }\end{array}$ & $\begin{array}{c}\text { Peri- } \\
\text { vascular } \\
\text { perimisial }\end{array}$ & Total \\
\hline 2283 & 6 & 0 & 0 & 0 & 6 & 1 & 0 & 2 & 0 & 3 & 0 & 0 & 0 & 0 & 0 \\
\hline 2286 & 4 & 0 & 6 & 0 & 10 & 5 & 0 & 0 & 0 & 5 & 0 & 0 & 0 & 0 & 0 \\
\hline 2291 & 149 & 18 & 150 & 17 & 334 & 6 & 16 & 1 & 5 & 28 & 1 & 0 & 0 & 0 & 1 \\
\hline 2362 & 0 & 0 & 0 & 0 & 0 & 36 & 3 & 0 & 0 & 39 & 0 & 0 & 0 & 0 & 0 \\
\hline 2370 & 0 & 0 & 0 & 0 & 0 & 7 & 0 & 0 & 0 & 7 & 0 & 0 & 0 & 0 & 0 \\
\hline 2395 & 0 & 0 & 0 & 0 & 0 & 17 & 0 & 0 & 0 & 17 & 4 & 0 & 0 & 0 & 4 \\
\hline 2414 & 0 & 0 & 0 & 0 & 0 & 1 & 0 & 0 & 0 & 1 & 2 & 0 & 0 & 0 & 2 \\
\hline
\end{tabular}


Anexo 4: Análise semi-quantitativa de CD68, MHC-I e II, C5b-9, ICAM-1 e VCAM-1 na DMJ

\begin{tabular}{|c|c|c|c|c|c|c|c|c|c|c|c|c|c|c|c|c|c|c|}
\hline \multirow[b]{2}{*}{ Caso } & \multicolumn{4}{|c|}{ CD68 } & \multirow{2}{*}{$\begin{array}{l}\text { MHC-I } \\
\text { Fibra } \\
\end{array}$} & \multirow{2}{*}{$\begin{array}{c}\text { MHC- II } \\
\text { Fibra } \\
\end{array}$} & \multicolumn{4}{|c|}{ C5b-9 } & \multicolumn{4}{|c|}{ ICAM-1 } & \multicolumn{4}{|c|}{ VCAM-1 } \\
\hline & $\begin{array}{l}\text { Endo- } \\
\text { misial }\end{array}$ & $\begin{array}{l}\text { Peri- } \\
\text { misial }\end{array}$ & $\begin{array}{c}\text { Perivascular } \\
\text { endomisial }\end{array}$ & $\begin{array}{l}\text { Perivascula } \\
\text { r perimisial }\end{array}$ & & & $\begin{array}{l}\text { Vaso } \\
\text { endo- } \\
\text { misial }\end{array}$ & Capilar & $\begin{array}{c}\text { Vaso } \\
\text { peri- } \\
\text { misial }\end{array}$ & Fibra & $\begin{array}{l}\text { Vaso } \\
\text { endo- } \\
\text { misial }\end{array}$ & Capilar & $\begin{array}{c}\text { Vaso } \\
\text { peri- } \\
\text { misial }\end{array}$ & Fibra & $\begin{array}{l}\text { Vaso } \\
\text { endo- } \\
\text { misial }\end{array}$ & Capilar & $\begin{array}{c}\text { Vaso } \\
\text { peri- } \\
\text { misial } \\
\end{array}$ & Fibra \\
\hline 1756 & + & - & - & + & - & - & ++ & ++ & ++++ & - & ++ & +++ & + & - & - & - & - & - \\
\hline 1767 & - & - & - & + & +++ & - & + & + & +++ & - & + & ++ & ++ & - & - & - & - & - \\
\hline 1784 & - & ++ & - & ++ & ++++ & ++++ & - & - & + & - & - & ++ & + & - & - & - & - & - \\
\hline 1811 & +++ & + & + & ++ & ++ & + & + & + & ++++ & + & - & ++ & + & - & - & - & - & - \\
\hline 1878 & - & - & - & + & + & - & + & - & ++++ & - & + & ++ & ++ & - & - & - & - & - \\
\hline 1903 & - & ++ & - & + & + & - & - & - & ++++ & - & ++ & ++ & ++ & - & - & - & - & - \\
\hline 1904 & + & ++ & - & ++ & + & ++ & ++ & +++ & +++ & + & - & + & - & - & - & - & + & - \\
\hline 1915 & - & - & - & + & + & - & ++ & ++ & + & - & + & + & ++ & + & + & - & - & - \\
\hline 1937 & + & + & - & + & + & + & - & - & - & - & + & + & + & - & - & + & - & + \\
\hline 1972 & + & + & - & + & ++ & - & +++ & +++ & ++++ & - & - & - & ++ & - & - & - & - & - \\
\hline 1980 & + & + & - & + & + & - & - & ++ & - & + & ++ & +++ & ++ & - & - & - & - & - \\
\hline 1993 & - & + & - & + & + & - & + & + & - & + & + & + & ++ & - & - & - & - & - \\
\hline 1997 & + & + & - & + & + & - & + & - & ++++ & + & + & ++ & ++ & - & - & - & - & - \\
\hline 2033 & - & + & - & + & + & - & - & - & - & - & ++ & +++ & + & +++ & - & - & - & - \\
\hline 2088 & - & + & - & + & ++ & + & ++ & ++ & +++ & + & + & ++ & ++ & - & - & - & - & - \\
\hline 2106 & - & - & - & + & + & - & - & - & +++ & - & + & ++ & + & - & - & - & - & - \\
\hline 2116 & + & ++ & - & + & ++++ & - & ++ & +++ & +++ & + & + & ++ & ++ & - & - & - & + & - \\
\hline 2127 & ++ & - & - & - & + & + & + & - & + & + & + & + & + & - & - & - & - & + \\
\hline 2135 & - & - & - & + & ++ & - & + & + & +++ & + & + & ++ & ++ & - & - & - & + & - \\
\hline 2146 & - & + & - & + & + & - & + & - & ++ & + & ++ & ++ & + & - & - & + & - & - \\
\hline 2152 & - & - & - & - & +++ & - & + & - & + & - & + & + & ++ & - & - & - & + & - \\
\hline 2158 & - & + & - & + & ++ & - & - & +++ & + & + & - & + & + & - & - & - & + & - \\
\hline 2162 & + & + & - & + & ++++ & - & ++ & + & + & + & + & + & ++ & - & - & - & + & - \\
\hline 2165 & + & + & - & + & + & - & + & +++ & + & - & ++ & +++ & ++ & - & - & - & - & - \\
\hline 2198 & - & + & - & + & +++ & - & + & +++ & ++ & ++ & ++ & ++ & ++ & - & - & - & - & - \\
\hline 2225 & - & + & - & + & ++ & - & - & - & - & - & ++ & + & + & - & - & - & - & - \\
\hline 2229 & + & + & - & + & ++ & + & - & - & - & - & ++ & + & - & - & + & - & + & - \\
\hline 2243 & +++ & + & - & + & ++++ & - & + & ++ & ++ & + & + & + & + & - & - & - & - & - \\
\hline 2255 & + & ++ & - & ++ & ++ & - & + & + & ++ & + & ++ & + & ++ & - & - & - & - & - \\
\hline
\end{tabular}




\begin{tabular}{|c|c|c|c|c|c|c|c|c|c|c|c|c|c|c|c|c|c|c|}
\hline \multirow[b]{3}{*}{ Caso } & \multirow{2}{*}{\multicolumn{4}{|c|}{ CD68 }} & \multirow{3}{*}{$\begin{array}{l}\text { MHC-I } \\
\text { Fibra } \\
\end{array}$} & \multirow{3}{*}{$\begin{array}{c}\text { MHC- II } \\
\text { Fibra } \\
\end{array}$} & & & & & & & & & \multicolumn{4}{|c|}{ Continuação Anexo 4} \\
\hline & & & & & & & \multicolumn{4}{|c|}{ C5b-9 } & \multicolumn{4}{|c|}{ ICAM-1 } & & $\mathrm{VCA}$ & & \\
\hline & $\begin{array}{l}\text { Endo- } \\
\text { misial }\end{array}$ & $\begin{array}{l}\text { Peri- } \\
\text { misial }\end{array}$ & $\begin{array}{l}\text { Perivascular } \\
\text { endomisial }\end{array}$ & $\begin{array}{l}\text { Perivascula } \\
\text { r perimisial }\end{array}$ & & & $\begin{array}{l}\text { Vaso } \\
\text { endo- } \\
\text { misial }\end{array}$ & Capilar & $\begin{array}{l}\text { Vaso } \\
\text { peri- } \\
\text { misial }\end{array}$ & Fibra & $\begin{array}{l}\text { Vaso } \\
\text { endo- } \\
\text { misial }\end{array}$ & Capilar & $\begin{array}{l}\text { Vaso } \\
\text { peri- } \\
\text { misial }\end{array}$ & Fibra & $\begin{array}{l}\text { Vaso } \\
\text { endo- } \\
\text { misial }\end{array}$ & Capilar & $\begin{array}{l}\text { Vaso } \\
\text { peri- } \\
\text { misial }\end{array}$ & Fibra \\
\hline 2265 & - & + & - & + & + & - & + & - & - & - & + & +++ & ++ & - & - & - & - & - \\
\hline 2283 & - & + & - & + & + & - & - & - & - & - & + & +++ & +++ & - & - & - & - & - \\
\hline 2286 & + & + & - & + & ++ & - & - & - & - & - & - & + & + & - & - & - & - & - \\
\hline 2291 & - & + & + & ++ & +++ & + & - & - & ++++ & + & - & - & - & - & - & - & - & - \\
\hline 2362 & + & - & - & - & ++++ & - & + & ++ & + & ++ & + & +++ & ++ & - & - & - & - & - \\
\hline 2370 & ++ & ++ & - & ++ & + & - & + & + & + & + & + & ++ & ++ & - & - & - & - & - \\
\hline 2395 & ++ & ++ & - & ++ & + & - & - & - & + & - & + & +++ & ++ & - & - & - & + & - \\
\hline 2414 & + & ++ & - & ++ & + & - & ++ & - & ++ & - & + & ++ & + & - & - & - & - & - \\
\hline
\end{tabular}


Anexo 5: Análise quantitativa de CD4, CD8 e CD20 na DM, PM e distrofia

\begin{tabular}{|c|c|c|c|c|c|c|c|c|c|c|c|c|c|}
\hline & & \multicolumn{4}{|c|}{ CD4 } & \multicolumn{4}{|c|}{ CD8 } & \multicolumn{4}{|c|}{ CD20 } \\
\hline & Caso & Endomisial & Perimisial & $\begin{array}{c}\text { Perivascular } \\
\text { endomisial }\end{array}$ & $\begin{array}{c}\text { Perivascular } \\
\text { perimisial }\end{array}$ & Endomisial & Perimisial & $\begin{array}{c}\text { Perivascular } \\
\text { endomisial }\end{array}$ & $\begin{array}{c}\text { Perivascular } \\
\text { perimisial }\end{array}$ & Endomisial & Perimisial & $\begin{array}{c}\text { Perivascular } \\
\text { endomisial }\end{array}$ & $\begin{array}{l}\text { Perivascular } \\
\text { perimisial }\end{array}$ \\
\hline \multirow{8}{*}{ PM } & 1598 & 11 & - & - & - & - & - & - & - & 2 & - & - & 45 \\
\hline & 1944 & 13 & - & - & - & - & - & - & - & - & - & - & - \\
\hline & 1948 & 61 & - & - & - & 54 & - & 5 & - & 5 & - & 28 & - \\
\hline & 2091 & 115 & - & 2 & - & 224 & - & 22 & - & - & - & 7 & 5 \\
\hline & 2140 & - & - & - & - & 33 & 10 & 2 & - & - & - & - & - \\
\hline & 2213 & 9 & - & - & - & 17 & - & - & - & - & - & - & - \\
\hline & 2222 & 97 & - & - & - & 277 & - & 6 & - & 63 & - & - & - \\
\hline & 2224 & 17 & - & 4 & 3 & 26 & - & 6 & - & 2 & - & - & - \\
\hline \multirow{5}{*}{ DM } & 1685 & 92 & - & 13 & - & 50 & - & - & 35 & 1 & - & - & 16 \\
\hline & 1794 & 3 & - & - & - & - & - & - & - & - & - & - & - \\
\hline & 2072 & 5 & - & - & - & - & - & - & - & - & - & - & - \\
\hline & 2178 & 18 & - & - & - & 28 & - & - & - & - & - & - & - \\
\hline & 2258 & 4 & - & 14 & - & 185 & - & 53 & - & 69 & - & 13 & - \\
\hline \multirow{4}{*}{ Distrofia } & 1902 & - & - & - & - & - & - & - & - & - & - & - & - \\
\hline & 2081 & 9 & - & - & - & 2 & - & - & - & - & - & - & - \\
\hline & 2123 & 64 & - & 14 & 23 & 83 & - & 35 & - & 8 & - & - & - \\
\hline & 2228 & - & - & - & - & - & - & - & - & - & - & - & - \\
\hline
\end{tabular}


Anexo 6: Análise semi-quantitativa de CD68, C5b-9, MHC-I e II na DM, PM e distrofia

\begin{tabular}{|c|c|c|c|c|c|c|c|c|c|c|c|}
\hline & & \multicolumn{4}{|c|}{ CD68 } & \multicolumn{4}{|c|}{ C5b-9 } & \multirow{2}{*}{$\frac{\text { MHC-I }}{\text { Fibra }}$} & \multirow{2}{*}{$\frac{\text { MHC-II }}{\text { Fibra }}$} \\
\hline & Caso & Endomisial & Perimisial & $\begin{array}{c}\text { Perivascular } \\
\text { endomisial }\end{array}$ & $\begin{array}{l}\text { Perivascular } \\
\text { perimisial }\end{array}$ & Endomisial & Perimisial & Capilar & Fibra & & \\
\hline \multirow{8}{*}{ PM } & 1598 & ++ & ++ & + & ++ & + & ++ & - & ++ & ++++ & - \\
\hline & 1944 & + & + & - & + & - & + & - & - & ++ & + \\
\hline & 1948 & ++++ & ++ & ++ & ++ & + & - & - & + & ++++ & + \\
\hline & 2091 & + & + & - & + & - & + & - & - & ++++ & + \\
\hline & 2140 & + & + & - & + & + & ++ & - & - & - & + \\
\hline & 2213 & + & ++ & - & ++ & - & + & - & + & ++++ & + \\
\hline & 2222 & ++ & + & + & + & + & + & - & + & ++++ & + \\
\hline & 2224 & + & + & - & + & - & - & - & + & + & + \\
\hline \multirow{5}{*}{ DM } & 1685 & ++++ & ++ & ++ & ++ & + & ++ & - & & ++++ & + \\
\hline & 1794 & +++ & ++ & ++ & ++ & - & + & - & + & ++++ & + \\
\hline & 2072 & +++ & + & + & - & + & + & - & ++ & ++ & + \\
\hline & 2178 & +++ & - & - & - & - & + & - & - & ++++ & + \\
\hline & 2258 & +++ & +++ & - & +++ & + & + & - & + & +++ & + \\
\hline \multirow{4}{*}{ Distrofia } & 1902 & + & - & + & - & - & + & - & - & - & - \\
\hline & 2081 & + & ++ & - & ++ & - & - & - & - & - & - \\
\hline & 2123 & + & + & + & + & - & ++ & - & - & + & - \\
\hline & 2228 & + & - & - & - & - & - & - & - & - & - \\
\hline
\end{tabular}


Anexo 7

\section{HOSPITAL DAS CLÍNICAS}

DA

FACULDADE DE MEDICINA DA UNIVERSIDADE DE SÃO PAULO

TERMO DE CONSENTIMENTO LIVRE E ESCLARECIDO

(Instruções para preenchimento no verso)

\section{I - DADOS DE IDENTIFICAÇÃO DO SUJEITO DA PESQUISA OU RESPONSÁVEL LEGAL}

1. NOME DO PACIENTE:

DOCUMENTO DE IDENTIDADE $\mathrm{N}^{\circ}$

SEXO : $M \square \quad F$

DATA NASCIM

/...............

$\mathrm{N}^{\circ}$

BAIRRO:

CIDADE

CEP:

TELEFONE: DDD (

APTO: )

2.RESPONSÁVEL LEGAL

NATUREZA (grau de parentesco, tutor, curador etc.)

DOCUMENTO DE IDENTIDADE : SEXO: $M$

DATA NASCIMENTO .: .....................

ENDEREÇO:

BAIRRO:

CEP:

TELEFONE: DDD

\section{CIDADE:}

$\mathrm{N}^{\circ}$

APTO:

..).

\section{II - DADOS SOBRE A PESQUISA CIENTÍFICA}

1. TÍTULO DO PROTOCOLO DE PESQUISA

Expressão de MHC-I e II, C5b9 e fenotipagem das células inflamatórias

em tecido muscular na dermatomiosite juvenil (DMJ)

2. PESQUISADOR: Profa Dra Suely Kazue Nagahashi Marie

CARGO/FUNÇÃO: livre-docente

INSCRIÇÃO CONSELHO REGIONAL N ${ }^{\circ}$

UNIDADE DO HCFMUSP: Lim-15

3. AVALIAÇÃO DO RISCO DA PESQUISA:

SEM RISCO $\quad \mathbf{X} \quad$ RISCO MÍNIMO

RISCO MÉDIO

RISCO BAIXO $\square \quad$ RISCO MAIOR

(probabilidade de que o indivíduo sofra algum dano como consequência imediata ou tardia do estudo)

4.DURAÇÃO DA PESQUISA : 3 anos 


\section{III - REGISTRO DAS EXPLICAÇÕES DO PESQUISADOR AO PACIENTE OU SEU REPRESENTANTE LEGAL SOBRE A PESQUISA, CONSIGNANDO:}

1. justificativa e os objetivos da pesquisa ; 2. procedimentos que serão utilizados e propósitos, incluindo a identificação dos procedimentos que são experimentais; 3 . desconfortos e riscos esperados; 4. benefícios que poderão ser obtidos; 5 . procedimentos alternativos que possam ser vantajosos para o indivíduo.

A criança já foi submetida a uma biópsia muscular para confirmação do diagnóstico de dermatomiosite. Durante essa biópsia, um pedaço do músculo foi retirado e parte dele foi usado para confirmar o diagnóstico da doença, a outra parte restante ficou estocada e congelada. Para entender porque a criança apresenta comprometimento muscular, precisamos estudar como isso ocorre dentro do músculo e para isso precisaremos usar o pedaço do músculo que ficou congelado. Não haverá qualquer desconforto ou risco para a criança. $A$ criança continuará tendo atendimento e tratamento caso não concorde com a utilização desse material.

\section{IV - ESCLARECIMENTOS DADOS PELO PESQUISADOR SOBRE GARANTIAS DO SUJEITO DA PESQUISA:}

1. acesso, a qualquer tempo, às informações sobre procedimentos, riscos e benefícios relacionados à pesquisa, inclusive para dirimir eventuais dúvidas.

2. liberdade de retirar seu consentimento a qualquer momento e de deixar de participar do estudo, sem que isto traga prejuízo à continuidade da assistência.

3. salvaguarda da confidencialidade, sigilo e privacidade.

4. disponibilidade de assistência no HCFMUSP, por eventuais danos à saúde, decorrentes da pesquisa.

5. viabilidade de indenização por eventuais danos à saúde decorrentes da pesquisa.

\section{INFORMAÇÕES DE NOMES, ENDEREÇOS E TELEFONES DOS RESPONSÁVEIS PELO ACOMPANHAMENTO DA PESQUISA, PARA CONTATO EM CASO DE INTERCORRÊNCIAS CLÍNICAS E REAÇÕES ADVERSAS.}

\section{OBSERVAÇÕES COMPLEMENTARES:}

\section{VII - CONSENTIMENTO PÓS-ESCLARECIDO}

Declaro que, após convenientemente esclarecido pelo pesquisador e ter entendido o que me foi explicado, consinto em participar do presente Protocolo de Pesquisa

São Paulo, de de 19 
Ansell BM. Juvenile dermatomyositis. Rheum Dis Clin North Am. 1991;17:931-42.

Ansell BM. Juvenile dermatomyositis. J Rheumatol. 1992;19:60-2.

Appleyard ST, Dubowitz V, Dunn MJ, Rose ML. Increased expression of HLA ABC class I antigens by muscle fibers in Duchenne muscular dystrophy, inflammatory myopathy, and other neuromuscular disorders. Lancet. 1985;16:361-3.

ARA Glossary Committec: dictionary of the rheumatic diseases. Diagnostic Testing. American Rheumatism Association. ed. New York: Bayport; 1985. v. II

Arahata K, Engel AG. Monoclonal antibody analysis of mononuclear cells in myopathies I. Quantitation of subsets according to diagnoses and sites of accumulation and demonstration and counts of muscle fibres invaded by $\mathrm{T}$ cells. Ann Neurol. 1984;16:193-208.

Askari AD, Huettner TL. Cardiac abnormalities in polymiositis. Semin Arthritis Rheum. 1982;12:208-19.

Banker BQ, Victor M. Dermatomyositis (systemic angiopathy) of childhood. Medicine. 1966;45:261-89.

Banker BQ. Dermatomyositis of childhood: ultrastructural alterations of muscle and intramuscular blood vessels. J Neuropathol Exp Neurol. 1975;34:46-75.

Banker BQ. Dermatomyositis of childhood: ultrastructural alterations of muscle and intramuscular blood vessels. Am J Pathol. 1974;74:46-75.

Bartoccioni E, Gallucci S, Scuderi F, Ricci E, Servidei S, Broccolini A, Tonali P. MHC class I, MHC class II and intercellular adhesion molecule -1 (ICAM-1) expression in inflammatory myopathies. Clin Exp Immunol. 1994;95:166-72.

Basta M, Dalakas MC. High-dose intravenous immunoglobulin exerts its beneficial effect in patients with dermatomyositis by blocking endomysial deposition of activated complement fragments. J Clin Invest. 1994;94:1729-35.

Behan WMH, Behan PO. Disturbance of regulatory lymphocyte subsets in polymyositis. Ann Neurol. 1984;15:112-4. 
Behan WMH, Behan PO. Immunological features of polymyositis/dermatomyositis. Semin Immunopathol. 1985;8:267-93.

Benveniste O, Cherin P, Maisonobe T, Merat R, Chosidow O, Mouthon L, Guillevin L, Flahaut A, Burland MC, Klatzmann D, Herson S, Boyer O. Severe perturbations of the blood T cell repertoire in polymyositis, but not dermatomyositis patients. $J$ Immunol. 2001;167:3521-9.

Bitnum S, Daeschner CW, Travis LB, Dodge WF, Hopps HC. Dermatomyositis. $J$ Pediatr. 1964;64:101-31.

Bohan A, Peter JB. Polymiositis and dermatomyositis. N Engl J Med. 1975;13:344-7.

Bowyer SL, Blane CE, Sullivan DB, Cassidy JT. Childhood dermatomyositis: factors predicting functional outcome and development of dystrophic calcification. $J$ Pediatr. 1983;103:882-8.

Boyer SL, Clark RAF, Ragsdale CG, Hollister R, Sullivan DB. Juvenile dermatomyositis: histological findings and pathogenetic hypothesis for the associated skin changes. $J$ Rheumatol. 1986;13:753-9.

Bresnan MJ, Hauser SL, Weiner HL, Reinhertz E, Borel Y, Bhan A. Characterization of $\mathrm{T}$ cell subsets in peripheral blood and muscle in childhood dermatomyositis. Ann Neurol. 1986;10:283.

Bronner IM, Linssen WHJP, Van der Meulen MFG, Hoogendijk JE, De Visser M. Polymyositis: an ongoing discussion about a disease entity. Arch Neurol. 2004;61:132-4.

Bunch TW, Worthington JW, Combs JJ, Ilstrup DM, Engel AG. Azatioprine with prednisone for polymyositis. Ann Intern Med. 1980;92:365-90.

Burgos Vargas R, Vasquez-Mellado J, Gomez-Gordko Y, Reulas M, Katona G. Estudio clinico de la dermato/polymiositis de inicio en la enfancia. Bol Med Hosp Infant Mex. 1987;44:463-70.

Callen JP. Relationship of cancer to inflammatory muscle disease. Dermatomyositis, polymyositis and inclusion body myositis. Rheum Dis Clin North Am. 1994;20:943-53.

Caloew EE, Cavaliere MJ, Perez NM. Muscle pathology in juvenile dermatomyositis. São Paulo Med J. 1997;115:1555-9.

Casademont J, Grau JM, Estruch R, Pedro-Botet JC, Urbano-Marquez A. Relationship between capillary and muscle damage in dermatomyositis. Int $J$ Dermatol. 1990:29:117-20. 
Cassidy JT, Petty RE. Textbook of pediatric rheumatology. $2^{\text {nd }}$ ed. Philadelphia: WB Saunders; 1990. p.331-75: Juvenile dermatomyositis.

Cassidy JT, Petty RE. Textbook of pediatric rheumatology. $3^{\text {th }}$ ed. Philadelphia: WB Saunders Company; 1995. p.323-64: Juvenile dermatomyositis.

Cassidy JT. Dermatomyositis in children. In: Hicks RV. Vasculophaties of childhood. Massachusetts: PSG Publishing; 1988. p.205-42.

Chahade WH, Pereira JR, Novaes GS. Dermatomyositis. Rev Bras Med. $1985 ; 42: 337-47$.

Chiu HC, Hsieh KH, Hung TP. Imbalances in T cell subpopulation in myasthenia gravis. J Neurol Sci. 1981;52:53-9.

Choy EHS, Isenberg DA. Treatment of dermatomyositis and polymyositis. Rheumatology. 2002;41:7-13.

Chwalinska-Sadowska H, Maldykowa H. Polymiositis-dermatomyositis: 25 years of follow-up of 50 patients, disease course, treatment, prognosis factors. Matern Med Pol. 1990;3:213-8.

Cifuentes-Diaz C, Delaporte C, Dautreaux B, Charron D, Fardeau M. Class II MHC antigens in normal human skeletal muscle. Muscle Nerve. 1992;3:295-302.

Compeyrot-Lacassagne S, Feldman BM. Inflammatory myopathies in children. Pediatr Clin North Am. 2005;25:493-520.

Cook CD, Rosen FS, Banker BQ. Dermatomyositis and focal scleroderma. Pediatr Clin North Am. 1963;10:979.

Crespi HG, Chacon CFD, De Francesco S. Dermatomyositis en la infancia: remission clinico-terapeutica. Arch Argent Dermatol. 1990;40:15-35.

Cronin ME, Plotz PH. Idiopathic inflammatory myopathies. Rheum Dis Clin North Am. 1990;16:655-65.

Crowe WE. Dermatomyositis and polymiositis In: Gershwin ME, Robbins DL. Musculoskeletal diseases of children. New York: Grune e Stratton; 1983. p.113-37.

Darr AS, Fuggle SV, Fabre JW, Ting A, Morris PJ. The detailed distribution of MHC Class II antigens in normal human organs. Transplantation. 1984;8:293-8.

Dalakas MC. Immunopathogenesis of inflammatory myopathies. Ann Neurol. 1995;37(Suppl 1):S74-S86.

Dalakas MC. Polymyositis, dermatomyositis and inclusion-body myositis. $N$ Engl $J$ Med. 1991;325:1487-98. 
Dalakas MC, Hohfeld R. Polymyositis and dermatomyositis. Lancet. 2003;362:971-82.

Dalakas MC. Inflammatory disorders of muscle: progress in polymyositis, dermatomyositis and inclusion body myositis. Curr Opin Neurol. 2004;17:561-7.

Denbow CE, Lie JT, Tancredi RG, Bunch TW. Cardiac involvement in polymiositis. Arthritis Rheum. 1979;22:1088-92.

Dickey BF, Myers AR. Pulmonary disease in polymiositis/dermatomyositis. Semin Arthritis Rheum. 1984;14:60-76.

Downey EC, Wooley MM, Hanson V. Required surgical therapy in the pediatric patient with dermatomyositis. Arch Surg. 1988;123:117-20.

Dubowitz V. Muscle biopsy: a practical approach. $2^{\text {nd }}$ ed. London: Saunders; 1985. p.19-40: Histological and histochemical stains and reactions.

Duffau J, Crespi H, Zocchi G, Diaz M, Roccataglia G, Araraki J, Magallon J. Manifestations tempranas de la dermatomyositis infantil. Rev Hosp Niños. 1984;111:11-6.

Eisenstein DM, O'Gorman MR, Pachman LM. Correlatios between change in disease activity and change in peripheral blood lymphocyte subsets in patients with juvenile dermatomyositis. J Rheumatol. 1997;24:1830-2.

Emslie-Smith AM, Arahata K, Engel AG. Major histocompatibility complex class I antigen expression, immunolocalization of interferon subtypes, and $\mathrm{T}$ cell-mediated cytotoxicity in miopathies. Hum Pathol. 1989;20:224-31.

Emslie-Smith AM, Engel AG. Microvascular changes in early and advanced dermatomyositis: a quantitative study. Ann Neurol. 1990;27:343-56.

Engel AG, Arahata K. Monoclonal antibody analysis of mononuclear cells in myopathies II: Phenotypes of autoinvasive cells in polymyositis and inclusion body myositis. Ann Neurol. 1984;16:209-15.

Engel AG, Arahata K. Mononuclear cells in myopathies: quantitation of functionally distinct subsets, recognition of antigen-specific cell-mediated cytotoxicity in some diseases, and implications for the pathogenesis of the different inflammatory myopathies. Hum Pathol. 1986;17:704-21.

Englund P, Lindroos E, Nennesmo I, Klareskog L, Lundberg IE. Skeletal muscle fibers express major histocompatibility complex class II antigens indepently of inflammatory infiltrates in inflammatory myopathies. Am J Pathol. 2001;159:1263-73. 
Englund P, Nennesmo I, Klareskog L, Lundberg IE. Interleukin-1 $\alpha$ expression in capillaries and major histocompatibility complex class I expression in type II muscle fibers from polymyositis and dermatomyositis patients. Arthritis Rheum. 2002;46:1044-55.

Estruch R, Grau JM, Fernandez-Sola J, Casademont J, Monforte R, UurbanoMarquez A. Microvascular changes in skeletal muscle in idiopathic inflammatory myopathy. Hum Pathol. 1992;23:888-95.

Fladby T, Kampman MT, Loseth S, Lindal S, Mellgren SI. Human leukocyte antigen class I in polymyositis: leukocyte infiltrates, regeneration and impulse block. Muscle Nerve. 1997;20:1534-40.

Goebels N, Michaelis D, Wekerle H, Hohlfeld R. Human myoblasts as antigenpresenting cells. J Immunol. 1992;149:661-7.

Goel KM, King M. Dermatomyositis: polymiositis in children. Scott Med J. 1986;31:15-9.

Gonçalves FG, Chimelli L, Sallum AM, Marie SK, Kiss MH, Ferriani VP. Immunohistochemical analysis of CD59 and membrane attack complex of complement in muscle in juvenile dermatomyositis. J Rheum. 2002;29:1301-7.

Gonçalves FGP. Expressão de uma proteína reguladora do sistema complemento (CD59) e sua relação com alterações histológicas presentes em tecido muscular de pacientes portadores de dermatomiosite juvenil. [Tese de Doutorado]. Ribeirão Preto; Faculdade de Medicina de Ribeirão Preto; 2004.

Gottdiener JS, Sherber HS, Hawley RJ, Engel W. Cardiac manifestations in polymiositis. Am J Cardiol. 1978;41:1141-9.

Greenberg SA, Amato AA. Uncertains in the pathogenesis of adult dermatomyositis. Curr Opin Neurol. 2004;17:359-64.

Greenberg SA, Pinkus JL, Pinkus GS, Burleson T, Sanoudou D, Tawil R, Barohn RJ, Saperstein DS, Briemberg HR, Ericsson M, Park P, Amato AA. Interferonalpha/beta-mediated innate immune mechanisms in dermatomyositis. Ann Neurol. 2005; 57:664-78.

Han GM, Chen SL, Shen N, Ye S, Bao CD, Gu YY. Analysis of gene expression profiles in human systemic lupus erythematosus using oligonucleotide microarray. Genes Immun. 2003; 4:177-186.

Hanson V. Dermatomyositis, scleroderma and polyarteritis nodosa. Clin Rheum Dis. 1976;2:445. 
Hanissian AC, Masi AT, Pitner SE, Cape CC, Medsger TA. Polymiositis and dermatomyositis in children: an epidemiologic and clinical comparative analysis. $J$ Rheumatol. 1982;9:390-4.

Harrison SM, Frenkel M, Grossman BI, Mayacon R. Retinopathy of childhood dermatomyositis. Am J Ophtalmol. 1973;76:786-90.

Hengstman GJD, Vogels OJM, Ter Laak MJ. Myositis during long-term interferon alpha treatment. Neurology. 2000;57:561-68.

Hofbauer M, Wiesener S, Babbe H. Clonal tracking of autoaggressive $\mathrm{T}$ cells in polymyositis by combining laser microdissection, single-cell PCR and CDR3spectratype analysis. Proc Natl Acad Sci USA. 2003;100:4090-5.

Hohlfeld R, Eengel AG. Lysis of myotubes by alloreactive cytotoxic T cells: relevance to myoblaste transplantation. J Clin Invest. 1990;86:370.

Hohlfeld R, Engel AG. Induction of HLA-DR expression on human myoblasts with interferon-gamma. Am J Pathol. 1990;136:503-8.

Hohlfeld R, Engel AG. Coculture with autologous myotubes of cytotoxic T cells isolated from muscle in inflammatory myopathies. Ann Neurol. 1991;29:498.

Hohfeld R, Engel AG, Goebels N, Behrens L. Cellular immune mechanisms in inflammatory myopathies. Curr Opin Rheumatol. 1997;9:520-6.

Iannone F, Cauli A, Yanni G. T lymphocyte immunophenotyping in polymyositis and dermatomyositis. Br J Rheumatol. 1996;35:839-45.

Isenberg DA, Rowe D, Shearer M, Novick D, Beverly PC. Localization of interferons and interleukin 2 in polymyositis and muscular dystrophy. Clin Exp Immunol. 1986;63:450-8.

Inukai A, Kuru S, Liang Y, Takano A, Kobayashi Y, Sakai M, Doyu M, Sobue G. Expression of HLA-DR and its enhancing molecules in muscle fibers in polymyositis. Muscle Nerve. 2000;23:385-92.

Ishida T, Matsumoto Y, Ohashi M, Sasaki R. Analysis of lymphocyte subpopulations in peripheral blood of adult and juvenile cases of dermatomyositis. J Dermatol. 1993;20:30-4.

Iyer V, Lawton AR, Fenichel GM. T cell subsets in polymyositis. Ann Neurol. 1983;13:452-3.

Kagen LT. Polymiositis/dermatomyositis. In: McCarthy DJ. Arthritis and allied conditions: a textbook of rheumatology. Philadelphia: Lea and Febinger; 1989. p.1092-117. 
Kalovidouris AE, Smith DB. Aberrant expression of class II and increased expression of class I MHC antigens in muscles of patients with polymyositisdermatomyositis (PM-DM). Arthritis Rheum. 1991;34:S148.

Karpati G, Pouliot Y, Carpenter S. Expression of immunoreactive major histocompatibility complex products in human skeletal muscles. Ann Neurol. 1988;23:64-72.

Kikuchi Y, Koarada S, Tada Y, Ushiyama O, Morito F, Suzuki N, Ohta A, Horiuchi T, Miyake K, Nagasawa K. Difference in B cell activation between dermatomyositis and polymyositis: analysis of the expression of RP105 on peripheral blood B cells.

Ann Rheum Dis. 2001;60:1137-40.

Kissel JT, Mendell JR, Rammohan KW. Microvascular deposition of complement membrane attack complex in dermatomyositis. N Engl J Med. 1986;314:329-34.

Kissel JT, Halterman RK, Rammohan KW, Mendell JR. The relationship of complement-mediated microvasculopathy to the histologic features and clinical duration of disease in dermatomyositis. Arch Neurol. 1991;48:26-30.

Kleckner FS. Dermatomyositis and its manifestations in the gastrointestinal tract. Am J Gastroenterol. 1970;53:141-6.

Kroemer G, Martinez AC. Cytokines and autoimmune disease. Clin Immunol Immunopathol. 1991;61:275-95.

Kroll M, Otis J, Kagen L. Serum enzyme, myoglobin and muscle strenght relationships in polymyositis and dermatomyositis. J Rheumatol. 1986;13:349-55.

Lemoine NR, Ryan JF, Cox EL, Mayston V, Revell PA, Swash M. Immunohistochemical analysis of mononuclear cell subsets in inflammatory and non-inflammatory myopathies.

J Clin Pathol. 1986;39:271-4.

Li CK, Varsani H, Holton JL, Gao B, Woo P, Wedderburn LR. Juvenile dermatomyositis research group. MHC Class I overexpression on muscles in early juvenile dermatomyositis. J Rheumatol. 2004;31:605-9.

Li C, Varsani H, Maillard S, Jones R, Holton J, Woo P, Wedderburn L. Does histological features parallel clinical severity in juvenile dermatomyositis: proposal of a novel scoring system. Clin Exp Rheumatol. 2004;22:529.

Lindberg C, Oldfors A, Tarkowski A. Local T-cell proliferation and differentiation in inflammatory myopathies. Scand J Immunol. 1995;41:421-6.

Lovell HB, Linsley CB. Late recurrence of childhood dermatomyositis. J Rheumatol. 1986;13:821-2. 
Lundberg IE. Idiopathic inflammatory myopathies: why do the muscles become weak. Curr Opin Rheumatol. 2001;13:357-460.

Lundberg I. E.The physiology of inflammatory myopathies: an overview. Acta Physiol Scand. 2001;171:207-13.

Lundberg IE, Dastmalchi M. Possible pathogenic mechanisms in inflammatory myopsthies. Rheum Dis Clin North Am. 2002;28:799-822.

Lundberg I, Ulfgren AK, Nyberg P, Anderson U, Klareskog L. Cytokine production in muscle tissue of patients with idiopathic inflammatory myopathies. Arthritis Rheum. 1997; 40:865-74.

Lundberg I, Kratz AK, Alexanderson H, Patarroyo M. Decreased expression of interleukin-1 $\alpha$, interleukin-1 $\beta$, and cell adhesion molecules in muscle tissue following corticosteroid treatment in patients with polymyositis and dermatomyositis. Arthristis Rheum. 2000;43:336-48.

Mallesson P. Juvenile dermatomyositis: a review. JR Soc Med. 1982;75:33-7.

Mantegazza R, Hughes SM, Mitchell D, Travis M, Blau HM, Steinman L. Modulation of MHC class II antigen expression in human myoblasts after treatment with IFN-gamma. Neurology. 1991;41:1128-32.

Marie I, Hachulla E, Hatron PY, Hellot MF, Levesque H, Devulder B, Courtois H. Polymyositis and Dermatomyositis: short term and longterm outcome, and predictive factors of prognosis. J Rheumatol. 2001;28:2230-7.

Marino M, Scuderi F, Mazzarelli P, Mannella F, Provenzano C, Bartoccioni E. Constitutive and cytokine-induced expression of $\mathrm{MHC}$ and intercellular adhesion molecule-1 (ICAM-1) on human myoblasts. J Neuroimmunol. 2001;116:94-101.

Mastaglia FL, Currie S. Immunological and ultrastructural observations on the role of lymphoid cells in the pathogenesis of polymyositis. Acta Neuropathol. 1971;18:1-16.

Mastaglia FL, Ojeda VJ. Inflammatory myophaties. Part I. Ann Neurol.1985;17:215-27.

Mastaglia FL, Ojeda VJ. Inflammatory myophaties. Part II. Ann Neurol. 1985;17:317-23.

McDouall RM, Dunn MJ, Dubowitz V. Expression of class I and class II antigens in neuromuscular diseases. J Neurol Sci.1989;89:213-26.

McDouall RM, Dunn MJ, Dubowitz V. Nature of the mononuclear infiltrate and the mechanism of muscle damage in juvenile dermatomyositis and Duchenne muscular dystrophy. J Neurol Sci. 1990;99:199-217. 
Medical Research Council. Aids to the examination of the peripheral nervous system. Memorandun n45 Londres. Her Majesty’s Stationery Office, 1981.

Mendez EP, Lipton R, Goldman-Ramsey R, Roettcher P, Bowyer S, Dyer A, Pachman L. US Incidence of juvenile drmatomyositis, 1995-1998: results from the National Institute of Arthritis and Musculoskeletal and Skin Diseases Registry. Arthritis Rheum. 2003;49:300-5.

Miller FW. Inflammatory myopathies. Annual Review Course $55^{\text {th }}$ Annual Scientific Meeting. Boston: Massachussets; 1991.

Miller FW, Love LA, Barbieri AS, Balow JE, Plotz PH. Lymphocyte activation markers in idiopathic myositis: changes with disease activity and differences among clinical and autoantibody subgroups. Clin Exp Immunol. 1990;81:373-9.

Miller LC, Smith Sa, Michael AF. Mononuclear cell profiles in muscle biopsies from patients with polymyositis and childhood dermatomyositis. $J$ Rheumatol. 1987;14:1068-70.

Miller III JJ, Koehler JP. Persistance of activity in dermatomyositis of childhood. Arthritis Rheum. 1997;20:332-7.

Miller LC, Michael AF, Kim Y. Childhood dermatomyositis. Clin Pediatr. 1987;16:561-6.

Mizuno K, Yachie A, Nagaoki S, Wada H, Okada K, Kawachi M, Toma T, Konno A, Ohta K. Oligoclonal expansion of circulating and tissue-infiltrating CD8+T Cells with killer effector phenotypes in juvenile dermatomyositis syndrome. Clin Exp Immunol. 2004;137:187-94.

Nagaraju K, Raben N, Loeffer L. Conditional up-regulation of MHC class I in skeletal muscle leads to self-sustaining auto-immune myositis and myositis specific autoantibodies. Proc Natl Acad Sci USA. 2000;97:9209-14.

Nick J, Prunieras M, Bakouche P, Reignier A, Nicolle MH. Inclusions dans les cellules endotheliales et les lymphocytes au cours d'un cas de dermatomyosite. Revue Neurologique. 1971;5:229-338.

Norins AL. Juvenile dermatomyositis. Med Clin North Am. 1989;73:1193-209.

Nyberg P, Wikman AL, Nennesmo I, Lundberg I. Increased expression of interleukin $1 \alpha$ and MHC class I in muscle tissue of patients with chronic, inactive polymyositis and dermatomyositis. J Rheum. 2000;27:4.

O`Gorman MRG, Corrochano V, Roleck J, Donovan M, Pachaman LM. Flow cytometric analyses of the lymphocyte subsets in peripheral blood of children with untreated active juvenile dermatomyositis. Clin Diag Lab Immunol. 1995;2:205-8. 
Olsson T, Henriksson KG, Klareskog L, Forsum U. HLA-DR expression, T lymphocyte phenotypes, OKM1 and OKT9 reactive cells in inflammatory myopathy. Muscle Nerve. 1985;8:419-25.

Pachman LM. Juvenile dermatomyositis: new clues to diagnosis and pathogenesis. Clin Exp Rheumatol. 1994;12:69-73.

Pachman LM, Cooke N. Juvenile dermatomyositis: a clinical and immunologic study. J Pediatr. 1980;96:226-34.

Pachman LM. Juvenile dermatomyositis. Natural history and susceptibility factors. In: Woo P, White P, Ansell BM. Paediatric rheumatology. Oxford: Oxford University Press; 1990. p.171-81.

Pereira RMR, Lerner S, Maeda WT, Goldstein-Schainberg C, Cossermelli W. Pericardial tamponade in juvenile dermatomyositis. Clin Cardiol. 1982;15:301-3.

Ramana Raju NU, Hart N, Maloney J, Zadi A, Afams K. Cardiac involvement in polymiositis: a case report and review of literature. Cleve Clin Q. 1984;51:89-91.

Ramanan AV, Feldman BM. Clinical outcomes in juvenile dermatomyositis. Curr Opin Rheumatol. 2002;14:658-62.

Ramanan AV, Feldman BM. The role of muscle enzymes in JDM. Avaliable from: http://www.pedrheumonlinejournal.org/

Ramirez Bosca A, Valcuende Cavero F, Castels Rodellas A. Estúdio de las poblaciones linfocitarias circulantes en esclerodermia sistemica, lupus eritematoso discóide crônico y dermatomiositis. Med Cut ILA. 1986;14:306-10.

Reed AM, Pachman L, Ober C. Molecular genetic studies of major histocompatibility complex genes in children with juvenile dermatomyositis: increased risk associated with HLA-DQA1*0501. Hum Immunol. 1991;32:235-40.

Reed AM. Myositis in children. Curr Opin Rheumatol. 2001;13:428-33.

Rider L. Childhood myositis: newly recognized diversity. 716-7. In: Plotz P. Moderator. Myositis: immunologic contributions to understanding cause, pathogenesis, and therapy. Ann Intern Med. 1995;122:715-24.

Rider LG, Miller FW. Classification and treatment of the juvenile idiopathic inflammatory myopathies. Rheum Dis Clin North Am. 1997;23:619-55. 
Roelofs RI. Pathology of polymiositis/dermatomyositis. Mt Sinai J Méd. 1988;55:453-8.

Rostasy KM, Piepkorn M, Goebel H, Menck S, Hanefeld F, Schultz-Schaeffer WJ. Monocyte/macrophage differentiation in dermatomyositis and polymyositis. Muscle Nerve. 2004;30:225-30.

Rowe D, Isenberg DA, Beverley PCL. Monoclonal antibosies to immune leukocyte antigens in polymyositis and muscular dystrophy. Clin. Exp. Immunol.; v.54, p.327$361,1983$.

Sallum AME, Kiss MHB, Sachetti S, Resende MBD, Moutinho KC, Carvalho MS, Silva CAA, Marie SKN. Juvenile Dermatomyositis: clinical, laboratorial, histological, therapeutical and evolutive parameters of 35 patients. Arq. Neuropsiquiatr. 2002;60:889-99.

Sallum AME, Silva CAA, Vianna MAAG, Wakamatsu A, Marie SKNM, Kiss MHB. ICAM-I expression of muscle biopsy predict the severity of juvenile dermatomyositis (JDM). American College of Rheumatology Congress. Arthritis Rheum. 2001;S263-1263.

Sallum AME, Vianna MAAG, Wakamatsu A, Silva CAA, Kiss MHB, Marie SKNM. Immunohistochemical analysis of adhesion molecule expression on muscle biopsy specimens from patients with juvenile dermatomyositis. J Rheumatol. 2004;31:801-7.

Sallum AME, Kiss MHB, Vianna MAAG, Wakamatsu A, Silva CAA, Marie SKNM. Difference on adhesion molecules expression on juvenile dermatomyositis, polymyositis, dermatomyositis and inclusion body myositis. Autoim Rev. 2005 (in press).

Sanoudou D, Kang PB, Haslett JN, Han M, Kunkel LM, Beggs AH. Transcriptional profile of postmortem skeletal muscle. Physiol Genomics. 2004;16:222-228.

Schullinger JN, Jacobs JC, Berdon WE. Diagnosis and management of gastrointestinal perforations in childhood dermatomyositis with particular reference to perforations of the duodenum. J Pediatr Surg. 1985;52:521-4.

Schaller JG, Szer IS. Dermatomyositis, scleroderma and vasculitis. In: Kelley WN, Harris ED, Ruddy S, Sledge LB. Textbook of rheumatology. Philadelphia: Saunders; 1989. p.1325-54.

Seelinger S, Vogl T, Engels IN. Expression of calcium-binding proteins MRP8 and MRP14 in inflammatory muscle diseases. Am J Pathol. 2003;163:947-56. 
Sewry CA, Dubowitz V, Abraha A, Luzio JP, Campbell AK. Immunocytochemical localisation of complement components $\mathrm{C} 8$ and $\mathrm{C} 9$ in human diseased muscle. $J$ Neurol Sci. 1987;81:141-53.

Singsen BH. Rheumatic diseases of childhood. Rheum Dis Clin North Am. 1990;16:581-99.

Sogabe T, Silva CAA, Kiss MHB. Clinical and laboaratory characteristics of 50 children with dermato/polymyositis. Rev Bras Reumatol. 1996;36:351-8.

Strongwater SI. Overview and clinical manifestations of inflammatory myositis, polymiositis and dermatomyositis. Mt Sinai J Med. 1988;55:435-46.

Sullivan DB, Cassidy JT, Petty RE. Dermatomyositis in pediatric patient. Arthritis Rheum. 1977;20:327-31.

Sullivan DB. Dermatomyositis. In: Cassidy JT. Textbook of pediatric rheumatology. New York: John Willey and Sons; 1982. p.407-32.

Thompson JW. Spontaneous perforation of the esophagus as a manifestation of dermatomyositis. Ann Otol Rhinol Laryngol. 1984;93:464.

Topaloglu H, Muntoni F, Dubowitz V, Sewry C. Expression of HLA class I antigens in skeletal muscle is a disease marker in juvenile dermatomyositis. $J$ Child Neurol. 1997;12:60-3.

Van Der Pas J, Hengstman GJ, Ter Laak HJ, Borm GF, Van Engelen BG. Diagnostic value of MHC class I staining in idiopathic inflammatory myopathies. J Neurol NeurosurgPsychiatry. 2004;75:136-9.

Van Der Meulen MF, Van Wichen DF, Van Blokland WT. Evidence for heterogeneity of $\mathrm{T}$ cell expansion in polymyositis and inclusion body myositis. $J$ Neuroimmunol. 2002;133: 198-204.

Viguier M, Fouéré S, De la Salmoniere P, Rabian C, Lebbe C, Dubertret L, Morel P, Bachelez H. Peripheral blood lymphocyte subset counts in patients with dermatomyositis. Clinical correlations and changes following therapy. Medicine. 2003;82:82-6.

Wargula JC. Update on juvenile dermatomyositis: new advances in understanding its etiopathogenesis. Curr Opin Rheumatol. 2003;15:595-601.

Wedderburn L, Li CKC. Paediatric idiopathic inflammatory muscle disease. Best Pract Res Clin Rheumatol. 2004;18:345-58.

Whitaker JN, Engel WK. Vascular deposits of immunoglobulin and complement in idiopathic inflammatory myopathy. N Engl J Med. 1972;286:333-8. 
Winfield J. Juvenile dermatomyositis with complications. Proc $R$ Soc Med. 1977;70:548-51.

Yoshioka M, Okuno T, Mikaha H. Prognosis and treatment of polymiositis with particular reference to steroid patients. Arch Dis Child. 1985;60:236-44.

Zuk JA, Fletcher A. Skeletal muscle expression of class II histocompatibility antigens (HLA-DR) in polymyositis and other muscle disorders with na inflammatory infiltrate. J Clin Pathol. 1988;41:410. 


\title{
JUVENILE DERMATOMYOSITIS
}

\section{Clinical, laboratorial, histological, therapeutical and evolutive parameters of 35 patients}

\author{
Adriana Maluf Elias Sallum', Maria Helena Bittencurt Kiss'2, Silvana Sachetti, \\ Maria Bernadate Dutra Resende ${ }^{4}$, Kelly Cristina Moutinho', Mary de Souza Carvalho6, \\ Clovis Arthur Almeida Silva', Suely Kazue Nagahashi Marie ${ }^{8}$
}

\begin{abstract}
This study was based on a prospective and a retrospective analysis of 35 patients who met Bohan and Peter criteria for juvenile dermatomyositis diagnosis. The mean follow-up time was three years ten months. Calcinosis was present in five (14.28\%) patients, cutaneous ulcers in four (11.42\%), and systemic involvement in nine $(27.71 \%)$ patients. All patients presented alterations in the serum levels of muscle enzymes, and all of them were submitted to muscle biopsy as a diagnostic procedure. Nine $(25.71 \%)$ patients received corticotherapy prior to and $26(74.28 \%)$ after the muscle biopsy. Chloroquine, methotrexate, cyclosporine, cyclophosphamide and intravenous immunoglobulin were used in patients with poor response to corticotherapy. Continuation of cutaneous manifestations was observed in $4(11.43 \%)$ patients, laboratorial activity in $1(2.85 \%)$, cutaneous and laboratorial activities in $3(8.57 \%)$. Ten (28.57\%) patients were out of activity, and $17(48.57 \%)$ in remission at study end-point, on March 2002. Two (5.71\%) patients died.
\end{abstract}

KEY WORDS: juvenile dermatomyositis, clinical findings, muscle biopsy, treatment, evolution, outcome.

Dermatomiosite juvenil: parâmetros clínicos, laboratoriais, histológicos, terapêuticos e evolutivos de 35 pacientes

RESUMO - Este estudo foi baseado na análise prospectiva e retrospectiva de 35 pacientes que preencheram os critérios diagnósticos de Bohan e Peter de dermatomiosite juvenil. 0 tempo médio de seguimento foi de 3 anos e 10 meses. Foi observado calcinose em $5(14,28 \%)$ pacientes, úlcera cutânea em $4(11,42 \%)$ e envolvimento sistêmico em $9(22,71 \%)$. Todos os pacientes apresentavam alteraçōes nos níveis séricos das enzimas musculares e todos foram submetidos a biópsia muscular como procedimento diagnóstico. Nove $(25,71 \%)$ pacientes receberam corticoterapia antes e $26(74,28 \%)$ depois da realização da biópsia muscular. Foram utilizados cloroquina, metotrexato, ciclosporina, ciclofosfamida e imunoglobulina endovenosa em todos os pacientes que não apresentaram boa resposta ao corticóide. Houve manutenção das manifestaçōes cutâneas em 4 $(11,43 \%)$ pacientes, atividade laboratorial em $1(2,85 \%)$, atividades cutânea e laboratorial em $3(8,57 \%)$. Dez (28,57\%) pacientes estavam fora de atividade e $17(48,57 \%)$ em remissão por ocasião do término do estudo em março de 2002 . Dois $(5,71 \%)$ pacientes faleceram.

PALAVRAS-CHAVE: dermatomiosite juvenil, achados clínicos, biópsia muscular, tratamento, evolução, prognóstico.

Dermatomyositis is a rare multisystem disease, whose etiology is unknown, characterized by a vasculitis that affects skin and muscles ${ }^{1-3}$. Most studies suggest that juvenile dermatomyositis (JDM) is autoimmune in pathogenesis and results from a vasculopathy. Both cell-mediate immunity to muscle anti- gens and immune-complex disease may play roles in pathogenesis'. Dermatomyositis is one of a heterogeneous group of acquired muscular diseases, an idiopathic inflammatory myositis marked by the presence of muscle weakness and histological evidence of inflammation in muscle biopsies. The characteri-

Pediatric Rheumatology Unit of Pediatric Department, Neurology Departament, Laboratory of Neurological Investigation, University of São Paulo Medical School (USPMS), São Paulo SP, Brazil: ' $M D$, Post-graduate student of Pediatric Department, USPMS: ${ }^{2} \mathrm{MD}$, PhD, Associate Professor of Pediatrics, Children's Institute, USPMS; ${ }^{3}$ MD, PhD, Head of Pediatric Rheumatology Unit, Santa Casa de Misericórdia of São Paulo Medical School; ${ }^{4} \mathrm{MD}$, Post-graduate student, Department of Neurology, USPMS; ${ }^{5}$ Graduate student; ${ }^{6} \mathrm{MD}$, PhD; Neurology Department, Clinical Hospital, USPMS; ${ }^{7} \mathrm{MD}$, PhD, Head of Pediatric Rheumatology Unit, Children's Institute, USPMS; ${ }^{8}$ MD, PhD, Associate Professor, Head of the Laboratory of Neuromuscular Diseases, Department of Neurology, USPMS. Grant from FAPESP 98/16290-6.

Received 10 April 2002, received in final form 2 July 2002. Accepted 17 July 2002.

Dra.Suely Kazue Nagahashi Marie - Faculdade de Medicina da Universidade de São Paulo - Departamento de Neurologia - Laboratório de Miopatias e Biologia Molecular - Avenida Dr. Arnaldo 455 sala 4110 - 01246-903 São Paulo SP - Brasil. FAX: 1130614036. E-mail: sknmarie@usp.br. 
zation of this group of diseases is based on muscular involvement, association of clinical manifestations, histological alterations, response to corticotherapy and prognosis ${ }^{4,5}$.

Although clinical, laboratorial, histological, therapeutical and evolutive aspects of this disease have been analyzed in many previous studies, the majority of these studies were carried out some years ago, and therefore may not accurately reflect the status of the disease as it currently stands.

We describe clinical, laboratorial, therapeutical, histological and outcome parameters of 35 patients with JDM, based on a mean follow-up of 3 years 10 months, ranging from one year nine months to ten years three months.

\section{METHOD}

Patient selection: Thirty-five JDM patients fulfilling Bohan and Peter criteria ${ }^{6}$, attending the Pediatric Rheumatology Unit at the Children's Institute of the University of São Paulo Medical School and Santa Casa de Misericórdia de São Paulo, have been studied. The evaluation was prospective from February/1999 to March/2002 in 25 patients, and retrospective over the period March/1991 to March/ 2002 in 10 patients. Bohan and Peter ${ }^{6}$ suggested a classification based upon the presence or absence of five major criteria for diagnosis, including symmetric muscle weakness, evidence of inflammatory myositis in muscle biopsy, elevation of serum muscle enzymes, electromyographic evidence of inflammatory myopathy and dermatological pathognomonic features of dermatomyositis (heliotrope and Gottron's papules). A diagnosis of JDM requires the presence of the pathognomonic rash and three of the other criteria'. A diagnosis of JDM is not excluded by the failure to meet one or more criteria'.

Clinical evaluation: The clinical parameters analyzed were cutaneous manifestations such as heliotrope, Gottron papulae, erithema malar, palmar, periungueal, and in trunk, skin ulcers and calcinosis; involvement of internal organs, and muscle involvement according to the scale established by the Medical Research Council (MRC) in $1943^{7}$ where: $0=$ no contractions, $I=$ flicker or trace of contraction, $\|=$ active movement with gravity eliminated, $\mathrm{III}=$ active movement against gravity, IV = active movement against gravity and resistance, and $\mathrm{V}=$ normal power.

Laboratory evaluation: Antinuclear and anti-Jo-1 antibodies, erythrocyte sedimentation rate, serum levels of the muscle enzymes AST, ALT, DHL and CK were analyzed at the time of the biopsy.

Histopathological evaluation of skeletal muscle: Muscle biopsy specimens were obtained from brachial biceps muscle in all patients and a total of 37 muscle fragments were submitted to histopathological analysis. Specimens 2 and
5 were from a boy who presented persistent atypical cutaneous alteration and was resubmitted to muscle biopsy, with a 40-month interval from the first procedure. Additionally, specimens 9 and 14 were from a girl presenting an atypical association with mental retardation and who was submitted to a second biopsy for diagnostic confirmation after an 8-month interval. Muscle biopsy was performed before corticotherapy in 26 patients, and after the introduction of the medication in 9 .

Routine standard histological and histochemical techniques were employed in muscle biopsies. Frozen sequential sections were stained with hematoxylin-eosin (H\&E), modified Gomori trichrome, periodic acid Schiff, cytochrome $\mathrm{C}$ oxydase, $\mathrm{NADH}$-tetrazolium-reductase, succinate dehydrogenase, adenosine triphosphatase $\mathrm{pH} 4.3$ and 9.4, alkaline and acid phosphatase. Each biopsy specimen was coded and analyzed concomitantly by two investigators (AMES and SKNM). Presence of internal nuclei, focal myofibrillar loss, necrotic fiber, regenerating fiber, perivascular inflammation, endomysial inflammation, and increased connective tissue was observed in all preparations. Degenerative aspects were confirmed in acid phosphatase reaction, regenerative aspects in alkaline phosphatase and proliferation of connective tissue in modified Gomori staining. These alterations were analyzed semiquantitatively where: $(-)=$ absent; $(+)=$ present in less than $25 \%$ of the analyzed fields; $(++)=$ present in $50 \%$; $(+++)=$ present in $75 \% ;(++++)=$ present in $100 \%$.

Therapeutical evaluation: All patients received corticotherapy (prednisone or metilprednisolone), and initial therapeutical response was analyzed at between 4 to 6 weeks following the introduction of medication; response was considered good, partial or bad, based on the improvement of muscle strength and/or cutaneous lesions. Chloroquine, methotrexate, cyclosporine, cyclophosphamide and/or intravenous immunoglobulin were administered to all patients that presented partial or bad initial responses.

Evolution analysis: Continuation of clinical activity was considered when there was persistent muscle weakness or cutaneous activity characterized by either the presence of erythema, heliotrope, Gottron papulae, cutaneous ulcers, or laboratorial activity during which, increased serum levels of muscle enzymes were maintained. Out of activity was deemed when there was an absence of symptoms and signs with continued medication and remissions when the children presented asymptomatic without medication. All patients were classified according to these different clinical criteria at study end-point, on March 2002.

\section{RESULTS}

Clinical characteristics: The mean age of disease onset was 6 years 10 months ( \pm 3 years), median: 7 years 5 months, ranging from 1 year 5 months to 12 years 8 months. The gender distribution showed a predominance of females, being 2.8 females to 1 
male (26 females and 9 males). All patients fulfilled Bohan and Peter criteria for dermatomyositis, with the presence of characteristic cutaneous lesion (Gottron's papules and/or heliotrope), in addition to three other criteria. It was noteworthy that cutaneous and subcutaneous involvement was severe in four $(11.42 \%)$, presenting cutaneous ulcer, while four other patients had calcinosis. Gastrointestinal tract involvement was observed in six (17.14\%) patients, whereas five presented pulmonary involvement $(14.28 \%)$, and three $(8.57 \%)$ presented cardiac involvement. The majority of the patients presented some degree of muscle weakness, according to the MRC scale, with the exception of 3 patients (cases 2/ 5,14 and 21) with normal muscle strength, in whom JDM diagnosis was established with the association of other signs (Table 1).

Laboratorial characteristics: The antinuclear antibody was positive in $14(40 \%)$ patients, in contrast to the negativity of the anti-Jo-1 antibody in all patients, even in those presenting pulmonary involvement. The erythrocyte sedimentation rate was positive in five $(14.28 \%)$ patients.

All patients presented at least one of the muscle serum enzyme altered. The serum levels of CK compared to serum levels of LDH, AST and ALT are shown in Graph 1. Interestingly, a normal range of CK was observed in $31.5 \%$, in contrast to $3 \%, 17 \%$ and $29 \%$ of normal values for ALT, LDH and AST, respectively. A similar percentage of patients presented CK levels which were either normal, 5 times normal or up to 15 times normal, whereas a higher percentage of patients presented 5 times normal level of LDH, AST and ALT.

Histopathological findings for skeletal muscle (Table 1): Morphological alterations on muscle fibers including miofibrillar loss, necrotic fibers, regenerating fibers were observed in all cases except four (Fig 2). Degenerating aspects of muscle fibers were noted in all specimens and better demonstrated in acid phosphatase reaction (Fig 3).

The mean time up to the biopsy was 11 months ( \pm 16 months 15 days) with median of 4 months, ranging from 1 to 64 months. Five patients had their biopsies performed more than one year after disease onset, including the two patients submitted to a second biopsy. Morphological alterations in muscle biopsies of these patients were markedly slight, ranging from absent, to $50 \%$ of the analyzed fields $(++)$, in concordance to the moderate muscle weakness to normal muscle strength observed. Their CK levels were also normal, except in Case 9/14, which presented 25 times the normal level at first biopsy, decreasing to 3 times at the second biopsy performed 8 months later. It is noteworthy that in spite of the marked CK level increase in the latter case, the muscles' structural alterations, including muscle fiber morphological derangement and presence of inflammatory infiltration, were negligible. Moreover, the perifascicular atrophy was only demonstrated in the second biopsy. The two se-

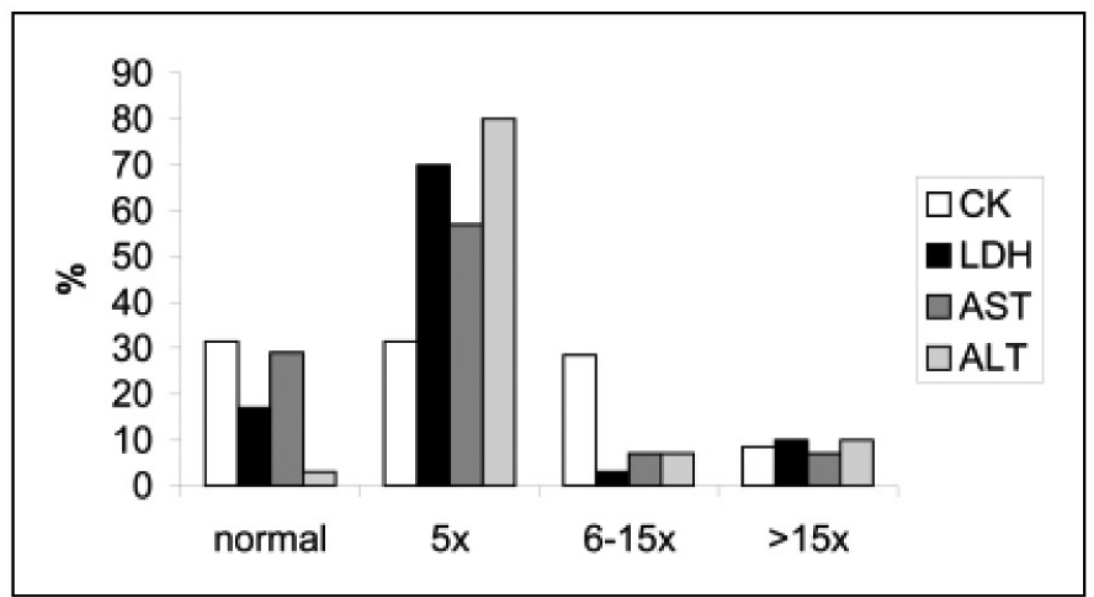

Graph 1. Comparative serum levels of muscle enzymes (CK, LDH, AST, ALT). $5 x=5$ times of normal value, $6-15 x=6$ to 15 times of normal value, $>15 x=$ more than 15 times of normal value. 


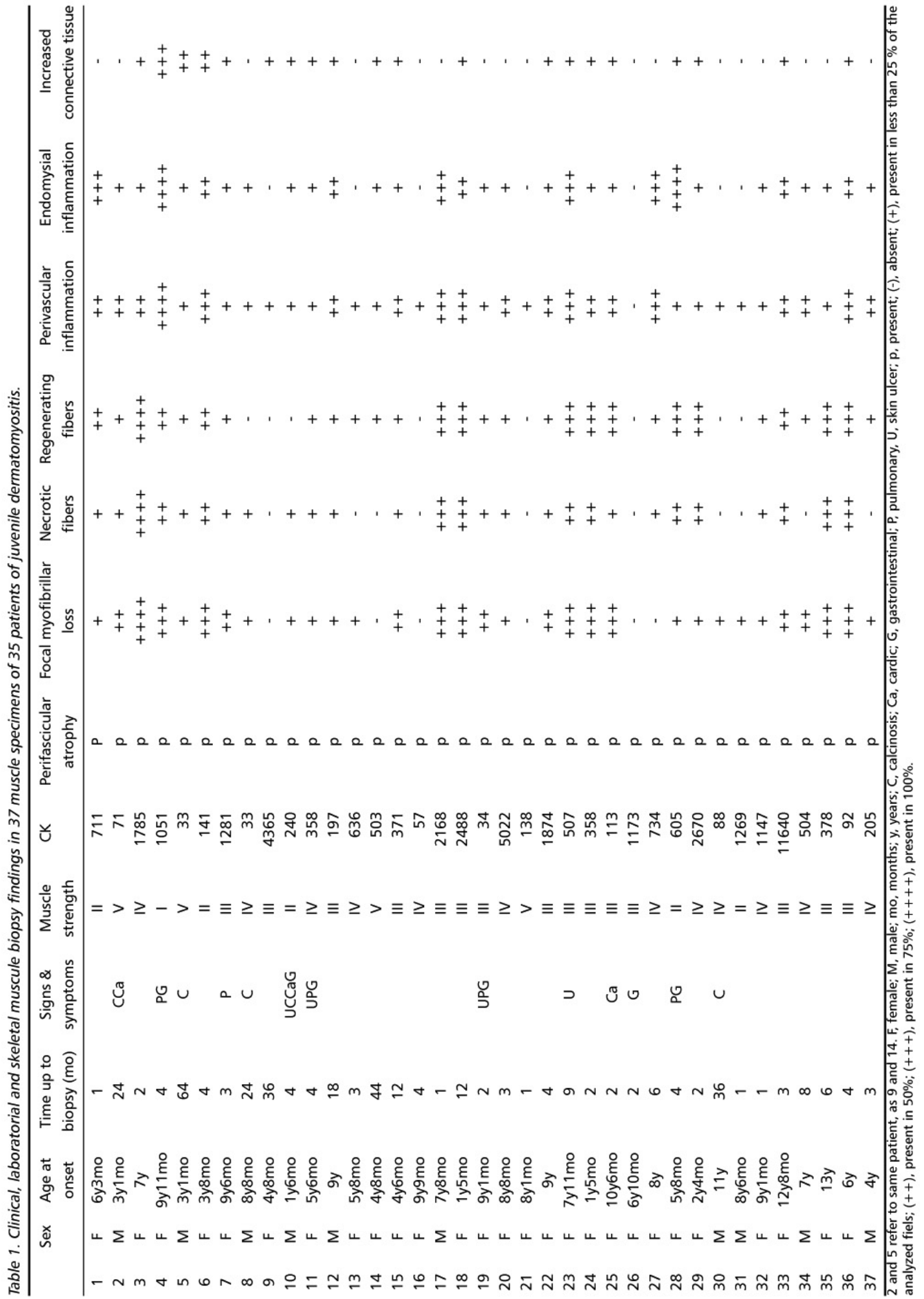




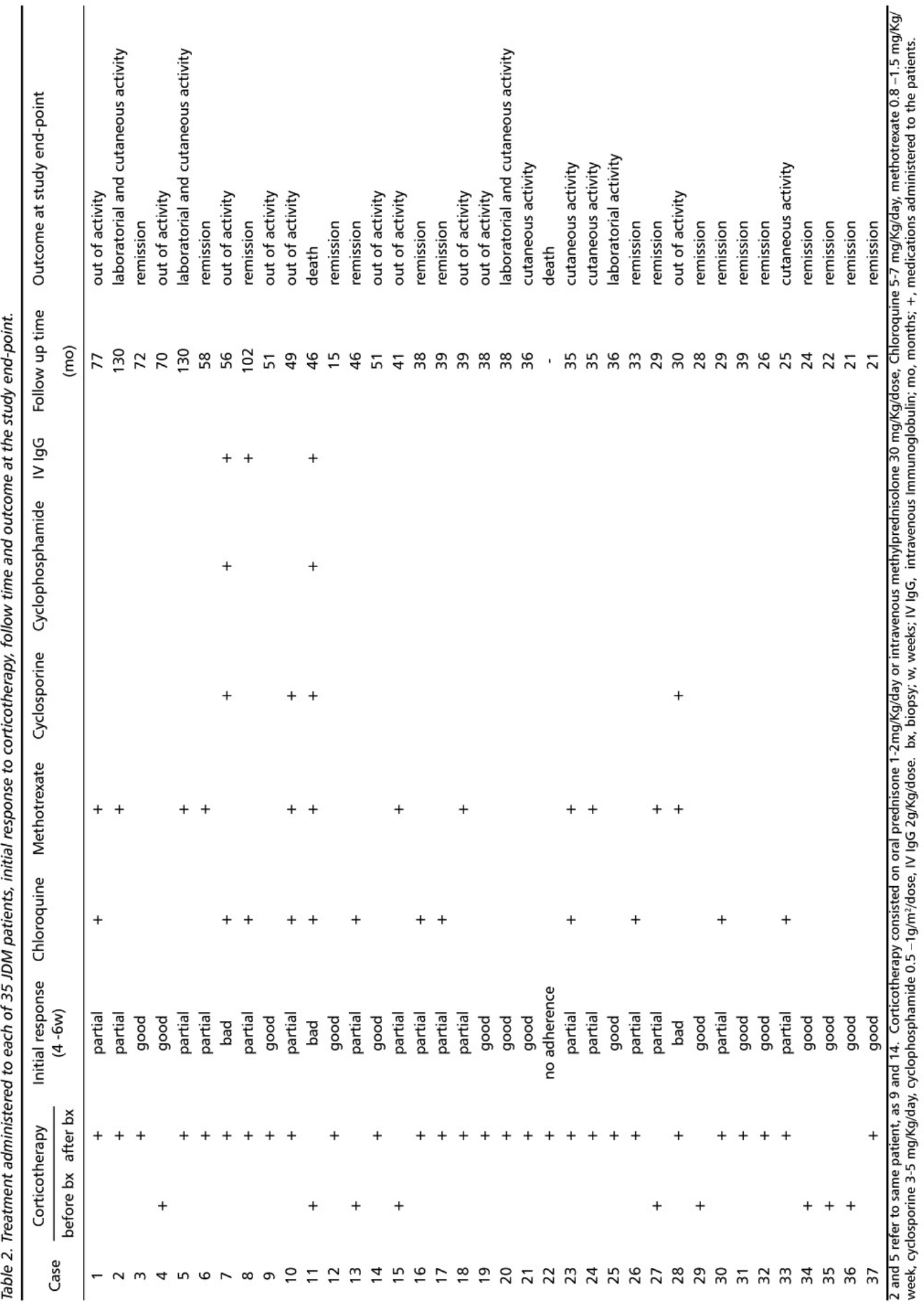


quential biopsies performed in another case $(2 / 5)$ with a 40-month time interval showed few differences between them. In the second biopsy, an increase in connective tissue and a slight decrease in perivascular inflammation, which had been scant from the outset, were observed.

30 biopsies were performed on patients during their first 12 months of symptoms, and among them 5 biopsies were carried out in the first month, 6 in the second month, 5 in the third month, 8 in the fourth month, 2 in the sixth month and 4 between the seventh and twelfth months of disease onset. Although the number of cases in each time interval was too small to permit statistical analysis, the muscle lesion and inflammatory infiltration were more evident in the group with less than one year of disease. $40 \%$ of biopsies performed in the first month presented muscle alteration for more than $50 \%(++)$ of fields studied, whereas the frequency of muscle lesions increased to $67 \%-100 \%$ of cases in subsequent time intervals up to 12 months.

Perifascicular atrophy was detected in all cases, independent of evolution time, being present even in the first month of the disease (Fig 1). Interestingly, slight proliferation of connective tissue was observed even in the first month since the onset of symptoms.

Surprisingly, striking inflammatory infiltration $(++/+++/++++)$, either endomysial or perivascular, was observed in 5 out of 9 patients who had been treated with corticotherapy before the biopsy procedure. Coincidentally, the great majority $(4 / 5)$ were female patients.

No relation was observed between degree of morphological muscle lesion, degree of inflammatory infiltration and CK serum level. Similarly, no association was found concerning CK level and evolution time interval up to biopsy and degree of muscle weakness.

Therapeutical and evolutional characteristics: All patients received corticotherapy, $9(25.71 \%)$ patients received therapy prior to muscle biopsy, and 26 (74.28\%) patients after it. 15 patients presented initial good response needing no complementary therapy. Partial response was observed in 16 patients, and bad response in 3, whom received additional associated therapy with Chloroquine (12 patients), Methotrexate (12), Cyclosporine (4), Cyclophosphamide (2) and intravenous Immunoglobulin (3). The medication administered to each patient, along with corresponding initial therapeutical status and outcomes at study end-point (March 2002), are listed in Tables 2 and 3.

Nine patients out of $19(47 \%)$ with partial or bad response, presented systemic involvement, in contrast to $20 \%$ involvement for those presenting good response (3/15). Additionally, patients with worse responses presented worse muscle weakness at the time of biopsy, as $62 \%$ of patients with an unsatisfactory response had grade I-III muscle strength, whereas similar muscle degree was observed in $46 \%$ of patients with good response.

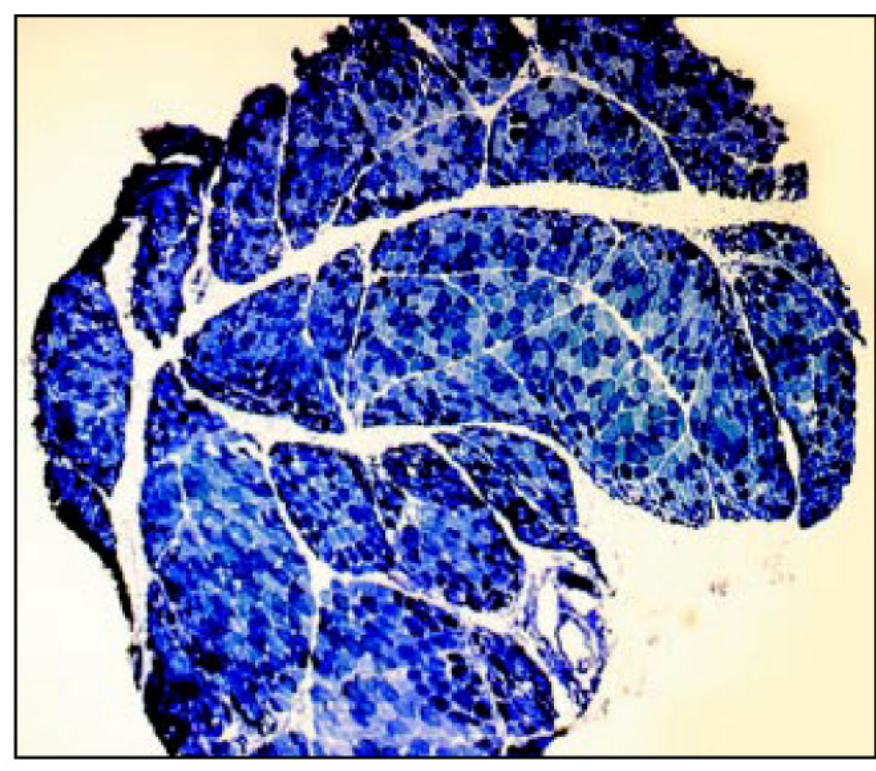

Fig 1. Transversal section of frozen skeletal muscle, $5 \mu$ of thickness, histochemical preparation of $\mathrm{NADH}, 40 \mathrm{x}$. All the fascicles in the fragment show perifascicular atrophy characterized by muscle fibers with decreased diameter distributed at periphery of the fascicle. 


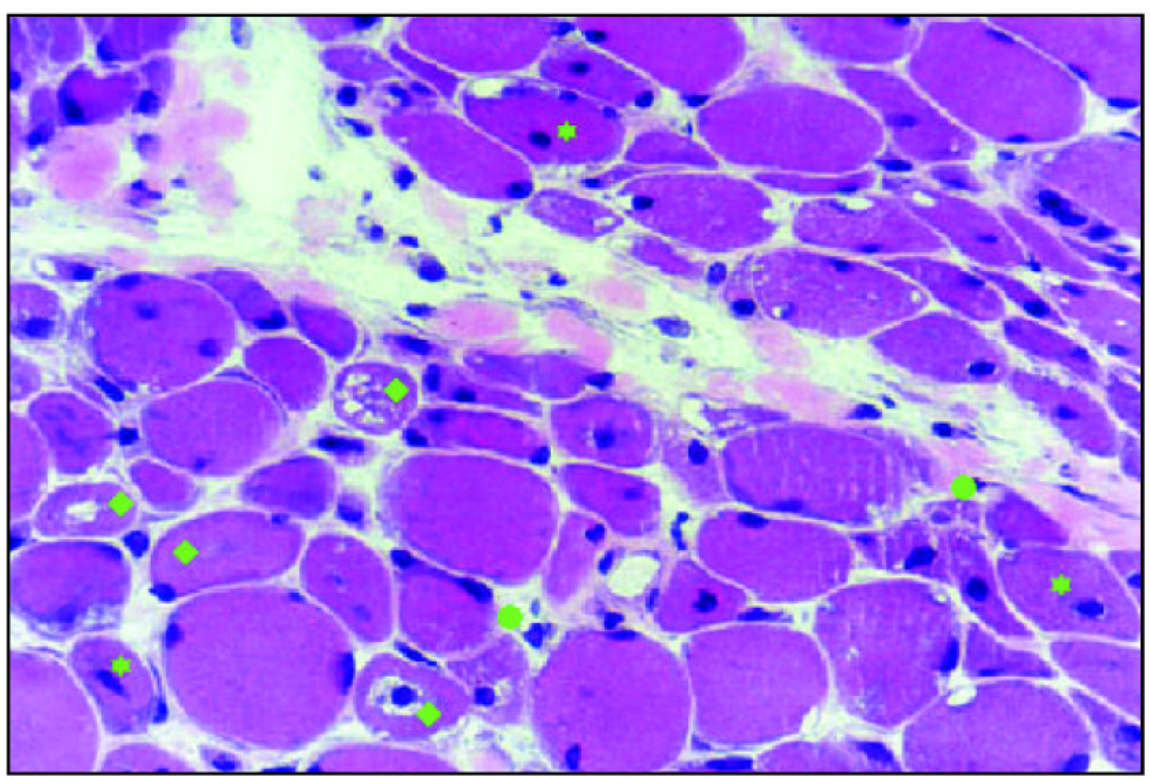

Fig 2. Transversal section of frozen skeletal muscle, $5 \mu$ of thickness, histological preparation of hematoxilineosin, 400x. Note the marked morphological alterations in the majority of muscle fibers characterized by the presence of internal nuclei ( ), focal myofibrillar losses with vacuolization ( ) and necrotic fibers ( ).

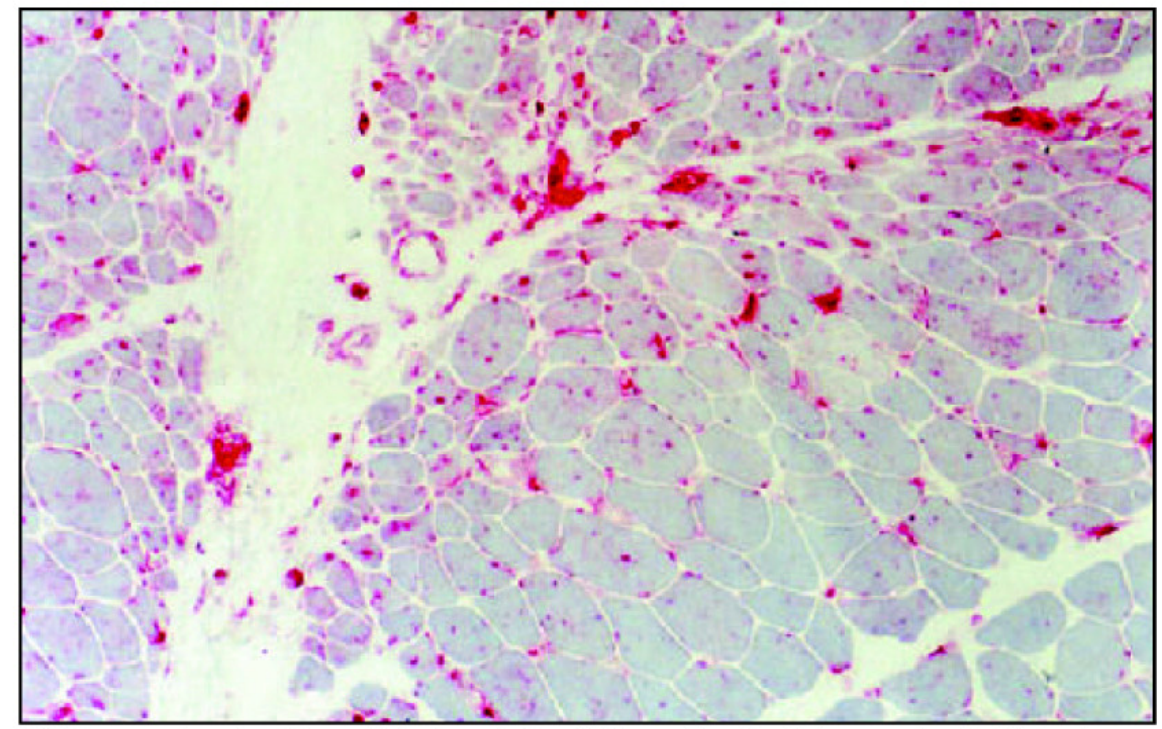

Fig 3. Transversal section of frozen skeletal muscle, $5 \mu$ of thickness, histochemical preparation of acid phosphatase, 200x. Red reaction in muscle fibers and vessels represent lisossomal activity distributed mainly at the periphery of fascicles.

The analysis of outcomes at study end-point revealed continuation of clinical activity associated to cutaneous manifestations in $4(11.43 \%)$ patients, laboratorial activity in 1 (2.85\%), cutaneous and laboratorial activities in $3(8.57 \%)$, out of activity in 10 (28.57\%), and remission in 17 (48.57\%) patients. Two (5.71\%) patients died: one with a complication of multisystemic involvement and another due to non-adherence to the treatment. $30 \%$ of female patients $(8 / 26)$ presented unsatisfactory evolution, in contrast to $11 \%$ of male patients (1/9). 
Table 3. Therapeutical response in 35 JDM patients.

\begin{tabular}{lcccccc}
\hline & Corticosteroids & Chloroquine & Methotrexate & Cyclosporine & Cyclophosphamide & IV IgG \\
\hline Good response & 15 & 9 & 6 & 3 & 1 & 1 \\
Partial response & 16 & 2 & 5 & 1 & 1 & 1 \\
Bad response & 3 & 1 & & & 1 \\
No adherence & 1 & 12 & 12 & 4 & 2 & 3 \\
Total of patients & 35 & & & & 1 \\
\hline
\end{tabular}

IV IgG, intravenous Immunoglobulin G.

No relapses were observed among patients in remission, follow-up being for 37 months on average. 11 out of 17 patients in remission had more than 2 years of follow-up.

Among 13 patients presenting systemic involvement, 8 patients $(61.5 \%)$ presented good outcomes, independent of the CK level, degree of muscle strength or inflammatory infiltration in muscle biopsy.

\section{DISCUSSION}

JDM makes up approximately $5 \%$ of annual visits to Pediatric Rheumatology reference centers ${ }^{4}$. In our experience, JDM ranks fourth among rheumatologic diseases, after rheumatic fever, juvenile rheumatoid arthritis and systemic lupus erythematosus ${ }^{8}$. It has been estimated that about one third of the 1000 or so cases published in the world literature, were in the pediatric age group (under 16 years).

JDM is different from the adult form of dermatomyositis. The clinical presentation in children is more frequently insidious and may be dominated by constitutional symptoms of fatigue, malaise, fever, anorexia and weight loss. Additionally, children have more often a multisystem vasculitis, which may involve the skin, gastrointestinal mucosa, heart, and retina. Children with longstanding, untreated disease, with generalized cutaneous vasculitis, frequently develop calcinosis. The association of malignancy with the development of myositis has been well described in adults, but only rarely reported in children. Once remission is achieved, children appear to return to normal muscle strength and function, more frequently than adults with dermatomyositis ${ }^{10-12}$.

Outcome depends on the precocity of diagnosis and treatment. Predictive parameters to guide the correct therapeutical approach, and for prognosis, are still lacking in JDM.

Therefore, this study was designed to describe clinical, laboratorial, and histological findings, and to correlate them to early response to the therapy adopted and to longstanding outcome features, in 35 JDM patients.

Age and gender distribution: It was previously reported that the most common age for onset of JDM was 6 years for boys, with two peaks of 6 years and 10 years for girls, with an overall average of 7 years for disease onset ${ }^{1}$. The mean age of disease onset in our study was in accordance with these reports, being 6 years 10 months on average, 6 years for boys, with peaks of 4 years 10 months and 9 years 6 months for girls.

A female predominance has been described in most of the rheumatic diseases in childhood, as was observed in the present study with a female to male proportion of 2.8:1.

Clinical findings: All patients in this study fulfilled these diagnostic criteria. An association with widespread vasculitis has also been made in this childhood disease. In fact, $34 \%$ of our patients presented systemic involvement including gastrointestinal tract, cardiac, respiratory and more severe cutaneous alterations, than predicted within the diagnostic criteria.

JDM may be associated with motor dysfunction of the entire gastrointestinal tract. Abnormal esophageal motor function is a complication of the disease and esophageal symptoms are frequently present. Small and large bowel involvement has also been documented ${ }^{13}$. Our patients presented esophageal gastric reflux, dysphagia and upper digestive tract bleeding.

There are few reports in the literature on cardiac involvement in $\mathrm{JDM}^{1}$. A few patients have cardiac murmurs or pericardial friction rubs and a high proportion show ECG changes ${ }^{14}$. In this study, three patients presented tachicardia with hypercinetic circulatory state shown by electrocardiogram. 
Lungs may be affected in JDM, primarily or through complications of muscle weakness ${ }^{15}$. In this study, aspirative pneumonia was present in two patients and interstitial disease in three patients. The pathological mechanisms of interstitial lung disease remain unknown. There is evidence that both cell mediated and humoral immunity play a role in the pathogenesis of this lesion. More recently, the role of the anti-Jo-I antibody has been highlighted ${ }^{15}$ in association with pulmonary interstitial disease. However, the anti-Jo-I antibody was negative in all patients in this study, even in those patients with interstitial disease, which corroborates previous reports describing the rarity of its presence in childhood.

Dystrophic calcification is two or three times more frequent in JDM than in adult dermatomyositis, occurring in $40 \%$ to $75 \%$ of children with $\mathrm{JDM}^{16}$. The calcification occurs in the interstitial of muscle or in the subcutaneous tissue, and it is readily visible on $X$ ray. Nodules of calcium may be extruded through perforations in the skin. We found a lesser incidence of calcinosis in our casuistic (11\%) than seen previously.

Skin ulceration may be considered among the systemic angiopathy referred to by Banker and Victor ${ }^{17}$. where necrotizing vasculitis has been identified. The same pathological condition has been described in skeletal muscle, subcutaneous tissue and gastrointestinal tract, resulting in muscle infarction, gastrointestinal ulceration, bleeding and perforation, constituting one of the major causes of death ${ }^{18}$. Few patients in the present study presented skin ulceration $(11 \%)$, however it was present in one of the 2 fatal cases, being part of the systemic angiopathy that lead to death.

Although muscle weakness is one of the criteria for diagnosis of inflammatory myopathy, it is not easy to assess this alteration objectively. The strength of muscles may be graded according to their ability to act against gravity and resistance offered by an examiner, as proposed by the well-known MRC grading system. However, such a system has the disadvantage of being subjective, depending on examiner impression. Moreover, about $40 \%$ of extremity muscles such as rotators and muscles moving fingers and toes, are not significantly affected by gravity. A careful examination of muscle strength, taking into account these difficulties, depicted only three patients with normal muscle power from our cases. A better, non-invasive method of assessing muscle function is necessary to permit correlation of this parameter to other findings, thus permitting a better search for predictive factors of evolution in $\mathrm{JDM}^{19}$.
Laboratorial and histopathological findings of skeletal muscle: It has been stressed that the serum levels of muscle enzymes are important for diagnosis and for monitoring the effectiveness of therapy ${ }^{1 .}$ However, CK levels were normal in $31 \%$ of our patients, in spite of presenting muscle weakness and/ or structural alterations and inflammatory infiltration in muscle biopsy. Unfortunately, the degree of increase in CK level did not also predict the outcome. The other muscle enzymes presented similar behavior.

Other serum specific markers for myositis have been considered, and antibody anti-Mi-2, an antibody against cytoplasmic ribonucleoprotein evolved in the translation process, is one of these candidates. However, in contrast to presence of anti-Mi-2 of up to $95 \%$ in dermatomyositis with classical cutaneous involvement, only $10-50 \%$ of cases of JDM presented this antibody. Therefore, most previous studies do not recommend routine clinical testing for anti-Mi2 since the yield is likely to be low. Moreover, it seems not to be a prognostic factor ${ }^{20}$.

Other non-specific indicators of inflammation, such as erythrocyte sedimentation rate, tend to correlate with the degree of clinical inflammation, and have are useful in differentiating inflammatory myopathies from non-inflammatory muscle disorders. However, the reported results are also variable and likely to be low.

On the other hand, muscle biopsy is important for establishing the diagnosis of an inflammatory myopathy and for understanding the character of the inflammatory change, such as its distribution and the degree of parenchyma involvement ${ }^{21}$. Although perifascicular atrophy may be present in other pathologies as dystrophies, it was described as a frequent finding in definite $\mathrm{DEM}^{22}$ and was found in all cases studied here (Fig 1). Perifascicular atrophy in the present study was observed as early as 1 month from the onset of symptoms and persisted for at least 64 months of the active disease. The inflammatory infiltration seems to be more evident from between two months of disease onset and up to one year, mostly in the first six months of the disease. After one year, there is apparently a decrease in the inflammatory alterations, even if untreated.

The introduction of corticotherapy tends to clear the inflammatory infiltration in lesioned tissues, but 5 of our treated patients presented inflammatory cells in muscle tissue and yet had good outcomes. However, the question as to whether the inflammatory reaction would have been greater without the treatment remains. 
Despite muscle biopsy being a fundamental diagnostic tool, its histological analysis is insufficient as a prognostic factor. Future biological markers, such as proteins involved in the pathomechanisms of tissue lesions, may be studied in muscle specimens by immunohistochemical methods to guide the best therapeutical approach ${ }^{23-25}$.

Therapeutical and evolutional characteristics: Treatment with corticosteroids does improve the prognosis. The death rate is reduced from around $33 \%$ to less than $10 \%{ }^{26}$. The acute stage, during which therapy is required, is generally self-limited and lasts for about two years ${ }^{27}$. Chloroquine has been used as a steroid-sparing agent, and as a drug that is effective in treating the dermatitis of JDM ${ }^{1}$. Glucocorticoid resistance or dependence is the primary indication for the use of immunosupressive drugs ${ }^{1}$. It is difficult to evaluate the efficacy of these drugs, since there have been no controlled trials in JDM treatment. However, some publications confirm the efficacy of corticotherapy, or other highly selective immunosuppressive therapy, in the management of this disease during its acute phase. Most authors agree that early diagnosis and early aggressive therapy, result either in reducing mortality or improving functional recovery ${ }^{28}$. Thus, the $74 \%$ remission or out of activity achieved by our patients at the study end-point, also corroborates these reports. The high incidence ( $88 \%$ ) of some extent of response to corticotherapy in our study, also confirms the efficacy of its use, and strongly suggests this as the drug of first choice.

The majority of fatalities occur within two years of disease onset, according to several reports ${ }^{29}$, although there are several periods of increased vulnerability to life-threatening complications, during the initial year of treatment. Gastrointestinal ulceration, hemorrhage and perforation, and myocardial and respiratory failure have been described as major causes of death in $\mathrm{JDM}^{30}$. Pulmonary involvement is another important cause of morbidity and mortality in JDM. Concordantly, one of our cases presented a fatal evolution owing to complications of multisystemic involvement. Non-adherence to treatment was the cause of our other fatal case. Later relapses with corticosteroid treatment programs (prednisone doses $<15 \mathrm{mg}$ ) in the first 24 months after cessation of treatment have also been described ${ }^{31}$. Our patients in remission, observed for more than 2 years on average, have not presented relapses to date. A lengthier follow-up will permit further conclusions to be drawn on the outcomes.
The present analysis of a representative number of cases of JDM, a rare childhood multisystemic disease, permitted us to conclude that:

1. Skeletal muscle involvement can be assessed by clinical evaluation, a qualitative method; by CK serum levels, not always corresponding to clinical or structural muscle condition; and by muscle biopsy, with perifascicular atrophy as a constant finding.

2. Adequate diagnosis and therapy resulted in a $74 \%$ good outcome within a mean follow-up period of 3 years 10 months.

3. None of the parameters analyzed, including muscle weakness, multisystemic alteration, CK level, degree of inflammatory infiltration and muscle fiber morphological alteration, presented predictive value.

4. Further studies are necessary aimed at finding biological markers to select and guide new therapeutical approaches for those patients presenting drawbacks.

\section{REFERENCES}

1. Cassidy JT, Petty RE. Juvenile dermatomyositis. In Cassidy JT, Petty RE (Eds.). Textbook of pediatric rheumatology. 3 Ed. Philadelphia: Saunders, 1995:323-364.

2. Ansell BM. Juvenile dermatomyositis. Rheum Dis Clin N Am 1991;17:931-942.

3. Ansell BM. Juvenile dermatomyositis. J Rheumatol 1992;19:60-62.

4. Mastaglia FL, Ojeda VJ. Inflammatory myophaties: Part I. Ann Neurol 1985;17:215-227

5. Mastaglia FL, Ojeda VJ. Inflammatory myophaties: Part II. Ann Neurol 1985:17:317-323

6. Bohan A, Peter JB. Polymyositis and dermatomyositis. N Engl J Med 1975;13:344-347.

7. Medical Research Council. Aids to the investigation of peripheral nerve injuries. War Memorandun No 7, 2.Ed. London: Her Majesty's Stationery Office, 1943.

8. Sogabe T. Dermato/polimiosite juvenil: estudo das características clínico-laboratoriais em 40 crianças. Dissertação (Mestrado) Universidade de São Paulo SP, 1993.

9. Bitnum S, Daeschner CW, Travis LB, Dodge WF, Hopps HC. Dermatomyositis. J Pediatr 1964;64:101-131.

10. Callen JP. Relationship of cancer to inflammatory muscle disease dermatomyositis, polymyositis and inclusion body myositis. Rheum Dis Clin N Am 1994;20:943-953.

11. Caloew EE, Cavaliere MJ, Perez NM. Muscle pathology in juvenile dermatomyositis. São Paulo Med J 1997;115:1555-1559.

12. Rider L. Childhood myositis: newly recognized diversity. In Plotz P (moderator). Myositis: immunologic contributions to understanding cause, pathogenesis, and therapy. Ann Intern Med 1995;122:715-724.

13. Horowitz M, McNeil JD, Maddern GJ, Collins PJ, Shearman DJC. Abnormalities of gastric and esophageal emptying in polymyositis and dermatomyositis. Gastroenterology 1986;90:434-439.

14. Dubowitz V. Inflammatory myopathies. In Dubowitz V (ed). Muscle disorders in childhood. 2.Ed. Philadelphia: Saunders, 1995:422-456.

15. Marie I, HatronP-Y, Hachulla E, Wallaert B, Michon-Pasturel U, Devulder B. Pulmonary involvement in polymiositis and in dermatomyositis. J Rheumatol 1998;25:1336-1343.

16. Bowyer SL, Blane CE, Sullivan DB, Cassidy JT. Childhood dermatomyositis: factors predicting functional outcome and development of dystrophic calcification. J Pediatr 1983;103:882-888.

17. Banker BQ, Victor M. Dermatomyositis (systemic angiopathy) of childhood. Medicine 1966:45:261-289.

18. Dillon MJ. Rare vasculitic syndromes. Ann Med 1997;29:175-179. 
19. Hoskimg GP, Bhat US, Dubowitz V, Edwards RHT. Measurements of muscle strength and performance in children with normal and diseased muscle. Arq Dis Child 1976;51:957-963.

20. Feldman BM, Reichlin M, Laxer RM, Targoff IN, Stein LD, Silverman ED. Clinical significance of specific autoantibodies in juvenile dermatomyositis. J Rheumatol 1996;23:1794-1797.

21. Dubowitz V. Histological and histochemical stains and reactions. In: Dubowtiz V (ed). Muscle biopsy: a practical approach. 2.Ed. London: Baillière Tindall, 1985:19-40.

22. Scola RH, Werneck LC, Prevenello DMS, Toderke EL, Iwamoto FM. Diagnosis of dermatomyositis and polymyositis: a study of 102 cases. Arq Neuropsiquiatr 2000;58:789-799.

23. Gonçalves FGP, Chimelli L, Sallum AME, Marie SKN, Kiss MHB, Ferriani VPL. Immunohistological analysis of CD59 and membrane attack complex of complement in muscle in juvenile dermatomyositis. J Rheumatol 2002;29:1301-1307.

24. Sallum AME. Expressão das moléculas de adesão (ICAM-1 e VCAM-1) em tecido muscular de pacientes com dermatomiosite juvenil. Dissertação
(Mestrado) Faculdade de Medicina da Universidade de São Paulo, 2002

25. Carvalho, AAS. Estudo imuno-histoquímico do complexo maior de histocompatibilidade classe I nas doenças neuromusculares. Importância no diagnóstico diferencial das miopatias inflamatórias. Tese (Doutorado), Universidade de São Paulo, São Paulo 1996.

26. Yoshioka M, Okuno T, Mikawa H. Prognosis and treatment of polymiositis with particular reference to steroid patients. Arch Dis Child 1985;60:236-244.

27. Miller JJ. Late progression in dermatomyositis in childhood. J Pediatr 1973;83:543-548.

28. Sullivan DB, Cassidy JT, Petty RE. Dermatomyositis in pediatric patient. Arthritis Rheum 1977;20:327-331.

29. Goel KM, Shanks RA. Dermatomyositis in childhood: review of eight cases. Arch Dis Child 1976:51:501-506.

30. Pachman LM, Cooke N. Juvenile dermatomyositis: a clinical and immunologic study. J Pediatr 1980;96:226-234.

31. Spencer BH, Stingien BH, Berstein BH, Kornreich HK, King KK. Course of treated juvenile dermatomyositis. J Pediatr 1984;105:399-408. 


\section{Immunohistochemical Analysis of Adhesion Molecule Expression on Muscle Biopsy Specimens from Patients with Juvenile Dermatomyositis}

ADRIANA M.E. SALLUM, SUELY K.N. MARIE, ALDA WAKAMATSU, SILVANA SACHETTI, MARIAAA.A.G. VIANNA, CLÓVIS A.A. SILVA, and MARIA H.B. KISS

ABSTRACT. Objective. To assess expression of intercellular adhesion molecule-1 (ICAM-1) and vascular cell adhesion molecule-1 (VCAM-1) on muscle biopsy specimens from patients with untreated juvenile dermatomyositis (JDM).

Methods. Histochemical and immunohistochemical tests for ICAM-1 and VCAM-1 were performed on serial frozen sections from 27 JDM muscle biopsy specimens. ICAM-1 and VCAM-1 expression was analyzed on capillaries, perimysial and endomysial large vessels, and muscle fibers. Expression was assessed and graded semiquantitatively.

Results. Increased ICAM-1 expression was observed on capillaries and perimysial large vessels on semiquantitative analysis, and was statistically more evident than on endomysial large vessels. In all cases, only a few muscle vessels showed expression of VCAM-1. Expression of ICAM-1 and VCAM-1 was observed on few muscle fibers.

Conclusion. The observation of ICAM-1 expression on muscle vessels, mainly on capillaries of patients with untreated JDM compared to controls, and VCAM-1 expression to a lesser extent, mostly on muscle vessels surrounded by inflammatory infiltrate, supports the participation of these adhesion molecules in the pathologic mechanism of vascular injury in JDM. (J Rheumatol 2004;31:801-7)

Key Indexing Terms:

JUVENILE DERMATOMYOSITIS ADHESION MOLECULES MUSCLE BIOPSY INTERCELLULAR ADHESION MOLECULE-1 VASCULAR CELL ADHESION MOLECULE-1

Juvenile dermatomyositis (JDM) is a rare systemic vasculopathy of unknown etiology and pathogenesis, with an incidence of 3.1 per million children per year ${ }^{1}$.

In JDM the most important target of immunopathologic attack seems to be the blood vessels of muscle, particularly the microvasculature, where deposits of immunoglobulin and activation of complement have been reported ${ }^{2,3}$. The activated complement might further/induce cytokine release, which will regulate expression of intercellular adhesion molecule-1 (ICAM-1) and vascular cell adhesion molecule-1 (VCAM-1) in the endothelial cells ${ }^{4,5}$. ICAM-1 and VCAM-1 are members of the immunoglobulin gene super-

$$
\text { imm }
$$

From the Department of Pediatrics, Department of Neurology, and Department of Rheumatology, Umversity of Säo Paulo Medical School: Department of Pediatrics, Santa Casa de Misericórdia de São Paulo Medical School; and the Adolfo Lutz Institute, Sāo Paulo, Brazil. Supported by a grant from EAPESP 98/16290-6.

A.M.E. Sallum, MD, Postgraduate Student; C.A.A. Silva, MD, PhD; M.H.B. Kiss, MD, PhD, Associate Professor, Department of Pediatrics; S.K.N. Marie, MD, PhD, Associate Professor, Department of Neurology, M.A.A.G. Vianna, MD, PhD, Department of Rheumatology, University of São Paulo Medical School; A. Wakamatsu, MS, Scientific Researcher, Adolfo Lutz Institute; S. Sachetti, MD, PhD, Department of Pediatrics,

Santa Casa de Misericordia de São Paulo Medical School.

Address reprint requests to Dr. A.M.E. Sallum, Avenida Jurit,

87 - apto 21, CEP 04520-000, Moema, São Paulo, Brazil. E-mail: adrianasallum@ig.com.br

Submitted February 5, 2003; revision accepted October 16, 2003. family. ICAM-1 expression on endothelial cells is constitutive, but can be markedly increased by exposure to cytokines. It is the major ligand for lymphocyte function associated antigen-1 (LFA-1), an adhesion molecule on leukocytes. VCAM-1 represents the endothelial cell ligand for very late activation antigen-4 (VLA-4), present on lymphocytes, eosinophils, and monocytes. Vascular endothelium in most normal tissues expresses little or no VCAM-1. Interactions of LFA-1/ICAM-1 and VLA4/VCAM-1 are likely responsible for the accumulation of inflammatory cells in autoimmune diseases ${ }^{6}$.

Reports suggest that the expression of adhesion molecules on vessels might be related to the pathologic mechanism of perivascular invasion of inflammatory cells, in addition to the activation of endothelial cells and E-selectin, which may also indicate the ongoing inflammatory process $^{7,8}$

Although some studies have investigated ICAM-1 and VCAM-1 expression in adult DM and other inflammatory myopathies such as polymyositis (PM) and inclusion body myositis (IBM) ${ }^{4,6-17}$, very few studies have been carried out $^{18,19}$ in JDM. We investigated the participation of these adhesion molecules in untreated JDM.

\section{MATERIALS AND METHODS}

We studied 27 out of 37 muscle biopsy specimens from patients fulfilling 
the Bohan and Peter criteria for $\mathrm{JDM}^{20,21}$ attending the Pediatric Rheumatology Unit of the Children's Institute, University of São Paulo Medical School and Santa Casa de Misericórdia de São Paulo Medical School. All patients were in the initial disease phase prior to introduction of any therapy. Nine cases that received corticosteroid therapy prior to biopsy were excluded, as well as one case in which the muscle specimen was not available for immunohistochemical preparations. The Bohan and Peter inclusion criteria were fulfilled as follows: (1) Muscle strength measured by Medical Research Council22: no patient presented degree I, 5 patients were degree II, 12 patients were degree III, 6 patients were degree IV, and 4 patients were degree V. (2) Serum muscle enzyme concentrations: (a) creatine kinase (CK): 18 patients presented increased level of CK; (b) AST, ALT, lactate dehydrogenase, aldolase: 9 patients presented alterations of at least one of the enzymes. (3) Electromyography was performed in only 6 patients, who showed alterations of myopathic pattern. (4) Muscle biopsy was performed in all patients, and showed inflammatory alterations. (5) Cutaneous involvement: heliotrope was present in 26 patients and Gottron's papules in 22.

The mean age of disease onset was 6 years, 7 months, ranging from 1 year, 5 months to 11 years.

The mean time up to the biopsy was 8 months (range 1 to $64 \mathrm{mo}$ ).

Nineteen out of 27 patients were mulatto, while 7 were caucasian, and one was black.

Fourteen age matched controls, with muscle weakness but without myositis, were also included. The mean age of controls was 8 years, ranging from 1 year and 9 months to 15 years of age. The controls were chosen from among untreated cases presenting only muscle weakness and/or hypotonia of unknown origin who underwent biopsy as a diagnostic procedure to exclude degenerative or structural diseases. No morphological Iterations or inflammatory infiltration of any kind were observed.

Prior to the muscle biopsy, patients were informed of the objectives of the examination and their written consent was obtained. The study was approved by the local ethics committee.

Histopathological and immunohistochemical methods. Muscle biopsy specimens were obtained from brachial biceps muscle in all patients, including patients with JDM and controls. All presented weakness in upper extremities, except Patients 2, 4, 11, and 17, who presented muscle strength grade V. A total of 27 muscle biopsy specimens of JDM paste strength 作 . mis. mployed me HeE, xydase, NADH -eerese adenosine triphosphase, pH 4.3 and 9.4, and alkaline and acid phosphatase ${ }^{23}$. Each muscle biopsy specimen was coded and analyzed separately by 2 investigators (AMES and SKNM), and any discrepancy was reviewed concomitantly. When consensus was not achieved, analysis was carried out by a third observer $(\mathrm{AW})$. Perifascicular atrophy was observed in all patients, and findings of focal myofibrilar loss, necrotic and regenerating fibers, perivascular and endomysial inflammation, and increased connective tissue were assessed semiquantitatively as described ${ }^{2}$

Immunoreagents. The monoclonal antibodies (Dakopatts) used in ICAM-1 and VCAM-1 were clone 6.5B5 (M7063) and 1.4C3 (M7106), in dilution of $1: 200$ and $1: 100$, respectively.

Strept-ABC-complex/HRP immunohistochemical procedure. Serial frozen sections of $5 \mu \mathrm{m}$ thickness were fixed for $10 \mathrm{~min}$ in acetone at $4^{\circ} \mathrm{C}$. Endogenous peroxidase was blocked with $\mathrm{H}_{2} \mathrm{O}_{2} 1 \%$ in absolute methanol 4 times, for 5 min each. After a rinse in distilled water followed by phosphate buffered saline (PBS; $0.01 \mathrm{M}, \mathrm{pH} 7$.4) for 5 min, the specimen was incubated in fetal calf serum in a wet chamber for $1 \mathrm{~h}$ at $37^{\circ} \mathrm{C}$. The primary antibody diluted in PBS and bovine serum albumin $1 \%$ was applied in a wet chamber at $37^{\circ} \mathrm{C}$ overnight. The slides were then washed in PBS, and the prepared secondary mouse biotinylated Strept-ABC-complex/HRP was applied for $30 \mathrm{~min}$ at $37^{\circ} \mathrm{C}$, then rinsed in PBS. Subsequently, the prepared
Strept-ABC-complex/HRP in 1:100 dilution was applied for $30 \mathrm{~min}$ at $37^{\circ} \mathrm{C}$, and after rinsing in PBS was incubated with a chromogenic substrat solution for peroxidase $3.3^{\prime}$-diaminobenzidine tetrahydrochloride (DAB) After a final rinse, hematoxylin counterstaining was performed. The slide were mounted and coverslipped with an aqueous mounting medium. Preparations of all muscle specimens were done at the same time as a batch. Each biopsy specimen was also analyzed separately by 2 investigator (AMES and SKNM). Ten random fields with $400 \times$ magnification, representing almost the entire area of the specimen and including an average of 500-1000 muscle fibers, were analyzed for capillaries and large vessels o endomysial and perimysial locations and muscle fibers. The expression of ICAM-1 and VCAM-1 was observed on lumen (at the luminal side of the vessel wall) and adventitia (on adjacent structures including vasa vasorum but not resident macrophages) of the large vessels (endomysial and perimysial vessels).

Immunohistochemical analysis. Expression of ICAM-1 and VCAM-1 was asse $\mathrm{d}$ by a semiqu assed by a $1-25 \%$ on al $51-75 \% ;$ and $(+++4)=76-100 \%$.

Statistical analysis. Semiquantitative analysis of ICAM-1 and VCAMexpression was interpreted with the Mann-Whitney and Kruskal-Wallis tests for independent samples. Comparison between the expression o endomysial and perimysial large vessels and capillaries in relation to the semiquantitative analysis was done using the Friedman test for relate samples. Accordance between the distribution of reaction results on endomysial and perimysial large vessels was tested by the McNemar test. Significance of $0.05(\alpha=5 \%)$ was adopted and descriptive levels (p) below that value were considered significant.

\section{RESULTS}

Expression of ICAM-1. Expression of ICAM-1 was positive on $100 \%$ of the muscle biopsy specimens (Table 1). The expression of ICAM-1 on vessels, especially capillaries and perimysial large vessels, was remarkable when compared to the low expression on muscle fibers (Figure 1). ICAM-1 expression on perimysial vessels and capillaries was similar and more marked than on endomysial large vessels an muscle fibers $(\mathrm{p}<0.001)$, as shown in Table 1 . No statistically significant difference was found between ICAM-1 expression on lumen and adventitia of endomysial and perimysial large vessels $(\mathrm{p}=0.228$; Table 1$)$. There was a remarkable statistical difference between ICAM-1 expression on JDM and control samples on capillaries $(\mathrm{p}=0.034)$ and endomysial $(\mathrm{p}=0.009)$ and perimysial large vessels $(\mathrm{p}$ $<0.001$ ), and no significant statistical difference between ICAM-1 expression on JDM and control samples on muscle fibers ( $\mathrm{p}=0.135$; Tables 1 and 2, Figure 1E).

No relevant correlation was found between the expression of ICAM-1 on capillaries, endomysial and perimysial vessels, and muscle fibers compared to the presence of focal myofibrilar loss, necrotic regenerating fibers, and increased connective tissue. Moreover, no difference was observed fo perivascular and endomysial inflammation in comparison to ICAM-1 expression.

Expression of VCAM-1. VCAM-1 expression was positive on 11 muscle biopsy specimens $(40.7 \%$; Table 1$)$ and on $9 / 11$ positive cases on vessels surrounded by inflammatory infiltrate. Among those, positive expression was found in 2 
Table 1. Immunohistochemical analysis of ICAM-1 and VCAM-1 in 27 untreated JDM muscle biopsy specimens.

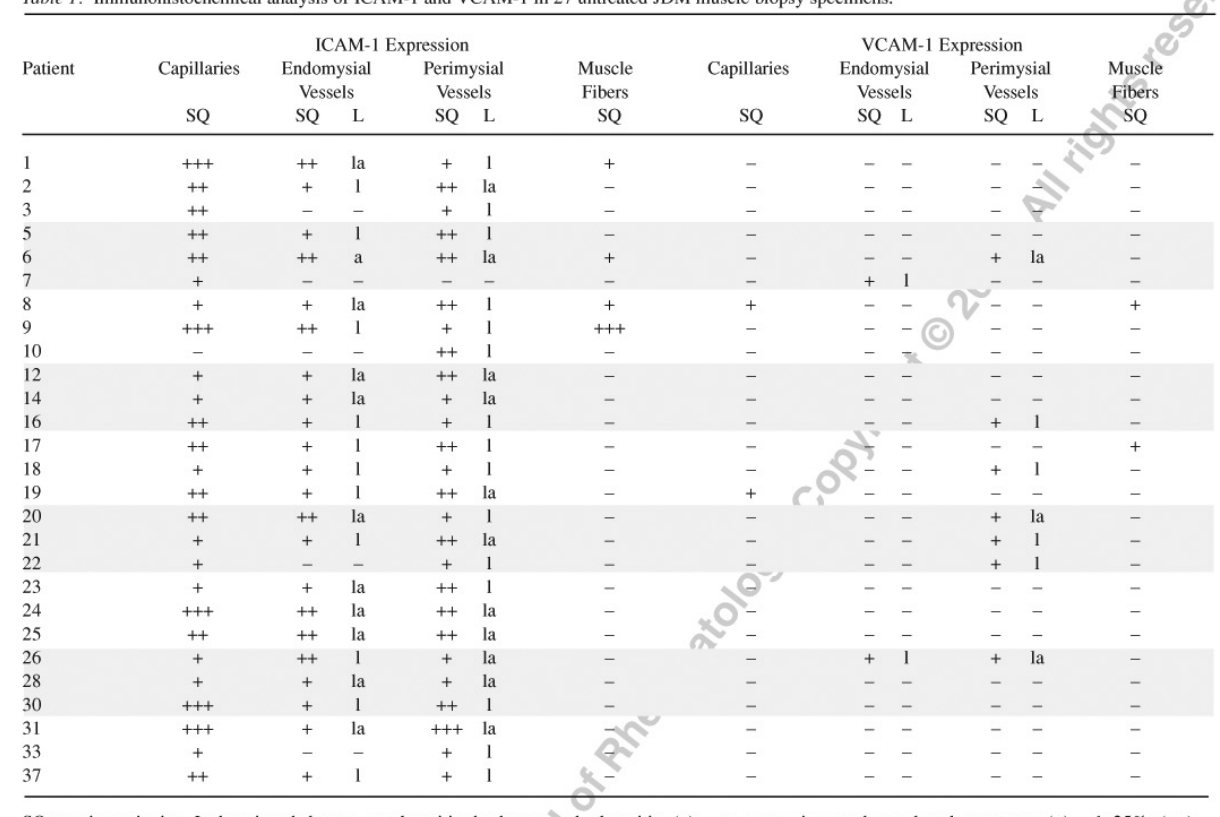

SQ: semiquantitative. L: location; 1: lumen, a: adventitia, la: lumen and adventitia. $(-)=$ no expression on the analyzed structures; $(+)=1-25 \% ;(++)=$ $26-50 \% ;(+++)=51-75 \% ;(++++)=76-100 \%$.

Table 2. Immunohistochemical analysis of ICAM-1 andyCAM-1 of 14 control muscle biopsy specimens.

\begin{tabular}{|c|c|c|c|c|c|c|c|c|}
\hline \multirow{3}{*}{ Controls } & \multicolumn{4}{|c|}{ ICAM-1 Expression } & \multicolumn{4}{|c|}{ VCAM-1 Expression } \\
\hline & Capillaries & $\begin{array}{c}\text { Endomysial } \\
\text { Vessels }\end{array}$ & $\begin{array}{c}\text { - Perimysial } \\
\text { Vessels }\end{array}$ & $\begin{array}{l}\text { Muscle } \\
\text { Fibers }\end{array}$ & Capillaries & $\begin{array}{l}\text { Endomysial } \\
\text { Vessels }\end{array}$ & $\begin{array}{c}\text { Perimysial } \\
\text { Vessels }\end{array}$ & $\begin{array}{l}\text { Muscle } \\
\text { Fibers }\end{array}$ \\
\hline & SQ & SQ & SQ & SQ & SQ & SQ & SQ & SQ \\
\hline
\end{tabular}

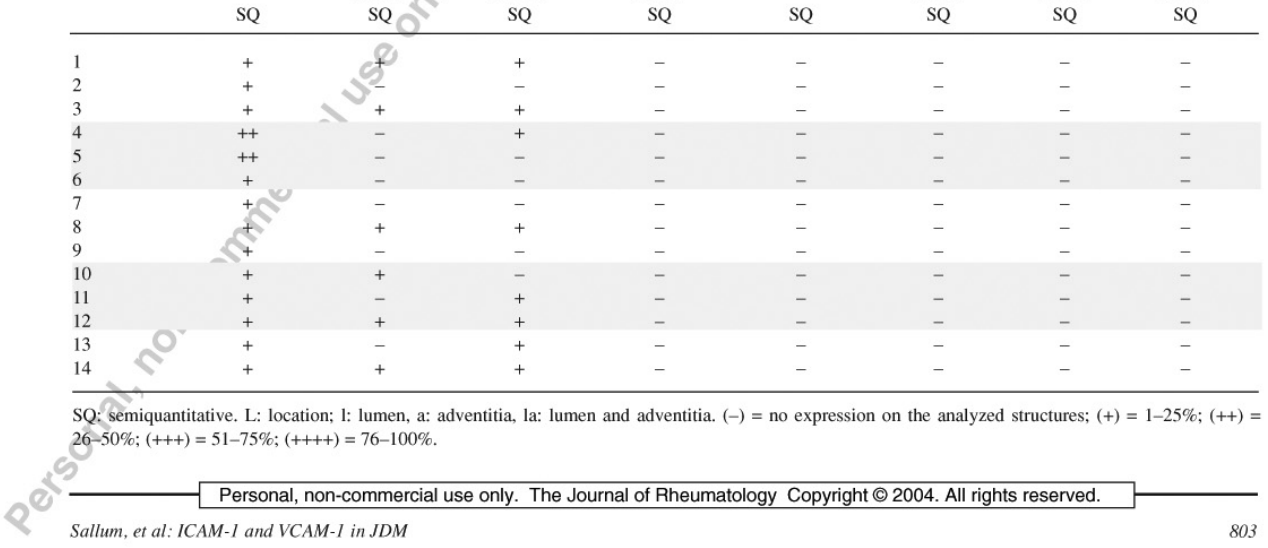


COLOUR

ICAM - 1

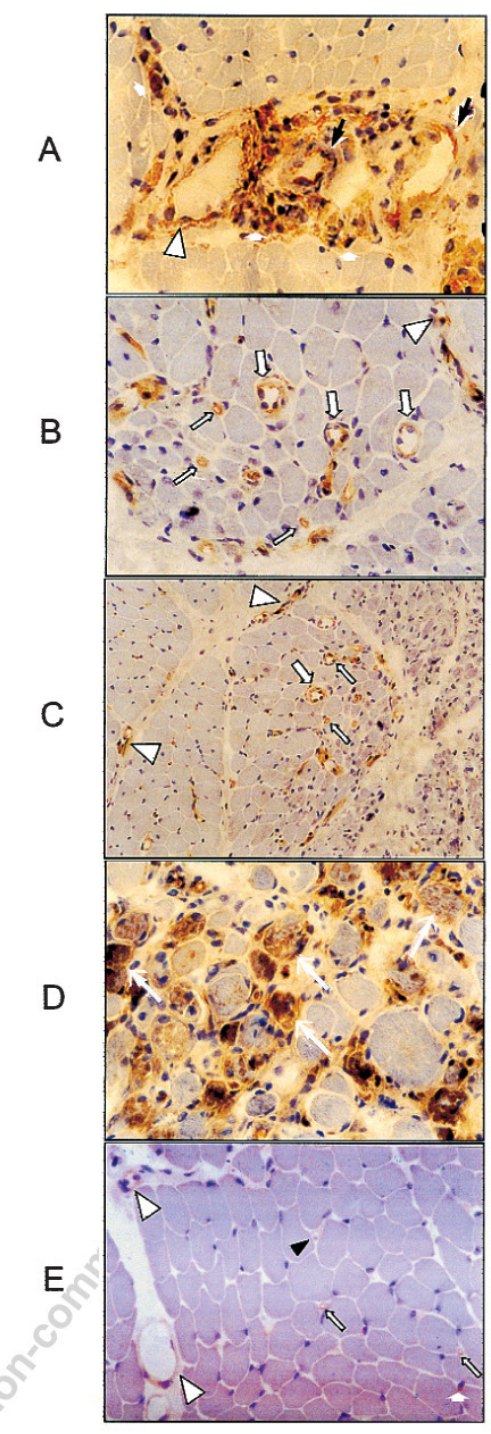

VCAM - 1

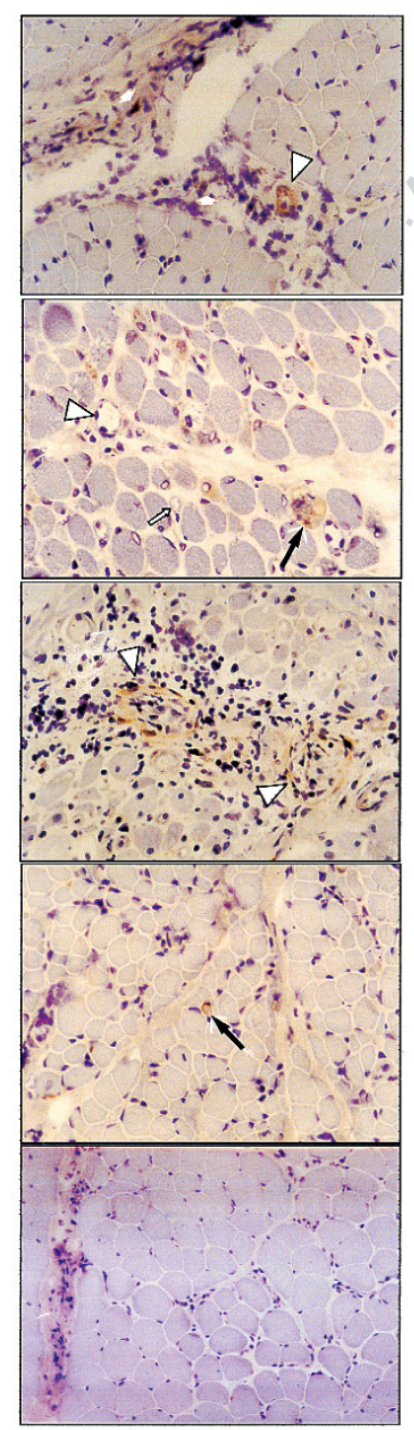

Personal, non-commercial use only. The Journal of Rheumatology Copyright $\odot$ 2004. All rights reserved. 
Figure I. Transverse serial sections of frozen muscle biopsy specimens. Immunohistochemical reaction Strept-ABC-complex for ICAM-1 and VCAM-1. JDM samples: A: Positive expression of ICAM-1 on adventitia (large arrowhead), and on lumen and adventitia (black arrows) of perimysial vessels. Positive expression of VCAM-1 on lumen of perimysial vessels (large arrowhead) (400x). B: Positive expression of ICAM-1 on capillaries (small arrows), endomysia large vessels (larger arrows), and on the lumen of perimysial vessels (large arrowhead). Positive expression of VCAM-1 on a degenerating fiber (black arrow), and negative expression of VCAM-1 on perimysial vessels (large arrowhead) and capillaries (small arrow) (400x). C: Positive expression of ICAM-1 on capillaries (small arrows), endomysial large vessels (larger arrow), and lumen of perimysial vessels (large arrowhead) (200x). Positive expression of VCAM 1 on perimysial vessels (large arrowheads) surrounded by inflammatory infiltrate (400x). D: Positive expression of ICAM-1 on degenerating fibers (white arrows). Positive expression of VCAM-1 on a single muscle fiber (black arrow) (400x). Controls, E: Positive expression of ICAM-1 on perimysial vessels (large white arrowheads), capillaries (small arrows), and a lymphoid cell (small white arrow, right); negative expression on some capillaries (black arrowhead). Negative expression of VCAM-1 (400x).

(7.4\%) cases on capillaries, $2(7.4 \%)$ on endomysial large vessels, and $8(29.6 \%)$ on perimysial large vessels. The positive expression was mostly on the lumen of the large vessels. Further, only 2 specimens $(7.4 \%)$ presented positive expression on muscle fibers. There was no meaningful statistical difference between VCAM-1 expression on capillaries, endomysial and perimysial large vessels, and muscle fibers ( $\mathrm{p}=0.093$; Table 1).

There was no significant statistical difference between VCAM-1 expression on JDM and controls on capillaries ( $\mathrm{p}$ $=0.714)$, endomysial $(p=0.714)$ and perimysial large vessels $(p=0.185)$, and muscle fibers $(p=0.302$; Tables 1 and 2, Figure 1E).

Similarly, no relevant correlation was found between the expression of VCAM-1 on capillaries, endomysial vessels, perimysial vessels, and muscle fibers and the morphological parameters analyzed on histological and histochemical preparations.

Time to biopsy. No statistically significant difference was found in the semiquantitative analysis of ICAM-1 and VCAM-1 on capillaries $(\mathrm{p}=0.534$ and $\mathrm{p}=0.820$, respectively), endomysial ( $p=0.900$ and $p=0.485)$ and perimysial large vessels $(\mathrm{p}=0.987$ and $\mathrm{p}=0.704)$, and muscle fibers ( $\mathrm{p}$ $=0.387$ and $p=0.820)$ and time to biopsy.

DISCUSSION

Our main finding was the increased ICAM-1 expression on intramuscular vessels, markedly on capillaries of patients with untreated JDM, compared to control muscle biopsies. In contrast, less striking VCAM-1 expression was observed on muscle vessels, mostly surrounded by inflammatory infiltrate. To our knowledge, this is the first study analyzing ICAM-1 and VCAM-1 expression on muscle biopsy specimens from patients with JDM. Previous studies on JDM just assessed serum levels of soluble adhesion molecules ${ }^{16,17}$. Studies concerning ICAM-1 expression on skeletal muscle vessels were carried out only on adult DM, and showed positive ICAM-1 immunostaining on muscle microvessels was much more intense than on PM or control biop$\operatorname{sies}^{4,10-12}$. Additionally, angiopathy in adult DM was confirmed by demonstration of active focal destruction of capillaries, and the presence of complement-induced vessel injury has been established by consistent evidence of activation of the complement cascade, with capillary damage mediated by membrane attack complex ${ }^{24-30}$. The activated complement C5a binds to endothelial cells and upregulates adhesion molecule expressions. Therefore, it might be possible that ICAM-1 and VCAM-1 expression on vessels is induced by complement activated products in sublethal endothelial cell injury ${ }^{4}$. As well, sublethal injury stimulates interleukin $1 \alpha(\mathrm{IL}-1 \alpha)$ production that induces ICAM-1 expression $^{31}$. Thus, the idea that complement activation products might induce cytokines that in turn induce ICAM1 and VCAM-1 expression is very attractive. It has been demonstrated that these adhesion molecules, not expressed on mature myofibers under physiological conditions, can be induced on myoblast culture ${ }^{32}$. As well, increased ICAM-1 expression on a variety of tissues including kidney, joint, skin, and salivary gland has also been described in other diseases with vascular involvement, such as antineutrophil cytoplasmic antibody-positive small vessel vasculitis, systemic lupus erythematosus, systemic sclerosis, rheumatoid arthritis, Behçet's disease, and Sjögren's syndrome ${ }^{33-38}$ Our findings of striking ICAM-1 expression mainly on muscle capillaries of JDM samples suggest that its induction on microvessels occurred during the pathophysiologic mechanism of vascular injury and persisted independently of the duration of symptoms and the intensity of the inflammatory process measured by the presence of inflammatory cells, since no correlations were observed between these variables. A previous study showed that ICAM-1 expression reaches its plateau and remains at this elevated level as long as active cytokines are present ${ }^{38}$, and it might be a possible explanation for the persistent ICAM-1 expression on muscle vessels of our JDM biopsies.

In contrast, we found VCAM-1 expression on only $40.7 \%$ of muscle biopsy specimens, compared to absent expression on control muscle biopsies. Moreover, those cases showed positive immunostaining in only $25 \%$ of the total vessels analyzed in each sample, whereas positive expression on vessels surrounded by inflammatory infiltrate was notable $(82 \%)$.

The role of VCAM-1 induction on endothelial cells in inflammatory myopathies remains controversial, as some reports show significant increases of VCAM-1 expression on microvessels in DM, and other studies describe its expression on some arterioles surrounded by inflammatory cells, but not on capillaries ${ }^{4,10,12}$. It has been reported that 
VCAM-1 is upregulated on the surface of endothelial cells after 6 hours, with peak expression after 24 hours ${ }^{39}$, from stimulation by the inflammatory cytokines IL-1 or tumor necrosis factor- $\alpha$, and remains at high levels for at least 72 hours after induction. VCAM-1 plays a role in recruiting immune-competent cells ${ }^{40}$. A possible explanation for the absence of VCAM-1 immunostaining on vessels of the remaining biopsies in our patients might be the time elapsed from induction.

The divergent results concerning VCAM-1 expression could also be due to different sensitivity of immunohistochemical protocols or the use of different antibodies.

Muscle fibers seem to play no role in the endothelial activation by these adhesion molecules, given that very few fibers presented reactivity to ICAM-1 or VCAM-1, as shown by others ${ }^{10,12,13,15}$.

We found no correlation between the time interval to muscle biopsy, the degree of the inflammatory process, and the expression of adhesion molecules on muscle vessels, in accord with a previous study ${ }^{11}$. The difficulties in establishing the exact time of onset of the disease based on clinical measures enhances the variability of these results.

We found ICAM-1 expression on muscle vessels, mainly on capillaries, of patients with JDM as compared to control muscle specimens; and we found VCAM-1 expression to a lesser extent, mostly on muscle vessels surrounded by inflammatory infiltrate, supporting the participation of these adhesion molecules in the pathologic mechanism of vascular injury in juvenile dermatomyositis.

\section{REFERENCES}

. Mendez E, Lipton R, Ramsey-Goldman R, et al. US incidence of juvenile dermatomyositis, 1995-1998: results from the National Institute of Arthritis and Musculoskeletal and Skin Disease Registry. Arthritis Rheum 2003:49:300-5.

2. Pachman LM, Cooke N. Juvenile dermatomyositis? a clinical and immunologic study. J Pediatr 1980;96:226-34

3. Estruch R, Grau JM, Fernández-Solá J, Casademont J, Monforte R, Urbano-Árquez A. Microvascular changes in skeletal muscle in idiopothic inflammatory myop thy Hum Pothe 1992,23 :888 95 .

4. Cid MC, Grau JM, Casademont J, et al. Leucocyte/endothelial cell adhesion receptors in muscle biopsies from patients with idiopathic adhesion receptors in muscle biopsies from patients with idiopathic
inflammatory myopathies. Clin Exp Immunol 1996:104:467-73.

5. Lozada CJ, Levin RL, Huie M, et al. Identification of Clq as the heat-labile serum cofactor required for immune complexes to heat-labile serum cofactor required for immune complexes to
stimulate endothelial expression of the adhesion molecules Estimulate endothelial expression of the adhesion molecules E-
selectin and intercellular and vascular cell adhesion molecules 1. Proc Natl Acad Sci USA 1995;92:8378-82.

6. Hausmann G, Mascaró JM Jr, Herrero C, Cid MC, Palou J, Mascaró JM. Cell adhesion molecule expression in cutaneous lesions of dermatomyositis. Acta Derm Venereol (Stock 1996;76:222-5

7. Kubo M, Inn H, Yamane K, et al. Increased serum levels of soluble vascular cell adhesion molecule-1 and soluble E-selectin in patients with polymyositis/dermatomyositis. Br J Dermatol 2000;143:392-8.

8. Banks RE, Gearing AJ, Hemingway IK, Norfolk DR, Perren TJ, Selby PJ. Circulating intercellular adhesion molecule-1, E-selectin and vascular cell adhesion molecule-1 in human malignancies. $\mathrm{Br}$ J Cancer 1993;68:122-4.
9. Bartoccioni E, Gallucci S, Scuderi F, et al. MHC class I, MHC class II and intercellular adhesion molecule-1 expression in inflammatory myopathies. Clin Exp Immunol 1994;95:166-72.

0. De Bleecker JL, Engel AG. Expression of cell adhesion molecules in inflammatory myopathies and duchenne dystrophy. J Neuropathol Exp Neurol 1994;53:369-76.

11. Kumamono T, Abe T, Ueyama H, Sugihara R, Shigenaga T, Tsuda T. Elevated soluble intercellular adhesion molecules- 1 in inflammatory myopathy. Acta Neurol Scand 1997;95:34-7.

12. Liprandi A, Figarella-Branger D, Daniel L, Lepidi H, Bartoli C, Pellissier JF. Expression des molécules d'adhésion dans les myopathies inflammatoires idiopathiques: étude immunohistochimique de 17 cas. Ann Pathol 1999;19:12-8.

13. Tews DS, Goebel HH. Expression of cell adhesion molecules in inflammatory myopathies. J Neuroimmunol 1995;59:185-94.

14. Lundberg I, Kratz AK, Alexanderson H, Patarroyo M. Decreased expression of interleukin-1 $1 \alpha$, interleukin-1B, and cell adhesion molecules in muscle tissue following corticosteroid treatment in patients with polymyositis and dermatomyositis. Arthritis Rheum 2000;43:336-48

15. Lindberg C, Oldfors A, Tarkowski A. Local T-cell proliferation and differentiation in inflammatory myopathies. Scand J Immunol 1995;41:421-6.

16. Matsubara S, Hirai S, Sawa Y. Pulsed intravenous

methylprednisolone therapy for inflammatory myopathies: methylprednisolone therapy for inflammatory myopathies:
evaluation of the effect by comparing two consecutive biopsies from the same muscle. J Neuroimmunol 1997;76:75-80

17. Englund P, Nennesmo I, Klareskog L, Lundberg IE. Interleukin-1a expression in capillaries and major histocompatibility complex class I expression in type II muscle fibers from polymyositis an dermatomyositis patients. Arthritis Rheum 2002;46:1044-55.

18. O'Gorman MRG, Bianchi L, Zaas D, Corrochano V, Pachman LM Decreased levels of CD54 (ICAM-1)-positive lymphocytes in the peripheral blood in untreated patients with active juvenile dermatomyositis. Clin Diagn Lab Immunol 2000; 7:693-7.

19. Bloom BJ, Miller LC, Blier PR. Soluble adhesion molecules in pediatric rheumatic diseases. J Rheumatol 2002;29:832-6.

20. Bohan A, Peter JB. Polymyositis and dermatomyositis. N Eng J Med 1975;13:344-7.

21. Sallum AME, Kiss MHB, Sachetti S, et al. Juvenile dermatomyositis: clinical, laboratorial, histological, therapeutical and evolutive parameters of 35 patients. Arq Neuropsiquiatr 2002;60:889-99.

22. Medical Research Council. Aids to the investigation of peripher nerve injuries. War Memorandun No. 7, 2nd ed. London: Her Majesty's Stationery Office; 1943

23. Dubowitz V. Muscle biopsy: a practical approach. Histological and histochemical stains and reactions. 2nd ed. Philadelphia: W.B. Saunders; $1985: 19-40$.

24. Banker BQ, Victor M. Dermatomyositis (systemic angiopathy) of childhood. Medicine 1966;45:261-89.

25. Jerusalem F, Rakusa M, Engel AG, Macdonald RD. Morphometric analysis of skeletal muscle capillary ultrastructure in inflammatory myopathies. J Neurol Sci 1974:23:391-401.

26. Carpenter S, Karpati G, Rothman S, Watters G. The childhood type Carpenter S, Karpati G, Rothman S, Watters G.
of dermatomyositis. Neurology 1976;26:952-62.

27. Whitaker JN, Engel WK. Vascular deposits of immunoglobulin and complement in idiopathic inflammatory myopathy. N Engl J Med complement in

28. Kissel JT, Mendell JR, Rammohan KW. Microvascular deposition of complement membrane attack complex in dermatomyositis. N Engl J Med 1986;314:329-34

29. Emslie-Smith AM, Engel AG. Microvascular changes in early and advanced dermatomyositis: a quantitative study. Ann Neurol 1990;27:343-56. 
30. Goncalves FG, Chimelli L, Sallum AM, Marie SK, Kiss MH, Ferriani VP. Immunohistochemical analysis of CD59 and membrane attack complex of complement in muscle in juvenile dermatony

31. Shreeniwas R, Koga S, Karakurum M, et al. Hypoxia-mediated induction of endothelial cell interleukin-1 alpha. An autocrine mechanism promoting expression of leukocyte adhesion molecules on the vessel surface. J Clin Invest 1992;90:2333-9.

32. Marino M, Scuderi F, Mazzarelli P, Mannella F, Provenzano C, Bartoccioni E. Constitutive and cytokine-induced expression of MHC and intercellular adhesion molecule-1 on human myoblasts. J Neuroimmunol 2001;116:94-101.

33. Andersen GN, Caidahl K, Kazzam E, et al. Correlation betwee increased nitric oxide production and markers of endothelial activation in systemic sclerosis. Arthritis Rheum 2000;43:1085-93.

34. Fuiano G, Sepe V, Magri P, et al. Intercellular adhesion molecule-as a marker of activity in lupus nephropathy. Contrib Nephrol 1992;99:131-4.
35. Kapsogeorgou EK, Dimitriou ID, Abu-Helu RF, Moutsopoulus HM, Manoussakis MN. Activation of epithelial and myoepithelial cells in the salivary glands of patients with Sjögren's syndrome: hig expression of intercellular adhesion molecule-1 in biopsy

specimens and cultured cells. Clin Exp Immunol 2001;124:126-33. . Lehner T. Immunopathogenesis of Behçet's disease. Ann Med Interne 1999;150:483-7.

37. Takagi T, Okamoto R, Suzuki K, et al. Upregulation of CD44 in rheumatoid chondrocytes. Scand J Rheumatol 2001;30:110-3.

38. Tanaka Y, Nomi M, Fujii K, et al. Intercellular adhesion molecule underlies the functional heterogeneity of synovial cells in patients with rheumatoid arthritis. Arthritis Rheum 2000;43:2513-22.

39. Pober J, Cotran RS. What can be learned from the expression of endothelial adhesion molecules in tissues? Lab Inves 1991;64:301-5.

40. Osborn L, Hession C, Tizard R, et al. Direct expression cloning of vascular cell adhesion molecule 1 , a cytokine-induced endothelial protein that binds to lymphocytes. Cell 1989;59:1203-11.

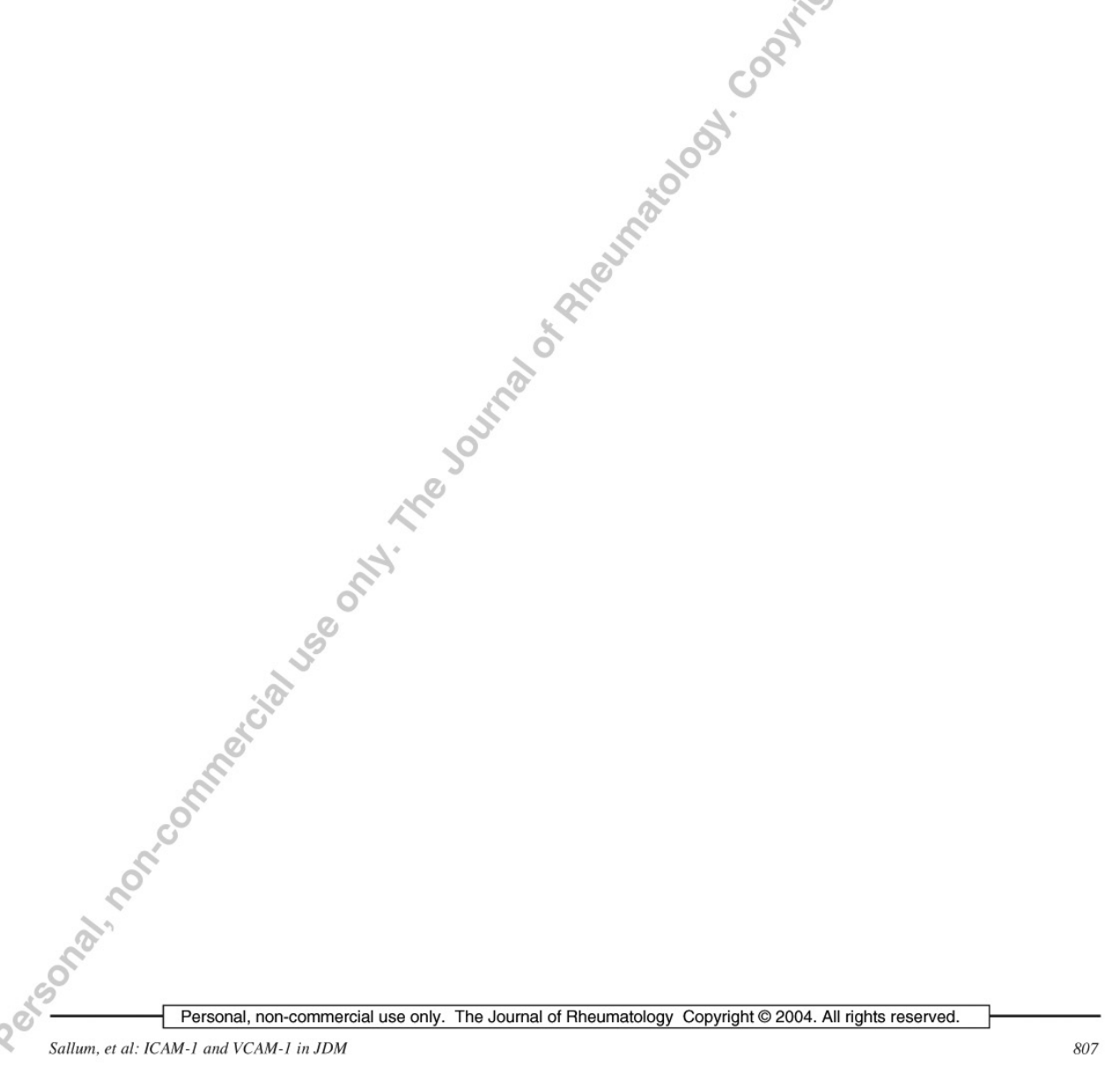




\section{ARTICLE IN PRESS}

\section{Difference in adhesion molecule expression}

(ICAM-1 and VCAM-1) in juvenile and adult dermatomyositis, polymyositis and inclusion body myositis

Adriana M.E. Sallum ${ }^{\text {a,* }}$, Maria H.B. Kiss ${ }^{\text {a }}$, Clovis A.A. Silva ${ }^{\text {a }}$, Alda Wakamatsu ${ }^{\text {, }}$, Maria A.A.G. Vianna ${ }^{c}$, Silvana Sachetti ${ }^{\text {d }}$, Suely K.N. Marie ${ }^{\mathrm{e}}$

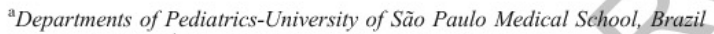
bAdolfo Lutz Institute São Paulo, Brazil

${ }^{\mathrm{c}}$ Rheumatology Department-University of São Paulo Medical School, Brazil

${ }^{\mathrm{d}}$ Departments of Pediatrics-Santa Casa Misericórdia de São Paulo Medical School, Brazil

${ }^{\mathrm{e}}$ Departments of Neurology-University of São Paulo Medical School, Brazil

Received 18 April 2005; accepted 25 May 2005

\section{Abstract}

To assess the differential expression of adhesion molecules ICAM-1 and VCAM-1 in vessels and muscle fibers in acquired inflammatory myopathy, a series comprising thirty-seven muscle biopsy specimens from patients with JDM, fifteen with DM, fifteen with PM and seven with IBM was studied. Histochemical and immunohistochemical tests (StreptABCcomplex/HRP) for ICAM-1 and VCAM-1 (Dakopatts) were performed in serial frozen sections. ICAM-1 expression in vessels was significantly $(p<0.0001)$ more present in JDM than PM, DM or IBM. However, in muscle fibers, ICAM-1 expression was absent in both JDM and IBM, but present in $33.4 \%$ and $40 \%$ in PM and DM respectively $(p<0.0001)$. VCAM-1 expression in vessels was significantly more present in PM and DM than JDM and IBM $(p<0.0001)$ while VCAM-1 expression in muscle fibers was almost absent in the four groups $(p=0.2632)$. These findings emphasize the importance of adhesion molecules in the pathophysiology of the inflammatory myopathies, mainly the marked ICAM-1 expression in vessels in JDM, corroborating the microvascular involvement in this disease. In contrast, VCAM-1 seems not to play a major role in JDM, as previously described in PM, DM and IBM. Adhesion molecule expression in JDM presents a differential characteristic when compared to PM, DM and IBM.

C 2005 Published by Elsevier B.V.

Keywords: Inflammatory myopathies; Adhesion molecules; ICAM-1; VCAM-1; Muscle biopsy

Grant from FAPESP 98/16290-6.

* Corresponding author. Av. Juriti, 187 apto 21, Cep: 04520-000, São Paulo, São Paulo, Brazil. Tel./fax: +55 1132140032.

E-mail address: adrianasallum@ig.com.br (A.M.E. Sallum).

1568-9972/\$ - see front matter C 2005 Published by Elsevier B.V.

doi:10.1016/j.autrev.2005.05.008 


\section{ARTICLE IN PRESS}

Contents

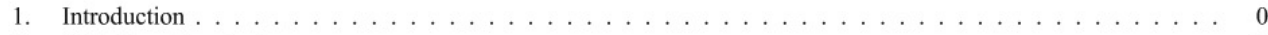

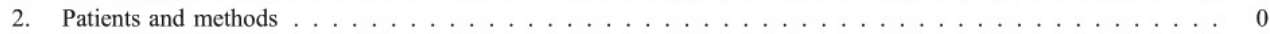

2.1. Histopathological and immunohistochemical methods . . . . . . . . . . . . . . . . . . . . . . 0

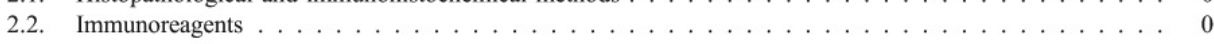

2.3. StreptABComplex/HRP Immunohistochemical procedure . . . . . . . . . . . . . . . . . . . 0

2.4. Immunohistochemical analysis . . . . . . . . . . . . . . . . . . . . . . 0

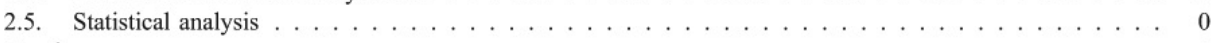

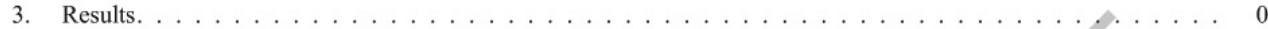

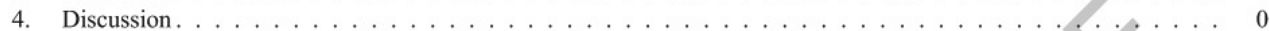

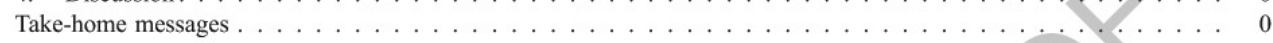

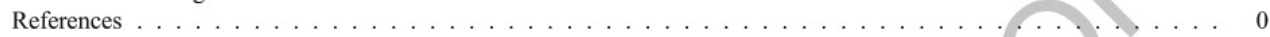

\section{1. Introduction}

Distinct clinical, histological, and immunopathological characteristics allow classification of the acquired inflammatory myopathies into dermatomyositis, polymyositis and sporadic inclusion body myositis [1-6]. Juvenile dermatomyositis (JDM) is the most common inflammatory myopathy in children, followed by far fewer cases of juvenile polymyositis, amyopathic dermatomyositis, overlap myositis and inclusion body myositis $[1,7,8]$. It is well known that JDM is characterized by marked vasculitis, more so than PM and DM $[9,10]$.

In JDM the most important target of immunopathologic attack has been shown to be the muscle blood vessels, particularly microvasculature, where deposits of immunoglobulin and activation of complement have been reported [11-14].

Moreover, there is a body of evidence pointing to microangiopathy and muscle ischemia in DM, whereas an antigen-directed cytotoxicity mediated by a cytotoxic T cells mechanism leads to skeletal muscle damage in PM and IBM $[15,16]$. This immunopathogenic mechanism involving antigen-specific cytotoxic $\mathrm{T}$ cells is a restricted MHC class I-dependent process [17]. Additionally, MHC-I and -II dependent processes require expression of ICAM-1, which is necessary to stabilize the interactions between the cell receptor and MHC-peptide complex in antigen recognition [18].
In this context, the expression analysis of these 71 adhesion molecules could be of value to further the 72 understanding of differences in the pathomechanisms 73 of the acquired inflammatory myopathies.

\section{Patients and methods}

Thirty-seven muscle biopsy specimens from patients fulfilling Bohan and Peter definite criteria for JDM [1,10], fifteen for DM, fifteen for PM, and seven for IBM, and attending the Pediatric and Rheumatology Units-University of São Paulo Medical School and Santa Casa de Misericórdia de São Paulo Medical School, were studied.

Prior to the muscle biopsy, the patients were informed of the objectives of the examination and their written consent was obtained. The study was approved by the local ethics committee.

\subsection{Histopathological and immunohistochemical methods}

Muscle biopsy specimens were obtained from brachial biceps muscle in all patients. A total of thirtyseven muscle biopsy specimens of JDM patients, fifteen of DM, fifteen of PM and seven of IBM were submitted to histopathological and immunohistochemical analysis. Routine standard histological and

Fig. 1. Immunohistochemical reactions with ICAM-1 and VCAM-1 antibodies in JDM, DM, PM and IBM. [JDM]: positive ICAM-1 expression (A) and negative VCAM-1 expression (B) in vessels. Muscle fibers with positive ICAM-1 expression (C) and negative VCAM-1 expression (D). [DM]: positive ICAM-1 (E) and VCAM-1 (F) expressions in muscle fibers (arrowheads) and vessels (arrows). [PM]: positive ICAM-1 (G) and VCAM-1 (H) in muscle fibers (arrowheads) and vessels (arrow), markedly near the inflammatory cell infiltration. VCAM-1 expression was observed in the sarcolemma (arrowheads). [IBM]: negative ICAM-1 (I) and VCAM-1 (J) in muscle fibers and vessels. 


\section{ARTICLE IN PRESS}

A.M.E. Sallum et al. / Autoimmunity Reviews $x x$ (2005) $x x x-x x x$
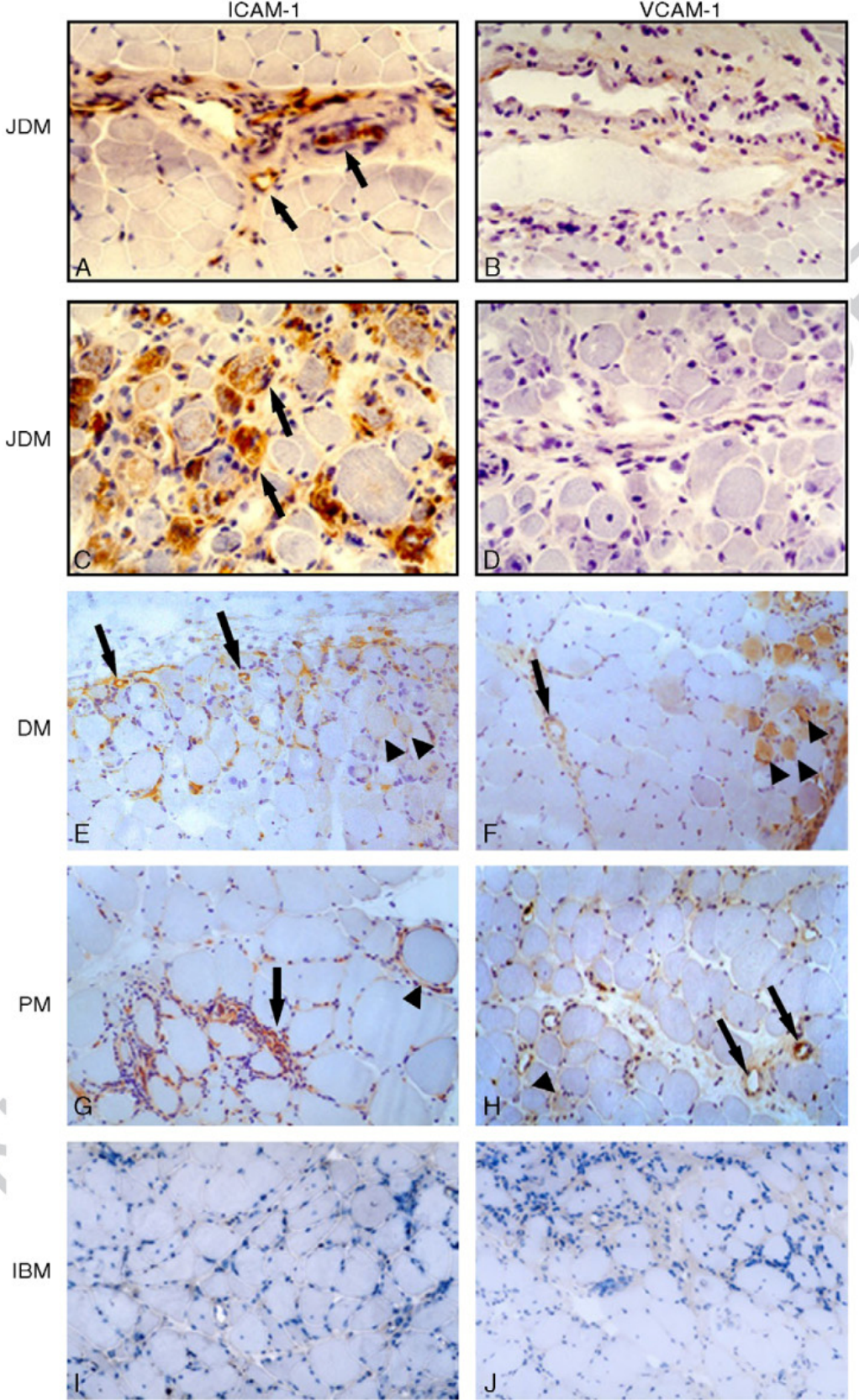


\section{ARTICLE IN PRESS}

95 histochemical techniques were employed in muscle 96 biopsies. Sequential frozen sections were stained 97 with $\mathrm{H}$ and $\mathrm{E}$, modified Gomori trichrome, periodic 98 acid Schiff, cytochrome C oxydase, NADH-tetrazoli99 um-reductase, succinate dehydrogenase, adenosine tri100 phosphatase $\mathrm{pH} 4.3$ and 9.4, and alkaline and acid 101 phosphatase [19]. Each muscle biopsy specimen was 102 coded and analyzed separately by three investigators 103 (AMES, MAAGV, SKNM), where any discrepancies 104 arising were reviewed concomitantly. Further, when 105 consensus was not reached, analysis by a fourth ob106 server (AW) was performed.

\section{2.2. Immunoreagents}

108 The monoclonal antibodies (Dakopatts) used in 109 ICAM-1 and VCAM-1 were clone 6.5B5 (M7063) 110 and $1.4 \mathrm{C} 3$ (M7106), in dilution of $1: 200$ and $1: 100$, 111 respectively.

112 2.3. StreptABComplex/HRP Immunohistochemical 113 procedure

114 Serial frozen sections of $5 \mu \mathrm{m}$ thickness were 115 fixed for $10 \mathrm{~min}$ in acetone at $4{ }^{\circ} \mathrm{C}$. Endogenous 116 peroxidase was blocked with $\mathrm{H}_{2} \mathrm{O}_{2} 1 \%$ in absolute 117 methanol four times, for $5 \mathrm{~min}$ each. After a rinse in 118 distilled water followed by phosphate-buffered-saline 119 (PBS $0.01 \mathrm{M}, \mathrm{pH} 7.4$ ) for $5 \mathrm{~min}$, the specimen was

120 incubated in fetal serum in a wet chamber for $1 \mathrm{~h}$ at

$12137{ }^{\circ} \mathrm{C}$. The primary antibody diluted in PBS and BSA

$1221 \%$ was applied in a wet chamber at $37{ }^{\circ} \mathrm{C}$, over-

123 night. The slides were then washed in PBS, the

124 prepared secondary mouse biotinylated (StreptAB-

125 Complex/HRP) was applied for $30 \mathrm{~min}$ at $37{ }^{\circ} \mathrm{C}$,

126 and rinsed in PBS. Subsequently, the prepared Strep-

127 tABComplex/HRP complex in 1:100 dilution was

128 applied for $30 \mathrm{~min}$ at $37^{\circ} \mathrm{C}$, and, after rinsing in

129 PBS, was incubated with a chromogenic substrate

130 solution for peroxidase $3.3^{\prime}$-diaminobenzidine tetra-

131 hydrochloride (DAB). After a final rinse, haematox-

132 ylin counterstaining was performed. The slides were

133 mounted and coverslipped with an aqueous based

134 mounting medium. The preparation of all muscle

135 specimens were done at the same time as a batch.

136 Each biopsy specimen was also analyzed separately

137 by three investigators (AMES, MAAGV and SKNM).

138 Ten random fields with $400 \times$ magnification, repre- senting almost the entire area of the specimen, and including an average of 500-1000 muscle fibers were analyzed for capillaries and large vessels on endomysial and perimysial location and muscle fibers. The expression of ICAM-1 and VCAM-1 was observed on lumen (at the luminal side of the vessel wall) and adventitia (on the neighboring structures including vasa vasorum but not resident macrophages) of the large vessels (endomysial and perimysial vessels).

2.4. Immunohistochemical analysis

ICAM-1 and VCAM-1 expressions were semiquantitatively analyzed in vessels and muscle fibers, where $(-)=$ no expression; $(+)=$ expression between $1 \%$ and $25 \%$ of the analyzed structures; $(++)=$ expression between $26 \%$ and $50 \%$ of the analyzed structures; $(+++)=$ expression between $51 \%$ and $75 \%$ of the analyzed structures; $(++++)=$ expression between $76 \%$ and $100 \%$ of the analyzed structures.

2.5. Statistical analysis

The results of ICAM-1 and VCAM-1 expression in 158 semi-quantitative analysis were achieved using Mann- 159 Whitney and Kruskal-Wallis tests. Significance of 160 $0.05(\alpha=5 \%)$ was adopted and descriptive levels $(p) \quad 161$ below this value were considered significant.

\section{Results}

ICAM-1 expression in vessels was more evident 164 $(p<0.0001)$ in JDM than PM, DM and IBM. On the 165 other hand, in muscle fibers, ICAM-1 expression was 166

Table 1

Positive expression $(++/+++)$ of adhesion molecule expression in vessels and muscle fibers in JDM, PM, DM and IBM

\begin{tabular}{llllll}
\hline$++1++$ & JDM & PM & DM & IBM & t1.3
\end{tabular}

$\begin{array}{llllll} & \overline{\%} & \overline{\%} & \overline{\%} & \overline{\%} & \mathrm{t} 1.4\end{array}$

\begin{tabular}{lllllll}
\hline ICAM-1 & Vessels & 81 & 33 & 40 & 0 & t1.5
\end{tabular}

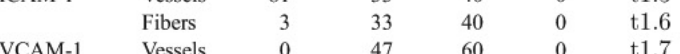

$\begin{array}{lllrrrr}\text { VCAM-1 } & \text { Vessels } & 0 & 47 & 60 & 0 & \mathrm{t} 1.7 \\ & \text { Fibers } & 0 & 0 & 7 & 0 & \mathrm{t} 1.8\end{array}$

$(++)=$ expression between $26 \%$ and $50 \%$ of the analyzed structures $(+1+)=$ expression between $51 \%$ and $75 \%$ of the analyzed $(++)=$ expression between $51 \%$ and $75 \%$ of the analyzed
structures. 


\section{ARTICLE IN PRESS}

A.M.E. Sallum et al. / Autoimmunity Reviews $x x$ (2005) $x x x-x x x$

Table 2

Semi-quantitative analysis of adhesion molecule (ICAM-1 and VCAM-1) expression in vessels and muscle fibers in JDM, PM, DM and IBM

t2.2

t 2.4

$\mathrm{t} 2.5$

$\mathrm{t} 2.6$
$\mathrm{t} 2.7$

t 2.8

t 2.9

$\mathrm{t} 2.10$

$\mathrm{t} 2.11$

t2.12

$\mathrm{t} 2.13$

t2.14

t2.15

t2.16

t2.17

t2.18

t2.19

$\mathrm{t} 2.20$

t 2.21

$\mathrm{t} 2.22$

$\mathrm{t} 2.23$

t2.24

+2.25

t 2.27

t 2.28

t2.29

t 2.30

t2.31

t 2.32

t 2.33

t2.34

$\mathrm{t} 2.35$

$\mathrm{t} 2.36$

t 2.37

$\mathrm{t} 2.38$

t2.39

t2.40

t2.41

t2.42 P

t 2.43

t2.44

t 2.45

t 2.46

t 2.47

$\mathrm{t} 2.48$

t2.49

t 2.50

t2.51

t 2.52

$\mathrm{t} 2.53$

$\mathrm{t} 2.54$

t2.55

t2.56 ICAM-1 VCAM-1

\begin{tabular}{lllll} 
& VESSELS & FIBERS & VESSELS & FIBERS \\
\hline DMJ & 1 & + & -
\end{tabular}

\begin{tabular}{llllll}
\hline DMJ & 1 & $H+$ & + & - & - \\
2 & $+H$ & - & - & -
\end{tabular}

3
4

3
4
5

6

10

11

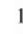

14
15

16

16
17

18
19

20

21

23

24
25

26
27

28

30
31

31
32

33

34
35

M

M

36
-17
-1

$\frac{1}{2}$

2
3
4

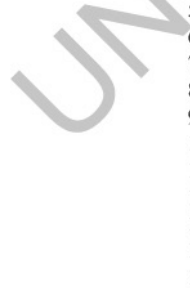

5

$7+$

$\begin{array}{ll}8 & + \\ 10 & + \\ 10 & +\end{array}$

$+$

$+$

$+$

$\begin{array}{ll}4+ & 2 \\ H+ & + \\ H+ & + \\ H+\end{array}$

$+$

+
+

+
+

+
+
+

+
+
+

$++$

++
+

++
+
+

$+$

$+1+$

$+1$

$++$

$+$

$11++$

13

15

+
+
+

$\begin{array}{lll}- & - \\ - & - & - \\ - & - & -\end{array}$




\section{ARTICLE IN PRESS}

6

A.M.E. Sallum et al. / Autoimmunity Reviews $x x$ (2005) $x x x-x x x$

Table 2 (continued)

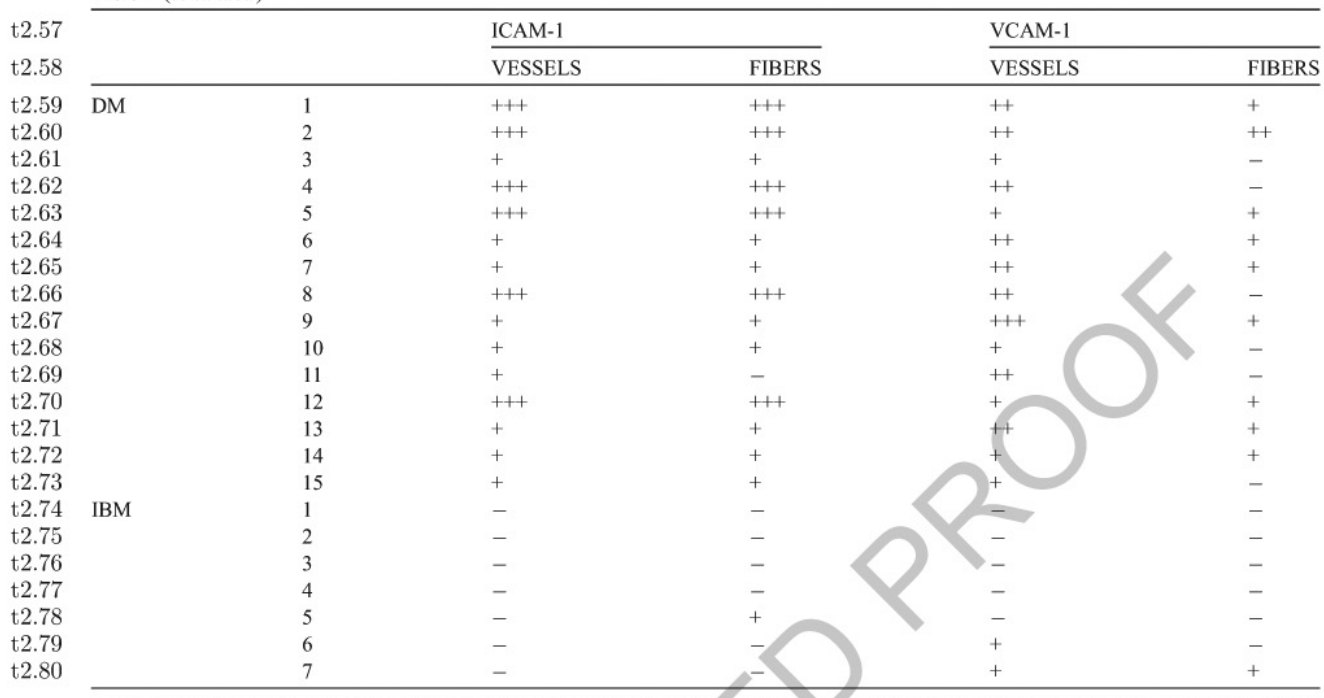

$(-)=$ no expression; $(+)=$ expression between $1 \%$ and $25 \%$ of the analyzed structures; $(++)=$ expression between $26 \%$ and $50 \%$ of the analyzed structures; $(+++)=$ expression between $51 \%$ and $75 \%$ of the analyzed structures; $(+1++)=$ expression between $76 \%$ and $100 \%$ of the analyzed structures.

167 absent in JDM and IBM, but present in $33.4 \%$ and $16840 \%$ respectively of $\mathrm{PM}$ and $\mathrm{DM} \quad(p<0.0001)$

169 VCAM-1 expression in vessels was more significant

170 for PM and DM than JDM and IBM $(p<0.0001)$ and

171 VCAM-1 expression in muscle fibers was virtually

172 absent in the four groups $(p=0.2632)$ (Fig. 1; Tables 1731 and 2).

\section{4. Discussion}

175 In the present study, we demonstrated that ICAM-1 176 expression in muscle vessels was more evident for 177 JDM, than for DM, PM and IBM, corroborating the 178 microvascular involvement in JDM.

179 In our previous study we had demonstrated an 180 increased ICAM-1 expression in intramuscular ves181 sels, markedly in capillaries, in contrast to a less 182 striking VCAM-1 expression in the same muscle 183 vessels of patients with JDM, compared with normal 184 age-matched muscle biopsies [14]. An increased ex185 pression of ICAM-1 has been reported in muscle vessels and fibers of patients with adult DM when 186 compared to PM, whereas no difference in the expres- 187 sion of VCAM-1 has been observed [20]. Further- 188 more, more marked ICAM-1 expression in skeletal 189 muscle vessels in adult DM than in PM, or in 190 control muscle biopsies has also been described 191 $[17,18,21,22]$. Whether ICAM-1 expression in vessels 192 points to the microvascular involvement in JDM, the 193 enrollment of VCAM-1 induction in endothelial cells 194 in inflammatory myopathies remains controversial. In 195 our present study, VCAM-1 expression in vessels was 196 more significant for PM and DM, than for JDM and 197 IBM. Several reports have shown marked increase of 198 VCAM-1 expression in microvessels, and also in 199 some arterioles surrounded by inflammatory cells, 200 but not in capillaries [17,21,22]. Angiopathy in adult 201 DM was confirmed by demonstrating active focal 202 destruction of capillaries. The presence of comple- 203 ment-induced vessel injury have been established by 204 consistent evidence of activation of the complement 205 cascade, with capillary damage mediated by mem- 206 brane attack complex [13,16,23-25]. The activated 207 


\section{ARTICLE IN PRESS}

208 complement C5a binds to endothelial cells and up209 regulates adhesion molecule expression [26]. There210 fore, it might be possible that ICAM-1 and VCAM-1

211 expressions in vessels are induced by complement 212 activated products in sublethal endothelial cell injury 213 [27]. In any case, sublethal injury stimulates IL-1 $\alpha$ 214 production, which induces ICAM-1 expression [28].

215 Thus, the idea that complement activation products 216 might induce cytokines which in turn induce ICAM-1 217 and VCAM-1, gains credence. The presence of de218 generation muscle fiber and inflammatory cell infil219 trates are usual histopathological findings in acquired 220 inflammatory myopathies for PM and IBM. The mus221 cle fibers are surrounded, invaded and destroyed by 222 mononuclear inflammatory cells. Majority of these 223 cells are T lymphocytes, most of them CD8+ cells, 224 favoring a $T$ cell-mediated cytotoxic process against 225 muscle fibers. In DM, the cell-mediated inflammatory 226 reactions seem to be of lesser importance [16]. ICAM2271 expression in muscle fibers was absent for JDM and 228 IBM, but present in PM and DM. VCAM-1 expres229 sion in muscle fibers was virtually absent in the four 230 groups. Cell surface adhesion molecules mediated 231 important cellular interactions in acute and chronic 232 inflammatory responses. Under physiological condi233 tions, mature myofibres express neither MHC class I 234 or II, nor ICAM-I [29]. In vivo studies based on 235 muscle biopsies of inflammatory myopathies, and in 236 vitro experiments with myoblast cultures, have dem237 onstrated that the adhesion molecules are both present 238 in pathological specimens, and inducible in muscle 239 cells in vitro [30]. MHC-I and -II dependent processes 240 require expression of ICAM-1. The molecule is nec-

241 essary to stabilize the interactions between the cell 242 receptor and MHC-peptide complex for antigen rec243 ognition. Therefore, the adhesion molecule, essential 244 for cell adhesion, also triggers the cytotoxic mecha245 nism. The observation of the differential positive 246 ICAM-1 expression in muscle fibers for PM and 247 DM, in contrast to absent fiber expression in JDM, 248 strengthens the myocytotoxic mechanism in the adult 249 inflammatory myopathies (PM/DM), as opposed to 250 muscle lesion through the involvement of the micro251 vasculature in JDM.

252 In summary, the adhesion molecule expressions 253 present a distinct characteristic in JDM when com254 pared to PM, DM and IBM, suggesting a different 255 pathomechanism of muscle injury in children.

\section{Take-home messages}

AM-1 expression is increased in muscle vessels for JDM, corroborating the microvasculature involvement.

- VCAM-1 expression in muscle vessels is more significant in DM and PM.

- Expression of adhesion molecules does not differentiate DM from PM.

- JDM has a characteristic differential expression of ICAM-1/VCAM-1 in comparison to adult inflammatory myopathy.

\section{References}

[1] Bohan A, Peter JB. Polymyositis and dermatomyositis. N Engl J Med 1975;13:344-7.

[2] Dalakas MC. Molecular immunology and genetics of inflammatory muscle diseases. Arch Neurol 1998:54:1509-12.

[3] Lundberg IE. Idiopathic inflammatory myopathies: why do the muscles become weak? Curr Opin Rheumatol 2001;13: $457-60$.

[4] Civatte M, Schleinitz N, Krammert P, et al. Class I MHC detection as a diagnostic tool in noninformative muscle biopsies of patients suffering from dermatomyositis (DM). Neuropathol Appl Neurobiol 2003;29:546-52.

[5] Arahata K, Engel AG. Monoclonal antibody analysis of mononuclear cells in myopathies: I. Quantitation of subsets according to diagnosis and sites of accumulation and demonstration and counts of muscle fibers invaded by T cells. Ann Neurol 1984;16:193-208.

[6] Dalakas MC, Sivakumar K. The immunopathologic and inflammatory differences between dermatomyositis, polymyositis and sporadic inclusion body myositis. Curr Opin Neurol 1996;9:235-9.

[7] Wedderburn LR, Li CKC. Paediatric idiopathic inflammatory muscle disease. Best Pract Res Clin Rheumatol 2004;18: $345-58$.

[8] Compeyrot-Lacassagne S, Feldman BM. Inflammatory myopathies in children. Pediatr Clin North Am 2005;25:493-520.

[9] Rider L. Childhood myositis: newly recognized diversity. pp. 716-7 In: PLOTZ P, editor. Myositis: immunologic contributions to understanding cause, pathogenesis, and therapyAnn Intern Med 1995;122. 1995. p. 715-24.

[10] Sallum A.M.E, Kiss MHB, Sachetti S, et al, Juvenile dermatomyositis: clinical, laboratorial, histological, therapeutical and evolutive parameters of 35 patients. Arq Neuropsiquiatr 2002; 60:889-99.

[11] Pachman LM, Cooke N. Juvenile dermatomyositis: a clinical and immunologic study. J Pediatr 1980;96:226-34.

[12] Estruch R, Grau JM, Fernández-Solá J, et al. Microvascular changes in skeletal muscle in idiopathic inflammatory myopathy. Hum Pathol 1992;23:888-95. 


\section{ARTICLE IN PRESS}

13] Gonçalves FG, Chimelli L, Sallum AM, et al. Immunohistochemical analysis of CD59 and membrane attack complex of complement in muscle in juvenile dermatomyositis. J Rheumatol 2002;29:1301-7.

[14] Sallum AME, Vianna MAAG, Wakamatsu A, et al. Immunohistochemical analysis of adhesion molecule expression on muscle biopsy specimens from patients with juvenile dermatomyositis. J Rheumatol 2004;31:801-7.

15] Bartoccioni E, Gallucci S, Scuderi F, et al. MHC class I, MHC class II and intercellular adhesion molecule-1 (ICAM-1) expression in inflammatory myopathies. Clin Exp Immunol 1994:95:166-72

6] Emslie-Smith AM, Engel AG. Microvascular changes in early and advanced dermatomyositis: a quantitative study. An Neurol 1990;27:343-56.

7] Cid MC, Grau JM, Casademont J, et al. Leucocyte/endothelial cell adhesion receptors in muscle biopsies from patients with idiopathic inflammatory myopathies (IIM). Clin Exp Immuno 1996; 104:467-73

8] Kumamono T, Abe T, Ueyama H, et al. Elevated soluble intercellular adhesion molecules-1 in inflammatory myopathy. Acta Neurol Scand 1997;95:34-7.

19] Dubowitz V. Muscle biopsy: a practical approach. Histological and histochemical stains and reactions. 2nd ed. Saunders. p. 19-40 Section 1.

20] Vianna MAAG, Borges CTL, Borba EF, et al. Myositis in mixed connective tissue disease. A unique syndrome characterized by immunohistopathologic elements of both polymyositis and dermatomyositis. Arq Neuropsiquiatr 2004;62(4) 923-34.

1] De Bleecker JL, Engel AG. Expression of cell adhesion molecules in inflammatory myopathies and duchenne dystrophy. J Neuropathol Exp Neurol 1994;53:369-76.
[22] Liprandi A, Figarella-Branger D, Daniel L, et al. Expression des molécules d'adhésion dans les myopathies inflammatoires idiopathiques: étude immunohistochimique de 17 cas. Ann Pathol 1999;19:12-8.

[23] Banker BQ, Victor M. Dermatomyositis (systemic angiopathy) of childhood. Medicine 1966:45:261-89.

[24] Kissel JT, Mendell JR, Rammohan KW. Microvascular deposition of complement membrane attack complex in dermatomyositis. N Engl J Med 1986;314:32934.

[25] Whitaker JN, Engel WK. Vascular deposits of immunoglobulin and complement in idiopathic inflammatory myopathy. $\mathrm{N}$ Engl J Med 1972;286:333-8.

[26] Lozada CJ, Levin RL, Huie M, et al. Identification of Clq as the heat-labile serum cofactor required for immune complexes to stimulate endothelial expression of the adhesion molecules E-selectin and intercellular and vascular cell adhesion molecules 1. Proc Natl Acad Sci U S A 1995;92:8378-82.

[27] Cid MC, Grau JM, Casademont J, et al. Leucocyte/endothelial cell adhesion receptors in muscle biopsies from patients with idiopathic inflammatory myopathies. Clin Exp Immunol 1996; 104:467-73.

[28] Shreeniwas R, Koga S, Karakurum M, et al. Hypoxia-mediated induction of endothelial cell interleukin-1 alpha. An autocrine mechanism promoting expression of leukocyte adhesion molecules on the vessel surface. J Clin Invest 1992; 90:2333-9.

[29] Hohfeld R, Engel AG, Goebels N, et al. Cellular immune mechanisms in inflammatory myopathies. Curr Opin Rheumatol 1997;9:520-6.

[30] Nagaraju K. Update on immunopathogenesis in inflammatory myopathies. Curr Opin Rheumatol 2001;13:461-8. 